\title{
MICROTUBOS E NANOTUBOS DE SILÍCIO FABRICADOS POR PROCESSOS QUÍMICOS E ELETROQUÍMICOS
}

\author{
Tese de doutorado apresentada a Escola \\ Politécnica da Universidade de São Paulo \\ para a obtenção do Titulo de Doutor em \\ ciências.
}

Área de concentração:

Microeletrônica.

Orientador:

Prof. Dr. Walter Jaimes Salcedo

São Paulo

2010 
Este exemplar foi revisado e alterado em relação à versão original, sob responsabilidade única do autor e com a anuência de seu orientador.

São Paulo, .08. de julho de 2010

Assinatura do autor

Assinatura do orientador

\section{FICHA CATALOGRÁFICA}

\section{Huanca, Danilo Roque}

Microtubos e nanotubos de silício fabricados por processos químicos e eletroquímicos / D.R. Huanca. -- São Paulo, 2010.

p. 237

Tese (Doutorado) - Escola Politécnica da Universidade de São Paulo. Departamento de Engenharia de Sistemas Eletrônicos.

1.Fabricação (Microeletrônica) 2.Processos de microeletrônica 3.Materiais 4.Eletroquímica 5.Corrosão 6.Semicondutores (Físico-Química) 7.Nanotecnologia 8.Materiais nanoestruturados 9.Nanopartículas I.Universidade de São Paulo. Escola Politécnica. Departamento de Engenharia de Sistemas Eletrônicos II.t. 
Dedico este trabalho à mulher que se torno em minha amiga, e amante companheira, sem cujo amor não teria sido possível finalizar este trabalho: minha esposa Ana María Sullca Farfán. Sua constante presença na minha vida encorajou-me a encarar as dificuldades até atingir o alvo desejado. Dedico também este trabalho às maiores jóias que Deus pode dar a um homem: meus três filhos: Gerson Jonatan, Nadia Ângela e Betsabe Sulamita, que alegram meus dias com sua só presença, mesmo naqueles momentos difíceis. 


\section{AGRADECIMENTOS}

Meu maior agradecimento é para meu fiel amigo e companheiro: O senhor Jesus, que andou e continua a andar junto comigo no dia-a-dia da minha vida, com sua santa presença, dando-me forças na luta diária e permaneceu sempre junto à mim tanto nos momentos difíceis quanto nos momentos de alegria. Obrigado meu Deus pela tua amizade e cuidado desinteressado.

Meu eterno agradecimento para o amor da minha vida, minha amiga, companheira e amante esposa Ana Maria Sullca Farfán pela sua dedicação, paciência e amor, que me motivaram a continuar na luta diária, especialmente nos momentos difíceis. Estou também plenamente agradecido aos meus amados filhos Gerson, Nadia e Betsabe, pela sua paciência e compreensão, especialmente naqueles momentos que mais precisavam de mim. Eles são o principal motivo de minha luta diária, sem cujo amor, que alimenta minha perseverança, não teria sido possível atingir o alvo desejado, que foi resumido na finalização deste trabalho.

Minha maior gratidão também vai, sem dúvida nenhuma, para meu orientador Prof. Dr. Walter Jaimes Salcedo, pela acertada orientação durante 0 desenvolvimento do presente trabalho. Sua rigorosidade, durante as análises e discussões, motivou-me à contínua pesquisa sobre o assunto em questão, o que tem me ajudado no meu crescimento acadêmico e contribuído, significativamente, ao enriquecimento do presente trabalho, deixando em mim um sentimento de satisfação e gratidão pelo trabalho concluído.

Também agradeço às pessoas que compartilharam comigo alegrias da convivência mutua durante o desenvolvimento deste trabalho. Sua amizade e alegria ajudaram-me a superar as dificuldades próprias da pesquisa. Assim, grato sou com o Mauro, Filipe, Alan, Rina, Keth, Fátima, Dante, Mário, Bruno e Joel, entre outros. Especial gratidão para o Vinícius e o Adir pela sua desinteressada ajuda na obtenção das imagens no MEV. Finalmente, tenho de agradecer ao CNPq e à CAPES pelo suporte econômico da bolsa. 


\section{RESUMO}

\section{HUANCA, D.R. MICROTUBOS E NANOTUBOS DE SILÍCIO FABRICADOS}

POR PROCESSOS QUÍMICOS E ELETROQUÍMICOS. 2010. f. Tese (Doutorado) - Escola Politécnica, Universidade de São Paulo, 2010.

O objetivo do presente trabalho foi a fabricação de micro e nanotubos de silício através de métodos eletroquímicos, utilizando como material de partida o silício poroso. Os resultados obtidos durante o desenvolvimento deste trabalho apresentam contribuições significativas nos campo da micro e nanotecnologia, bem como no campo da eletroquímica do silício. Esses resultados mostraram que a formação dos microtubos é sensível às variações do $\mathrm{pH}$, tipo e concentração dos oxidantes, tempo de corrosão, espessura das camadas porosas e tratamento prévio da superfície polida das amostras com alumínio e posterior recozimento térmico. A análise estrutural, via microscopia eletrônica de varredura (MEV), mostra que os microtubos de silício (MTS) podem ser formados em valores de pH entre 5,5 a 7,5, dependendo do tipo e concentração dos oxidantes. A análise da composição química dos MTS, realizada mediante a espectroscopia por dispersão de energia (EDS). Os resultados da espectroscopia Raman,indicaram que as estruturas são tubos de Silício, cuja estequiometria é a mesma que a do cristal de Silício. Foi demonstrada a possibilidade de formação de microtubos metálicos através do controle das condições químicas e eletroquímicas da solução, utilizadas na formação das estruturas tubulares de silício. A condição da solução eletroquímica com nível de $\mathrm{pH}$ 6,5 permitiu formar microtubos de níquel, enquanto que estruturas tubulares de manganês foram obtidas em soluções com nível de pH 7,5. Em ambos os casos, foram utilizados agentes oxidantes originados de sais de níquel e manganês, respectivamente. Os resultados indicam que o processo de formação destas estruturas acontece por efeito do deslocamento galvânico. Os resultados apresentados neste trabalho são completamente inéditos e mostram-se vantajosos em relação àqueles reportados na literatura, já que estes últimos são obtidos mediante processos de alto custo que requerem sofisticados equipamentos, enquanto os microtubos de silício obtidos mediante técnicas eletroquímicas, aqui usadas, são de baixo custo e fácil montagem.

Palavras-chave: Microtubos de silício, Nanotubos de silício. 


\section{ABSTRACT}

\section{HUANCA, D.R. SILICON MICROTUBES AND NANOTUBES}

MANUFACTURED WITH CHEMICAL AND ELECTROCHEMICAL PROCESSES. 2010. f. Tese (Doutorado) - Escola Politécnica, Universidade de São Paulo, 2010.

The aim of this work was to fabricate micro and nanotubes of silicon, through electrochemical methods and using the porous silicon as starting material. The results achieved during the development of this work present significant contributions into the micro and nanotechnology field, as well as in the silicon electrochemistry field. The obtained results have shown that the formation of the microtubes is sensitive to variations of $\mathrm{pH}$, type and concentration of the oxidants, time of corrosion, thickness of the porous layers, and previous treatment of the polished silicon surface with aluminum and subsequent thermal annealing. The results of the structural analysis by scanning electron microscopy (SEM) show that the silicon microtubes can be formed at $\mathrm{pH}$ values ranging between 5,5 and 7,5 , depending on the type and concentration of the oxidants. The chemical analysis upon the composition of these silicon tubular structures was carried out by Energy Dispersion Spectroscopy (EDS). Raman spectroscopy results indicated that the tubular structures are silicon tubes, whose stoichiometric structure is similar to the silicon crystal. The possibility of formation of metallic microtubes, just by controlling the chemical and electrochemical conditions of the etching solution used to form the silicon tubular structures was shown. The electrochemical condition of the solution with level of $\mathrm{pH} \mathrm{6,5}$ allowed the formation of nickel microtubes structures, and the formation of manganese tubular structures was obtained in solutions with $\mathrm{pH}$ of 7,5 . In both cases there have been used oxidants agents originated from nickel and manganese salts, respectively. The results indicate that the formation process of these metallic structures happens by a galvanic displacement process. The results presented in this work are completely unpublished and reveal advantageous in relation to those reported in literature because these last ones are obtained by using high cost processes which require sophisticated equipment, while the silicon microtubes obtained by electrochemical techniques used in the present work are of low cost and of easy assembly.

Keywords: Silicon microtubes, Silicon Nanotubes. 


\section{LISTA DE FIGURAS}

Figura 2.1. Possíveis arranjos dos átomos de silício na estrutura dos NTS. A coluna A apresenta a hipotética formação dos NTS, tipo armchair e zigzag, na hibridação $\mathrm{sp}^{2}$

Figura 2.2. Síntese de NTS via: (a) CVD usando como molde Alumina porosa; (b) MBE sobre substrato de Alumina porosa; (c, d) Arco de Plasma; (e) hidrotérmico supercrítico; e (f) plasma catalítico.

Figura 2.3. Taxa de corrosão do silício em meio fluorado em função do $\mathrm{pH}$.

Figura 2.4 Mecanismo de dissolução anódica em solução diluída de HF e em solução concentrada.

Figura 2.5 Mecanismo de dissolução química e eletroquímica do silício em fluoreto de amônia; e superfície $\mathrm{Si}(111)$ mostrando os sítios kink

Figura 2.6. Mecanismo de dissolução do silício em $\mathrm{KOH}$ proposto por Palik nos planos cristalinos (100), e (111).

Figura 3.1. (a) Célula eletrolítica de simples; e (b) diagrama esquemático da anodização

Figura 4.1 Imagens MEV da superfície frontal e perfil das amostras: D34, P17 e P61.

Figura 4.2 Histograma da distribuição dos poros das amostras nãometalizadas e metalizadas

Figura 4.3. Imagens MEV da superfície e do perfil de amostras metalizadas na face polida

Figura 4.4. Histograma da freqüência de poros semicirculares e retangulares.

Figura 4.5. Dependência da espessura das camadas de SMP com o tempo.

Figura 4.6. Imagens MEV da morfologia superficial e da espessura das amostras metalizadas.

Figura 4.7. Histograma da densidade de poros semicirculares e 
retangulares das amostras metalizadas com $1 \mu \mathrm{m}$ de Al.

Figura 4.8. Variação da espessura e a resistência elétrica em função do tempo de recozimento das amostras B54 a B57.

Figura 4.9. Variação da tensão anodização ao longo do tempo para as amostras metalizadas na face polida

Figura 4.10. Perfil da amostra metalizada nas costas e na face polida.

Figura 4.11. Diagrama esquemático da intensificação do campo elétrico local devido às agulhas formadas nas costas das amostras.

Figura 4.12. Imagem da superfície do silício mostrando os pits, e diagrama esquemático da formação dos pits.

Figura 4.13. Diagrama de fase do sistema Si-Al, e solubilidade do Si em Al.

Figura 4.14. Imagens MEV das amostras $\mathrm{P} 77$ imersas em $5 \times 10^{-2} \mathrm{M}$ $\mathrm{Na}_{2} \mathrm{SO}_{4}+0,25 \mathrm{M} \mathrm{NH}_{4} \mathrm{~F}$ com pH entre 4,5 a 7,5.

Figura 4.15. Imagens MEV da amostra B89 imerso em $5 \times 10^{-2} \mathrm{M}$ $\mathrm{Na}_{2} \mathrm{SO}_{4}+0,25 \mathrm{M} \mathrm{NH}_{4} \mathrm{~F}$ com pH entre 6,5 a 9,5.

Figura 4.16. Curvas voltamétricas, corrente e potencial de corrosão, e PECA em função do tempo das imersas em $5 \times 10^{-2} \mathrm{M}$ $\mathrm{Na}_{2} \mathrm{SO}_{4}+0,25 \mathrm{M} \mathrm{NH}_{4} \mathrm{~F}$.

Figura 4.17. Valores teóricos da concentração das espécies fluoradas em função do $\mathrm{pH}$.

Figura 4.18. Comparação do potencial de circuito aberto (PECA) com o potencial redox das possíveis reações favorecidas das espécies presentes no eletrólito de $5 \times 10^{-2} \mathrm{M} \mathrm{Na}_{2} \mathrm{SO}_{4}+0,25 \mathrm{M} \mathrm{NH}_{4} \mathrm{~F}$ em pH 4,5; 5,5; 6,5; 7,$5 ; 8,5$ e 9,5 .

Figura 4.19. Espectro EDS da analise química das amostras imersas em pH entre 5,5 a 9,5, e resumo elementos presentes na amostras. 
Figura 4.20. Curvas Mott-Schottky; $\mathrm{V}_{\mathrm{FB}}$, PECA, e $\mathrm{V}_{\mathrm{s}}$; largura de depleção; e Coeficiente de transferência em função do $\mathrm{pH}$.

Figura 4.21. Diagrama esquemático qualitativo da transferência de elétrons e lacunas durante a corrosão do $\mathrm{Si}$.

Figura 4.22. Diagrama esquemático da formação da camada de depleção do SMP imerso em solução ácida, e em solução fluorada para diferentes tempos de imersão que permitem a formação do MTS.

Figura 4.23. Vista de topo e do perfil dos microtubos formados em $5 \times 10^{-2} \mathrm{M} \mathrm{NiSO}_{4}+0,25 \mathrm{M} \mathrm{NH}_{4} \mathrm{~F}$.

Figura 4.24. Diagrama esquemático da vista de topo e do perfil da formação e dissolução das paredes dos tubos ao longo do tempo.

Figura 4.25. Evolução da formação dos tubos em solução $5 \times 10^{-2} \mathrm{M}$ $\mathrm{CoSO}_{4}+0,25 \mathrm{M} \mathrm{NH}_{4} \mathrm{~F}$ durante cinco dias.

Figura 4.26. Estrutura superficial e espectro EDS da amostras B20 imersas em pH entre 4,5 a 7,5

Figura 4.27. Microtubos de níquel obtidos na amostra B20C, B24C e B50 imersos em pH 6,5.

Figura 4.28. Concentração de $\mathrm{Si}, \mathrm{O}$ e $\mathrm{Ni}$ detectado nas amostras B20 após a formação dos MTN.

Figura 4.29. Curvas voltamétricas, potencial e corrente de corrosão das amostras imersas em $5 \times 10^{-2} \mathrm{M} \mathrm{NiSO}_{4+0,25 \mathrm{M}}$ $\mathrm{NH}_{4} \mathrm{~F}$

Figura 4.30. Coeficientes de transferência, e potencial de eletrodo a circuito aberto em $5 \times 10^{-2} \mathrm{M} \mathrm{NiSO}_{4}+0,25 \mathrm{M} \mathrm{NH}_{4} \mathrm{~F}$.

Figura 4.31. Formação parcial dos MTN via deslocamento galvânico dos microtubos de silício B71 e B88.

Figura 4.32. Imagens MEV e espectro EDS da amostra B27 imersa em $5 \times 10^{-2} \mathrm{M} \mathrm{CoSO}_{4}+0,25 \mathrm{M} \mathrm{NH}_{4} \mathrm{~F}$ com pH entre $4,5 \mathrm{e}$ 7,5 
Figura 4.33 Concentração de elementos detectados via EDS após terem sido mergulhados no eletrólito fluorado com cátions $\mathrm{Co}^{2+}$.

Figura 4.34. Curvas voltamétricas, e PECA e corrente de corrosão da amostra B102.

Figura 4.35 monitoramento do potencial de eletrodo ao longo do tempo para amostra B102 imersa em $5 \times 10^{-2} \mathrm{M}$ $\mathrm{CoSO}_{4}+0,25 \mathrm{M} \mathrm{NH}_{4} \mathrm{~F}$.

Figura 4.36. Curvas Mott-Schottky, $\mathrm{V}_{\mathrm{FB}}$ e corrente de corrosão, PECA, $V_{S}, V_{F B}$, e camada de depleção em função do $\mathrm{pH}$.

Figura 4.37. Imagens MEV e espectro EDS da amostra B101 imersa em $5 \times 10^{-2} \mathrm{M} \mathrm{Mn}\left(\mathrm{NO}_{3}\right)_{2}+0,25 \mathrm{M} \mathrm{NH}_{4} \mathrm{~F}$ com pH entre 5,5 e 8,5 .

Figura 4.38. Visão panorâmica da amostra B101; e estrutura obtida da região "B" em pH 5,5.

Figura 4.39 Microtubos de silício formados em regiões longe do centro da amostra, e estrutura formada em $\mathrm{pH}$ 8,5

Figura 4.40. Concentração de elementos em função do $\mathrm{pH}$; e formação de aglomerados de Mn sobre os MTSs

Figura 4.41. Curvas voltamétrica e variação do potencial e corrente de corrosão da amostra B101

Figura 4.42. Perfil da variação do potencial de eletrodo em circuito aberto sobre a amostra B102.

Figura 4.43. Diagrama esquemático da localização dos potencias redox das reações do $\mathrm{NO}_{3}^{-}$em relação às bandas do $\mathrm{Si}$ tipo $p$.

Figura 4.44 Formação das barras de manganês dentro dos MTS da amostra imersa em $\mathrm{pH} 6,5$

Figura 4.45. Imagens MEV e espectro EDS da amostra B36 imersa em $0,25 \mathrm{M} \mathrm{NH}_{4} \mathrm{~F}$ com pH entre 4,5 e 7,5.

Figura 4.46. Região dissolvida da amostra $\mathrm{B} 36 \mathrm{em} \mathrm{pH} 5,5$; e região 
central, onde a formação dos MTS é mais lenta em pH 6,5

Figura 4.47. Concentração de elementos químicos detectados na superfície da amostra B36

Figura 4.48. Curvas voltamétricas da amostra B36, corrente e potencial de corrosão em diferentes $\mathrm{pHs}$.

Figura 4.49. Monitoramento do PECA da amostra B36 ao longo do tempo.

Figura 4.50. (a) comparação das curvas voltamétricas em pH 6,5, (b) corrente de corrosão, e (c) corrente catódica em diferentes $\mathrm{pHs}$; e (d) eletronegatividade versus raio iônico dos elementos presentes nas soluções.

Figura 4.51. Concentração de (a) oxigênio, e (b) carbono na superfície das amostras imersas em soluções com diferentes oxidantes. A linha verde em (b) representa a concentração de enxofre na solução com $\mathrm{CoSO}_{4}$.

Figura 4.52. Evolução do PECA para os diferentes oxidantes em $\mathrm{pH} 5,5$; e 7,5 .

Figura 4.53. Análise estrutural e química da amostra B106 imersa em pH entre 5,5 e 8,5 .

Figura 4.54 Comparação da composição química das amostras B101 e B106.

Figura 4.55 Curvas voltamétricas em diferentes $\mathrm{pH}$ das amostras B101 e B106.

Figura 4.56 Comparação da variação da corrente anódica e catódica das amostras B101 e B106 em diferentes pH.

Figura 4.57. Dissolução do Si tipo p (100) não-metalizado e 164 recozido em 1, 2, 4, e 8 horas pós metalização com Al e subseqüente remoção; imerso em solução de $\mathrm{HF}: \mathrm{NHO}_{3}: \mathrm{CH}_{2} \mathrm{O}(1: 1: 1)$ durante 5 minutos.

Figura 4.58. Comparação da variação do $E_{c o r r}$ e $i_{c o r r}$ das amostras B01 e B106; e monitoramento do PECA da amostra 
B106.

Figura 4.59. Estrutura superficial da amostra B71 imersa em pH 5,5

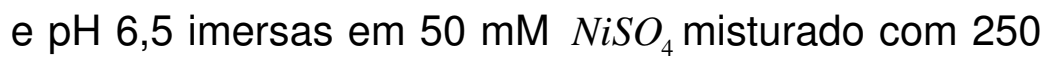
$\mathrm{mM} \mathrm{NH} \mathrm{H}_{4} \mathrm{~F}$.

Figura 4.60. Curvas voltamétricas; $E_{c o r r}$ e $i_{c o r r}$; e PECA da amostra B71.

Figura 4.61 Estrutura superficial e analise química da amostra B58 168 imersa em $50 \mathrm{mM} \mathrm{NiSO}_{4}+250 \mathrm{mM} \mathrm{NH} \mathrm{NH}_{4}$, com pH entre 5,5 e 7,5.

Figura 4.62. Formação dos MTS nas amostras B99 e B100 em pH 6,5 e 7,5 .

Figura 4.63. Comparação das curvas voltamétricas, $E_{c o r r}$ e $i_{c o r r}$; e PECA das amostras B99 e B100.

Figura 4.64. Estrutura superficial e analise química da amostra B25 imersa em $50 \mathrm{mM} \mathrm{NiSO}_{4}+250 \mathrm{mM} \mathrm{NH}_{4} \mathrm{~F}$ com pH entre 4,5 e 7,5 .

Figura 4.65. Histogramas da freqüência de poros semicirculares, retangulares, e distância entre poros vizinhos da amostra B25 e B20.

Figura 4.66. Imagens MEV dos nanotubos de silício obtidas nas amostras D80 e D82 em pH 5,5 e 6,5, respectivamente.

Figura 4.67 Imagens MEV dos nanotubos de silício obtidas nas amostras $\mathrm{A} 7$ e $\mathrm{A} 8 \mathrm{em} \mathrm{pH} \mathrm{5,5} \mathrm{e} \mathrm{6,5,} \mathrm{respectivamente.}$

Figura 4.68. Espectros EDS das amostras: D80, D82, A7 e A8.

Figura 4.69. Variação do PECA ao longo do tempo, e) histograma da distribuição do diâmetro dos NTS.

Figura 4.70. Imagens MEV das paredes de diferentes MTS obtidos em solução baseado em $\mathrm{NH}_{4} \mathrm{~F}$ e oxidante, em pH 6,5.

Figura 4.71. Espectros Raman das amostras P44, B99C e B101C. 


\section{LISTA DE TABELAS}

Tabela 3.1. Amostras imersas em eletrólito com diferentes sais oxidantes, previamente metalizadas.

Tabela 4.1. Tempo de recozimento dos filmes de Al depositados nas superfícies das diferentes amostras e espessura da camada macroporosa obtida nestas amostras.

Tabela 4.2: Resistência, tempo de recozimento, e espessura das camadas macroporosa obtidas em amostras metalizadas na face polida ( $1 \mu \mathrm{m} \mathrm{Al})$

Tabela 4.3: Valores obtidos da analise das curvas voltamétricas usando a amostra B99.

Tabela 4.4 Parâmetros extraídos da analise C-V da amostra B90.

Tabela 4.5. Concentração de elementos presentes nas amostras B20.

Tabela 4.6. Coeficientes de transferência, potencial e corrente de corrosão obtidos em $50 \mathrm{mM} \mathrm{NiSO}_{4}+250 \mathrm{mM} \mathrm{NH}_{4} \mathrm{~F}$.

Tabela 4.7 Resumo dos elementos presentes nas amostras mergulhadas na solução $\mathrm{CoSO}_{4}+\mathrm{NH}_{4} \mathrm{~F}$

Tabela 4.8. Parâmetros eletroquímicos extraídos da amostra B102 usando o eletrodo de referência $\mathrm{Ag} / \mathrm{AgCl}$.

Tabela 4.9 Composição química dos MTS da amostra B101.

Tabela 4.10. Coeficiente de transferência, potencial e corrente de corrosão da amostra B101

Tabela 4.11. Parâmetros eletroquímicos e composição química extraídos da amostra B36 


\section{LISTA DE ABREVIATURAS E SIGLAS}

$\begin{array}{ll}\mathrm{Al} & \text { Alumínio } \\ \mathrm{Al}_{2} \mathrm{O}_{3} & \text { Óxido de alumínio } \\ \beta_{a} & \text { Coeficiente de transferência anódica } \\ \beta_{c} & \text { Coeficiente de transferência catódica } \\ \mathrm{BC} & \text { Banda de condução } \\ \mathrm{BN} & \text { Nitreto de boro } \\ \mathrm{BV} & \text { Banda de valência } \\ \mathrm{CoSO} \mathrm{H}_{4} & \text { Sulfato de cobalto } \\ \mathrm{Co}(\mathrm{OH})_{2} & \text { Hidróxido de cobalto } \\ \mathrm{Cu} & \text { Cobre } \\ \mathrm{CuO} & \text { Óxido de cobre } \\ \mathrm{CMOS} & \text { Complementary metal oxide semiconductor } \\ \mathrm{CVD} & \text { Chemical Vapor deposition } \\ \mathrm{CrO} \mathrm{S}_{3} & \text { Óxido de cromo } \\ c_{o x} & \text { Concentração do oxidante } \\ \mathrm{CuSO} & \text { Sulfato de cobalto } \\ \mathrm{CN}-\mathrm{FET} & \text { Transistores de efeito campo de nanotubos de carbono } \\ D_{n} & \text { Coeficiente de difusão do elétron } \\ \mathrm{DMF} & \text { Dimetilformamide } \\ E_{a} & \text { Energia de ativação } \\ E_{a}^{\|} & \text {Energia de ativação paralela à direção }<100> \\ E_{a}^{\perp} & \text { Energia de ativação perpendicular à direção }<100> \\ E_{c o r r} & \text { Potencial de corrosão } \\ E_{\|} & \text {Campo elétrico paralelo à direção }<100> \\ E_{\perp} & \text { Campo elétrico perpendicular à direção }<100> \\ \mathrm{EDS} & \text { Espectroscopia por Dispersão de Energia } \\ & \end{array}$




$\begin{array}{ll}\mathrm{ER} & \text { Espectroscopia Raman } \\ \mathrm{EELS} & \text { Espectroscopia de perda energia de elétrons } \\ \mathrm{FET} & \text { Transistor de efeito campo } \\ \mathrm{Fe}_{2} \mathrm{O}_{3} & \text { óxido férrico } \\ H^{+} & \text {Íon de hidrogênio } \\ h^{+} & \text {Lacuna } \\ \mathrm{HF} & \text { Ácido fluorídrico } \\ \mathrm{HNO}_{3} & \text { Ácido nítrico } \\ \mathrm{H}_{2} \mathrm{SO}_{4} & \text { Ácido sulfúrico } \\ i_{c o r r} & \text { Corrente e corrosão } \\ i_{o a} & \text { Corrente de troca anódica } \\ i_{o c} & \text { Corrente de troca catódica } \\ i_{o c}^{\|} & \text {Corrente de troca catódica paralela à direção }<100> \\ i_{o c}^{\perp} & \text { Corrente de troca catódica perpendicular à direção }<100> \\ \mathrm{KOH} & \text { Hidróxido de potássio } \\ k_{o} & \text { Constante de transferência } \\ \mathrm{MEB} & \text { Molecular Epitaxial Beam } \\ \mathrm{MEV} & \text { Microscopia eletrônica de Varredura } \\ \mathrm{Mg}\left(\mathrm{NO}_{3}\right)_{2} & \text { Nitrato de magnésio, } \\ \mathrm{MOEMS} & \text { Sistemas micro opto-eletro-mecânico } \\ \mathrm{Mn}\left(\mathrm{NO}_{3}\right)_{2} & \text { Nitrato de Manganês } \\ \mathrm{Mn}(\mathrm{OH})_{2} & \text { Hidróxido de Manganês } \\ \mathrm{MC} & \text { Metalizada nas costas } \\ \mathrm{MP} & \text { Metalizada na face polida } \\ \mathrm{MPC} & \text { Metalizado na face polida e nas costas } \\ \mathrm{MTS} & \text { Microtubos de silício } \\ \mathrm{MTN} & \text { Microtubos de níquel } \\ n_{s} & \text { Densidade de elétrons na superfície } \\ n_{s}^{\|} & \text {Densidade de elétrons na paralela à direção }<100> \\ \end{array}$




\begin{tabular}{|c|c|}
\hline$n_{s}^{\perp}$ & Densidade de elétrons na perpendicular à direção $<100>$ \\
\hline $\mathrm{NaOH}$ & Hidróxido de sódio \\
\hline $\mathrm{NH}_{4} \mathrm{~F}$ & Fluoreto de amônio \\
\hline $\mathrm{NH}_{4} \mathrm{OH}$ & Hidróxido de amônio \\
\hline $\mathrm{NH}_{4}^{+}$ & Íon de amônio \\
\hline $\mathrm{NH}_{3}$ & Amônia \\
\hline NM & Não metalizado \\
\hline NTC & Nanotubos de carbono \\
\hline NTCPU & Nanotubos de carbono de parede única \\
\hline NTCPM & Nanotubos de carbono de parede múltipla \\
\hline NTS & Nanotubos de Silício \\
\hline NTN & Nanotubos de níquel \\
\hline $\mathrm{NTVO}_{x}$ & Nanotubos de óxido de vanádio \\
\hline $\mathrm{NiCl}_{2}$ & Cloreto de níquel \\
\hline $\mathrm{Ni}\left(\mathrm{NO}_{3}\right)_{2}$ & Nitrato de níquel \\
\hline $\mathrm{NiO}$ & óxido de níquel \\
\hline $\mathrm{NiSO}_{4}$ & Sulfato de níquel \\
\hline $\mathrm{Ni}(\mathrm{OH})_{2}$ & Hidróxido de níquel \\
\hline NO & Óxido nitroso \\
\hline $\mathrm{OH}^{-}$ & Hidroxila \\
\hline PECA & Potencial de eletrodo em circuito aberto \\
\hline $\mathrm{pH}$ & Potencial de hidrogênio \\
\hline $\mathrm{SiCl}_{4}$ & Cloreto de silício \\
\hline $\mathrm{SnO}_{2}$ & Óxido de estanho \\
\hline $\mathrm{SiO}$ & Monóxido de silício \\
\hline $\mathrm{SiO}_{2}$ & Dióxido de silício \\
\hline $\mathrm{SO}_{4}^{2-}$ & Íon de sulfato \\
\hline STM & scanning tuneling microscopy \\
\hline STS & scanning tuneling spectroscopy \\
\hline $\mathrm{SiO}_{2}(\mathrm{OH})_{2}^{2-}$ & Silicato \\
\hline
\end{tabular}




$\begin{array}{ll}\mathrm{SP} & \text { Silício poroso } \\ \mathrm{SMP} & \text { Silício macroporoso } \\ \mathrm{V}_{\mathrm{Ag} / \mathrm{AgCl}} & \text { Potencial em relação ao eletrodo de referência } \mathrm{Ag} / \mathrm{AgCl} \\ \mathrm{V}_{\mathrm{SHE}} & \text { Potencial em relação ao eletrodo de referencia de } \\ & \text { hidrogênio } \\ \mathrm{V}_{\mathrm{FB}} & \text { Potencial de banda plana } \\ \mathrm{V}_{\mathrm{S}} & \text { Potencial de barreira } \\ W_{\perp} & \text { Camada de depleção sobre a superfície (100) } \\ W_{\|} & \text {Camada de depleção sobre a superfície da parede } \\ \mathrm{XPS} & \text { Espectroscopia de fotoelétrons excitados por raios X } \\ z & \text { Número de elétrons transferidos } \\ \mathrm{Zn}(\mathrm{OH})_{2} & \text { Hidróxido de zinco }\end{array}$




\section{SUMARIO}

Resumo

Abstract

Lista de figuras

Lista de tabelas

Lista de siglas e abreviaturas

Sumario

CAPÍTULO I

Introdução.

CAPÍTULO II

2.1 Sistemas unidimensionais.............................................. 9

2.2 Nanotubos de Silício........................................................... 13

2.3 Aplicações dos micro e nanotubos......................................... 20

2.4 Dissolução do silício em solução aquosa fluorada ácida ........... 25

2.4.1 Dissolução em ausência de oxidante................................... 25

2.4.2 Dissolução em presença de oxidante................................ 30

2.4.3 Dissolução do silício em soluções fluoradas alcalina .............. 32

2.4.4 Dissolução do silício em soluções alcalina não fluoradas........ 35

2.5 Aplicações da eletroquímica dos semicondutores à formação

de estruturas................................................................ 38

2.6 Conclusões parciais...................................................... 42

CAPÍTULO III

Procedimento experimental................................................ 44

3.1 Materiais e equipamento................................................. 45

3.2 Formação dos micro e nanotubos de silício............................... 45

3.2.1 Limpeza e preparação das amostras.................................... 45

3.2.2 Formação das camadas de silício poroso............................ 46

3.2.3. Formação das estruturas tubulares.................................. 48

3.2.4 Caracterização das amostras.......................................... 48 


\section{CAPÍTULO IV}

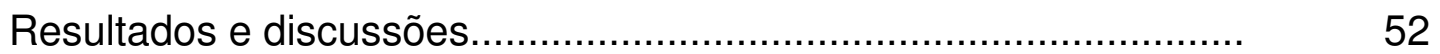

4.1 Formação das camadas de silício macroporoso.......................... 52

4.2 Formação das estruturas tubulares de silício a partir do em silício

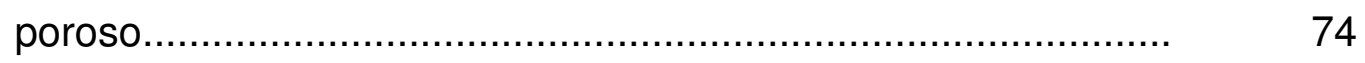

4.2.1 efeito do $\mathrm{pH}$ na formação de microtubos de silício.................... $\quad 75$

4.2.2 Mecanismo de formação dos microtubos de silício.................. 102

4.2.3 Efeito do oxidante na formação dos microtubos de silício......... 114

4.2.3.1 Microtubos formados em $50 \mathrm{mM} \mathrm{NiSO}_{4}+250 \mathrm{mM} \mathrm{NH}_{4} \mathrm{~F} \ldots \ldots . \quad 115$

4.2.3.2 Microtubos formados em $50 \mathrm{mM} \mathrm{CoSO}_{4}+250 \mathrm{mM} \mathrm{NH}_{4} \mathrm{~F} \ldots . . . \quad 127$

4.2.3.3 Microtubos formados em $50 \mathrm{mM} \mathrm{Mn}\left(\mathrm{NO}_{3}\right)_{2}+250 \mathrm{mM} \mathrm{NH}_{4} \mathrm{~F} \quad 136$

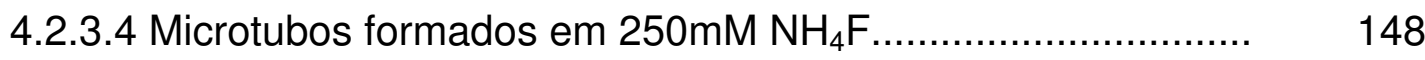

4.2.3.5 Análise comparativa do comportamento eletroquímico da formação dos microtubos de silício........................................ 155

4.2.4 Efeito do substrato na formação de microtubos de silício........... 160

4.2.4.1 Efeito da metalização do substrato sobre a formação dos microtubos de silício........................................................ 161

4.2.4.2 Efeito da porosidade das camadas MPS sobre a formação dos microtubos de silício........................................ 172

4.2.4.3 Efeito da concentração de dopantes do substrato silício sobre a formação dos microtubos de silício........................... 177

4.2.5. Analises Raman dos microtubos de silício.............................. 185 CAPÍTULO V

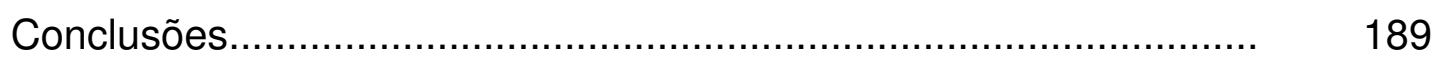

Apêndice............................................................................... 192

Artigos e trabalhos aceitos em eventos.......................................... 200

Referência Bibliográfica.......................................................... 202 


\section{CAPÍTULO I}

\section{Introdução}

Desde a descoberta dos nanotubos de carbono (NTC) por S. Lijima [1] em 1991, muitos esforços têm sido direcionados à pesquisa, tanto na parte experimental [1-4], quanto na teórica [5-6] com o intuito de entender suas propriedades físicas e químicas visando às diferentes aplicações possíveis nos diversos campos da ciência e tecnologia [7-10]. Algumas das propriedades físicas e químicas que tornam singulares os NTC referem-se a seu pequeno diâmetro, sua grande razão de aspecto, alta resistência mecânica, alta estabilidade térmica e química e excelente condução de calor [1-6]. Outra característica destes materiais está relacionada com 0 arranjo atômico das ligações do carbono, que determinam os tipos de estruturas, podendo ser estes zig-zag, armchair e chiral [2-6]; e é esse arranjo atômico que define as propriedades eletrônicas que determinarão um comportamento metálico ou semicondutor do material [6-7]. No caso dos NTC com comportamento semicondutor, a banda proibida (band gap) também depende do diâmetro do tubo e da assimetria estrutural do arranjo dos átomos, conhecida como "chirality", comprimento dos tubos e distância entre eles $[3,6,7]$.

Experimentalmente, tem-se desenvolvido diferentes técnicas que permitiram a obtenção de nanotubos de carbono de parede única (NTCPU) e de parede múltipla (NTCPM) que diferem entre si na razão de aspecto, diâmetro, estrutura da superfície, densidade de defeitos e o emaranhamento físico $[3,11,12]$. Os NTCPU são caracterizados principalmente por serem de aparência cilíndrica constituído apenas por uma folha de átomos de carbono, enquanto que os NTCPM estão constituídos por vários cilindros concêntricos espaçados pelas distâncias interplanares do grafite $[3,11]$. Dentre as diferentes técnicas usadas para a síntese dos NTC, podemos citar a deposição química em fase de vapor (CVD , Chemical Vapour Deposition), arco de descarga elétrica e remoção 
por laser, além de suas respectivas variações. Estas técnicas, também permitem obter os NTC sobre diferentes substratos, tais como silício, vidro e alumínio visando diferentes aplicações [3,11,12].

Atualmente a comunidade científica mundial tem dedicado esforços no estudo das propriedades ópticas e elétricas dos NTC visando sua aplicação nas diferentes áreas da ciência e tecnologia tais como o avanço da microeletrônica e o desenvolvimento de sensores [3,7,9-12]. Foram propostas diversas aplicações na biologia, medicina, indústria automotiva e aero espacial, bem como na microeletrônica, onde se pretende fabricar dispositivos de maior rapidez de resposta e menor tamanho através do uso dos NTC como canal entre a fonte e o dreno dos transistores de efeito de campo conhecidos como CN-FET [3,7,13]. De fato, a propriedade eletrônica dos NTC apresenta-se como a mais vantajosa, podendo estas cumprir, em princípio, a mesma função do silício, porém a nível molecular onde o silício e outros semicondutores deixam de agir como tal [7]. Embora a indústria eletrônica seja capaz de fabricar transistores comerciais com dimensões críticas abaixo de 100 nm, a comunidade científica ainda encara grandes dificuldades que terão que superar para promover a contínua miniaturização dos dispositivos. Ainda na década passada, os materiais e as técnicas empregadas na microeletrônica, que possibilitaram a revolução tecnológica na área dos computadores, certamente atingirão suas limitações físicas fundamentais em um futuro próximo [7]. Assim, a necessidade de miniaturização fez com que a comunidade científica e a indústria eletrônica direcionassem suas atenções aos NTC como uma solução a essa problemática [7,13].

Devido às propriedades eletrônicas e ópticas dos NTC que permitem o desenvolvimento de novos dispositivos fotônicos e sensores [3,7], cresceu o interesse nos materiais que possuem características estruturais semelhantes às do carbono e que permitem também a formação de nanotubos de diferentes materiais, tanto orgânicos, quanto inorgânicos $[4,14]$. Muitos compostos inorgânicos têm estrutura semelhante à do 
grafite, sendo exemplos típicos os metais dicalcogênios (sulfatos e selenetos), dialóides (cloretos, brometos e iodetos), óxidos metálicos e diversos compostos ternários e quaternários [3,4]. Nesse sentido, foram desenvolvidos nanotubos de $\mathrm{Ni}, \mathrm{Cu}, \mathrm{Ag}, \mathrm{WS}, \mathrm{MoSe}_{2}, \mathrm{MoO}_{3}, \mathrm{BN}, \mathrm{SiO}_{2}$, $\mathrm{V}_{2} \mathrm{O}_{5}, \mathrm{ZnO}$, entre outros [3,4]; usando os mesmos métodos de síntese dos NTC com pequenas variações [3,4,14]. Porém, os nanotubos metálicos, em particular, podem ser obtidos por CVD ou feixe de elétrons (electronbeam) sobre membranas de alumina porosa [3,4] ou mediante deposição eletroquímica $[15,16]$. Apesar da diversidade de nanotubos sintetizados usando os mais diversos materiais inorgânicos, sua aplicação na área da microeletrônica e a optoeletrônica estão ainda restritas devido ao fato de que esses processos não são totalmente compatíveis com os processos CMOS (complementary metal oxide semiconductor).

Sob o ponto de vista tecnológico e econômico, é desejável a obtenção de nanomateriais de silício por já existir uma tecnologia desenvolvida há muito tempo que permitiria sua fácil integração em dispositivos semicondutores usando diversas técnicas, tais como CVD, crescimento epitaxial, electron-beam, eletroquímicas e outras [17]. Nesse sentido, durante muito tempo foram produzidos nanofios de silício com diâmetro médio aproximado de $15 \mathrm{~nm}$ e comprimento variando entre algumas dezenas de nanômetros e centenas de micrômetros [3]. Posteriormente foram produzidos nanofios com diâmetros ainda menores, na ordem de $3 \mathrm{~nm}$ a $7 \mathrm{~nm}$ [18]. Dentro da área da microeletrônica, a aplicação imediata sugerida foi como canal dos transistores FET, o que permitiria a fabricação de transistores com menor tempo de resposta e reduzido consumo de energia, em comparação com os atualmente existentes no mercado [18]. Adicionalmente, foram sugeridas aplicações como sensores químicos e biológicos [8,19]. Apesar da grande importância e dos resultados promissores dos nanofios de silício na área da tecnologia CMOS, o grande desafio continua ser a fabricação de nanotubos de silício (NTS), uma vez que este material apresenta grande potencial de aplicação nas diferentes áreas tais como a microeletrônica, sensores, 
entre outras. A principal dificuldade na fabricação dos NTS esta relacionada com a forma das ligações $S i-S i$ que diferem das ligações $C-C$. A diferença entre estes dois materiais (carbono e silício) é que o silício forma predominantemente hibridização estável $\mathrm{sp}^{3}$ em forma tetragonal igual à estrutura do diamante, que não permite a formação de folhas como o grafeno, enquanto para o carbono, as duas formas de hibridização $\left(\mathrm{sp}^{2}\right.$ e $\left.\mathrm{sp}^{3}\right)$ são estáveis. Devido a essas características, os átomos de $\mathrm{Si}$, quando crescidos, têm a tendência natural para formação de nanofios e não nanotubos [20].

Desde o início da década passada, tem-se indicado a existência hipotética de nanotubos de silício através de cálculos teóricos usando métodos computacionais [21-28] que sugeriam apenas a possibilidade de existência desses materiais na forma "armchair", devido ao fato de que, no silício, a formação dos nanotubos apenas seria favorecida pelas ligações $s p^{3}$ [24], enquanto que no carbono seus átomos podem se ligar como $\mathrm{sp}^{2}, \mathrm{sp}^{3}$ ou uma combinação de ambas [3,11,12]. Nessa configuração, de forma análoga aos NTC, os NTS apresentariam exclusivamente propriedades semicondutoras, independentemente do seu arranjo atômico e diâmetro, que no caso dos NTC são parâmetros que determinam suas propriedades eletrônicas [24-25].

Apesar dos diversos estudos teóricos que previam a existência dos NTS [21-28], as características estruturais das ligações dos átomos de $\mathrm{Si}$ e as limitações tecnológicas, por muito tempo, não permitiram sua fabricação. Assim, a síntese desses materiais mostrou-se possível apenas nestes últimos anos, onde vários grupos de pesquisa reportaram sua síntese [2935]. Inicialmente, através da técnica CVD, tem-se obtido NTS com diâmetro médio interno de $50 \mathrm{~nm}$, aproximadamente, crescido dentro de um molde de alumina porosa, usado como substrato, cujas paredes foram recobertas com ouro como material catalisador [32]. Resultados bem sucedidos também foram alcançados através da técnica do Crescimento Epitaxial via Feixe Molecular (MEB, Molecular Epitaxial Beam), onde não 
foi necessário o emprego do elemento catalisador para a formação dos NTS [33]. Posteriormente, foi reportada a síntese de NTS dispensando o uso dos moldes [31,34], onde foi possível obter NTS com diâmetros da ordem de $13 \mathrm{~nm}$. Estes foram produzidos através da técnica da sintetização hidrotérmica, usando como material base o monóxido de silício (SiO) [31]. No entanto, a fabricação de NTS com diâmetros ainda menores foram atingidos usando plasma como elemento sintetizador, onde o material de partida foi pó de silício sobre um substrato de grafite [34]. Embora em ambos os casos fosse demonstrada a viabilidade da produção dos NTS, os resultados foram questionados não apenas no que se refere a seu diâmetro aparente, mas também na sua composição química e estrutural, pois, em ambos os casos, os NTS teriam, necessariamente, um arranjo cristalino de seus átomos.

Desta forma, segundo o estado da arte, os NTS possuem propriedades ópticas e eletrônicas que permitiriam abrir a possibilidade de fabricação de novos dispositivos eletrônicos e optoeletrônicos, e sensores diversos devido à compatibilidade com a tecnologia CMOS. Porém a obtenção dos NTS ainda representa um desafio à comunidade científica devido às limitações tecnológicas e à dificuldade intrínseca da ligação dos átomos Si-Si que não favorece a sua formação. Apesar disso, nos últimos anos, tem-se conseguido significativos avanços na síntese dos NTS através de diversas técnicas que permitiram obter NTS com diâmetros entre $13 \mathrm{~nm}$ e $100 \mathrm{~nm}$ e comprimento da ordem de dezenas de micrômetros. Considerando que a fabricação dos NTS é uma área nova de pesquisa, cujos resultados até agora obtidos ainda estão em fase inicial, será necessário o desenvolvimento de novas técnicas de obtenção que permita atingir um nível de maturidade para poder usá-los nas diversas áreas da tecnologia. Nesse sentido, a proposta do presente trabalho teve por objetivo a fabricação de micro e nanotubos de silício mediante métodos eletroquímicos usando como material de partida o silício poroso. Estes materiais foram fabricados visando aplicações a sensores. Dentre as diversas vantagens que possuem as técnicas eletroquímicas podemos 
mencionar que elas são de baixo custo e não precisam de equipamentos sofisticados e os procedimentos empregados são relativamente simples.

Para a fabricação dos micro e nanotubos de silício, foram utilizadas amostras de silício macro e mesoporoso, como material de partida ou substrato, o que permitiu obter micro e nanotubos com diâmetro interno médio na ordem de $1 \mu \mathrm{m}$ e $50 \mathrm{~nm}$, respectivamente. Embora a possibilidade de fabricação de ambas as estruturas, o presente trabalho focou-se, principalmente, na fabricação de microtubos de silício, devido às suas dimensões relativamente grandes se comparados com os nanotubos, permitiram-nos estudar com maior detalhe os mecanismo envolvidos durante sua formação. A compreensão desses mecanismos é muito importante, pois permitirá aprimorar a fabricação das estruturas tubulares de silício por meio da adequada modulação de diversos parâmetros envolvidos em suas formações.

Durante o desenvolvimento do presente trabalho, os parâmetros considerados foram o $\mathrm{pH}$, tipo de oxidante, tempo de imersão, tratamento das superfícies do substrato com alumínio e seu subseqüente recozimento térmico, tempo de recozimento, espessura das camadas e concentração de dopantes. O comportamento eletroquímico das amostras, sob essas condições, foi estudado mediante a análise da curva voltamétrica, monitoramento do potencial de eletrodo em circuito aberto (PECA) e determinação do potencial de banda plana. Adicionalmente, as amostras também foram caracterizadas estrutural e quimicamente via Microscopia Eletrônica de Varredura (MEV) e Espectroscopia Dispersiva de Elétrons (EDS), respectivamente. Finalmente, empregou-se a Espectroscopia Raman (ER) para determinar a natureza da porosidade das paredes dos microtubos.

O texto do presente trabalho está organizado em cinco capítulos. No capítulo I (presente capítulo), como descrito acima, foi realizada uma síntese do estado da arte sobre os diferentes métodos de obtenção dos 
nanotubos e suas diferentes aplicações, isto permitiu contextualizar e localizar nossa área de pesquisa, bem como as motivações para seu desenvolvimento.

No capítulo II, são apresentados e discutidos com maiores detalhes os fundamentos teóricos e os resultados reportados na literatura sobre processos de fabricação dos nanotubos de carbono e de silício, fabricação de micro em nanotubos de materiais inorgânicos e suas diferentes aplicações, eletroquímica dos semicondutores e suas aplicações, colocando maior ênfase à eletroquímica dos processos de corrosão e deposição eletroquímica sobre substrato de silício, bem como as diferentes aplicações na fabricação de micro em nanoestruturas mediante métodos de corrosão e deposição química, eletroquímica e deslocamento galvânico.

No capítulo III, são descritos os procedimentos experimentais utilizados para a fabricação dos micro e nanotubos usando como material de partida o silício poroso. O processo de fabricação descrito divide-se em duas partes. A primeira parte descreve a fase de obtenção do silício meso e macroporoso via corrosão eletroquímica, onde as lâminas de silício são colocadas em uma célula eletroquímica preenchida com uma solução eletroquímica de ácido fluorídrico misturada com solvente orgânico (HF:solvente) e subseqüente polarização anódica. As características químicas e físicas das camadas porosas através desse procedimento são moduladas por meio do controle da concentração e composição química do eletrólito, densidade de corrente, tempo de anodização. Na segunda parte, descrevem-se os procedimentos a seguir para a formação das diferentes estruturas tubulares de silício, incluindo os diferentes parâmetros eletroquímicos empregados para sua obtenção. Ainda neste capítulo, também são descritas as técnicas utilizadas para a caracterização estrutural e química mediante MEV e EDS, respectivamente, enquanto que, a natureza estequiométrica das paredes, foi estudada mediante Espectroscopia Raman. 
No capítulo IV, são apresentados os resultados experimentais e as discussões relativas à formação das estruturas colocando maior ênfase na formação dos microtubos de silício devido a que este se mostrou adequado para estudar os diferentes mecanismos envolvidos na formação dos tubos devido a seu tamanho relativamente grande, cujo entendimento é de muita importância para aperfeiçoar a formação dos micro e nanotubos de silício, o que futuramente nos permitirá utilizá-los na área de sensores. Diferentes estruturas tubulares foram obtidas através do controle sistemático dos diferentes parâmetros envolvidos na formação dos microtubos de silício, tais como o tipo de oxidante, $\mathrm{pH}$, tempo de imersão, espessura da camada porosa, entre outros. O comportamento eletroquímico do sistema silício macroporoso/eletrólito, durante a formação dos tubos, tem sido estudado mediante técnicas eletroquímicas, tais como a análise de curva voltamétrica, monitoramento do potencial de eletrodo em circuito aberto ao longo do tempo e potencial de banda plana. Esses resultados foram correlacionados com as estruturas resultantes e nos permitiu discutir sobre os possíveis mecanismos envolvidos na formação das estruturas tubulares.

No capítulo V, são apresentadas as conclusões e perspectivas futuras como conseqüência dos resultados obtidos no presente trabalho, e, finalmente, apresenta-se um apêndice, onde são colocados os diagramas de Pourbaix dos diferentes materiais que foram usados nas discussões no capítulo IV. 


\section{CAPÍTULO II}

Neste capítulo, apresentam-se os resultados da revisão bibliográfica sobre o avanço na área das micro e nanoestruturas e suas diferentes aplicações. Adicionalmente, também é apresentada uma revisão sucinta sobre os diferentes processos de dissolução do silício em meio fluorado, colocando maior ênfase na formação do silício poroso e suas aplicações na formação de micro e nano estruturas. Isto permitira visualizar a importância de nossa proposta dentro do campo da micro e nanotecnologia e eletroquímica do silício.

\section{1 sistemas unidimensionais}

A dimensionalidade tem um papel importante na determinação das propriedades físicas e químicas dos materiais, devido, por exemplo, às diferentes formas de interação dos elétrons nas estruturas unidimensionais (1D), bidimensionais (2D) e tridimensionais (3D) [2, 3]. A anisotropia inerente nos sistemas 1D, 2D e 3D é um parâmetro importante que define as propriedades e fases que esses materiais exibem, apesar das pequenas, porém finitas, interações nos sistemas 1D ou 2D que os afastam do comportamento ideal dos sistemas de baixa dimensionalidade [2]. Os sistemas 1D são aqueles onde o comprimento é muito maior do que as outras dimensões [2, 11, 12]. Exemplos destes tipos de sistemas referem-se aos nanofios e os nanotubos, que são os sistemas de mais baixa dimensionalidade, e podem ser usados para um eficiente transporte dos elétrons e para excitação óptica. Portanto, espera-se que cumpram um papel crítico na integração de nanodispositivos [2]. Outra característica interessante desses sistemas tem a ver com a possibilidade de exibir densidade de estados singulares, isto é, podem ter energia molecular discreta que se estende por longas distâncias e podem, também, mostrar interessantes fenômenos tais como a separação spincarga $[6,11,14,36]$. 
Devido às características mencionadas e a outras que os tornam materiais com grande potencial de aplicações nas diferentes áreas da tecnologia, os nanotubos e os nanofios têm despertado um grande interesse na comunidade científica, que dedica muitos esforços na procura da síntese dessas estruturas, usando os mais diversos materiais orgânicos e inorgânicos [4,14]. Desde a descoberta dos nanotubos de carbono em 1991, como um produto da síntese do fulereno [1], houve notável progresso nos anos posteriores, que incluem a descoberta de que os nanotubos de carbono podem ser tanto de parede única, quanto de paredes múltiplas $[2,11,12]$. Trabalhos posteriores foram desenvolvidos ainda tentando entender os mecanismos de formação desses dois tipos de nanotubos de carbono [5,6,11], para serem aproveitados em diferentes aplicações, tais como na microeletrônica $[7,13]$ e sensores [9,10]. Para tanto, foram desenvolvidas diversas técnicas para a síntese dos NTC, que podem se dividir em dois grandes grupos: 1) sublimação do grafite e a subseqüente deposição e 2) decomposição dos compostos de carbono. As técnicas do primeiro grupo estão associadas a processos que acontecem a altas temperaturas (superiores a $4000{ }^{\circ} \mathrm{C}$ ), que podem ser obtidas com aplicação de arcos elétricos ou nos processos de ablação por laser, com uso de radiação solar concentrada ou aquecimento resistivo do grafite $[3,11,12,37]$. Nesse grupo de processos, o mais notável é aquele por descarga de arco, devido ao grande número de variações que permitem sua aplicação, não apenas em nitrogênio líquido, mas também em água e soluções aquosas [11,12,37]. Adicionalmente, ainda é possível usar esse procedimento, com ligeiras modificações, em meios gasosos, líquidos e em hidrocarbonetos $[3,11,12]$. Porém, a principal desvantagem dessa técnica refere-se à dificuldade de processos contínuos, formação simultânea de carbono amorfo e formação de clusters que recobrem os NTC [3]. O segundo grupo está formado por diversas técnicas, sendo algumas delas, a pirólise de gases (processos em CVD), de sólidos (pirólises de polímeros), solução aquosa (síntese hidrotérmica) ou soluções orgânicas (tolueno supercrítico) [3,6,11,12,37]. A diferença 
entre estas técnicas para se obter os NTC, é que, na técnica do segundo grupo, não são necessárias temperaturas tão altas, podendo ser implementadas à temperaturas entre $500^{\circ} \mathrm{C}$ e $1300{ }^{\circ} \mathrm{C}[3,6]$.

A descoberta das propriedades físicas e químicas dos NTC, diferentes daquelas em estado sólido, tem impulsionado os cientistas a procurar a síntese de nanotubos usando outros materiais orgânicos ou inorgânicos, que possuam características físicas e químicas similares às do carbono [3,4,14]. Esta possibilidade tem sido ainda mais motivada pelo conhecimento de que diversos materiais inorgânicos possuem uma estrutura cristalográfica semelhante à do grafite, que, também, poderia permitir a formação de nanotubos inorgânicos com esses materiais [3, 4]. Dentre esses materiais podemos mencionar os dicalcogênios (sulfetos e selenetos), halóides, óxidos e hidróxidos [3,4]. A diferença entre 0 carbono e os metais dicalcogênios é que estes existem na forma $\mathrm{MX}_{2}(\mathrm{M}$ = metal; $X=\mathrm{S}$ ou Se). Os metais dicalcogênios são constituídos por uma camada de metal em meio a duas camadas de calcogênios, cujos modos de coordenação podem ser em forma piramidal trigonal ou octaedral [3]; e devido à natureza metálica, os nanotubos sintetizados com esses materiais possuem uma rigidez intrínseca, que não permite sua deformação plástica [3,4], o que limita as possibilidades de aplicações. Dentre os materiais dicalcogênios mais usados para fabricar nanotubos encontram-se o molibdênio (Mo) e o tungstênio (W). Uma revisão mais detalhada pode se encontrar em $[3,4]$.

Os métodos usados para a síntese dos nanotubos de metais dicalcogênios e nitreto de boro (BN) são os mesmos usados para a síntese dos NTC, mudando apenas o material de partida que, em geral, são óxidos metálicos. Estes são aquecidos em atmosfera redutora e, posteriormente, reagem com $\mathrm{H}_{2} \mathrm{~S}$ ou $\mathrm{H}_{2} \mathrm{Se}$. Porém, no caso especifico do Mo e W, alternativamente, é possível obtê-los através da decomposição de sais de amônia $\left(\mathrm{NH}_{4}\right)_{2} \mathrm{MX}_{4}$ [38,39]. Da mesma forma, a literatura reporta que também é possível a síntese desses nanotubos mediante 0 
método hidrotérmico, onde um amino orgânico seria usado como parte da componente na mistura reativa e é, através deste método, que se tem preparado nanotubos de diversos óxidos metálicos, tais como $\mathrm{SiO}_{2}, \mathrm{~V}_{2} \mathrm{O}_{5}$, $\mathrm{TiO}_{2}$ e $\mathrm{ZnO}$ [39-42]. Também, tem se reportado à obtenção de nanotubos de diferentes óxidos metálicos, tais como o óxido de zircônio, óxido de alumínio e outros, através do recobrimento de NTC com gel de óxido metálico na presença de surfactantes ou adequados moldes para nanotubos. Um exemplo desse método constitui o recobrimento de NTC com óxidos metálicos para finalmente separar os nanotubos inorgânicos dos NTC, mediante calcinação deste último [3,4]. Esta técnica também pode ser usada em membranas de alumina porosa [4]. A grande gama de materiais empregados para a fabricação de nanotubos também se estende ao uso de metais, tais como o cobre, níquel, bismuto, ferro etc. [3]; e outros materiais, incluindo os nitretos (MoN, BN, GaN e AIN). Uma maior revisão sobre os processos de síntese dos nanotubos pode se encontrar na literatura $[3,4,43]$.

Após a descoberta dos NTC, surgiu um grande interesse na síntese e caracterização de outras estruturas 1D, incluindo nanofios, nanovaras e nanocintos $[2,3,14,44]$. A literatura tem reportado inúmeros trabalhos sobre as possíveis aplicações desses sistemas [3,4,8]. Um caso particular se refere à possibilidade de usar os nanofios como componentes ativos em dispositivos eletrônicos, permitindo a fabricação de dispositivos menores e com menores tempos de resposta [2,3,7,8]. Devido a essa potencialidade, tem-se desenvolvido técnicas de síntese e caracterização de vários materiais inorgânicos, tais como materiais elementares ( $\mathrm{Si}$, Ge, B), óxidos, nitretos, carbetos e calcogênios [3,4]. As diversas técnicas empregadas podem se dividir em duas: crescimento em fase de vapor e crescimento em fase de solução. No primeiro caso, o processo começa pela simples evaporação do material precursor em uma atmosfera adequada, e que se usa para produzir nanofios elementares e nanofios de óxido; no segundo caso, o procedimento consiste no crescimento anisotrópico promovido pela estrutura cristalográfica do material sólido e 
direcionado por moldes cineticamente controlados pela supersaturação ou pelo uso adequado de agentes catalisadores [3,4,14,45]. Os dois métodos mencionados possuem variações, resumidas a seguir:

Crescimento em fase de vapor

- Vapor-liquid-solid (VLS)

- Assistido por óxido

- Vapor-sólido (VS)

- Reação térmica do carbono
Crescimento em fase de solução

- Estruturas cristalinas altamente anisotrópicas

- Síntese baseada em molde

- Solução-líquido-sólido (SLS)

- Síntese em solvente térmico

Os detalhes procedimentais de cada uma dessas técnicas podem ser encontrados na literatura $[3,4,14,44,45]$.

\subsection{Nanotubos de Silício}

Os NTC têm motivado a comunidade cientifica do mundo a dedicar esforços na compreensão dos mecanismos de formação e suas propriedades eletrônicas, devido ao seu grande potencial para aplicações nas diversas áreas da ciência e da engenharia [2,3,6,11,37]. Nesse sentido, as propriedades eletrônicas desses tubos, como já comentado, são atribuídas à sua estrutura tubular quase unidimensional e pode ser do tipo semicondutor ou metálico, dependendo do diâmetro e vetor chiral $[3,6,11]$.

Os átomos de Si possuem uma configuração eletrônica similar aos do átomo de carbono, porém, em comparação aos NTC, a síntese de nanotubos de silício (NTS) tem apresentado sérias limitações tecnológicas, que são atribuídas ao fato de que o silício tem hibridação $\mathrm{sp}^{3}$, que não ajuda a formação de estruturas tubulares $[20,23]$. No entanto, através de diversas simulações computacionais, tem-se demonstrado a existência de NTS com propriedades eletrônicas iguais ou superiores as dos NTC, dependendo da forma da abertura [21,25], que 
permitiriam diversas aplicações, tanto na área da microeletrônica, quanto na área dos sensores. Isso tem motivado a comunidade cientifica experimental a dedicar esforços na procura de métodos que permitam a síntese dos NTS [29-35].

No inicio do ano 2000, foram desenvolvidos os primeiros trabalhos baseados em simulações computacionais, que sugeriram a existência hipotética dos NTS [21-28]. A partir dos resultados obtidos mediante essas simulações, utilizando diferentes métodos computacionais, tais como a teoria de densidade funcional (DFT) [21,22], Hartree-Fock [23], Simulação Dinâmica Molecular Tigh-Binding [27], entre outras [23,24], foram sugeridos, não apenas a existência dos NTS com arranjo dos átomos de Si em forma hexagonal, pentagonal, quadrada [25], mas, também, suas propriedades eletrônicas, comparando-as com as do NTC [26].

Sob o ponto de vista químico, o silício forma ligações covalentes em coordenação tetragonal (hibridação $\mathrm{sp}^{3}$ ) e, tipicamente, cristaliza-se em uma estrutura semelhante à do diamante, diferente do carbono, que facilmente forma fortes ligações $\pi$, mediante a hibridação $\mathrm{sp}^{2}$ (transportando uma enorme variedade de moléculas orgânicas e material carbono, tais como: grafite, fulerenos, nanotubos) [29]. Devido a essas características, as estruturas tubulares ou tipo gaiola se tornam difíceis de serem formadas em $\mathrm{Si}$, uma vez que, para formar essas estruturas é necessário que as ligações $\pi$ sejam fortes para promover hibridação $\mathrm{sp}^{2}$ estáveis [29], fato que não acontece no caso do $\mathrm{Si}$, onde essa ligação tipicamente é mais fraca do que no caso do carbono $(\approx 25 \mathrm{kcal} / \mathrm{mol}$ versus $\approx 60 \mathrm{kcal} / \mathrm{mol}$ ). Por essa razão, somado ao fato de serem as ligações $\pi$ altamente reativa, apenas poucas moléculas estáveis com ligação $\mathrm{Si}=\mathrm{Si}$ são conhecidas [29]. Assim, as estruturas unidimensionais formadas com silício são basicamente nanofios, já que a hibridação $\mathrm{sp}^{3}$ favorece esta estrutura mais do que as estruturas tubulares [20,23]. No caso do carbono, ocorre uma desestabilização na coordenação trigonal planar, 
promovendo a sua cristalização estrutural em forma planar, tubular e em forma de gaiola [23].

A
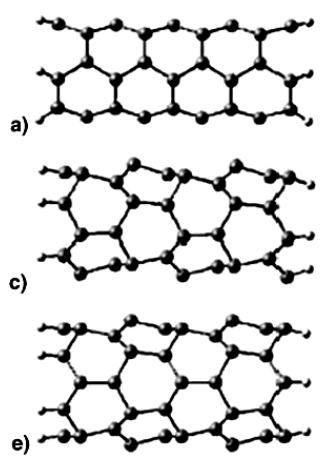
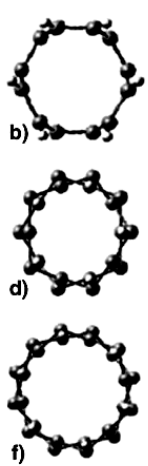

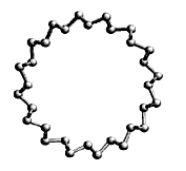

$x_{x+25}^{2 x}$

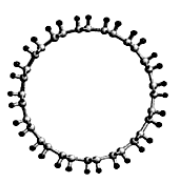

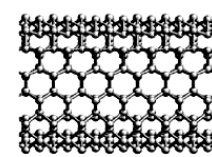

$\left(\mathrm{Si}^{-}\right)$
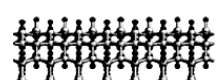

(SiH-io)

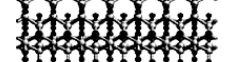

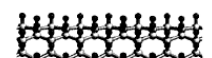

3303

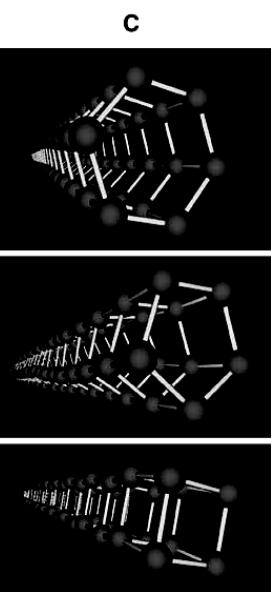

Figura 2.1. Possíveis arranjos dos átomos de silício na estrutura dos NTS. A coluna A apresenta a hipotética formação dos NTS, tipo armchair e zigzag, na hibridação $\mathrm{sp}^{2}$ [24]. A coluna B mostra três possíveis NTS baseados na hibridação $\mathrm{sp}^{3}$ [26] e a coluna C apresenta NTS com configuração tetraédrica [25].

No entanto, os modelos teóricos desenvolvidos incluem estruturas tubulares construídas em arranjos atômicos hexagonais em hibridação $\mathrm{sp}^{2}$ (estrutura do benzênico, Figura 2.1A) ou hibridação $\mathrm{sp}^{3}$ (estruturas com ligações Si-H ou aniônicas (silicatos), Figura 2.1B) [24]. Em recente trabalho, foi proposto outro tipo de estrutura, baseado em tetrágonos com átomos de silício com hibridação $\mathrm{sp}^{3}$ (Figura 2.1C) [25], o que foi interessante, já que este modelo considera a forma estável do silício. $\mathrm{Na}$ Figura 2.1 A, observa-se uma estrutura de NTS baseada na hibridação $\mathrm{sp}^{2}$ para as três configurações conhecidas, onde cada tipo de NTS é modelado com diferentes números de átomos de silício. Nessa figura, mostra-se um NTS tipo armchair $(3,3)$, que possui $\mathrm{Si}_{54} \mathrm{H}_{12}$ e duas diferentes configurações do tipo zigzag, sendo elas: $(5,0)$, onde o arranjo atômico correspondente é $\mathrm{Si}_{50} \mathrm{H}_{10}$ e $(6,0)$, que emprega um maior número de átomos $\mathrm{Si}_{60} \mathrm{H}_{10}$. Já no caso da Figura $1.1 \mathrm{~B}$, os NTS são modelados considerando os átomos de Si na hibridação $\mathrm{sp}^{3}$, com forma estrutural de siliceto (Si-) e terminações hidrogenadas, tais como $\mathrm{SiH}$-io, onde os átomos de hidrogênio se localizam em forma alternada, dentro e fora do tubo, e SiH-sf, onde os átomos $\mathrm{H}$ estão completamente localizados na 
superfície do tubo. Na coluna $\mathrm{C}$, da Figura 2.1, observam-se outras configurações sugeridas para os NTS, baseadas em tetrágonos com hibridação tetragonal $\mathrm{sp}^{3}$.

Apesar dos diversos estudos teóricos reportados sobre a possível existência dos NTS [21-28], a síntese deste material tem se tornado um desafio para a comunidade científica de todo o mundo, devido às dificuldades tecnológicas e estruturais antes comentadas [21]. No entanto, no início do ano 2000 , foram publicados os primeiros trabalhos sobre a síntese dos NTS, empregando para tal fim diversas técnicas, tais como o CVD (Figura 2.2a) [30,32], crescimento epitaxial por feixe molecular (MBE) (Figura 2.2b) [33], arco-dc de plasma (Figura 2.2c e 2.2d) [35], síntese hidrotérmica (Figura 2.2e) [31] e tratamento catalítico por plasma (Figura 2.2f) [34].

A técnica de CVD mostrou-se adequada para a síntese de NTS, tanto sobre um substrato catalisador $\mathrm{Ni}_{x} \mathrm{Mg}{ }_{y} \mathrm{O}$, quanto sobre nanocanais de alumina porosa $\left(\mathrm{Al}_{2} \mathrm{O}_{3}\right)$. Usando substrato catalisador, foram obtidos NTS com diâmetro interno entre $60 \mathrm{~nm}$ a $80 \mathrm{~nm}$ e $100 \mathrm{~nm}$ a $140 \mathrm{~nm}$ de diâmetro exterior, mediante a decloroção do $\mathrm{SiCl}_{4}$, seguido de uma deposição via CVD sobre um substrato catalisador de $\mathrm{Ni}_{x} \mathrm{Mg}_{\mathrm{y}} \mathrm{O}$, preparado através da mistura de nitrato de níquel $\left(\mathrm{Ni}\left(\mathrm{NO}_{3}\right)_{2}\right)$ ou nitrato de magnésio $\left(\mathrm{Mg}\left(\mathrm{NO}_{3}\right)_{2}\right)$ com acido cítrico. Neste trabalho, foi sugerido que a formação dos NTS poderia ter ocorrido devido a que as espécies cloradas favoreceriam a formação e encurvamento das ligações $\pi$ da estrutura do silício, o que, também, permitiria a formação de NTS em forma similar aos NTC. Os autores sugerem que o $\mathrm{SiCl}_{4} \mathrm{em}$ forma gasosa pode reagir com os átomos de Si para dar lugar a formação de híbridos e compostos clorosilício, que são de-hidrogenizados e declorados a altas temperaturas em ambiente de $\mathrm{H}_{2}$, dando lugar à formação de sistemas de silício. Os átomos superficiais do Si são passivados mediante hidrogênio, permitindo a estabilização dos NTS formados [30]. Por outro lado, os NTS também foram obtidos, como já comentado, em substrato de $\mathrm{Al}_{2} \mathrm{O}_{3}$. Nesse sentido, 
J. Sha et al. [32] reportaram a síntese de NTS, usando como molde os nanocanais de $\mathrm{Al}_{2} \mathrm{O}_{3}$, onde, previamente, foi metalizada uma camada de ouro dentro dos canais através de técnica sputtering magnético. A camada de ouro depositada serve como catalisador para o crescimento dos NTS durante o processo de CVD, porém, através desta técnica, a estrutura final é uma mistura de NTS e de nanofios de silício (NFS), dependendo se os canais têm ou não os dois lados abertos [32]. A formação dos NFS acontece naqueles canais que possuem um lado aberto e base fechada; nesta, também é depositado o ouro, que promoverá o crescimento do $\mathrm{Si}$, enquanto que nos nanocanais com os dois lados abertos, o crescimento do $\mathrm{Si}$ acontece apenas nas paredes, promovendo, assim, a formação dos NTS, com $50 \mathrm{~nm}$, aproximadamente, de diâmetro interno.

Diferentemente da técnica anterior, S. Y. Jeong et al. [33] sintetizaram NTS em substrato de alumina porosa através da técnica do MBE. Nesta técnica, os NTS são crescidos sobre as bordas e seguem o padrão estrutural dos poros da alumina porosa, porém eles estão recobertos de uma camada de $\mathrm{SiO}_{2}$ de aproximadamente $10 \mathrm{~nm}$ e as paredes possuem aproximadamente $4 \mathrm{~nm}$ a $5 \mathrm{~nm}$ de espessura, enquanto 0 diâmetro interno médio obtido é igual ao diâmetro dos poros do substrato, que, no caso, é de aproximadamente $40 \mathrm{~nm}$. $\mathrm{Na}$ análise química dos NTS, utilizando a técnica Raman, observou-se que os NTS recém-crescidos foram basicamente do tipo amorfo, porém, após tratamento térmico, a 600 ${ }^{\circ} \mathrm{C}$, durante 10 minutos, os átomos se arranjam em forma cristalina. Uma característica singular desses NTS em relação aos outros obtidos com as técnicas anteriores refere-se a que estas apresentam propriedades fotoluminescentes em $600 \mathrm{~nm}$ de comprimento de onda, que são atribuídas a efeitos de confinamento quântico [33]. 
(a)

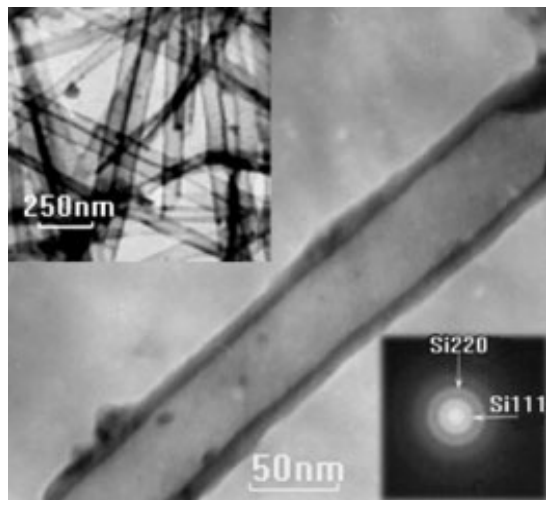

(c)

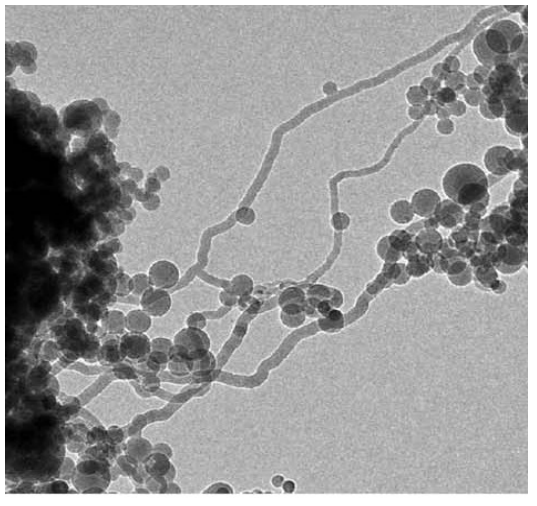

(e)

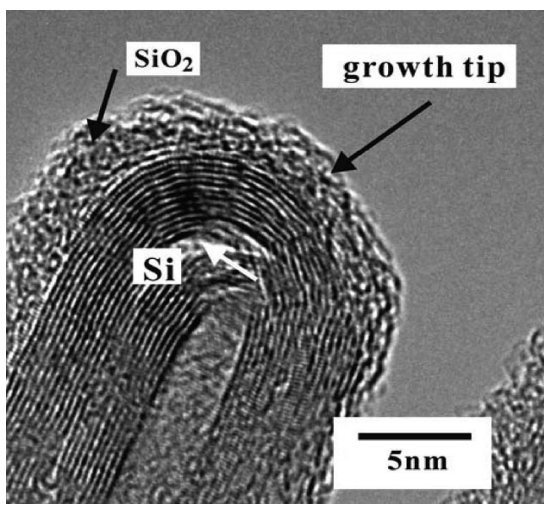

(b)

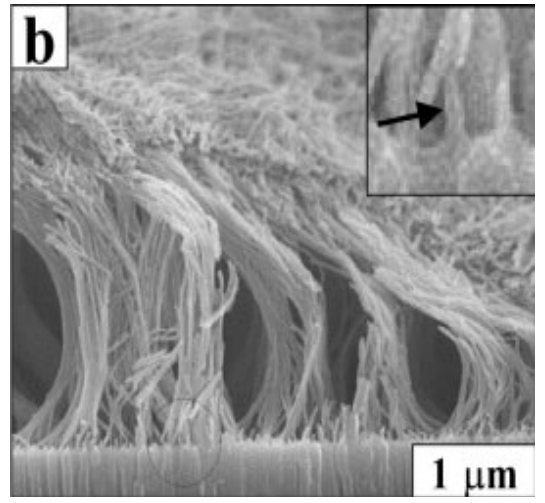

(d)

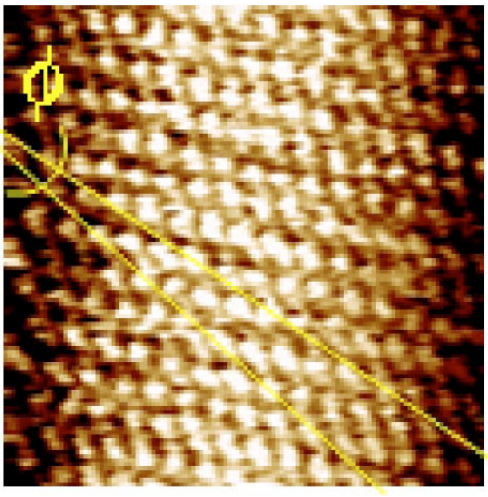

(f)

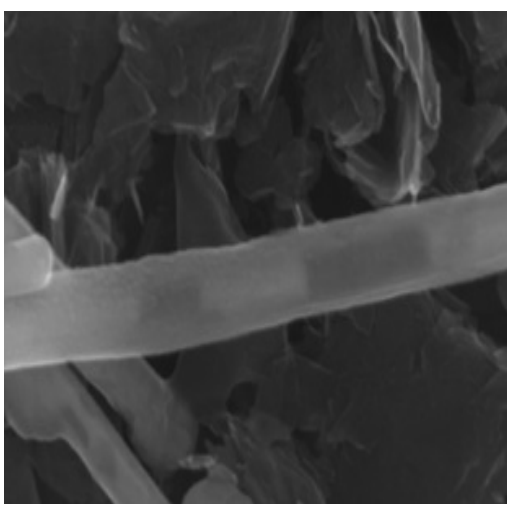

Figura 2.2. Síntese de NTS via: (a) CVD usando como molde Alumina porosa [30]; (b) MBE sobre substrato de Alumina porosa [33]; (c, d) Arco de Plasma [35]; (e) hidrotérmico supercrítico [31]; e (f) plasma catalítico [34].

Recentemente, Tang et al. [31] têm demonstrado que é possível a síntese de NTS através da técnica hidrotérmica, usando como material de partida - $\mathrm{SiO}_{2}$, o que permitiu obter NTS com diâmetro externo realmente pequeno, da ordem de $13 \mathrm{~nm}$ a $15 \mathrm{~nm}$, sem a necessidade de empregar material catalisador, enquanto que o diâmetro interno é de $3,5 \mathrm{~nm}$ [31]. Os autores sugerem que os NTS obtidos apresentam uma estrutura de paredes múltiplas separadas entre si a uma distância de 0,31 nm, aproximadamente, e cobertos por uma camada de óxido, que é removida 
com ácido fluorídrico (HF); porém, esses valores ainda estão sujeitos a questionamentos, uma vez que 0,31 $\mathrm{nm}$ poderiam apenas representar a separação entre os planos (111) e não o espaço interplanar entre as supostas múltiplas paredes do NTS. Portanto, ainda não é possível afirmar se os NTS reportados por Tang et al. [31] se tratam realmente, de uma estrutura de parede múltipla.

No entanto, De Crescenzi et al. [35] têm reportado a síntese de NTS de parede simples, empregando o método de arco-dc plasma, usando como material de partida pó de silício de alta pureza, onde o arco de plasma é obtido aplicando $75 \mathrm{~A}$ de corrente e $30 \mathrm{~V}$ de tensão. Através deste processo, apenas $10 \%$ das estruturas obtidas correspondem a NTS, enquanto os outros 90 \% estão constituídos por nano aglomerados de $\mathrm{Si}$. A análise estrutural através do MET de alta resolução mostra que esses NTS são caracterizados por apresentar diâmetros diferentes (2 nm-7 nm), com comprimento de algumas centenas de nanômetros, enquanto que a análise química, usando a técnica da espectroscopia de perda energia de elétrons (EELS), revela que os nanotubos formados são totalmente de silício e estão isentos de contaminação por oxigênio ou carbeto de silício (SiC), que poderia ter acontecido durante o processo [35]. Através da combinação das técnicas scanning tuneling microscopy (STM) e scanning tuneling spectroscopy (STS), tem se mostrado não apenas o arranjo dos átomos de silício nos NTS, mas também a correlação com suas propriedades eletrônicas. Assim, os NTS apresentam um arranjo tipo colméia, com uma estrutura que poderia corresponder ao do tipo poltrona (armchair) (Figura 2.2d) [31], que estaria em concordância com os trabalhos teóricos sugeridos [24], enquanto seu chiraliti sugere que os NTS apresentam um comportamento metálico para um ângulo zero do vetor chiral, isto é, para aquelas estruturas diferentes à configuração poltrona. Este fato representa uma característica singular dos NTS em comparação aos NTC, onde ocorre o contrário: estruturas com configuração chair possuem comportamento metálico e as outras configurações apresentam comportamento semicondutor [21]. De acordo 
com as predições teóricas reportadas na literatura para estruturas chair [21], este comportamento é típico de um arranjo com hibridação $\mathrm{sp}^{2}$, porém, devido à baixa oxidação dos NTS quando expostos a uma atmosfera de oxigênio ou ar, sugere-se que a hibridação dos NTS poderia ser a $\mathrm{sp}^{3}$ [29], já que esta estabilidade é uma característica inesperada para as ligações $\pi$ da hibridação $\mathrm{sp}^{2}[46,47,48]$.

Recentemente, a literatura tem reportado o crescimento de NTS tipo p, com diâmetro entre $50 \mathrm{~nm}$ a $80 \mathrm{~nm}$ e comprimento de $20 \mu \mathrm{m}$, aproximadamente, que foram formados sobre um substrato oxidado de $\mathrm{Si}$. As paredes desses NTS apresentam uma espessura entre $10 \mathrm{~nm}$ a 15 $\mathrm{nm}$, cujo crescimento é catalisado mediante o cobre $(\mathrm{Cu})$ em forma gasosa. Para tanto, empregou-se a técnica de tratamento do plasma por radio freqüência, onde se usou gás nitrogênio para gerar o plasma e um substrato oxidado de Si tipo p (100), como fonte do material, que se encontrava a temperatura de $500{ }^{\circ} \mathrm{C}$. A orientação de crescimento dos NTS é determinada pela orientação do campo elétrico aplicado sobre o substrato, enquanto que sua densidade e comprimento são determinados pela tensão aplicada. Outro parâmetro que afeta a formação dos NTS se refere à forma de abastecimento do $\mathrm{Cu}$, necessário para a catalisação do Si. Quando o Cu é vaporizado usando filamento cerâmico, não ocorre formação dos NTS, porém se o filamento usado é do mesmo material, isto é, também de $\mathrm{Cu}$, existe uma formação de NTS de comprimentos não muito grandes. No entanto, se o filamento para esquentar o $\mathrm{Cu}$ é trocado por um anel de molibdênio, os NTS serão de diâmetro menor e comprimento maior do que no caso anterior, podendo atingir comprimentos de até $20 \mu \mathrm{m}$ [34].

\subsection{Aplicações dos micro e nanotubos}

A morfologia tubular é altamente atrativa para aplicações em sensores, uma vez que estes podem prover três diferentes regiões de contato: superfície interna, externa, bem como as bordas dos tubos [49], o que os 
torna mais vantajosos frente às nanopartículas quando aplicados em dispositivos. Há, aproximadamente, uma década, os NTC têm se mostrado adequados para inúmeras aplicações em dispositivos nanoeletrônicos, sensores químicos e na nanobiotecnologia, devido a suas singulares propriedades químicas, eletrônicas [26] e mecânicas [48]. Os NTC têm se mostrado um ótimo material para aplicações em sensores de gases, devido a sua alta razão superfície-volume que torna suas propriedades elétricas altamente sensíveis às espécies absorvidas na sua superfície [50]. Adicionalmente, os NTC têm mostrado excelentes propriedades eletrocatalíticas e, portanto, mostroram-se como um material adequado para um novo tipo de eletrodo para aplicações em eletroanálises [51,52].

Por outro lado, como já discutido nas seções anteriores, tem-se desenvolvido diferentes métodos de síntese para a obtenção de nanotubos inorgânicos, através dos quais foram preparados um amplo número de nanotubos de óxido metálico $[3,4,45]$. Dentre esses diversos nanotubos, encontram-se os nanotubos de óxido de titânio, que são opticamente transparentes. $\mathrm{O}$ arranjo desses nanotubos mostrou-se como um ótimo sensor de hidrogênio, que exibe uma queda de resistência até quatro ordens de grandeza, quando exposto a 1000 ppm de hidrogênio à temperatura ambiente [53]. Uma nova estratégia foi desenvolvida para a síntese de nanotubos poroso e policristalino de $\ln _{2} \mathrm{O}_{3}$, com diâmetro entre $20 \mathrm{~nm}-60 \mathrm{~nm}$. Esta técnica consiste na formação camada por camada sobre o NTC, como molde em combinação, com uma subseqüente calcinação. Através desta técnica, tem-se sintetizado nanotubos com outros óxidos metálicos, tais como $\mathrm{NiO}, \mathrm{SnO}_{2}, \mathrm{Fe}_{2} \mathrm{O}_{3}, \mathrm{CuO}$ e outros, porém dentre esses nanotubos sintetizados, destacam-se os nanotubos de $\ln _{2} \mathrm{O}_{3}$, devido a sua sensitividade superior a $\mathrm{NH}_{3}$, à temperatura ambiente, bem como a sua boa reprodutibilidade e baixo tempo de resposta/recuperação, atribuído a sua alta razão superfície/volume, policristalinidade e estrutura porosa [54]. Um outro exemplo de sensor de gás desenvolvido refere-se à detecção de óxido nítroso (NO), utilizando 
nanotubos de óxido de vanádio $\left(\mathrm{NTVO}_{\mathrm{x}}\right)$. Este sensor consiste em um arranjo de $\mathrm{NTVO}_{\mathrm{x}}$, depositado sobre um chip cerâmico com dois eletrodos Ag-Pd, permitindo sua identificação por meio de elementos de aquisição e de processamento de sinais. A absorção dos diferentes gases pelo $\mathrm{NTVO}_{x}$ muda a permissividade e condutividade do material e, conseqüentemente, altera a tensão do sensor [55]. Os resultados da mudança da tensão, quando o sensor é submetido a diferentes concentrações de gás, foram determinados e mostram que a resposta do sensor ao NO é altamente sensível, bem como reversível à temperatura ambiente. Uma característica interessante deste sensor é que ele responde apenas ao NO e ao vapor de água no ar exalado, e, dependendo da concentração, torna-se útil em aplicações na detecção de contaminação envolvendo NO [55]. A literatura também reporta a síntese de nanotubos de $\mathrm{MCo}_{2} \mathrm{O}_{4}(\mathrm{M}=\mathrm{Ni}, \mathrm{Cu}, \mathrm{Zn})$, usando como molde uma membrana de alumina porosa, para aplicações em sensores de gases e mostraram-se ser altamente sensíveis a vários tipos de gases, incluindo o etanol e $\mathrm{SO}_{2}$ devido a sua característica de condutividade eletrônica 1D e sua estrutura oca [56]. Os nanotubos também têm se funcionalizado visando aplicações em biosensores, que basicamente são sensores químicos das reações bioquímicas que ocorrem no meio onde se encontra o sensor. Uma revisão detalhada sobre esse item encontra-se em $[3,57,58]$.

Algumas características gerais, que tornam os nanotubos excelentes materiais na aplicação em sensores, referem-se a sua cavidade uniforme ao longo do tubo, pois possui condutividade eletrônica e alta área superficial específica, bem como estabilidade física e química, adicionado ao fato de que, alguns desses nanotubos, também possuem uma estrutura porosa que permite incrementar ainda mais, tanto a sensibilidade quanto à seletividade. Em geral, a sensibilidade dos sensores de gases baseados em nanotubos é muito melhor do que aqueles baseados em nanofíos com a mesma composição química, devido a sua estrutura oca que pode enriquecer os gases [8]. 
Como já têm sido comentadas, as aplicações dos nanotubos não estão restringidas, apenas, à área de sensores, mas também em outros campos de interesse tecnológico. Assim, por exemplo, a literatura reporta a possibilidade do uso dos NTC como fontes emissoras de elétrons nos dispositivos de emissão de campo [3,7,59], cuja vantagem sobre os emissores de Si ou W é devida a sua configuração eletrônica covalente, tornando-o inerte à contaminação e à corrosão por sputtering [3].

Dentro da área da microeletrônica, as possibilidades de aplicação dos NTC são inúmeras, desde aplicações como interconexões com NTC metálicos [3,60] até transistores [3,7,59]. As aplicações baseadas nas propriedades eletrônicas dos NTC são de muita importância na miniaturização dos dispositivos semicondutores, uma vez que em dimensões nanométricas os semicondutores convencionais deixam de agir como tal, devido aos efeitos quânticos [3,7]. Frente a tal problemática, a alternativa de solução é a nanoeletrônica baseada em moléculas [3]. Nesse sentido, a possibilidade de usar os NTC tem despertado inusitado interesse, porém, para tal aplicação, é necessário desenvolver técnicas que permitam NTC de diferentes diâmetros e chirality [3,7]. Uma aplicação dentro da microeletrônica, refere-se ao uso dos NTC como canal entre a fonte e o dreno dos FET [3,7,13,59]. O uso dos NTC como supercapacitores também tem sido reportado, devido a sua alta acessibilidade eletroquímica da área superficial dos nanotubos, somada a sua alta condutibilidade eletrônica e suas propriedades mecânicas, que permitem a construção de capacitores com capacitância gigante, em comparação com os capacitores ordinários [3]. As aplicações dos nanotubos em sensores estão relacionadas com a facilidade de funcionalização da sua área superficial. Em forma análoga aos capacitores convencionais, os capacitores de NTC consistem em dois eletrodos separados por um material eletronicamente isolado, que é condutor iônico em dispositivos eletrônicos. Devido a esta separação ser de ordem nanométrica, resulta uma capacitância gigante, devido à grande área superficial acessível dos NTC ao eletrólito. Estas capacitâncias, 
tipicamente na ordem de $15 \mathrm{Fg}^{-1}$ a $200 \mathrm{Fg}^{-1}$, dependendo da área superficial do arranjo de nanotubos, resultam de uma grande injeção de cargas quando uma pequena tensão elétrica é aplicada [3,62,63]. Algumas outras aplicações dos NTC, reportadas na literatura, referem-se às baterias de lítio, adsorção de gases, armazenamento de hidrogênio, atuadores eletromecânicos, lasers de alta potência etc. Uma breve revisão sobre essas e outras aplicações podem ser encontradas em $[3,58]$

Desta forma, a partir da revisão do estado da arte, a existência hipotética dos NTS tem sido sugerida baseada nas simulações computacionais. Através dessa técnica, tem se estudado não apenas NTS com diferentes estruturas e formas, mas também suas propriedades eletrônicas [26] e mecânicas [48]. No entanto, após muitos anos de especulação sobre sua existência, recentemente tem se demonstrado a existência experimental dos NTS por diversos grupos de pesquisa no mundo, usando, basicamente, quatro diferentes técnicas, antes citadas [29-35]. A importância desses materiais potencializa a possibilidade de aplicações em novos dispositivos na área da nanoeletrônica, nanofotônica e sensores [29]. Contudo, apesar de ter se demonstrado a existência experimental dos NTS, é evidente que os NTS sintetizados estão longe de se ajustar às características daqueles sugeridos através dos cálculos computacionais, já que a maior parte deles apresenta paredes muito grossas, na ordem de $5 \mathrm{~nm}$ a $10 \mathrm{~nm}$, constituídas, possivelmente por ligações $\mathrm{sp}^{3}$. Adicionalmente, nenhum dos grupos descreve modelos realísticos sobre a formação e propriedades desses sistemas unidimensionais.

Ainda assim, a revisão do estado-da-arte nos mostra que os nanotubos são obtidos basicamente mediante processos de síntese do silício em diferentes substratos, e requerem a utilização de equipamentos e processos operacionais sofisticados. Nossa proposta é utilizar métodos eletroquímicos para a fabricação de micro e nanotubos, sendo necessário realizar uma revisão do estado-da-arte dos processos eletroquímicos em 
silício. Assim, a seguinte seção dedica-se a este item e suas aplicações na fabricação de micro e nanoestruturas.

\subsection{Dissolução do silício em solução aquosa fluorada ácida}

Sendo o silício instável em meio aquoso, tende a dissolver-se quando imerso em uma solução fluorada aquosa, devido a formação do óxido de silício que é removido constantemente pelas espécies fluoradas [64,65], liberando elétrons, que podem ser usados para reduzir cátions de diferentes materiais, dependendo das característica intrínsecas do material e do potencial de eletrodo. Assim, na interface silício/eletrólito ocorrem processos de oxidação e redução que, segundo o que seja predominante, pode levar à corrosão ou passivação da superfície [64-66]. Assim, dependendo da composição e concentração da solução fluorada, o eletrólito apresenta comportamentos diferentes. Nesse sentido, podemos dividir a interação do silício com o eletrólito em duas partes: (1) soluções fluoradas sem oxidantes, e (2) com oxidantes.

\subsubsection{Dissolução em ausência de oxidante}

A taxa de corrosão do silício, imerso em uma solução concentrada de HF à temperatura ambiente e em condições de potencial de eletrodo em circuito aberto (PECA), é da ordem de $10^{-4} \mathrm{~nm} / \mathrm{s}$ [67]. No entanto, em soluções diluídas, esta taxa aumenta e isto se atribui ao incremento da concentração da espécie $O H^{-}$[64,65,68]. Já que o incremento do $O H^{-}$, necessariamente, induz a um incremento no pH, então a dissolução depende fortemente do $\mathrm{pH}[69,70]$. Nesse sentido, tem sido observado, experimentalmente, que a taxa de corrosão incrementa-se rapidamente, até atingir seu valor máximo em pH 6,5, depois, decresce dramaticamente e torna-se quase nula em pH acima de 8,5 (Figura 2.3) [69]. O pico de máxima corrosão é atribuído à espécie $H F_{2}^{-}$, que mostra uma grande abundância no entorno de pH 6,5 [69-72], embora os cálculos teóricos tenham mostrado que a maior concentração desta espécie ocorre no 
entorno de $\mathrm{pH} 4,0$ [73]. Segundo Fukidome et al. [69,70], a taxa de corrosão na solução fluorada é determinada pela competência das espécies $\mathrm{HF}, \mathrm{HF}_{2}^{-}$e $\mathrm{OH}^{-}$para reagir com o Si. Mediante a Espectroscopia de Fotoelétrons Excitados por Raios X (XPS), tem-se determinado que a maior concentração das ligações $S i-F$ ocorrem em $\mathrm{pH} 6,5[70,74]$. No entanto, a baixa taxa de corrosão do Si em $\mathrm{pH}<4,5$ é decorrente da alta densidade de ligações $S i-H$, devido à abundância de íons $\mathrm{H}^{+}$resultantes da reação com o HF, enquanto que a abaixa taxa de corrosão em $\mathrm{pH}>8$ atribui-se ao decréscimo da espécie $H F_{2}^{-}$, que é altamente ativa na dissolução do $\mathrm{Si}$ e do $\mathrm{SiO}_{2}[69,70]$.

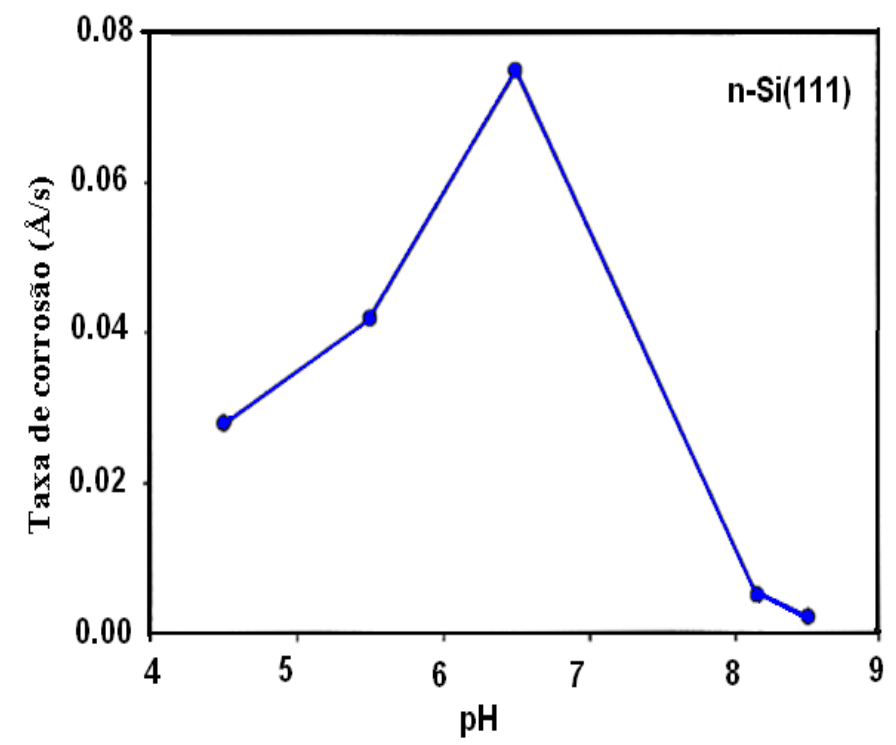

Figura 2.3. Taxa de corrosão do silício em meio fluorado em função do pH [69]

Adicionalmente, a taxa de dissolução do Si também depende do tempo [64]. Assim que o silício é imerso na solução fluorada, ocorre uma alta taxa de corrosão, decaindo ao longo do tempo. Esta alta taxa de corrosão inicial se deve à dissolução da camada do óxido de silício nativo formada sobre a superfície, que, após um período prolongado, é substituído pelas ligações $S i-H$, altamente estáveis. Isto porque as ligações $S i-H$ são praticamente não polarizadas [67]. Contrariamente, as ligações $S i-O$ são 46 \% iônicas, enquanto que as ligações $S i-F$ são $67 \%$, resultando em uma fortíssima polarização que promove o 
enfraquecimento das ligações $S i-S i$ dos átomos de silício, localizados no corpo do substrato. Assim, esses átomos tornam-se instáveis e fáceis de serem atacados pelas espécies da solução, tais como $\mathrm{OH}^{-}$e $H F$. Desta forma, no processo de dissolução do $\mathrm{Si}$ em uma solução de $\mathrm{HF}$, a substituição dos íons de hidrogênio absorvidos na superfície pelas espécies fluoradas ou pelo $\mathrm{OH}^{-}$, é o passo limitante (rate limiting step) para a corrosão, seguido de um rápido processo de quebra das ligações dos átomos de Si com o corpo (back bonds). Tal esquema de reação é mais provável em defeitos superficiais, resultando em sua remoção. De acordo com Willeke e Kellermann [67], longos períodos de imersão em uma solução de HF resultam uma superfície atomicamente plana e o decremento na taxa de corrosão devido à diminuição da densidade de defeitos sobre a superfície.

O silício pode ser dissolvido química e/ou eletroquimicamente, mesmo em soluções fluoradas, dependendo do valor de $\mathrm{pH}$ e da concentração de espécies fluoradas [75,76]. Em soluções ácidas ou concentradas, a dissolução é predominantemente eletroquímica, enquanto que em soluções diluídas, ou com pH elevado, predomina a dissolução química [64-66,69,70]. Já que em soluções concentradas a dissolução é completamente eletroquímica, a taxa de dissolução é desprezível, devido a superfície resultar passivada pelas ligações $S i-H$, que inibe a transferência de carga do $\mathrm{Si}$ ao eletrólito. Adicionalmente, em $\mathrm{pH}$ ácido, a concentração de $\mathrm{OH}^{-}$é praticamente desprezível [64,65,77-79]. Assim, o incremento na concentração de $\mathrm{OH}^{-}$provoca o incremento na taxa de corrosão em soluções diluídas. Entretanto, uma vez que a taxa de corrosão não é diretamente proporcional à concentração de $\mathrm{OH}^{-}$, isto sugere que a taxa depende da concentração superficial de $\mathrm{OH}^{-}$, onde sua absorção é muito rápida [68]. 
<smiles>C[Si](C)(C)[Si](C)(C)[Si](C)(C)[Si](C)(O)[Si](O)(O)[Si](C)(O)[Si](C)(O)[Si](C)(O)[Si](C)(C)[Si](C)(C)C</smiles><smiles>C[C@H](O)[Si](C)(C)[Si](C)(O)[Si](C)(O)[Si](O)(O)[Si](C)(O)[Si](C)(C)O</smiles><smiles>C[Si](C)(C)[Si](C)(F)[Si](C)(F)[Si](F)(F)[Si](C)(C)[Si](C)(F)[Si](C)(F)[Si](C)(C)[Si](C)(C)F</smiles>

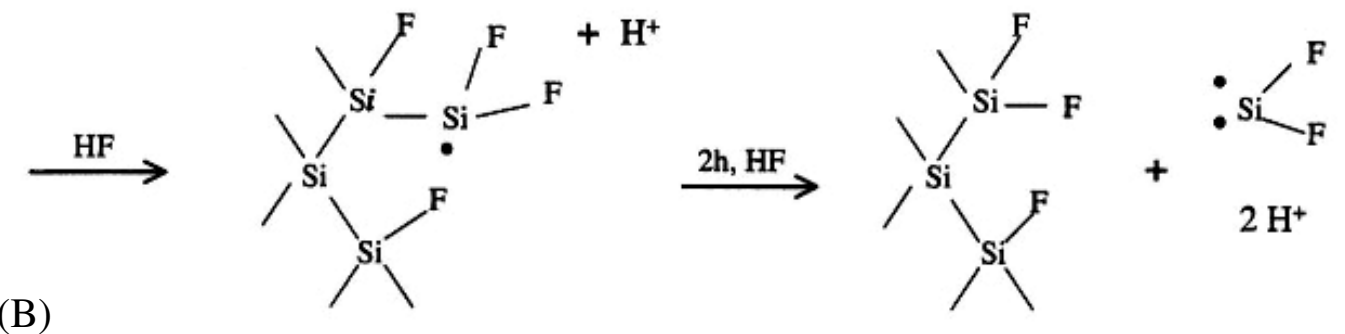

Figura 2.4 Mecanismo de dissolução anódica em solução diluída de HF (A) e em solução concentrada(B).

O mecanismo de dissolução em soluções aquosas tem se caracterizado por ser tetravalente, enquanto que em soluções concentradas é divalente $[64,65]$. Para ambos os casos, tem se sugerido diversos modelos que expliquem os mecanismos da dissolução do Si na solução fluorada, e um resumo desses modelos pode ser encontrado na literatura [64,65]. Embora a diversidade de modelos, todos concordam que, para tal fim, é necessária a presença de lacunas. O modelo proposto por Memming e Schwandt [80] para a dissolução eletroquímica segue dois caminhos diferentes, determinados pela presença dos reagentes $\mathrm{H}_{2} \mathrm{O}$ e $\mathrm{HF}$. 
Em uma solução fluorada diluída, a superfície é finalizada por grupos de hidroxilas e a reação anódica procede com a formação de $\mathrm{Si}(\mathrm{OH})_{4}$ :

$$
\mathrm{Si}+4 \mathrm{OH}^{-}+m h \longrightarrow \mathrm{Si}(\mathrm{OH})_{4}+(4-m) e \quad(m \leq 4)
$$

Onde $\mathrm{m}$ é o número de lacunas envolvidas na reação dependendo no tipo de silício. A Figura 2.4a ilustra os diferentes estágios envolvidos na reação (2.1). Nesta reação, o estágio (b) é o limitante da taxa, devido a requerer certa energia térmica de ativação para que o grupo $\mathrm{Si}(\mathrm{OH})_{2}$ consiga se impulsionar longe do respectivo átomo de silício. Em potenciais mais positivos do que o potencial de passivação, a reação rapidamente procede à formação de óxido de silício:

$$
\mathrm{Si}(\mathrm{OH})_{4} \longrightarrow \mathrm{SiO}_{2}+\mathrm{H}_{2} \mathrm{O}
$$

Sendo o $\mathrm{SiO}_{2}$ não solúvel em água, esta formação leva à passivação da superfície, porém na presença de HF, o óxido dissolve-se e produz formas complexas de flúor:

$$
\mathrm{SiO}_{2}+6 \mathrm{HF} \longrightarrow \mathrm{H}_{2} \mathrm{SiF}_{6}+2 \mathrm{H}_{2} \mathrm{O}
$$

A reação total das reações (2.1) a (2.3) são envolvidos quatro elétrons, e considera-se que ocorrem na região de eletropolimento em soluções de HF. Sendo as soluções diluídas de maior $\mathrm{pH}$ comparadas àquelas concentradas, diferentes espécies fluoradas coexistem simultaneamente e, dependendo do valor do $\mathrm{pH}$, umas prevalecerão sobre as outras $[69,70]$. Assim, em pH 6,5, predomina a espécie $H F_{2}^{-}$, portanto, esta será a principal espécie encarregada da dissolução do silício.

No caso do Si imerso em uma solução fluorada concentrada (dissolução divalente), foi proposto que o silício reage diretamente com o HF:

$$
S i+2 F^{-}+m h \longrightarrow S i F_{2}+(2-m) e \quad(m=2)
$$


A reação (2.4), ilustrada na Figura 2.4b, começa na superfície terminada por ligações $S i-F$. Quando um campo elétrico é aplicado e cruza a interface, lacunas deslocam-se para superfície. Assim, uma lacuna é capturada na superfície e uma ligação $S i-S i$ é enfraquecida (estágio a). Requer-se certa energia térmica de ativação para que o grupo $\mathrm{Si}-\mathrm{F}$ seja lançado longe do correspondente átomo de $\mathrm{Si}$, onde uma lacuna foi capturada (estágio b). Este processo é a etapa que determina a taxa (rate-determining) e podem reagir apenas se existirem lacunas capturadas por tempo suficientemente longo. O produto da reação (2.4) não é estável e tende a se transformar em uma forma tetravalente estável, mediante a subseqüente reação com o HF:

$$
\mathrm{SiF}_{2}+4 \mathrm{HF} \longrightarrow \mathrm{H}_{2} \mathrm{SiF}_{6}+\mathrm{H}_{2}
$$

A reação (2.5) resulta na evolução de $H_{2}$, que é de natureza eletroquímica e é a responsável pela valência efetiva 2 da dissolução. $\mathrm{O}$ modelo Turner-Memming explica todas as características das reações anódicas, isto é, dois caminhos diferentes de reação, uma, em soluções de HF e outra, isentas de HF. Na segunda, ocorre a passivação mediante a formação de uma camada de óxido. As espécies ativas envolvidas na dissolução, tanto em soluções diluídas quanto concentradas, são o $H F$, seu dímero $(H F)_{2}$, ou o $H F_{2}^{-}$, que se dissociam em $H F$ e $F^{-}$no entorno da superfície [65]. Porém, os íons $F^{-}$na solução não têm participação ativa nem cinética na dissolução [65,69,81].

\subsubsection{Dissolução em presença de oxidante}

Sendo que a dissolução eletroquímica do silício está condicionada à disponibilidade de lacunas, esta pode ser fornecida mediante diferentes formas, tais como: temperatura, polarização externa, iluminação e espécies oxidantes adicionadas no eletrólito [64,65,82]. Exemplos de espécies oxidantes são: $\mathrm{CrO}_{3}, \mathrm{HNO}_{3}, \mathrm{H}_{2} \mathrm{O}_{2}$, cátions de metais nobres, cujo potencial redox localiza-se na região da BV [64,65,83-85]. Dentre as 
espécies não-metálicas, a espécie mais usada é $\mathrm{HNO}_{3}$ [17,64,82], enquanto que, entre os cátions metálicos não existe uma preferência marcada sobre seu uso [85,82]. A despeito da sua capacidade de injetar lacunas na BV, ao menos duas características são comuns em todos os casos: promovem corrosão isotrópica e incrementam a taxa de corrosão [64-66].

Segundo Turner [86], a dissolução do Si em HF com oxidantes é um processo eletroquímico e ocorre em sítios anódicos locais, enquanto que, o agente oxidante é reduzido em sítios catódicos locais. Adicionalmente, sendo este um processo eletroquímico, apresenta maior taxa de corrosão em substratos altamente dopados, ao passo que em substratos levemente dopados, este é até 10 vezes menor $[87,88]$. Em conseqüência a essas reações, ocorre um deslocamento no PECA do sistema que, por sua vez, muda a concentração de dopantes na superfície [64]. Schwartz e Robbins [89] têm sugerido dois estágios na dissolução do silício em solução fluorada com espécies oxidantes. No primeiro estágio, o silício é oxidado pela espécie oxidante $\left(\mathrm{HNO}_{3}\right.$, por exemplo); seguido, no segundo estágio, da dissolução do óxido de silício pelas espécies fluoradas. Inúmeros modelos têm sido sugeridos para explicar a corrosão nestes regimes $[64,65,90]$, dentre os quais se encontra o modelo de Turner e nele se sugere que, quando o silício é imerso em uma solução aquosa de $\mathrm{HF}$ e $\mathrm{HNO}_{3}$, a dissolução segue a reação total [86]:

$$
3 \mathrm{Si}+4 \mathrm{HNO}_{3}+18 \mathrm{HF} \longrightarrow 3 \mathrm{H}_{2} \mathrm{SiF}_{6}+4 \mathrm{NO}+8 \mathrm{H}_{2} \mathrm{O}+3(4-m) h+3(4-m) e
$$

Assim, os agentes oxidantes não participam diretamente na dissolução, mas catalisam a formação da camada de $\mathrm{SiO}_{2}$, que logo é dissolvido pelas espécies fluoradas $[66,89]$. Apesar de que a análise do mecanismo de dissolução do silício, imerso em solução fluorada com oxidantes, tenha considerado apenas uma solução concentrada, o efeito catalítico dos 
oxidantes também incrementa a taxa de dissolução do silício imerso em solução diluída. Porém, dependendo do tipo de oxidante e pH, este pode ser do tipo anisotrópico [87]. Um exemplo disso é a dissolução do silício em meio de fluoreto de amônia, que apresenta uma corrosão predominantemente anisotrópica e cujos detalhes são descritos na seção seguinte.

\subsubsection{Dissolução do silício em soluções fluoradas alcalinas}

Diferente das soluções ácidas, as soluções alcalinas dissolvem o silício em forma anisotrópica [64,65]. Este é o caso do fluoreto de amônia $\left(\mathrm{NH}_{4} \mathrm{~F}\right)$, cuja taxa de corrosão é menor na direção <111>, enquanto que, a máxima taxa ocorre na direção <100>. Devido a esta característica, permite-se a obtenção de superfícies atomicamente planas em substrato (111) $[75,76]$ e completamente rugosas em substrato (100) $[74,77,78]$.

Uma vez que o $\mathrm{pH}$ do $\mathrm{NH}_{4} F$ varia entre 7 e 8 [78], a solução apresenta uma elevada concentração de $\mathrm{OH}^{-}$, que determina as características anisotrópicas da corrosão [74,75-78]. Assim, na dissolução do silício em solução de fluoreto de amônia, acontece simultaneamente, a corrosão química e eletroquímica [75,76], até mesmo em condições de circuito aberto.

Segundo a proposta de Allongue et al. [75], o mecanismo de dissolução é descrito, como segue:

Na reação química da Figura 2.5a, em soluções com $\mathrm{pH}>5$, os estágios necessariamente envolvem água molecular, desde que o HF esteja em seu estado completamente dissociado. A reação química começa com a hidrólise (estágio de A-C) das ligações superficiais $\mathrm{Si}-H$ nos sítios curvos (kink site), como mostrado na Figura 2.5c [66]. Este é um estágio ratedetermining, devido a não polaridade das ligações $S i-H$. Uma vez que as ligações $S i-H$ são substituídas pelas ligações superficiais $S i-H$, 
estas são substituídas pelas ligações $S i-F$ (estágio C - C'), polarizando as duas ligações $\mathrm{Si}-\mathrm{Si}$ que ligam o átomo superficial ao corpo, devido à forte eletronegatividade das ligações $S i-F$. Isto favorece o rompimento químico das ligações $\mathrm{Si}-\mathrm{Si}$ que sustentavam o átomo superficial ao corpo (estágio $\mathrm{C}-\mathrm{D}$ ) e, automaticamente, liga $\mathrm{o}$ átomo $\mathrm{H}$ ao átomo $\mathrm{Si}^{-\delta}$ ancorado na superfície, e o grupo $\mathrm{OH}^{-}$liga-se ao $\mathrm{Si}^{+\delta}$, que por sua vez, está ligado ao átomo $\mathrm{F}$. Finalmente, o átomo de silício entra na solução na forma instável $H \operatorname{SiF}(\mathrm{OH})_{2}$. A seguir, o $\mathrm{H}$ é hidrolisado na solução e é gerada uma segunda molécula de hidrogênio [91]. O estado $A$ ' é idêntico ao estado $A$, logo, o processo repete-se continuamente. A condição para que as ligações $\mathrm{Si}-\mathrm{OH}$ sejam substituídas pelas ligações $S i-F$ na superfície ou, após o átomo ter entrado na solução, depende unicamente da cinética. $O$ modelo apresentado é muito similar àquele proposto para a corrosão via $\mathrm{NaOH}$, exceto que os grupos $\mathrm{OH}^{-}$podem ser substituídos rapidamente pela espécie fluorada, antes de ser removido o átomo de silício da superfície [91].

Adicionalmente, são apresentadas duas situações na reação eletroquímica: uma com polarização anódica e outra em circuito aberto. Porém, neste caso, somente consideraremos aquele que ocorre em circuito aberto. $\mathrm{Em} \mathrm{pH}>4$, a dissociação das ligações $\mathrm{Si}-\mathrm{H}$ (estágio A B') torna-se reversível, já que os estados de superfície associados ao radical de silício são ocupados em circuito aberto. 
(a) Reação química

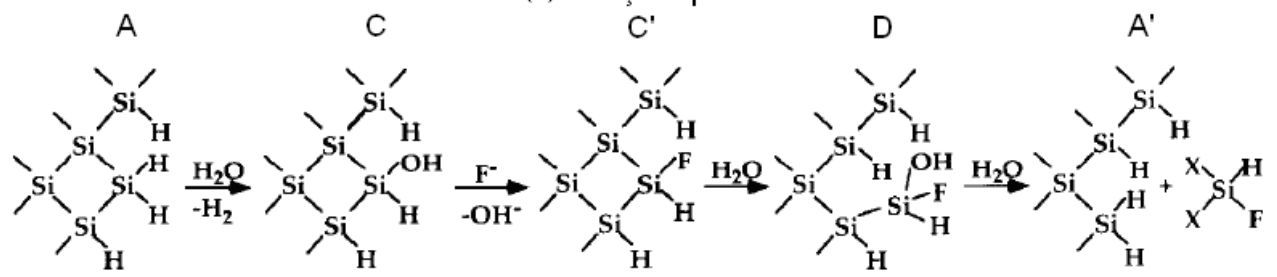

(b) Reação eletroquímica

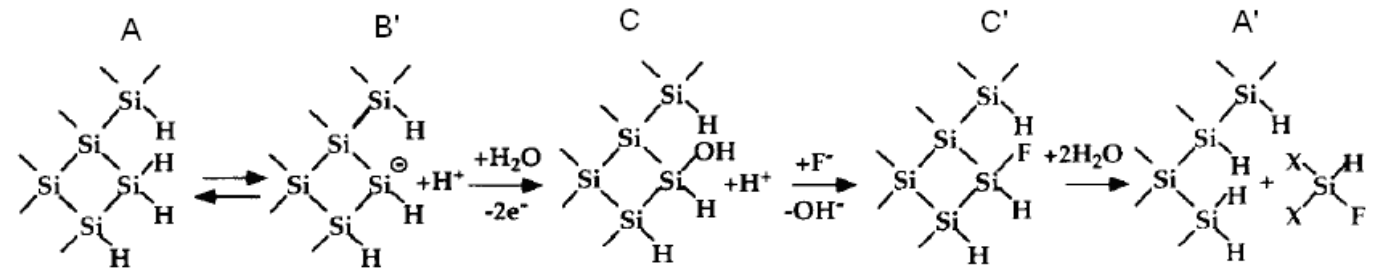

(c)

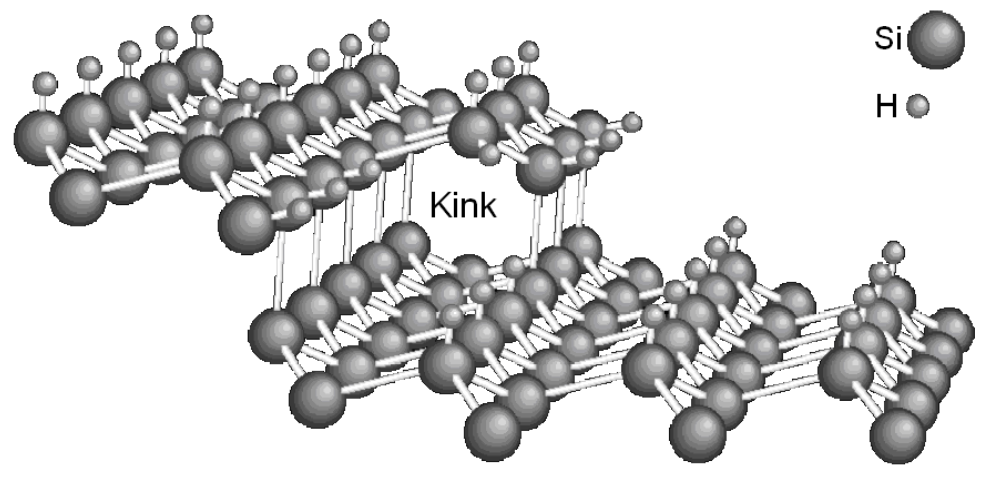

Figura 2.5 Mecanismo de dissolução (a) química e (b) eletroquímica do silício em fluoreto de amônia [75]; e (c) superfície Si(111) mostrando os sítios kink [66]

No primeiro passo, pode-se considerar a dissociação ácido-base com os íons $F^{-}$agindo como bases Lewis. $O$ grupo de átomos de silício, negativamente carregados (o estado B' é um átomo de silício com dois elétrons), reage com água molecular para formar as ligações $\mathrm{Si}-\mathrm{OH}$, como visto no caso do $\mathrm{NaOH}$ [91], e libera um segundo próton. No estágio B'- C, os dois elétrons excedentes são, provavelmente, injetados nos dois estágios subseqüentes. No primeiro estágio, durante a aproximação das moléculas $\mathrm{OH}_{2}$, os elétrons são termicamente ativados e reduzem as forças repulsivas entre os átomos superficiais e $\mathrm{O} \mathrm{OH}_{2}$, enquanto que, no segundo, os elétrons são injetados durante a formação das ligações $\mathrm{Si}-\mathrm{OH}$. Finalmente, a remoção dos átomos de Si segue o mesmo caminho daquele observado na reação química. 
É importante indicar que, no caso das soluções diluídas, estas também podem ser alcalinas (fluoreto de amônia, por exemplo), e, ainda nessas condições, as equações que descrevem o mecanismo de dissolução continuam a ser validas, embora que, no caso do $\mathrm{NH}_{4} \mathrm{~F}$, ocorre não apenas a dissolução pelas espécies fluoradas, mas também pela contribuição da amônia e das hidroxilas que a dotam da característica anisotrópica.

\subsubsection{Dissolução do silício em soluções alcalinas não fluoradas}

As soluções alcalinas pertencem a outro grupo amplamente usado na corrosão do silício. Nesse grupo, as soluções mais comumente usadas são o $\mathrm{KOH}$ e o $\operatorname{EDP}[17,64,65]$, enquanto que, o $\mathrm{NH}_{4} \mathrm{OH}$ e $\mathrm{O} \mathrm{NaOH}$ são usadas com menor freqüência $[64,65]$. Todas essas soluções apresentam similar comportamento na dissolução do silício, e este tem sido atribuído à participação ativa das espécies $\mathrm{OH}^{-}$e $\mathrm{H}_{2} \mathrm{O}$, sendo a participação dos cátions de pouca importância [65]. A seguir são citadas as características mais comuns da corrosão anisotrópica [64,65]:

- A taxa de corrosão dos planos cristalinos (111) do Si é duas ordens de grandeza menor do que em qualquer outro plano.

- A taxa de corrosão entre os outros planos cristalinos (100) e (110), dependem da concentração da solução e a temperatura, porém, nunca excedem o fator de dois.

- Agentes oxidantes adicionados à solução alcalina diminuem a anisotropia da corrosão.

- A taxa de corrosão do óxido de silício é muito menor daquele observado no silício.

- Substratos altamente dopados apresentam menor taxa de corrosão do que os substratos levemente dopados.

- A superfície do silício implantado com C, N, ou Ge resultam ser mais resistentes à corrosão alcalina e podem ser usados como máscaras. 
- A taxa de corrosão no plano (100) obedece à relação de Arrhenius com energias de ativação entre $0,3 \mathrm{eV}$ e $0,6 \mathrm{eV}$, dependendo da solução alcalina.

- A dissolução do silício em solução alcalina ocorre sob evolução de hidrogênio com uma proporção de duas moléculas de $H_{2}$ por cada átomo dissolvido. Porém, esta razão pode ser diminuída mediante a adição de espécies oxidantes na solução.

- Durante a dissolução alcalina, a superfície é coberta com ligações $\mathrm{Si}-\mathrm{OH}$ e $\mathrm{Si}-\mathrm{H}$, cuja razão depende do $\mathrm{pH}$ e a temperatura.

Como comentado anteriormente, a dissolução do silício em soluções alcalinas é atribuída às espécies $\mathrm{OH}^{-}$e $\mathrm{H}_{2} \mathrm{O}$ [64,65,92,93]. Isto foi comprovado mediante a imersão de amostras de silício em soluções alcalinas orgânicas, onde se observou, nessas condições, que a taxa de corrosão do Si aproximou-se de zero, enquanto que em soluções aquosas esta é incrementada em taxas na ordem de 0,2 $\mu \mathrm{m} / \mathrm{min}[64,65]$.

De forma análoga à dissolução do silício imerso em solução fluorada, tem-se proposto diversos mecanismos que expliquem a dissolução em meio alcalino. Uma revisão mais detalhada sobre esse item pode ser encontrado em [64,65]. Nesse sentido, Palik et al. [64,65,92-94] sugerem que a dissolução do silício, imerso em solução de $\mathrm{KOH}$ (circuito aberto) é de natureza química e envolve $\mathrm{O}$ ataque das moléculas $\mathrm{H}_{2} \mathrm{O}$ às ligações $\mathrm{Si}-\mathrm{Si}$, e este dá lugar à formação das ligações $\mathrm{Si}-\mathrm{H}$ e $\mathrm{Si}-\mathrm{OH}$. O ataque às ligações $S i-H$ da superfície (100) inicia-se com o ataque núcleofílico por parte do $\mathrm{OH}^{-}$, isto é, doando elétrons do $\mathrm{OH}^{-}$(estágio (1) da Figura 2.6a), através da qual uma ligação $S i-H$ é substituída pela ligação $\mathrm{Si}-\mathrm{OH}$ mediante a formação de $\mathrm{H}_{2}$. No estágio (2), a segunda ligação $\mathrm{Si}-\mathrm{H}$ também é substituída pela ligação $\mathrm{Si}-\mathrm{OH}$ e envolve nova evolução de $\mathrm{H}_{2}$. Assim, as ligações $\mathrm{Si}-\mathrm{OH}$ enfraquecem as ligações $\mathrm{Si}-\mathrm{Si}$ do átomo superficial com a do corpo, o suficiente para que as moléculas de água possam quebrar essas ligações. Este ataque é 
mostrado nos estágios (3) e (4) da Figura 2.6a. O produto final da dissolução dos átomos superficiais resulta em $\mathrm{SiO}_{2}(\mathrm{OH})_{2}^{2-}$, ao tempo que a superfície é coberta por ligações $S i-H[64,65]$. Se o estágio (1) é ratelimiting, a superfície será passivada por hidrogênio e torna-se hidrofóbica, ao passo que se é o estágio (3) for rate-limiting, então a superfície será hidrofílica e recoberta com silanol.

(a)

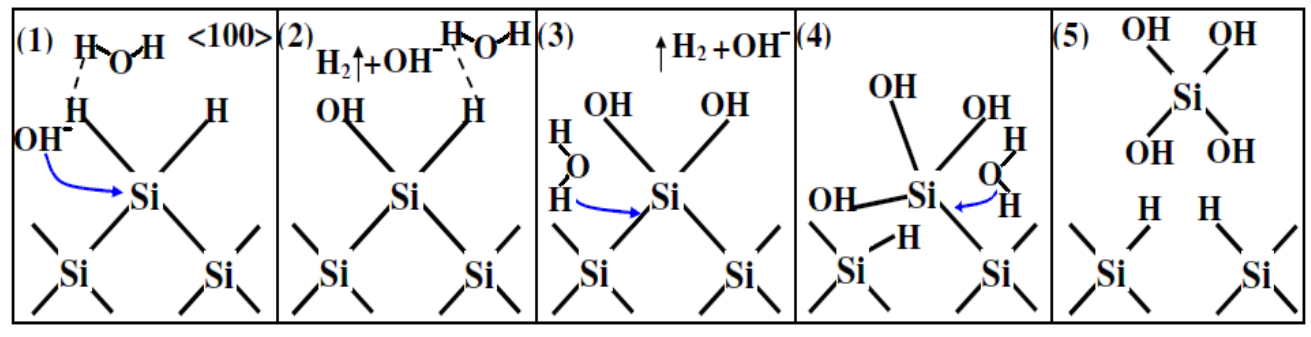

(b)

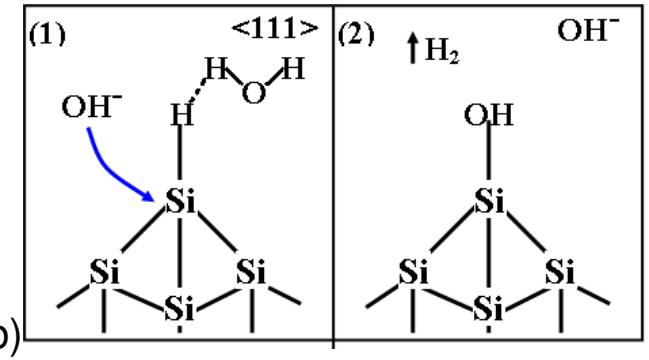

Figura 2.6. Mecanismo de dissolução do silício em $\mathrm{KOH}$ proposto por Palik [65] nos planos cristalinos (a) (100), e (b) (111).

Uma vez que o produto final é um silicato $\mathrm{SiO}_{2}(\mathrm{OH})_{2}^{2-}$, sugere-se que a reação total é:

$$
\mathrm{Si}+2 \mathrm{H}_{2} \mathrm{O}+2 \mathrm{OH}^{-} \longrightarrow \mathrm{Si}(\mathrm{OH})_{2} \mathrm{O}_{2}^{2-}+2 \mathrm{H}_{2}
$$

Esta reação, tem uma razão de Si: $H_{2}$ :portador (1:2:0). A baixa taxa de corrosão dos planos (111) pode ser interpretada como uma insuficiente polarização do átomo de Si pela ligação superficial $\mathrm{Si}-\mathrm{OH}$, sendo esta insuficiente para polarizar as três ligações $\mathrm{Si}-\mathrm{Si}$ com o corpo, como se mostra na Figura 2.6b. No entanto, as duas ligações $\mathrm{Si}-\mathrm{Si}$ podem ser facilmente polarizadas pelas duas ligações $\mathrm{Si}-\mathrm{OH}$ da superfície (100) ou (110), como se mostra na Figura 2.6a. Assim, a fraca polarização, induzida pela única ligação $\mathrm{Si}-\mathrm{OH}$ do plano cristalino (111), reduz a 
probabilidade do ataque nucleofílico das ligações com o corpo. $\mathrm{Na}$ superfície (111), a corrosão começa nos sítios kink (Figura 2.6c), presentes nas bordas dos terraços, enquanto que a superfície do terraço não é atacada [65,95].

\subsection{Aplicações da eletroquímica dos semicondutores à formação de estruturas.}

A eletroquímica do silício tem sido usada amplamente na área da microeletrônica [17,64,65,96], fotônica [97-100], sensores [97,99-102], micro [103-107] e nanotecnologia [85,107-109,113-120], entre outras aplicações, com muito sucesso. Para tanto, tem-se empregado as técnicas de corrosão e deposição química e eletroquímica, tanto com polarização externa, quanto em circuito aberto.

Processos de corrosão em substrato de silício foram desenvolvidos mediante diferentes técnicas, como exemplo, a anodização externa, assistência de metais e oxidantes fortes (stain etching). Através dessas técnicas, tem-se desenvolvido processo de eletropolimento, úteis na microeletrônica, e a formação de estruturas de silício poroso (SP), que possuem uma elevada densidade superficial na ordem de $700 \mathrm{~m}^{2} / \mathrm{cm}^{3}$ [97].

Desde a descoberta da fotoluminescência a temperatura ambiente no início da década 90, o PS tem sido utilizado em inúmeras aplicações para diversas áreas, tais como a eletrônica, fotônica, microestruturas, sensores etc. [64,99-102], devido as suas interessantes propriedades físicas e químicas que podem ser moduladas mediante a variação dos parâmetros eletroquímicos durante o processo de corrosão. Assim, na área da optoeletrônica, foram fabricados diodos emissores de luz (LED) de diferentes cores, aproveitando suas propriedades eletroluminescentes [98], enquanto que na área das microestruturas, tem se formado microestruturas estáticas, onde o SP apenas é usado como material sacrificial para a formação de cantilevers, membranas, agulhas, etc [121]. 
Porém, as aplicações do SP na área das microestruturas não estão unicamente restringidas a usá-las como material sacrificial, mas também como material estrutural dos MOEMS (micro-optoelectronic mechanics systems), podendo esta participar ativa e dinamicamente como parte da estrutura, como reportado por Lammel et al. [122] na fabricação de um microespectrômetro. Em aplicações no campo da fotônica, o SP tem sido usado para a fabricação de cristais fotônicos 1D, 2D e 3D, devido ao índice de refração do SP ser facilmente modulado através do adequado controle dos parâmetros eletroquímicos. Esta característica permite a formação de estruturas fotônicas 1D, 2D e, eventualmente, 3D [99101,123]. Os cristais fotônicos unidimensionais são formados através de estruturas multicamadas em forma periódica, onde cada camada obedece a Lei de Bragg [100,101,123]. Estas camadas são obtidas mediante a variação periódica da densidade de corrente e o tempo de anodização, enquanto que os cristais fotônicos bidimensionais são formados mediante o emprego de litografia para definir as células fotônicas unitárias e, subseqüentemente, procede-se à formação da camada porosa [97, 99].

Entre as diversas aplicações na área de sensores, podemos mencionar aquelas voltadas a sensores químicos e biológicos que são fabricados mediante a funcionalização de estruturas de SP, e são favorecidas pela alta reatividade da microestrutura aos agentes externos [97]. Este tipo de sensor pode ser agrupado em duas classes. No primeiro grupo, podemos considerar àqueles desenvolvidos em camadas simples e que, geralmente, são usados como sensores do tipo amperométrico ou potenciométrico. Estes sensores são condicionados em meios químicos e/ou biológicos e os resultados das reações que ocorrem na interface funcionalizada promovem variações de sinais elétricos [97]. O segundo grupo de sensores refere-se à aplicação das estruturas fotônicas, como sensores ópticos. Neste tipo de sensor, as estruturas são previamente funcionalizadas e as interações químicas ou biológicas que acontecem dentro da matriz porosa com o meio podem ser monitoradas através da variação da fotoluminescência [97,102], refletância, transmitância ou 
deslocamento da banda fotônica [13,101,123], dependendo da estrutura fotônica empregada.

Por outro lado, os processos stain etching foram empregados para a obtenção de estruturas porosas de silício [85,108,107,109] que, também, poderiam apresentar propriedades fotoluminescentes, de similar comportamento aqueles observados no SP formado por meio da corrosão anódica. Neste último caso, o comprimento de onda da fotoemissão está correlacionado com o tipo de oxidante [109,124]. Quando nos processos stain etching são adicionados, principalmente, cátions de metais nobres, estes se depositam sobre a superfície do silício em forma de nanopartículas e agem como ótimos catalisadores na corrosão do silício e, dependendo do tipo de metal, podem formar micro e nanoestruturas, tais como: agulhas, nanopartículas, e estruturas metálicas tipo dendritos $[82,85,108,107,113-120]$.

Recentemente, a literatura tem reportado muitos estudos sobre os processos eletroquímicos em substrato de SP, utilizados como matriz hospedeira para a deposição de metais [117] e/ou molde para a formação de micro e nanoestruturas [103-105,125]. Os estudos nesta área estão voltados principalmente à funcionalização e deposição de materiais orgânicos e metais, dentro da estrutura porosa, visando aplicações na área de sensores, microeletrônica, optoeletrônica e fotônica [117]. Nesse sentido, diferentes metais têm sido depositados por técnicas de imersão, químicas (electroless) e eletroquímicas [117,125]. Entre os metais depositados de maior importância, tanto tecnológica quanto científica, pode-se citar o $\mathrm{Au}, \mathrm{Ag}$, e $\mathrm{Cu}$, por serem utilizadas em contatos ôhmicos para a fabricação de diodos e sensores [117]. Entretanto, na atualidade despertou-se grande interesse na deposição de materiais magnéticos dentro do substrato de SP, com o intuito de adicionar-lhe propriedades magnéticas que o SP não apresenta na sua forma natural. Adicionalmente, as técnicas eletroquímicas também foram empregadas para a deposição de nanopartículas magnéticas sobre substrato de SP, 
devido as suas interessantes propriedades magnéticas e ópticas [118120]. A forma geométrica e as propriedades singulares dos materiais magnéticos formados dentro do SP dependem fortemente da microestrutura do matriz hospedeira, uma vez que elas assumem a forma geométrica da estrutura microporosa e definem as propriedades químicas e físicas das nanopartículas [118-120].

Como comentado anteriormente, existem diferentes métodos eletroquímicos de deposição que são empregadas para depositar metais na estrutura porosa do SP. Dentre essas técnicas, os métodos electroless e por imersão têm-se mostrado como os mais eficientes para depositar metais em camadas profundas com alta razão de aspecto [125]. Adicionalmente, as técnicas electroless e de imersão destacam-se, também, por serem técnicas de baixo custo e que permitem realizar uma deposição profunda [125]. Contudo, a principal desvantagem dessas técnicas é que metais menos nobres nem sempre podem ser depositados na estrutura porosa, devido a seu potencial redox ser mais negativo ao do hidrogênio. Através do método de imersão foram depositados Co, W, Mn, $\mathrm{Fe}, \mathrm{Ni}$, etc., usando eletrólitos baseados em sais metálicos, tais como: $\mathrm{NiSO}_{4}, \mathrm{CuSO}_{4}, \mathrm{NiCl}_{2}$, e outros [125-129].

Outros exemplos de aplicações utilizando as técnicas eletroquímicas, sobre substrato de SP, referem-se às formações de nanoestruturas tais como: nanocompositos [117], nanopartículas [119,120] e nanofios [105,113-116]. Adicionalmente, o SP, também, tem sido usado como molde, aproveitando sua estrutura tubular, para formar nanofios magnéticos sobre substrato tipo $\mathrm{n}$ e cujas propriedades magnéticas e magneto-ópticas são altamente anisotrópicos e dependem fortemente da forma da estrutura porosa, bem como da espessura de metal depositado e dos processos posteriores [113-116]. Analogamente, as nanopartículas magnéticas formadas na estrutura porosa podem apresentar propriedades superparamagnéticas em forma anisotrópica, dependendo da estrutura do SP e do tamanho das partículas magnéticas [118-120]. Adicionalmente, o 
SP também tem sido empregado como molde para replicar estruturas metálicas via eletrodeposição [105, 130-131] ou deslocamento galvânico [129].

Para a deposição de metais, tanto sobre substrato de $\mathrm{Si}$, quanto no SP, geralmente tem sido empregado banhos ácidos ou alcalinos, classicamente empregados na eletrodeposição [105,117], porém recentemente alguns trabalhos reportam o uso de banhos baseados em substancias fluoradas ( $\mathrm{HF}$ e $\mathrm{NH}_{4} \mathrm{~F}$ ) para a deposição electroless de alguns metais $(\mathrm{Ni}, \mathrm{Cu}, \mathrm{Fe})$ em meio fluorado ácido ou alcalino [126-129]. Em geral, esses dois produtos são empregados na corrosão do silício para a obtenção de SP ou decapagem nos processos de limpeza do $\mathrm{Si}$ $[17,97]$. Nas ultimas décadas, as técnicas de corrosão química e eletroquímica têm despertado muito interesse no campo da micro e nanotecnologia na pesquisa de novos materiais, devido a sua simplicidade e baixo custo do processo. Por outro lado, a literatura não revela algum processo de corrosão desenvolvido sobre o substrato de SP, além daquele empregado como forma de eletropolimento [17,97]. É por isso que nossa proposta é desenvolver nano e microtubos de silício mediante corrosão química e eletroquímica usando como material de partida o SP.

\subsection{Conclusões parciais}

Segundo o estado-da-arte, apesar de existir uma grande variedade de nanotubos fabricados com os mais diversos materiais e empregando diferentes técnicas, o grande desafio para a comunidade cientifica é a síntese dos nanotubos de silício devido a suas propriedades físicas e químicas que são superiores à dos nanotubos de carbono. Embora que tem se sugerido a existência hipotética de esses materiais, através de métodos computacionais, existem ainda dificuldades tecnológicas para a sua síntese, e estas estão basicamente relacionados com as características estruturais do $\mathrm{Si}$ que não favorecem a formação de 
estruturas tubulares, devido às ligações $\mathrm{sp}^{3}$. Considerando que a fabricação dos NTS é uma nova área de pesquisa, os resultados até agora conseguidos ainda estão em fase inicial e para atingir um nível de maturidade, que permita usá-los nas diversas áreas da tecnologia, será necessário o desenvolvimento de novas técnicas de obtenção e da elucidação dos diferentes mecanismos de formação em cada técnica. Nesse sentido, a nossa proposta de pesquisa é o desenvolvimento de micro e nanotubos de silício baseados em processos de corrosão química e eletroquímica que, a diferença das outras tecnologias, é uma técnica de baixo custo, uma vez que não precisa de equipamentos sofisticados, nem materiais precursores, que são caros e tóxicos, para seu funcionamento e limitam sua produção em massa. Os micro e nanotubos de silício serão obtidos usando o SP como material de partida que, além de ser uma tecnologia de baixo custo, é de amplo domínio em nosso grupo de pesquisa que vem trabalhado, na atualidade, no desenvolvimento das diferentes potenciais aplicações visando seu uso principalmente na área de sensores. 


\section{CAPÍTULO III}

\section{Procedimento Experimental}

Neste CAPÍTULO são apresentados os materiais e equipamentos empregados durante o desenvolvimento deste trabalho para a obtenção das diferentes estruturas tubulares mediante a tecnologia do SP usando métodos eletroquímicos.

\subsection{Materiais e equipamento}

- Silício tipo p com resistividades de $10 \Omega \mathrm{cm}$ e 0,005 $\Omega \mathrm{cm}$ e orientação cristalográfica (100) em ambos os casos.

- Ácido fluorídrico (48\%) grau p.a

- Alumínio grau eletrônico.

- Etanol grau p.a

- Pentano grau p.a

- Dimetilformamida (DMF)

- Água deionizada

- Sulfato de níquel $\left(\mathrm{NiSO}_{4} \cdot 6 \mathrm{H}_{2} \mathrm{O}\right)$

- Nitrato de níquel $\left.\left(\mathrm{Ni}\left(\mathrm{NO}_{3}\right)_{2} \cdot 6 \mathrm{H}_{2} \mathrm{O}\right)\right)$

- Sulfato de cobalto $\left(\mathrm{CoSO}_{4} \cdot 6 \mathrm{H}_{2} \mathrm{O}\right)$

- Sulfato de sódio $\left(\mathrm{Na}_{2} \mathrm{SO}_{4} \cdot 6 \mathrm{H}_{2} \mathrm{O}\right)$

- Nitrato de manganês $\left(\mathrm{Mn}\left(\mathrm{NO}_{3}\right)_{2}\right)$

- Fluoreto de amônia $\left(\mathrm{NH}_{4} \mathrm{~F}\right)$

- Fonte de corrente continua Keithey 236 modulável entre 0-100 mA controlada por computador

- Célula eletrolítica de simples compartimento com diâmetro de 0,8 $\mathrm{cm}^{2}$ de área de anodização

- Eletrodos de platina com área de $1 \mathrm{~cm}^{2}$ aproximadamente.

- Eletrodo de referência $\mathrm{Ag} / \mathrm{AgCl}$.

- Capilar de Luggin 
- $\mathrm{pH}$-metro

- equipamento potenciostático $\mu \mathrm{AUTOLAB}$ type III/FRA2.

- Forming gas $\left(\mathrm{H}_{2}+10 \% \mathrm{~N}_{2}\right)$

- Programa GRANUL desenvolvido pelo prof. Dr. Hae Yong Kim do Laboratório de Processamento de Sinais da USP [134].

- Espectro Raman fornecido pelo Instituto de Química da USP

- Microscópio de varredura (MEV) NOVA 400 Nano SEM e PHILIPS $\mathrm{XL}-30$.

\subsection{Formação dos micro e nanotubos de silício.}

O procedimento experimental para a obtenção das estruturas tubulares passa por três estágios: (1) Limpeza inicial e metalização das amostras, (2) Obtenção das camadas de silício (macro ou mesoporoso), e (3) obtenção dos nano ou microtubos de silício, conforme o caso. Os detalhes são apresentados a seguir.

\subsubsection{Limpeza e preparação das amostras.}

Para o processo de formação das estruturas tubulares mediante a tecnologia do PS foi necessário o estudo prévio do efeito do alumínio sobre a estrutura porosa e sobre o processo de corrosão química no meio alcalino. Para tanto, todas as amostras foram previamente limpas mediante o procedimento padrão de limpeza inicial usado na microeletrônica [97], cujo procedimento é apresentado sucintamente a seguir:

- Imersão durante 15 minutos em $\mathrm{H}_{2} \mathrm{SO}_{4}: \mathrm{H}_{2} \mathrm{O}_{2}(3: 1)$ a $105^{\circ} \mathrm{C}$

- Enxágüe durante 10 minutos em água deionizada

- Imersão durante 5 minutos em cascatinha

- Imersão durante 15 minutos em $\mathrm{H}_{2} \mathrm{O}: \mathrm{NH}_{4} \mathrm{OH}: \mathrm{H}_{2} \mathrm{O}_{2}(5: 1: 1)$ a $75 \stackrel{\circ}{\circ} \mathrm{C}$

- Enxágüe durante 10 minutos em água deionizada

- Imersão durante 5 minutos em cascatinha 
Algumas dessas amostras foram metalizadas com uma camada de $500 \mathrm{~nm}$ de alumínio $(99,998 \%$ de pureza) na face polida ou nas costas da amostra, bem como em ambas as faces. Para isso foi empregada a técnica de evaporação que permite atingir facilmente a espessura mencionada. Apesar de que a maior parte das amostras foi metalizada com $500 \mathrm{~nm}$ de $\mathrm{Al}$, algumas delas foram metalizadas com espessuras menores ou maiores e estão resumidas na Tabela 3.1, onde as siglas MP, MC e MCP identificam as amostras metalizadas na face polida, nas costas e em ambas às faces, respectivamente, enquanto que as amostras não metalizadas estão identificadas com a sigla NM. Após a metalização, as amostras foram submetidas a recozimento térmico em ambiente de forming gas $\left(\mathrm{N}_{2}+10 \% \mathrm{H}_{2}\right)$ a $500{ }^{\circ} \mathrm{C}$ durante diferentes intervalos de tempo ( 0,5 horas -8 horas) com o intuito de promover uma maior difusão do $\mathrm{Al}$ dentro do Si permitindo assim a formação de spikes ou agulhas dentro do substrato de silício $[96,135,136]$. Posteriormente, a camada de Al sobre o Si é removido mergulhando as amostras em uma solução de HF por um período de 5 minutos a 30 minutos, dependendo da espessura do $\mathrm{Al}$ depositado. Este processo deixa visível a formação de orifícios com forma de pirâmide invertida conhecidas como pits. Estes são formados como conseqüência da migração do $\mathrm{Si}$ dentro do $\mathrm{Al}$ e vice-versa durante $\mathrm{O}$ processo de recozimento térmico [87,96]. Durante o processo de anodização das amostras, os pits darão lugar à formação de poros com forma retangular, como serão discutidos na seção a seguir.

\subsubsection{Formação das camadas de silício poroso}

Após o processo de preparação das amostras, segundo detalhado na seção anterior, seguiu-se a formação das camadas de silício macro e mesoporoso. A formação da estrutura macroporosa foi feita sobre substrato tipo $p$ em solução eletrolítica não-aquosa baseada em uma mistura de dimetilformamide (DMF) e ácido fluorídrico (HF) com pureza analítica (48 \%) cuja proporção em volume foi de (3:22, v/v). A formação dos poros teve lugar na face polida do Si mediante a polarização da célula 
eletrolítica com $12 \mathrm{~mA} / \mathrm{cm}^{2}$ de densidade de corrente durante 20 minutos. Para tanto, a amostra foi colocada sobre uma placa de cobre e fixada mediante a tampa que também é encarregada de delimitar a área de corrosão e vedar aquelas áreas que não serão corroídas. Durante o processo de anodização, o eletrólito foi agitado mecanicamente por meio de um motor destinado a remover as bolhas de hidrogênio que evoluem durante o processo de corrosão decorrente da anodização do Si [64], e também manter constante a concentração de HF na interface de corrosão.

Para a formação dos nanotubos de silício usou-se como material de partida amostras mesoporosas obtidas mediante a anodização do silício altamente dopado tipo $p$ com $\rho=0,005 \Omega \mathrm{cm}$ em uma solução aquosa de HF:etanol (3:7) aplicando uma densidade de corrente de $50 \mathrm{~mA} / \mathrm{cm}^{2}$. As amostras foram colocadas dentro da célula eletrolítica seguindo o mesmo processo indicado na formação das camadas macroporosas (MPS), como mostrado na Figura 3.1. Em ambos os casos, o processo de secagem das amostras foi realizado conforme o seguinte roteiro:

- Enxágüe durante 10 minutos em água deionizada

- Enxágüe durante 5 minutos em etanol

- Enxágüe durante 5 minutos em pentano

- Secagem com jato fino de nitrogênio.

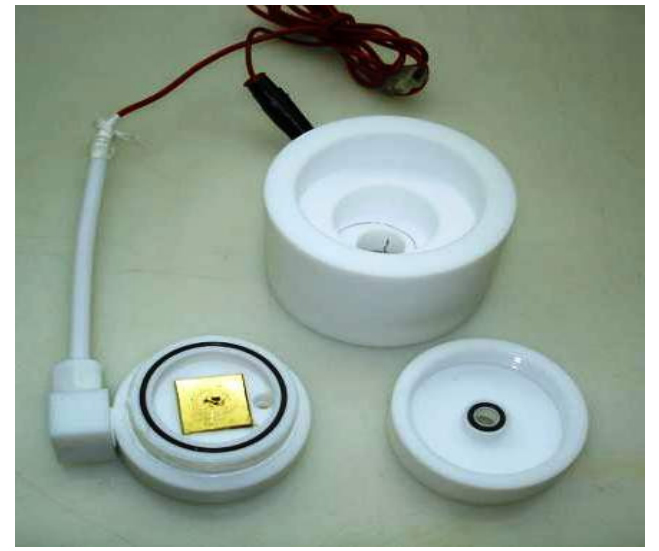

(a)

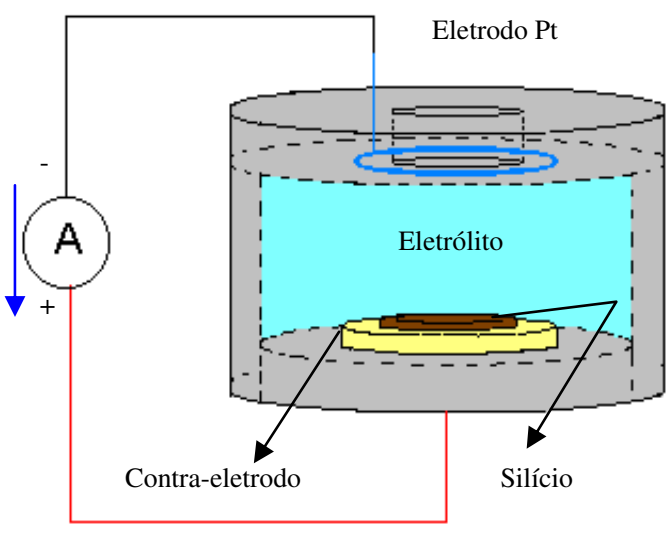

(b)

Figura 3.1 (a) célula eletrolítica de simples; e (b) Diagrama esquemático da anodização 
É importante também mencionar que varias amostras não foram metalizadas em nenhuma das fases, isto é, a formação dos tubos foi obtida em amostras sem efeito do alumino sobre eles.

\subsubsection{Formação das estruturas tubulares}

A formação dos micro e nanotubos de Si ocorreram após imersão das amostras de silício macro e mesoporosas, respectivamente, em uma solução de HF com o intuito de remover o óxido anódico formado durante a formação da camada porosa e ter as mesmas condições iniciais para todas as amostras. Após remoção dessa camada de óxido, as amostras foram mergulhadas em uma solução eletrolítica (banho) constituída por uma mistura de $0,25 \mathrm{M}$ de fluoreto de amônia $\left(\mathrm{NH}_{4} \mathrm{~F}\right)$ e $5 \times 10^{-2} \mathrm{M}$ de sais oxidantes. Tanto a concentração do $\mathrm{NH}_{4} \mathrm{~F}$ quanto a dos sais oxidantes mantiveram-se fixos na maior parte das amostras, porém algumas amostras foram imersas em soluções eletrolíticas diferentes que serão especificadas em momento oportuno. Para formação dos nano e microtubos de silício foram controlados os seguintes parâmetros: $\mathrm{pH}$, tipo de oxidante, tempo de corrosão, espessura das camadas macroporosas, e recozimento térmico após metalização. As amostras foram imersas em soluções com pH que variam na faixa de 4,5 a 7,5 , porém algumas foram obtidas em um intervalo de $\mathrm{pH}$ maior $(4,5-9,5)$ com o propósito de determinar a região de $\mathrm{pH}$ ótima para a formação das estruturas. $\mathrm{O} \mathrm{pH}$ foi modulado a valores ácidos adicionando, gota a gota, pequenas quantidades de $\mathrm{H}_{2} \mathrm{SO}_{4}$ ou $\mathrm{NH}_{4} \mathrm{OH}$ para deslocar o $\mathrm{pH}$ para a região alcalina. Em todos os casos os tubos foram formados a temperatura ambiente. Os parâmetros eletroquímicos usados para cada caso estão resumidos na Tabela 3.1.

\subsubsection{Caracterização das amostras}

Diferentes técnicas de caracterização foram empregadas tanto antes quanto depois da formação das camadas de SP, bem como após a formação das estruturas tubulares. Antes da formação dos MPS, as 
amostras foram caracterizadas eletricamente em função do tempo de recozimento, após a remoção da camada de $\mathrm{Al}$ sobre o $\mathrm{Si}$, usando o método de quatro pontas com o intuito de estudar o efeito do Al sobre as propriedades elétricas do substrato. A caracterização estrutural das estruturas macro e mesoporosas foram realizadas através da microscopia eletrônica de varredura (MEV) em função do tempo de recozimento a fim de correlacionar a estrutura final com os parâmetros empregados. Esta técnica também tem sido usada para caracterizar estruturalmente os micro e nanotubos, enquanto que sua composição química tem sido analisada mediante a técnica de EDS. Dois tipos de MEV têm sido usados, sendo eles a NOVA 400 Nano SEM, do Laboratório de Sistemas Integráveis (LSI), e a PHILIPS XL-30 do Laboratório de Microscopia Eletrônica da Engenharia de Materiais da USP. Este último tem sido empregado principalmente para a análise EDS. A natureza da porosidade das paredes e a estequiometria dessas estruturas foram estudadas mediante o Espectrômetro Raman (RENISHAW) do Laboratório de Espectroscopia Molecular (LEM) do Instituto de Química da USP, usando um laser vermelho com comprimento de onda $\lambda=632,8 \mathrm{~nm}$.

O comportamento eletroquímico das reações na interfase SP/eletrólito que promovem a formação dos micro e nanotubos foi estudado analisando as curvas de polarização usando o software General Purpose Electrochemical System (GPES) Version 4.9, que permitiu determinar a corrente de corrosão, potencial de corrosão e os coeficientes de transferência anódica e catódica. Esses parâmetros foram determinados em função do oxidante para todos os valores de $\mathrm{pH}$ empregados no presente trabalho $(4,5$ a 9,5$)$. Para tanto, as curvas voltamétricas foram levantadas polarizando o eletrodo de trabalho (silício poroso) com uma tensão contínua na faixa entre $-1,0 \mathrm{~V}_{\mathrm{Ag} / \mathrm{AgCl}}$ a $1,0 \mathrm{~V}_{\mathrm{Ag} / \mathrm{AgCl}}$, e usando uma lâmina de platina como contra-eletrodo. $O$ potencial na interface SP/eletrólito foi monitorado mediante o eletrodo de referência montado sobre o capilar de Luggin. A polarização começou pela região catódica usando $300 \mathrm{mV} / \mathrm{s}$ como potencial de varredura. 
Tabela 3.1- Amostras imersas em eletrólito com diferentes sais oxidantes, previamente metalizadas.

\begin{tabular}{|c|c|c|c|c|c|c|}
\hline Amostra & $\begin{array}{l}\text { Eletrólito } \\
\text { para SP }\end{array}$ & $\begin{array}{c}\text { Proporção } \\
(\mathrm{v} / \mathrm{v})\end{array}$ & $\begin{array}{c}\text { Oxidantes I } \\
\text { usados }\end{array}$ & Metalização & $\begin{array}{l}\text { Espessura } \mathrm{F} \\
\text { do } \mathrm{Al}(\mathrm{nm})\end{array}$ & $\begin{array}{l}\text { Recozimento } \\
\text { (horas) }\end{array}$ \\
\hline$\overline{A 7}$ & HF:etanol & $(3: 7)$ & $\mathrm{NiSO}_{4}$ & MP & 500 & 0,5 \\
\hline A8 & HF:etanol & (3:7) & $\mathrm{NiSO}_{4}$ & MP & 500 & 0,5 \\
\hline D80 & HF:etanol & (3:7) & $\mathrm{NiSO}_{4}$ & NM & $X$ & $x$ \\
\hline D82 & HF:etanol & $(3: 7)$ & $\mathrm{NiSO}_{4}$ & NM & $X$ & $x$ \\
\hline P44 & HF:DMF & (3:22) & $\mathrm{NiSO}_{4}$ & MP & 500 & 1,0 \\
\hline P64 & HF:DMF & (3:22) & $\mathrm{NiSO}_{4}$ & MPC & 500 & 3,0 \\
\hline P65 & HF:DMF & (3:22) & $\mathrm{NiSO}_{4}$ & MPC & 500 & 0,5 \\
\hline P69 & HF:etanol & $(1: 1)$ & $\mathrm{NiSO}_{4}$ & MPC & 500 & 0,5 \\
\hline P77 & HF:DMF & (3:22) & $\mathrm{Na}_{2} \mathrm{SO}_{4}$ & MP & 100 & 0,5 \\
\hline P86 & HF:DMF & (3:22) & $\mathrm{CoSO}_{4}$ & MP & 200 & 0,5 \\
\hline P91 & HF:DMF & (3:22) & $\mathrm{CoSO}_{4}$ & MP & 350 & 0,5 \\
\hline B20 & HF:DMF & (3:22) & $\mathrm{NiSO}_{4}$ & MP & 500 & 0,5 \\
\hline B24 & HF:DMF & (3:22) & $\mathrm{NiSO}_{4}$ & MP & 500 & 0,5 \\
\hline B25 & HF:etanol & $(1: 1)$ & $\mathrm{NiSO}_{4}$ & MP & 500 & 0,5 \\
\hline B27 & HF:DMF & (3:22) & $\mathrm{CoSO}_{4}$ & MPC & 500 & 0,5 \\
\hline B33 & HF:DMF & (3:22) & $\mathrm{Na}_{2} \mathrm{SO}_{4}$ & MPC & 500 & 0,5 \\
\hline B36 & HF:DMF & (3:22) & $\mathrm{H}_{2} \mathrm{O}$ & MP & 500 & 0,5 \\
\hline B50 & HF:DMF & (3:22) & $\mathrm{NiSO}_{4}$ & MP & 500 & 8,0 \\
\hline B54 & HF:DMF & (3:22) & $\mathrm{CoSO}_{4}$ & MP & 1000 & 1,0 \\
\hline B55 & HF:DMF & (3:22) & $\mathrm{CoSO}_{4}$ & MP & 1000 & 2,0 \\
\hline B56 & HF:DMF & (3:22) & $\mathrm{CoSO}_{4}$ & MP & 1000 & 4,0 \\
\hline B57 & HF:DMF & (3:22) & $\mathrm{CoSO}_{4}$ & MP & 1000 & 8,0 \\
\hline B58 & HF:DMF & (3:22) & $\mathrm{NiSO}_{4}$ & MC & 500 & 0,5 \\
\hline B61 & HF:DMF & (3:22) & $\mathrm{NiSO}_{4}$ & $\mathrm{MN}$ & $X$ & $x$ \\
\hline B65 & HF:DMF & (3:22) & $\mathrm{Na}_{2} \mathrm{SO}_{4}$ & MP & 500 & 1,0 \\
\hline B71 & HF:DMF & (3:22) & $\mathrm{NiSO}_{4}$ & MC & 500 & 0,5 \\
\hline B72B & HF:DMF & $(3: 22)$ & $\mathrm{CoSO}_{4}$ & MP & 500 & 1,0 \\
\hline B72C & HF:DMF & (3:22) & $\mathrm{Na}_{2} \mathrm{SO}_{4}$ & MP & 500 & 1,0 \\
\hline B73 & HF:DMF & (3:22) & $\mathrm{Na}_{2} \mathrm{SO}_{4}$ & MP & 500 & 1,0 \\
\hline B88 & HF:DMF & (3:22) & $\mathrm{NiSO}_{4}$ & NM & $X$ & $X$ \\
\hline B89 & HF:DMF & (3:22) & $\mathrm{Na}_{2} \mathrm{SO}_{4}$ & $\mathrm{MC}$ & 500 & 0,5 \\
\hline B90 & HF:DMF & (3:22) & $\mathrm{NiSO}_{4}$ & MP & 500 & 0,5 \\
\hline B99 & HF:DMF & (3:22) & $\mathrm{Na}_{2} \mathrm{SO}_{4}$ & $\mathrm{MC}$ & 500 & 0,5 \\
\hline B100 & HF:DMF & (3:22) & $\mathrm{Na}_{2} \mathrm{SO}_{4}$ & NM & $X$ & $X$ \\
\hline B101 & HF:DMF & (3:22) & $\mathrm{Mn}(\mathrm{NO} 3)_{2}$ & MP & 500 & 0,5 \\
\hline B102 & HF:DMF & (3:22) & $\mathrm{CoSO}_{4}$ & MP & 500 & 0,5 \\
\hline B106 & HF:DMF & (3:22) & $\mathrm{Mn}(\mathrm{NO} 3)_{2}$ & MC & 500 & 0,5 \\
\hline M4 & HF:DMF & (3:22) & $\mathrm{Na}_{2} \mathrm{SO}_{4}$ & NM & $X$ & $X$ \\
\hline M7 & HF:DMF & (3:22) & $\mathrm{Na}_{2} \mathrm{SO}_{4}$ & NM & $x$ & $x$ \\
\hline M12 & HF:DMF & (3:22) & $\mathrm{Na}_{2} \mathrm{SO}_{4}$ & NM & $x$ & $x$ \\
\hline M13 & HF:DMF & (3:22) & $\mathrm{CoSO}_{4}$ & NM & $x$ & $X$ \\
\hline M15 & HF:DMF & (3:22) & $\mathrm{Na}_{2} \mathrm{SO}_{4}$ & NM & $x$ & $x$ \\
\hline M16 & HF:DMF & (3:22) & $\mathrm{Na}_{2} \mathrm{SO}_{4}$ & NM & $X$ & $X$ \\
\hline M18 & HF:DMF & (3:22) & $\mathrm{Na}_{2} \mathrm{SO}_{4}$ & NM & $X$ & $X$ \\
\hline
\end{tabular}


Adicionalmente, os processos de oxirredução foram estudado através do monitoramento das curvas de potencial de eletrodo em circuito aberto (PECA) usando o GPES durante aproximadamente 20 minutos para todos os níveis de $\mathrm{pH}$ empregados, bem como para os diferentes tipos de oxidantes. Os parâmetros que determinam o comportamento do SMP durante a interação com eletrólito, tais como a posição do potencial de banda plana $\left(\mathrm{V}_{\mathrm{FB}}\right)$, a altura da barreira de energia $\left(\mathrm{V}_{\mathrm{S}}\right)$ e a largura da camada de depleção (W), foram determinados através do estudo das curvas Mott-Schottky, levantadas usando $10 \mathrm{kHz}$, com o software Frequency response Analysis (FRA) version 4.9. A tensão empregada para tal fim foi entre $-2,5 \mathrm{~V}_{\mathrm{Ag} / \mathrm{AgCl}}$ e $1,0 \mathrm{~V}_{\mathrm{Ag} / \mathrm{AgCl}} \mathrm{l}$, todavia, durante a análise tem sido empregado apenas na faixa de $-2,5 \mathrm{~V} \mathrm{Ag} / \mathrm{AgCl}$ a $0,0 \mathrm{~V} \mathrm{Ag} / \mathrm{AgCl}$, porque acima desta região aparecem efeitos aleatórios e não reproduzíveis de amostra para amostra. Os parâmetros eletroquímicos acima mencionados foram estudados utilizando 0 equipamento $\mu$ AUTOLAB type III/FRA2, localizado no Laboratório de Microeletrônica (LME) da USP. Os resultados obtidos para todos os casos são apresentados no capítulo IV e serão usados nas discussões apenas para uma análise qualitativa do comportamento dos processos de dissolução do silício, uma vez que estes parâmetros mudam em função do tempo de imersão em virtude da natureza complexa da dissolução do silício. 


\section{CAPÍTULO IV}

\section{Resultados e discussões}

Neste capítulo, apresentam-se os resultados experimentais obtidos durante $\mathrm{O}$ desenvolvimento deste trabalho. $\mathrm{Na}$ primeira parte deste capítulo, são discutidos e analisados os efeitos da metalização da lâmina de silício com Al (costas e/ou frente) na formação das camadas de silício poroso com diferentes morfologias contendo desde poros semicirculares até poros de formato quadrado. É importante mencionar que camadas porosas processadas após metalização da superfície polida do $\mathrm{Si}$ mostraram-se eficientes na formação de microtubos de silício. $\mathrm{Na}$ segunda parte deste capítulo, são apresentadas as principais contribuições da tese, onde é discutido e proposto um mecanismo de formação de microtubos e nanotubos de silício a partir de substratos de silício poroso.

\subsection{Formação das camadas de silício macroporoso.}

Diferentes amostras foram metalizadas com Al tanto na face polida quanto nas costas ou em ambos os lados com o intuito de estudar o efeito deste tratamento na formação de camadas de silício macroporoso. $\mathrm{Na}$ Tabela 4.1 são apresentados os tempos de recozimento térmico das diferentes amostras metalizadas com $\mathrm{Al}$ e a espessura das camadas porosas obtidas nestas amostras após o processo de anodização eletroquímica. Os filmes de $\mathrm{Al}$ depositados nas diferentes amostras apresentaram espessura da ordem de $500 \mathrm{~nm}$, exceto na amostra D34 onde não foi depositado nenhum filme de Al. Na Tabela 4.1, as diferentes amostras foram identificadas por D34 e P17 até P64 e os termos NM, MC, MP e MPC indicam as amostras não metalizadas, metalizadas somente nas costas, metalizadas somente na superfície polida e metalizada em ambas as fases, respectivamente, como já comentado no capítulo III. 
Os diferentes filmes de silício macroporoso foram analisados através do MEV $e$ as imagens obtidas posteriormente foram submetidas a processamento de imagens com a finalidade de determinar uma distribuição estatística do tamanho dos poros e classificar a forma dos poros em circulares ou quadradas. Para tal fim foi desenvolvido um algoritmo de granulometria denominado GRANUL [134].

Tabela 4.1- Tempo de recozimento dos filmes de Al depositados nas superfícies das diferentes amostras e espessura da camada macroporosa obtida nestas amostras.

\begin{tabular}{cccc}
\hline Amostra & Superfície & $\begin{array}{c}\text { Tempo de } \\
\text { recozimento } \\
\text { (horas) }\end{array}$ & $\begin{array}{c}\text { Espessura da } \\
\text { camada }(\mu \mathrm{m})\end{array}$ \\
\hline D34 & NM & 0 & 24 \\
P17 & MC & 0,5 & 34 \\
P43 & MP & 0,5 & 32 \\
P44 & MP & 1,0 & 38 \\
P47 & MP & 1,5 & 44 \\
P61 & MC & 1,5 & 42 \\
P64 & MPC & 3,0 & 53 \\
\hline
\end{tabular}

Na Figura 4.1 é mostrada a superfície morfológica e a seção transversal das amostras D34, P17 e P61. A primeira amostra não foi metalizada e as outras duas foram metalizadas somente nas costas e recozidas por 0,5 horas e 1,5 horas respectivamente. Em particular, a amostra não metalizada (D34) apresenta uma característica morfológica com aspecto de maior porosidade se comparada com as amostras P17 e P61 (Figura 4.1), e adicionalmente a profundidade dos poros na amostra D34 é menor que nas outras amostras (Tabela 4.1). Isto significa que filmes de silício macroporoso com elevada porosidade apresentam poros de menor profundidade. Nas três amostras (D34, P17 e P61) os poros apresentaram uma elevada razão de aspecto mostrando uma característica tubular (Figura 4.1). A partir das imagens MEV mostradas nas Figuras $4.1 \mathrm{~b}, 4.1 \mathrm{~d}$ e $4.1 \mathrm{f}$ foram determinadas as profundidades das camadas porosas nas amostras D34, P17 e P61 respectivamente (Tabela 4.1). 

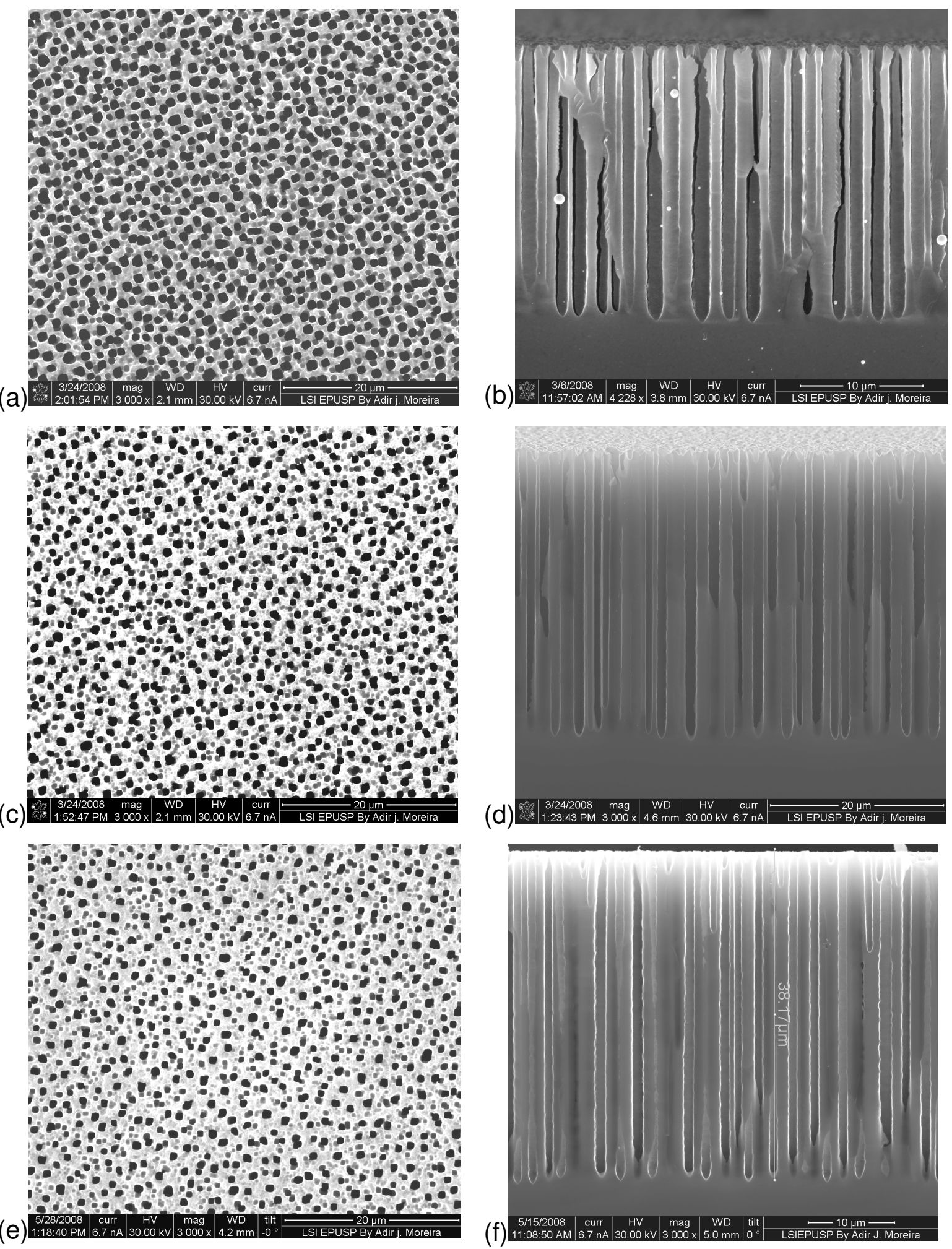

Figura 4.1 Imagens MEV da superfície frontal das amostras: a) D34, c) P17, e) P61. As imagens das secções transversais destas amostras são mostradas em (b), (d) e (f) respectivamente. 
Os resultados desta medição apontam claramente que as amostras de MPS obtidas após a metalização das suas costas e seguida de recozimento térmico, apresentam maior profundidade, o que sugere que em lâminas metalizadas a taxa de corrosão do silício cresce e que esta taxa também depende diretamente do tempo de recozimento da amostra metalizada, já que a amostra D61, com maior tempo de recozimento, apresenta uma camada porosa de maior espessura se comparada com a da amostra P17 que foi recozida por um tempo menor (Tabela 4.1).

A análise quantitativa dos principais parâmetros morfológicos das amostras D34, P17 e P61 foi realizada com o auxilio do algoritmo de granulometria denominada GRANUL [134]. Os resultados da análise são mostrados na Figura $4.2 \mathrm{em}$ forma de histogramas de distribuição. A estrutura de SMP obtida em substrato de Si não-metalizado (NM) apresenta poros de diâmetros efetivos contidos no intervalo de $0,7 \mu \mathrm{m}$ a 1,5 $\mu \mathrm{m}$. As amostras de SMP, P17 e P61, que foram metalizadas nas costas apresentaram poros com diâmetros efetivos compreendidos entre $0,7 \mu \mathrm{m}$ e 1,0 $\mu \mathrm{m}$ (Figura 4.2). Assim, nas amostras identificadas por MC na Tabela 4.1 formam-se poros com menor diâmetro efetivo e ao mesmo tempo mais profundos, o que sugere uma taxa de corrosão maior nestas amostras. A taxa de corrosão é diretamente proporcional à densidade de corrente de anodização. Como nestas três amostras a densidade de corrente externa foi da mesma intensidade, a maior taxa de corrosão nas amostras metalizadas nas costas (MC) sugere a existência de densidades de correntes locais mais elevadas nestas amostras e este comportamento está correlacionado com a menor porosidade destas amostras já que as imagens MEV das amostras metalizadas mostram poros distribuídos em menor densidade que na amostra não-metalizada (Figuras 4.1 (a), (c), (e), respectivamente). 


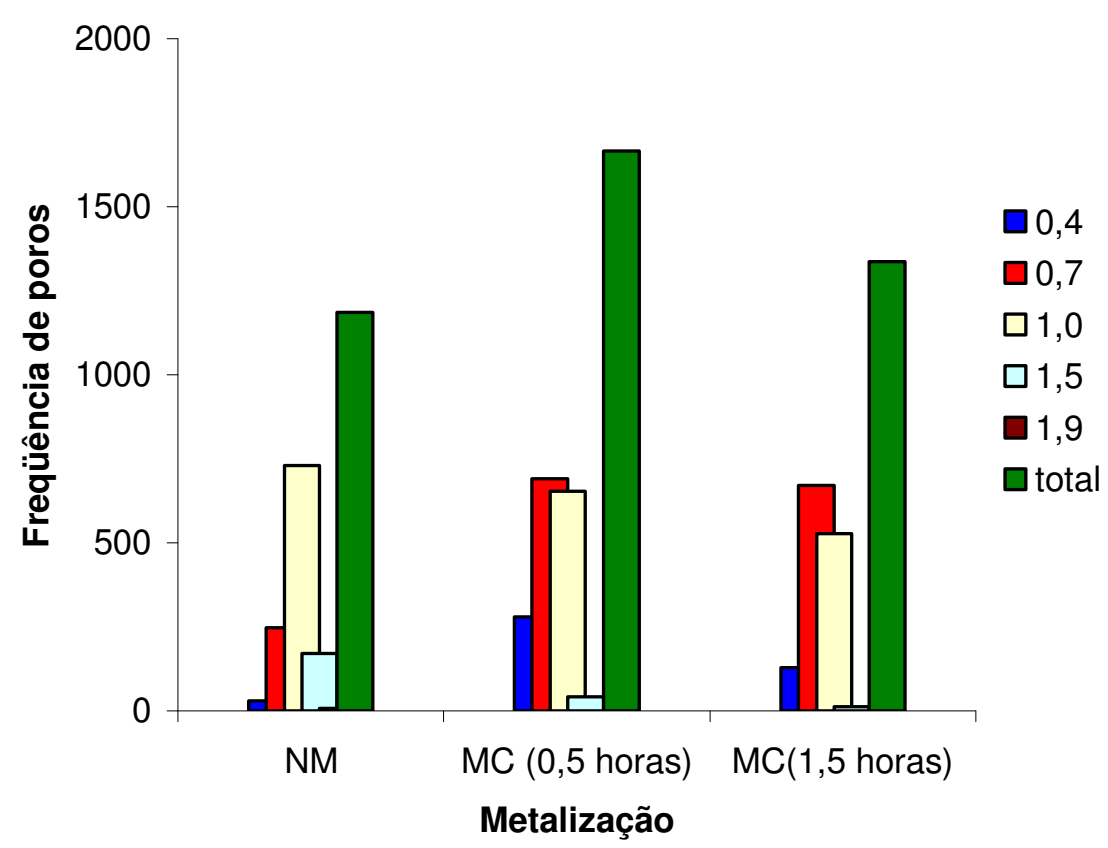

Figura 4.2 Histograma da freqüência do diâmetro médio $(\mathrm{em} \mu \mathrm{m})$ de poros da amostra não-metalizada (D34) e as metalizadas e recozidas por 0,5 horas (P17) e 1,5 horas (P61), respectivamente.

A deposição do Al sobre a face polida (MP) seguida de recozimento térmico modifica as propriedades químicas e físicas da superfície de tal forma que durante a anodização formam-se poros semicirculares característicos das camadas macroporosas e poros com forma retangular (Figura 4.3). A forma e densidade dos poros retangulares mostram-se dependentes não apenas da metalização, mas também do tempo de recozimento anterior à anodização (Figura 4.3). Nesse sentido, resultados observados na amostra P64 (MPC), após o recozimento de três horas, mostram poros retangulares com bordas levemente suavizadas (Figura 4.3e). 


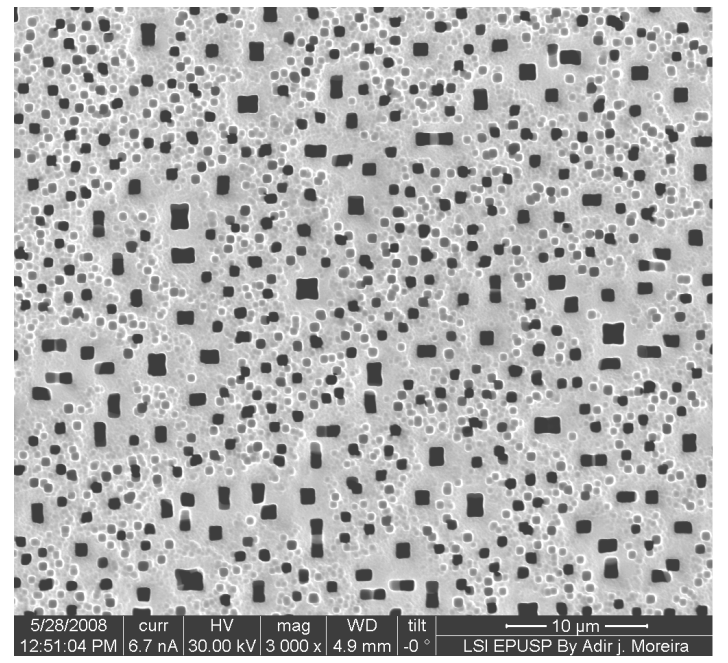

(a)

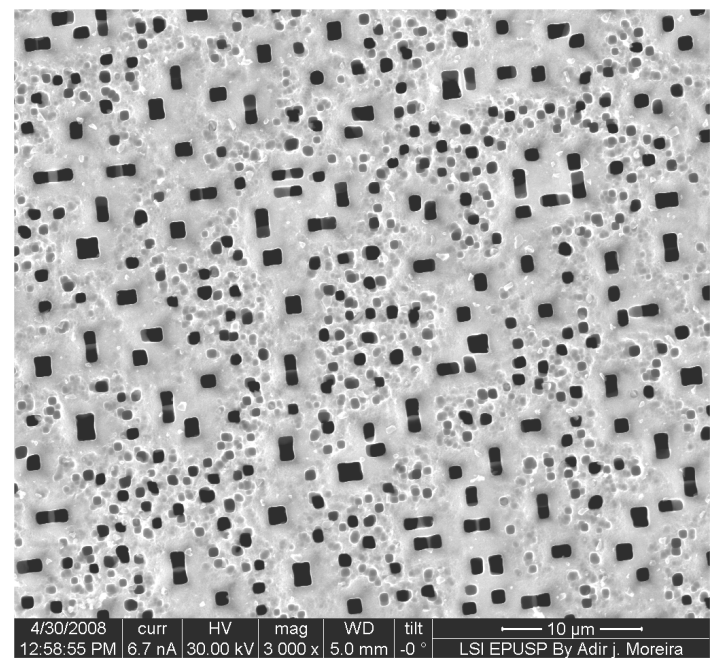

(c)

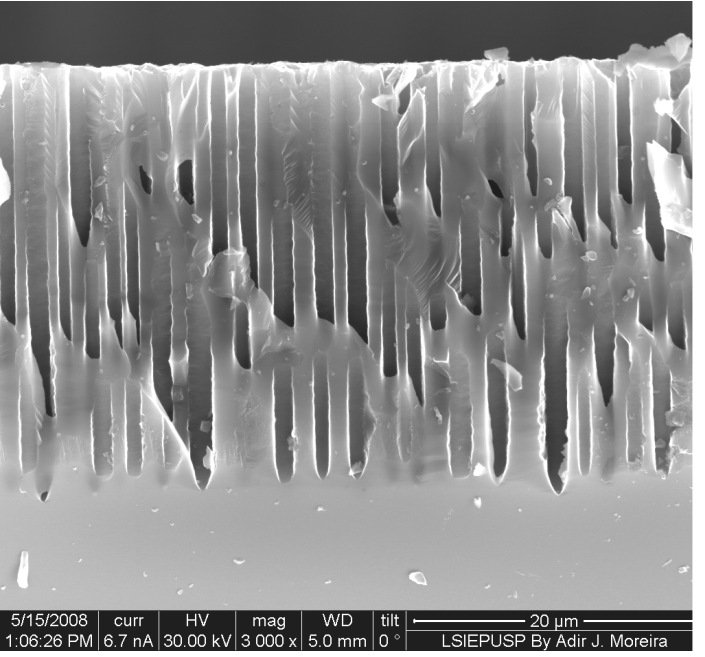

(b)

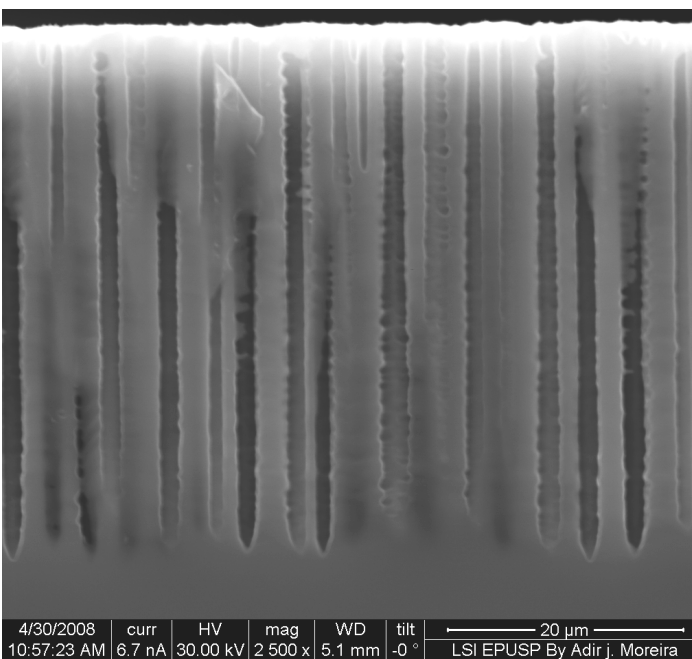

(d)

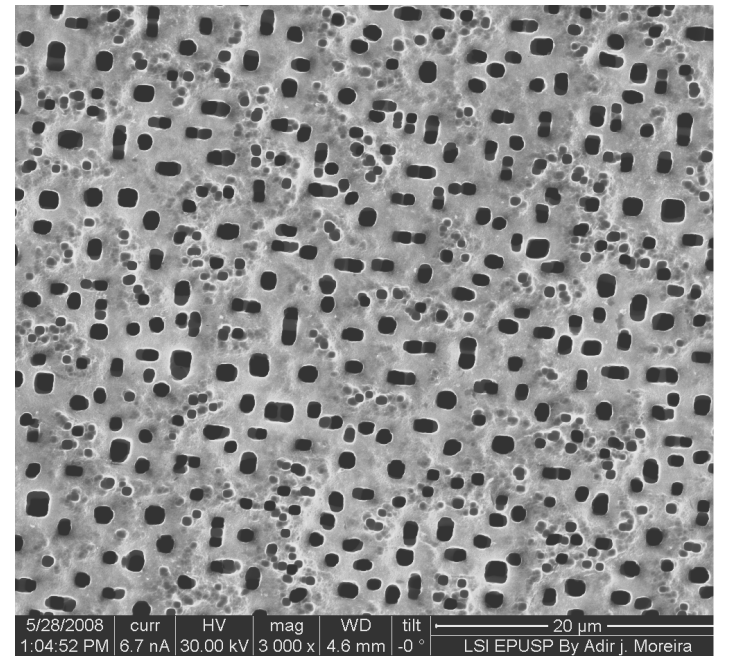

(e)

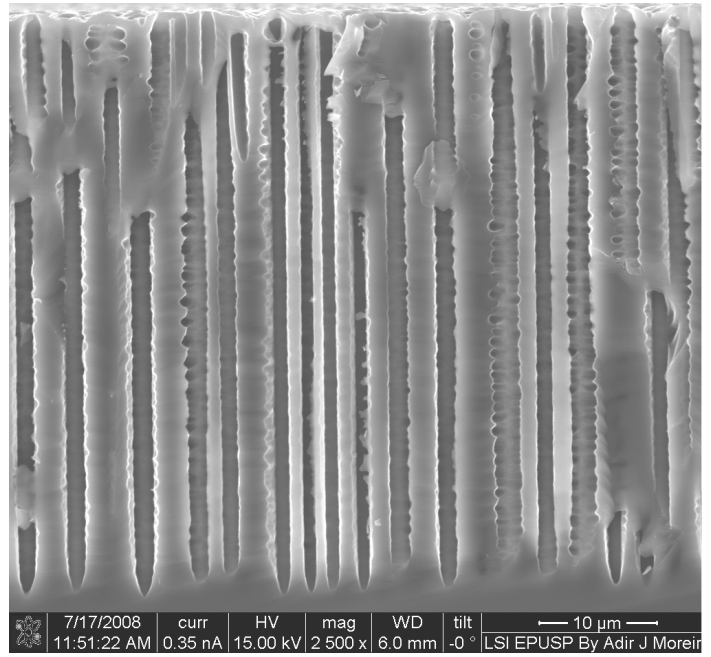

(f)

Figura 4.3. Imagens MEV da superfície e do perfil de amostras metalizadas na face polida e recozidas durante 0,5 horas $(a, b), 1,5$ horas $(c, d)$, e 3 horas $(e, f)$ metalizada em ambas as faces. 
(a)
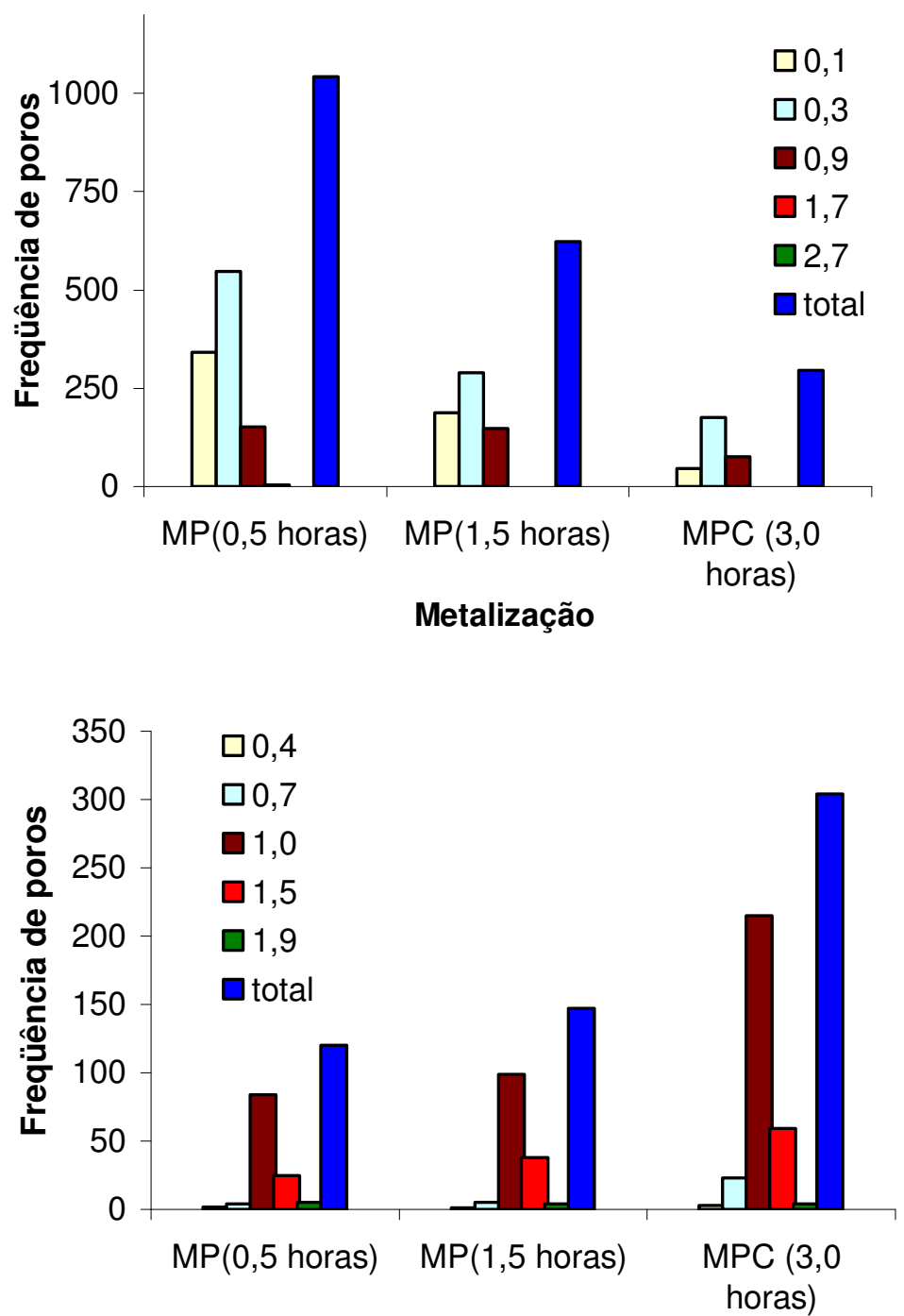

(b)

Metalização

Figura 4.4. (a) Histograma da freqüência do diâmetro médio (em $\mu \mathrm{m})$ dos poros

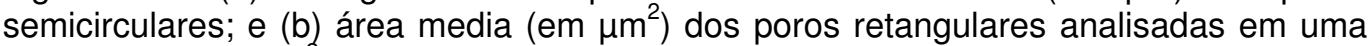
área de $(43 \times 50) \mu \mathrm{m}^{2}$.

A análise quantitativa das amostras foi realizada em uma área de (43×50) $\mu \mathrm{m}^{2}$ (área das fotos da Figura 4.3), utilizando-se o algoritmo GRANUL [134]. Os resultados revelam que há uma mudança na densidade de ambos os tipos de poros em função da temperatura de recozimento pósmetalização, como mostrado nos histogramas da Figura 4.4. Enquanto os poros semicirculares sofrem uma queda na sua densidade total, os poros retangulares comportam-se de forma oposta, isto é, incrementam sua 
densidade com o aumento do tempo de recozimento (Figura 4.4). A densidade dos poros semicirculares está composta principalmente por regiões com área media entre $0,3 \mu \mathrm{m}^{2}$ e $0,9 \mu \mathrm{m}^{2}$ que correspondem a poros com diâmetro médio 0,7 $\mu \mathrm{m}$ e $1.0 \mu \mathrm{m}$, respectivamente, enquanto que a densidade de poros retangulares está composta majoritariamente por regiões com áreas entre $0,9 \mu \mathrm{m}^{2}$ e 1,7 $\mu \mathrm{m}^{2}$. Porém, na medida em que se incrementa o tempo de recozimento, a densidade de poros quadrados com área de $0,9 \mu \mathrm{m}^{2}$ passa a predominar sobre as outras.

Adicionalmente, a semelhança do acontecido com as amostras MC, nas amostras MP observou-se também um incremento na espessura das camadas macroporosas $(d)$, seguindo o mesmo comportamento daquelas metalizadas nas costas (MC), como mostrado na Tabela 4.1, cujos valores foram extraídos a partir das imagens MEV mostradas nas Figuras 4.3b, 4.3d e 4.3f. Este incremento segue uma dependência com o tempo de recozimento $(\mathrm{t})$ do tipo raiz (equação 4.1), como se observa na Figura 4.5. Sendo assim:

$$
d(\mu m)=\sqrt{a+b t}
$$

Os valores dos coeficientes para o caso são: $a=620.75\left(\mu \mathrm{m}^{2}\right)$; e $b=770.038\left(\mu \mathrm{m}^{2} /\right.$ hora). O termo $a$ representa o quadrado da espessura esperada nas amostras não-metalizadas, enquanto que as unidades do termo $b$ sugerem ser o coeficiente de difusão do Al no substrato de silício. A diferença das amostras metalizadas nas costas, o perfil daquelas metalizadas na face polida mostra não apenas poros com alta razão de aspecto, mas também paredes altamente rugosas com forma serrilhada (Figura 4.3f), possivelmente devido à intensificação local do campo elétrico, que, segundo o modelo da "martelada", produz também estruturas macroporosas com ramificações [98]. Adicionalmente, quando ambas as faces são metalizadas e recozidas por três horas, as espessuras das camadas porosas sofrem um incremento de até 2,5 vezes aproximadamente em relação aquelas obtidas em substrato não metalizado (Tabela 4.1). 


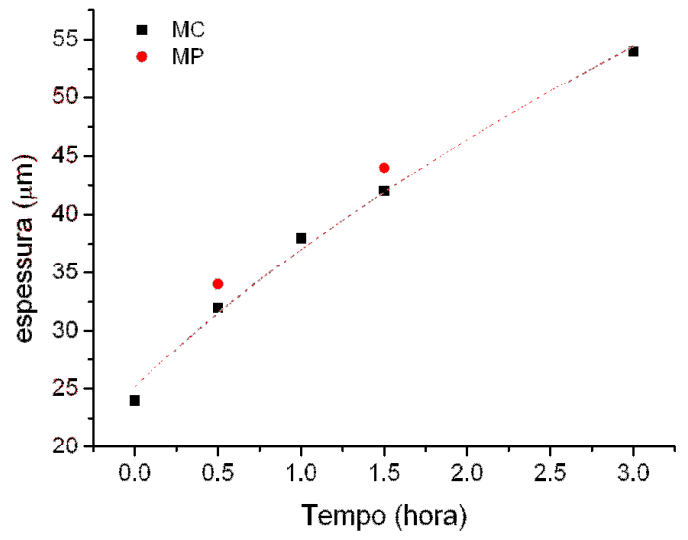

(a)

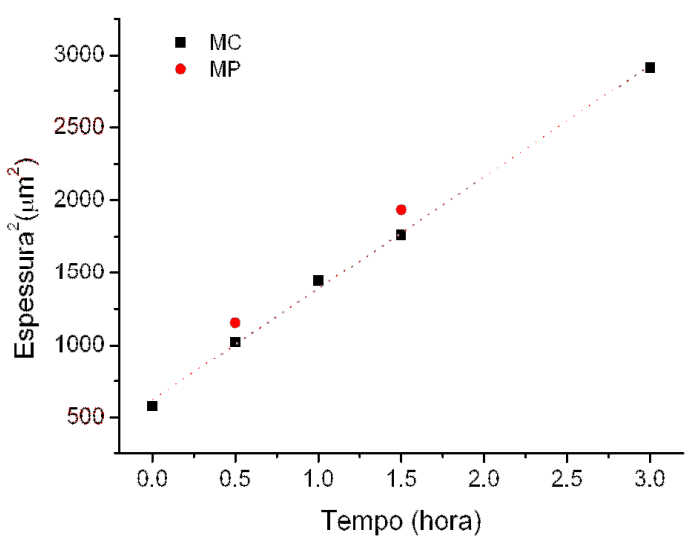

(b)

Figura 4.5. (a) Dependência da espessura das camadas de SMP com o tempo; e (b) ajuste do quadrado das espessuras em função do tempo.

Um estudo mais sistemático sobre o efeito do alumínio depositado sobre a face polida das amostras e do tempo de recozimento, tanto sobre a espessura e morfologia das camadas de SMP quanto sobre as propriedades elétricas, tem se realizado através do monitoramento do comportamento de várias amostras, todas com filme depositado de $\mathrm{Al}$ de $1 \mu \mathrm{m}$, com a diferença de que elas foram submetidas a diferentes tempos de recozimento de acordo com o procedimento previamente descrito no CAPÍTULO III. Os parâmetros utilizados bem como os resultados são resumidos na Tabela 4.2 e Figura 4.6, e apresentam um comportamento similar aos filmes de 0,5 $\mu \mathrm{m}$ (Figura 4.3), isto é, houve incremento na espessura da camada porosa (Figura 4.8), devido ao incremento da taxa de corrosão, bem como a formação de poros retangulares e semicirculares (Figura 4.6).

Tabela 4.2- Resistência, tempo de recozimento, e espessura das camadas macroporosa obtidas em amostras metalizadas na face polida ( $1 \mu \mathrm{m} \mathrm{Al})$

\begin{tabular}{cccc}
\hline Amostra & $\begin{array}{c}\text { Resistência } \\
(\text { Ohm })\end{array}$ & $\begin{array}{c}\text { Tempo de } \\
\text { recozimento } \\
\text { (horas })\end{array}$ & $\begin{array}{c}\text { Espessura da } \\
\text { camada porosa } \\
(\mu \mathrm{m})\end{array}$ \\
\hline B52 & 105 & - & 22,0 \\
B86 & 82,3 & 0,5 & 30,2 \\
B55 & 104 & 1,0 & 26,9 \\
B56 & 102 & 2,0 & 30,7 \\
B54 & 141 & 4,0 & 36,6 \\
B57 & 275 & 8,0 & 41,8 \\
\hline
\end{tabular}


Embora a morfologia dos poros das amostras B54 a B57 seja semelhante àquelas observadas na Figura 4.3, estas mostram também uma variação da densidade de poros quadrados em função da temperatura de recozimento, e é máxima naquela amostra recozida durante quatro horas (Figura 4.6e); enquanto que as espessuras das camadas apresentam um comportamento em função do tempo de recozimento semelhante àquele já observado na Figura 4.5. A partir dos resultados na Figura 4.6 e usando o algoritmo GRANUL [134] tem-se quantificado a freqüência ou densidade de poros retangulares em função da temperatura de recozimento, e cujos resultados são apresentados na Figura 4.7. A freqüência dos poros retangulares é máxima na amostra recozida por quatro horas, e predominam aquelas regiões com área média igual a $3.72 \mu \mathrm{m}^{2}$ (Figuras 4.6e e 4.7b). É importante mencionar também que na freqüência de poros semicirculares predominam aquelas regiões de área média entre 0,48 $\mu \mathrm{m}^{2}$ e 1,20 $\mu \mathrm{m}^{2}$ que correspondem a poros com diâmetro médio de 0,78 $\mu \mathrm{m}$ e $1,23 \mu \mathrm{m}$, enquanto que naquelas com forma retangular predominam as que apresentam área $2,34 \mu \mathrm{m}^{2}, 3,72 \mu \mathrm{m}^{2}$ e $9,38 \mu \mathrm{m}^{2}$. Isto é mais apreciável naquela recozida durante quatros horas (Figura 4.6f e 4.7b), e em contraparte também é muito notória a predominância dos poros com menor diâmetro médio (Figura 4.7a).

Em todos os casos das amostras metalizadas na face polida observa-se que os lados dos poros quadrados seguem a orientação (110), em forma semelhante à corrosão anisotrópica em meio alcalino $[69,75,76]$, típico dos processos termicamente ativados que dependem da orientação cristalina do substrato semicondutor [64,65]. No caso do $\mathrm{Si}$, esse comportamento é devido ao fato do silício requerer maior energia para poder arrancar os átomos do plano (111) em relação àqueles localizados nos planos (110) e (100), respectivamente [96,135-138]. 


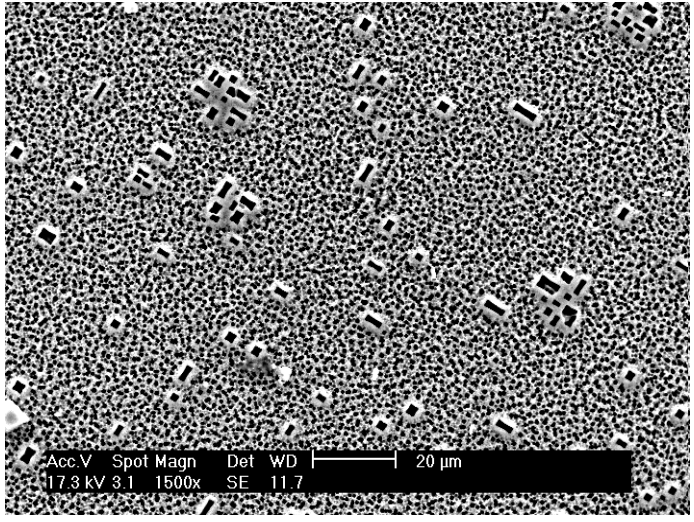

(a)

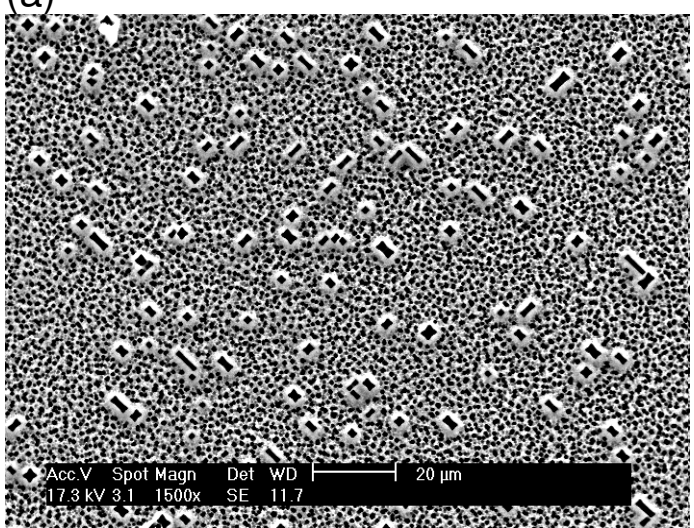

(c)

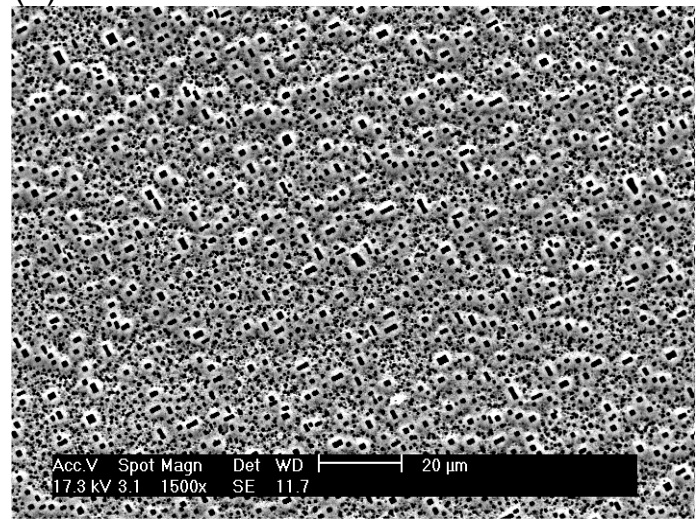

(e)

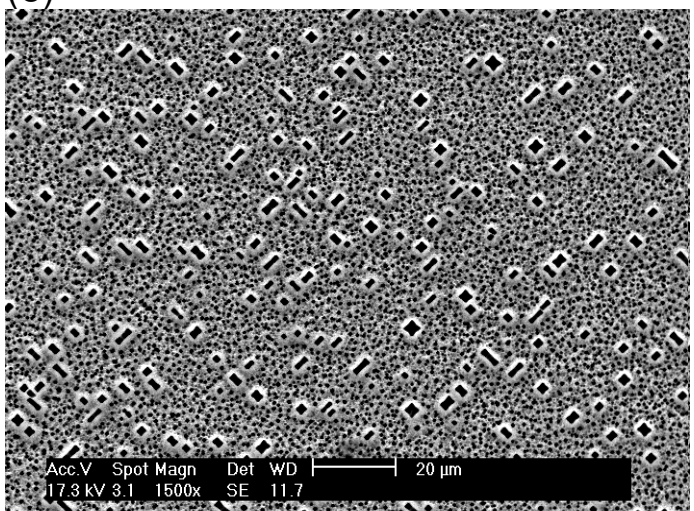

(g)

Figura 4.6. Imagens MEV da morfologia superficial e da com $1 \mu \mathrm{m}$ de Al e recozidas durante 1 hora $(a, b), 2$ horas $(c, d), 4$ horas $(e, f)$ e 8 horas $(g, h)$. (b)

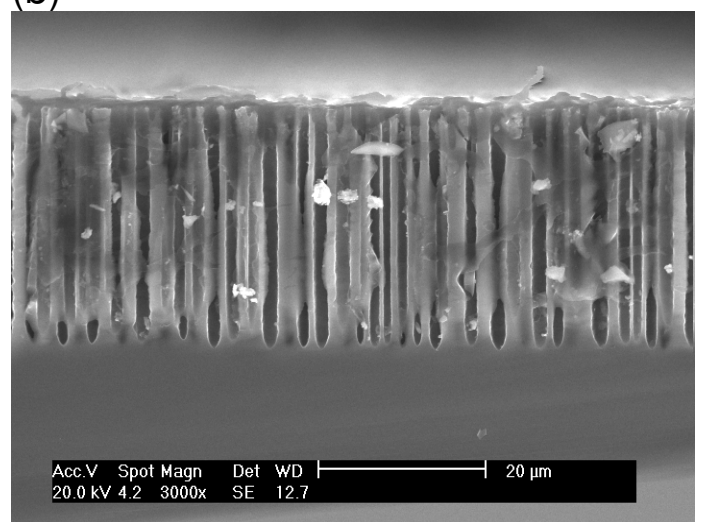

(d)

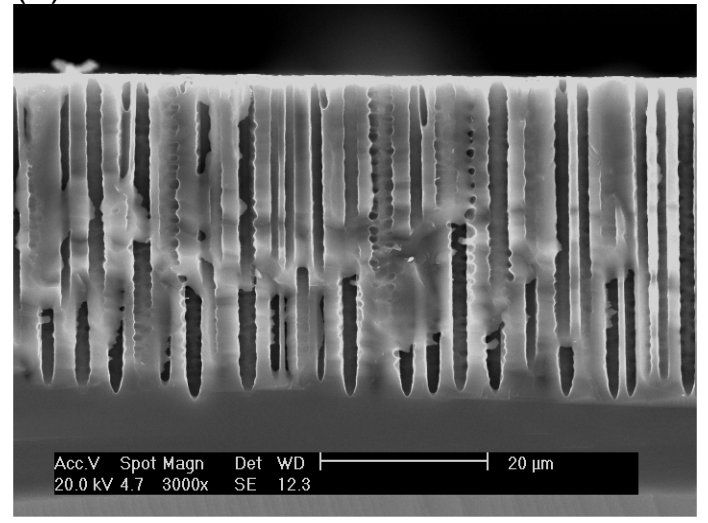

(f)

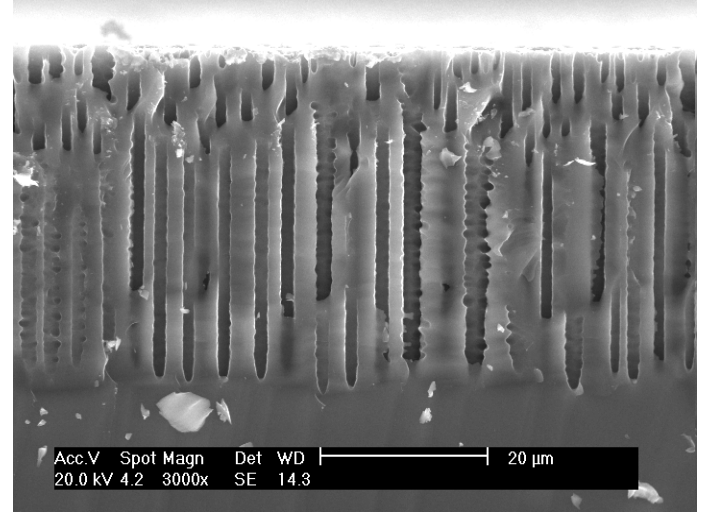

(h)

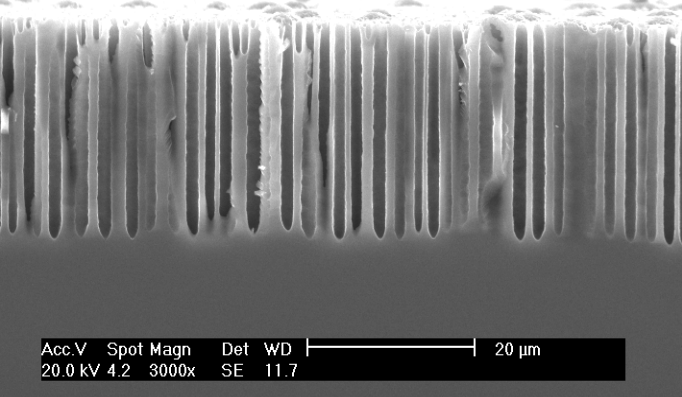

da espessura das amostras metalizadas 


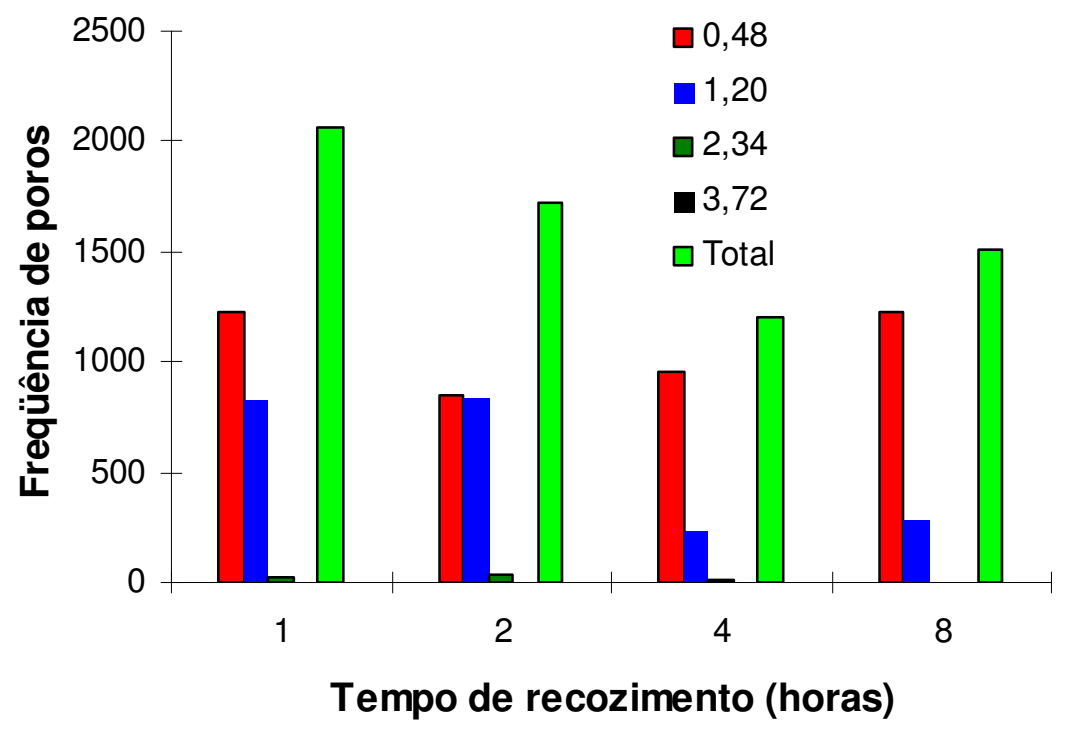

(a)

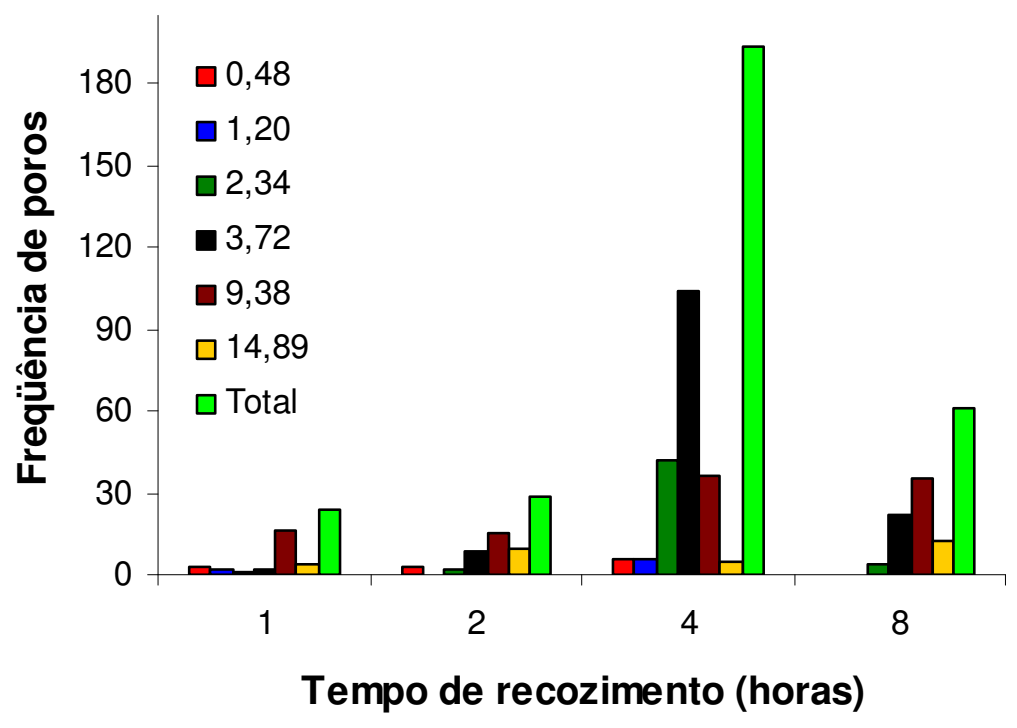

(b)

Figura 4.7. (a) Histograma da densidade dos poros semicirculares com diferentes diâmetros médios (em $\mu \mathrm{m}$ ); e dos (b) poros retangulares com diferentes áreas (em $\mu \mathrm{m}^{2}$ ) formados sobre as amostras metalizadas com $1 \mu \mathrm{m}$ de Al na face polida e recozidas durante diferentes tempos.

Outro detalhe importante nestas amostras refere-se ao incremento exponencial da resistência elétrica das amostras B54 a B57 em função do tempo de recozimento (Figura 4.8) descrita pela relação (4.2). É importante indicar que as resistências foram medidas antes das amostras serem anodizadas. 


$$
R(o h m)=R_{0}+R_{s} e^{t / t_{1}}
$$

A soma dos termos $R_{o}=34,20(\mu \Omega)$, e $R_{s}=47,63(\mu \Omega)$ em $\mathrm{t}=0$ representa a resistência esperada na amostra não-metalizada (B52), como mostrada na Tabela 4.2; enquanto que o termo $R_{s} e^{t / t_{1}}$ representa a contribuição do efeito do Al para determinado tempo de recozimento; e $t_{1}=4,94$ (1/hora) é o coeficiente temporal. Contudo, quando comparadas as resistências medidas na amostra B52 (Tabela 4.2) com aquela definida pela equação (4.2) para $t=0$, observa-se uma discrepância de aproximadamente $20 \%$ que poderia atribuir-se a efeitos secundários não contemplados durante nossa análise. Por outro lado, observa-se na Figura 4.8a que 0 comportamento do incremento da espessura parece seguir aquele observado na Figura 4.5a, isto é, segue um comportamento potencial em função do tempo de recozimento descrito pela equação (4.1), onde desta vez definem-se os termos $a=498,16\left(\mu^{2}\right)$, e $b=213,46 \mu \mathrm{m}^{2} /$ hora sendo este último aproximadamente três vezes menor daquele observado na Figura 4.5. Isto pode ter ocorrido devido ao fato destas últimas amostras serem metalizadas em equipamento diferente das primeiras, logo as condições não são as mesmas. Adicionalmente, na Figura 4.8b, que mostra a dependência linear entre o quadrado da espessura e o tempo de recozimento, os resultados afastam-se do comportamento linear em $t=1 / 2$ hora e $\mathrm{t}=8$ horas. Os detalhes serão discutidos mais adiante.

Apesar das curvas da resistência elétrica e da espessura em função do tempo de recozimento seguirem um comportamento descrito pelas equações (4.1) e (4.2), respectivamente, existem alguns aspectos importantes que precisam ser destacados. Nesse sentido, observa-se que em $t=1 / 2$ hora a resistência do substrato é menor e sai da curva exponencial, enquanto que a espessura da camada porosa obtida nessa amostra também sai da curva potencial. Em termos de resistência, resultados similares tem se reportado na literatura $[135,139,140]$ que comumente usa procedimento semelhante para otimizar o contato ôhmico da junção metal/semicondutor. Um maior tempo de recozimento 
incrementa a resistência elétrica do substrato [136]. A literatura reporta que a resistência incrementa-se com o incremento de defeitos devido ao fato destes dificultarem o transporte dos elétrons [71], e este incremento dos defeitos obedece a relação de Arrhenius [17,137] e podem tornar amorfas as estruturas cristalinas [17]. Isto sugere que sobre a superfície das amostras tratadas com Al tem-se formado uma camada fina de silício amorfo que incrementa a resistência do substrato em função do tempo de recozimento devido ao maior tempo de recozimento aumentar a penetração do Al [138]. Faith et al [140] têm reportado o incremento da resistência elétrica de dispositivos semicondutores e atribuiu à presença de impurezas na superfície do Si devido à contaminação pós limpeza inicial. Assim, a formação de uma camada amorfa resulta ser a causa mais provável do incremento da resistência com o tempo de recozimento, embora também poderia ser atribuída à formação de $\mathrm{Al}_{2} \mathrm{O}_{3}$ na interface, porém na presença de HF esta se dissolve rapidamente [141].
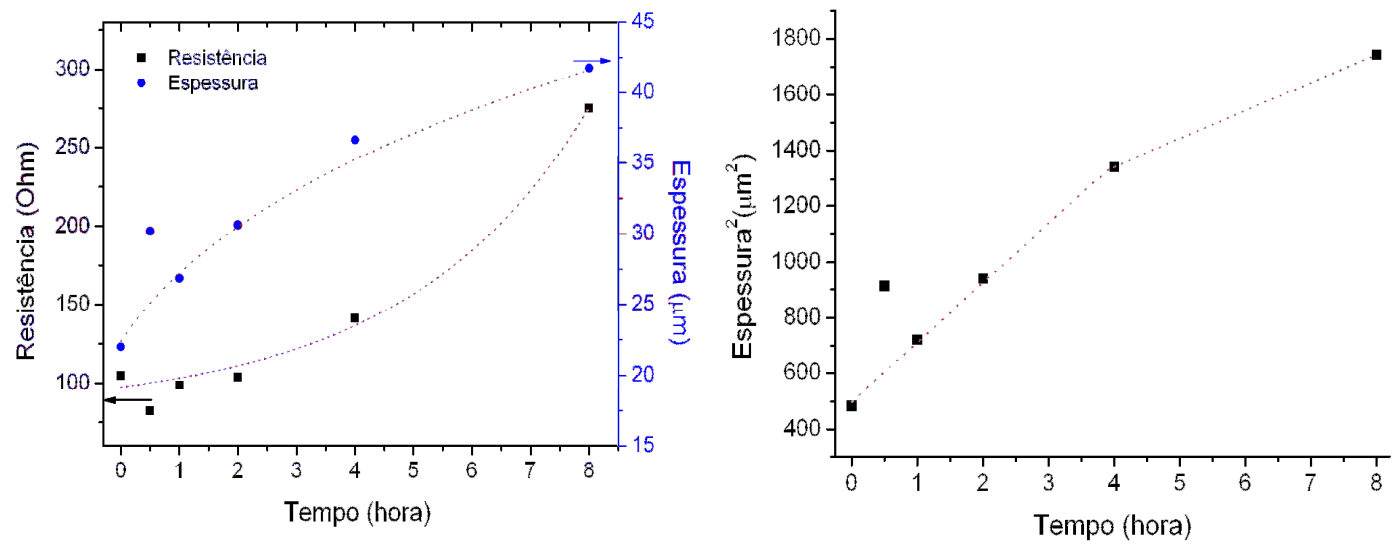

Figura 4.8. Variação da espessura e a resistência elétrica em função do tempo de recozimento das amostras B54 a B57.

Na Figura 4.8a é mostrado que existe uma correlação entre a resistência da amostras metalizadas e recozidas e a espessura da camada de SMP sobre ela formadas. Quanto maior for a resistência do substrato, maior será a espessura. Como antes comentado, a espessura das camadas afastam-se em $t=1 / 2$ hora e $t=8$ horas. No primeiro caso, sabe-se da literatura [141,142], que amostras metalizadas com Al nas costas e 
recozidas durante meia hora promovem espessuras maiores em relação àquelas não-metalizadas e este incremento na taxa de corrosão atribui-se à formação de agulhas no substrato durante a metalização, enquanto que no segundo caso, o decréscimo na taxa de corrosão poderia estar relacionada com a saturação na difusão do alumínio no silício que, de acordo com a segunda lei de Fick decai, com o tempo e a espessura de penetração [17], ou com o incremento na camada amorfa dificultando ainda mais o passo da corrente através do substrato[17].

Se compararmos a resistência elétrica da amostra não-metalizada com àquelas recozidas até durante duas horas, observa-se a semelhança entre elas (Figura 4.8), apenas havendo um incremento notório nas amostras recozidas acima de duas horas. Assim, a anodização desta amostra levará à formação de uma camada macroporosa com menor espessura que qualquer outra. Embora a resistência das amostras B52 e B56 sejam aproximadamente iguais, a espessura das suas respectivas camadas porosas são diferentes, sendo a da amostra B56 maior. Isto mais uma vez evidencia a formação de uma camada resistiva na superfície da amostra que é removida rapidamente durante a anodização.

Durante o processo de anodização das amostras observou-se que a curva da tensão versus o tempo de anodização (Figura 4.9) das amostras metalizadas na face polida apresenta um comportamento contrário daquelas não-metalizadas na face polida (NM e $\mathrm{MC}$ ). No caso destas últimas observa-se que a tensão incrementa-se ao longo do tempo com tendência a atingir o estado estacionário. No entanto, no caso das amostras metalizadas observa-se que a variação do potencial ao longo do tempo segue o padrão do decaimento exponencial, exceto no caso da amostra recozida durante 1 hora (B55) a qual inicialmente tem a tendência a seguir o mesmo comportamento da amostra não-metalizada, mas logo de aproximadamente 5 minutos tende a se comportar tanto quanto as outras amostras apresentando uma diminuição do potencial ao longo do tempo, como se observa na Figura 4.9. 


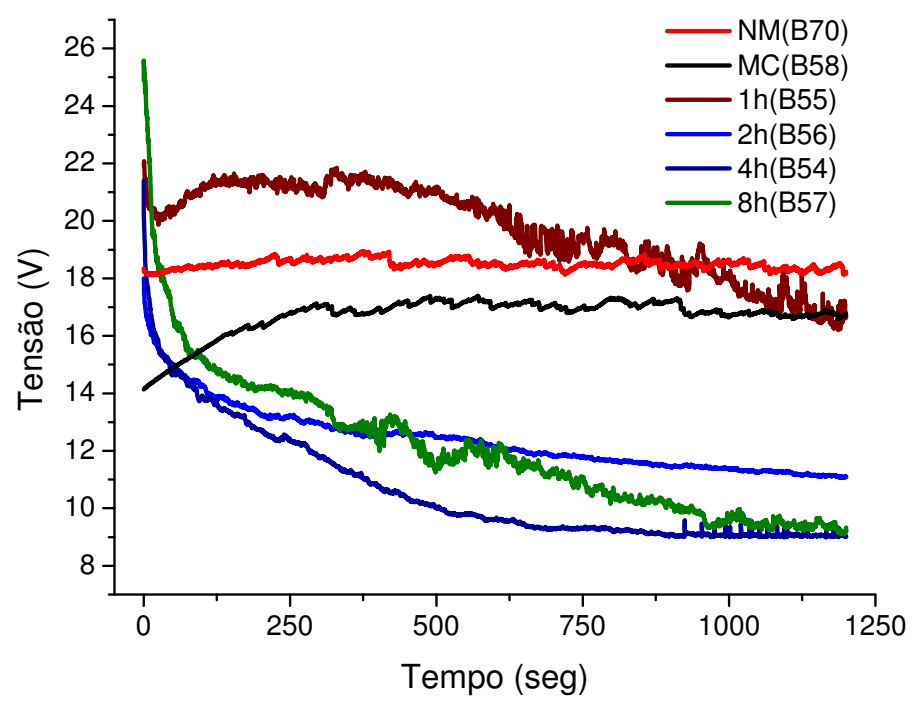

Figura 4.9. Variação da tensão anodização ao longo do tempo para as amostras metalizadas na face polida e recozida durante 1, 2, 4, e 8 horas.

O comportamento ao longo do tempo da amostra B52 e B58 é típico na formação do silício poroso [143], e atribui-se o incremento da resistividade do substrato decorrente do incremento na resistividade das camadas porosas que em termo efetivos apresenta uma resistividade maior $[64,65]$; enquanto que o perfil do potencial ao longo do tempo das amostras metalizadas, excetuando a amostra B55, apresentam um comportamento de decrescimento exponencial que é típico dos processo onde a formação do silício poroso ocorre por ruptura do silício decorrente da alta resistência do substrato [98], que segundo o modelo sugerido por H. Föll. et al. [98] seria semelhante a ruptura do silício mediante "marteladas". A probabilidade de ocorrer uma "martelada" é dado pela probabilidade de nucleação de uma corrente de ruptura e esta é mais provável nos lugares onde há lacunas que são considerados como lugares "menos duros", enquanto que as regiões isentas de lacunas são consideradas como lugares "mais duros" e é nesses que a formação de poros é menos provável [98]. A Figura 4.9 também mostra que o potencial cai mais abruptamente naquela amostra que foi recozida durante 4 horas e onde também houve maior concentração de poros retangulares, enquanto que 
o maior potencial na amostra B57 ocorre no instante inicial, e depois também segue 0 mesmo comportamento das outras amostras metalizadas, exceto a B55.

A partir dos resultados observados nas amostras de silício macroporoso MC ou MP, observa-se que o tratamento das amostras com Al e subseqüente recozimento térmico modificam substancialmente a taxa de corrosão das amostras independentemente da face tratada com Al, apenas sendo dependente no tempo de recozimento. Adicionalmente, observa-se que nas amostras metalizadas na face polida há a formação de poros retangulares cuja densidade e tamanho dependem levemente do tempo de recozimento. No entanto, nas amostras metalizadas apenas nas costas e recozidas, observa-se que o principal efeito sobre os poros está relacionado à distância entre os poros e levemente sobre o tamanho médio dos poros em relação aos tamanhos nas amostras nãometalizadas em nenhuma das faces.

Embora a espessura das camadas tratadas com Al apresente taxas de corrosão semelhantes, estruturalmente encontram-se diferenças importantes. No caso da amostra metalizada nas costas, observa-se que as paredes aparecem isentas de perfurações secundárias dotando-a de uma aparência suave e homogênea (Figura 4.10a e 4.10b), ao contrário daquelas observadas nas amostras metalizadas na face polida onde as paredes apresentam poros secundários em forma perpendicular dotando ao perfil uma aparência muito rugosa (Figura 4.10c e 4.10d) com aspecto serrilhado. Como antes comentado, os poros secundários podem ter sido produzidos por processos de ruptura do silício devido à intensificação local do campo elétrico nas paredes dos poros perpendiculares à superfície do silício, isto é, de acordo com o modelo da "martelada" [98]. Existem mais lugares "menos duros" nas paredes dos poros das amostras metalizadas na face polida que nas paredes dos poros formados nas amostras não metalizadas. 

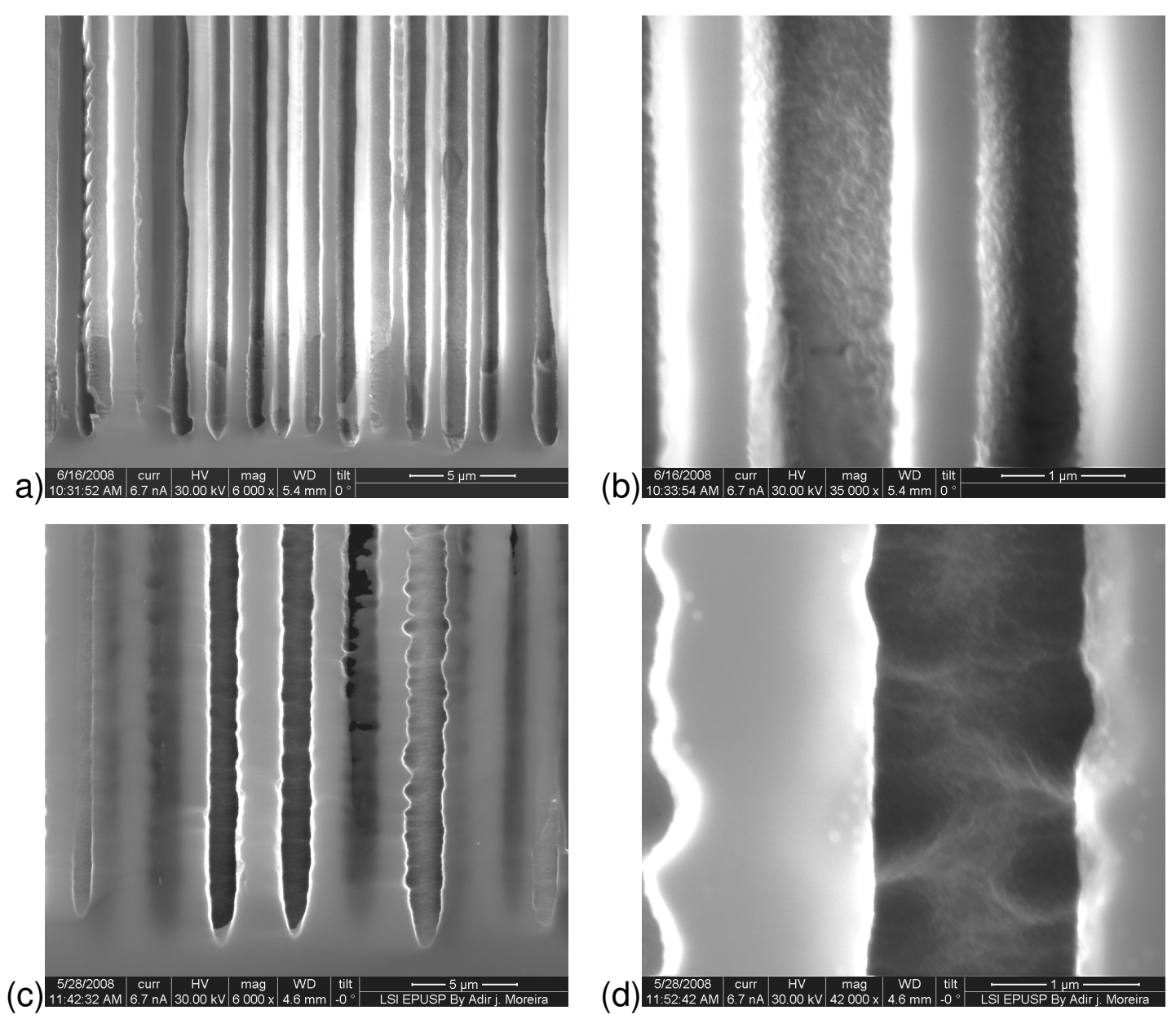

Figura 4.10. Perfil da amostra metalizada nas costas (a,b) e metalizada na face polida (c,d)

O incremento da taxa de corrosão nas amostras tratadas com Al pode acontecer devido ao seguinte mecanismo: quando as amostras são metalizadas nas costas e recozidas, o Al difunde-se no silício de forma não-homogênea dando lugar à formação de estruturas semelhantes a agulhas ou estacas que crescem em forma proporcional ao tempo de recozimento e à espessura do Al depositado nas costas [96,135,138]. Independentemente do tipo de eletrólito utilizado para a formação do SMP, sabe-se que para a formação dos poros é necessária a existência de lacunas e de um campo elétrico que promova os processos eletroquímicos na interface silício/eletrólito $[64,65,97,98]$. No sistema em questão, as lacunas são levadas do corpo do substrato à interface devido ao campo elétrico que surge da polarização externa [64-67]. Sabe-se que 
a formação e crescimento dos poros acontecem preferentemente nos lugares onde o campo elétrico é mais intenso [142]. Quando o Al é depositado e recozido, o campo elétrico é intensificado localmente na ponta das agulhas ou estacas de Al formadas dentro do substrato, e esta intensificação aparece também nas proximidades da interface Si/eletrólito, mesmo que estes estejam longe das mesmas. Este efeito promove uma rápida formação cuja taxa de crescimento resulta ser maior que nas amostras não metalizadas. Como ○ Al difunde-se em maior proporção quanto maior é o tempo de recozimento [96,135,138], espera-se que as agulhas também cresçam em função do tempo. Assim, quanto maior é o tempo de recozimento, maior é o tamanho da agulha e esta fica mais próxima da interface Si/eletrólito, logo, a intensificação local do campo elétrico na ponta das agulhas sente-se também na interface Si/eletrólito (Figura 4.11a) o que promove um incremento ainda maior na taxa de corrosão quanto maior for o tempo de recozimento, como se observa nas Figuras 4.3 e 4.6 .

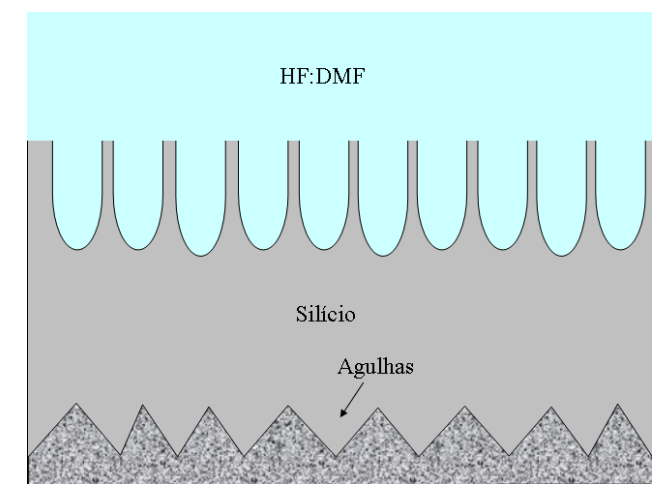

(a)

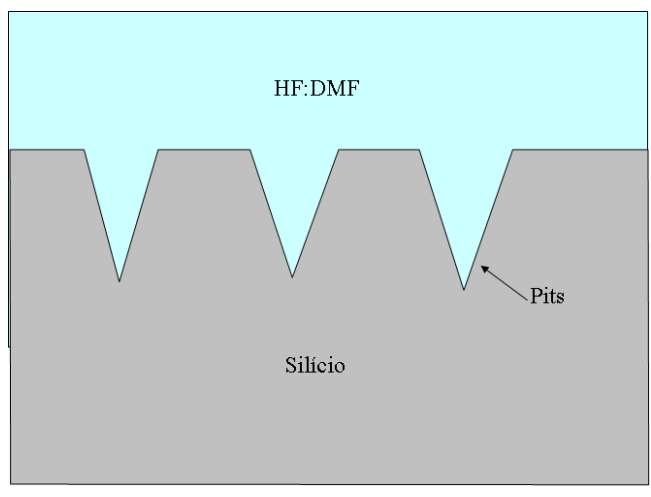

(b)

Figura 4.11. Diagrama esquemático da intensificação do campo elétrico local, devido às agulhas (a), e aos pits na face polida (b)

No caso do substrato não-metalizado a formação ocorre única e exclusivamente naqueles lugares onde há defeitos superficiais que incrementam o campo elétrico e o campo na interface Si/eletrólito incrementa-se só na medida em que os poros crescem, pois este se intensifica na ponta dos poros $[97,144,145]$, portanto a taxa de corrosão resulta ser menor. 
Diferente das amostras metalizadas nas costas, aquelas que foram metalizadas na face polida não apenas mostram um incremento na taxa de corrosão, mas também se formam nelas poros com forma retangular, como se observa nas Figuras 4.3 e 4.6. No caso destas amostras, o incremento da taxa de corrosão segue um mecanismo diferente daquele nas metalizadas nas costas já que neste caso a camada de Al é removida após o recozimento e antes da anodização, seguindo o procedimento já descrito no capítulo III.

O incremento na taxa de corrosão dessas amostras relaciona-se com a intensificação do campo elétrico local na ponta dos furos ou "pits" (Figura 4.11b)[142]. Como já foi antes mencionado, os "pits" resultam da difusão do Si no Al e vice-versa devido ao efeito Kinkerdall e a eletromigração [96,135-138]. Porém, se apenas considerarmos que a taxa de corrosão é incrementada devido à intensificação do campo elétrico localmente, não conseguiríamos explicar porque as áreas isentas de pits também apresentam quase a mesma taxa de corrosão. Adicionalmente, observase na Figura 4.8 que na medida em que se incrementa o tempo de recozimento também se incrementa a resistência elétrica das amostras. Sob estas condições espera-se que a taxa de corrosão seja menor em todas as amostras metalizadas [144,146], mas os resultados experimentais mostram o contrário. Assim, esses resultados sugerem que o Al após recozimento não apenas modifica as propriedades elétricas, mas também modifica suas propriedades químicas, tornando o substrato mais sensível à dissolução pelo HF. Na Figura 4.9 observa-se esse efeito na queda de potencial abrupta nos primeiros minutos em contraste com o perfil da amostra não-metalizada na qual se observa um incremento na queda de tensão. O incremento na queda de tensão indica que o material torna-se mais resistivo, enquanto uma diminuição indica menor resistividade.

Por outro lado, a formação dos poros retangulares é atribuída à forma inicial dos pits que surgem durante o recozimento das amostras após 
terem sido metalizados e posterior remoção da camada de Al, como se vê na Figura 4.12, e sua distribuição superficial ocorre aleatoriamente apenas sendo controlado pela espessura do óxido nativo que se forma sobre a superfície do $\mathrm{Si}$, e pelo tempo de recozimento $[17,137,138]$. A camada de oxido nativo não é homogênea ao longo da superfície e apresenta pontos nos quais esta espessura é menor [96,135]. Após a deposição, durante o recozimento das amostras, a camada de óxido nativo é consumida pelo $\mathrm{Al}$ transformando-se em $\mathrm{Al}_{2} \mathrm{O}_{3}$ e atinge $\mathrm{O}$ substrato [135].
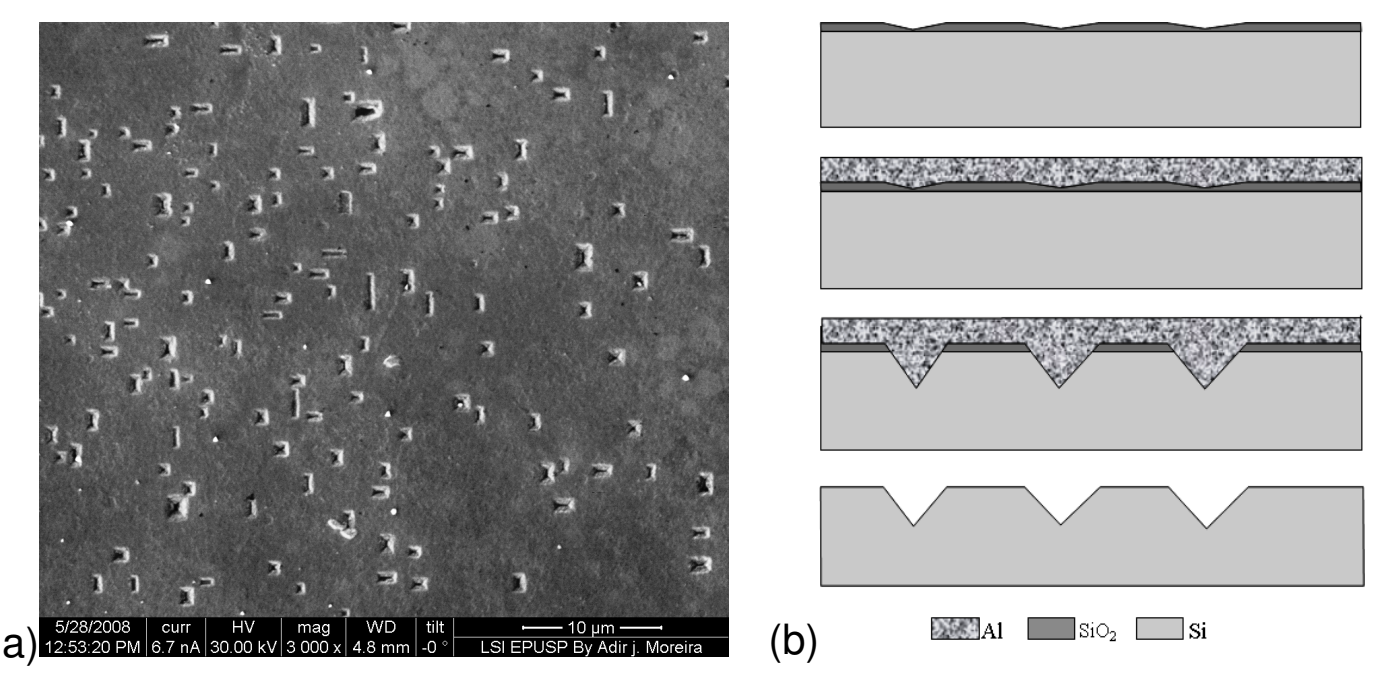

Figura 4.12. Imagem da superfície do silício mostrando os pits (a), que ocorre seguindo a seqüência mostrada no diagrama esquemático (b).

O diagrama de fase Si-Al, mostrado na Figura 4.13, indica que a solubilidade do Al varia com a temperatura atingindo aproximadamente 1 $\%$ de átomos de Si a $500{ }^{\circ} \mathrm{C}$, isto é, se um pedaço de Al puro for recozido a $500{ }^{\circ} \mathrm{C}$ e uma fonte infinita de silício for providenciada, apenas $1 \%$ de silício difundir-se-á dentro do Al [96,135-138]. No momento que o Al atinge o substrato, atravessando aqueles pontos onde a camada de óxido nativo é mais fina, o Si difundir-se-á dentro da camada de $\mathrm{Al}$, deixando dessa forma um vazio que é preenchido pelo alumínio o que leva à formação das agulhas [96,135], que durante o processo de anodização serão os responsáveis pela intensificação local do campo elétrico. Este efeito é conhecido como efeito Kinkerdall [96,135]. Quanto maior é o 
tempo de recozimento, maior é a quantidade de Si dissolvido $[137,138]$ e, eventualmente, dois ou mais pits próximos um do outro podem se juntar dando lugar a um pit de tamanho maior. É devido a esse efeito que na amostra com maior tempo de recozimento observam-se poros retangulares com maior tamanho como observado na Figura 4.6g e 4.7b. O digrama esquemático do processo de formação é resumido na Figura 4.12b.

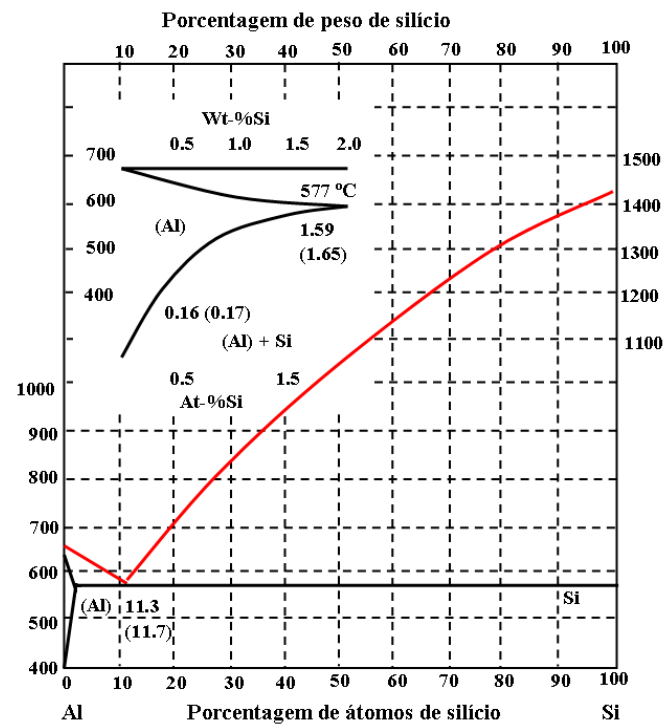

(a)

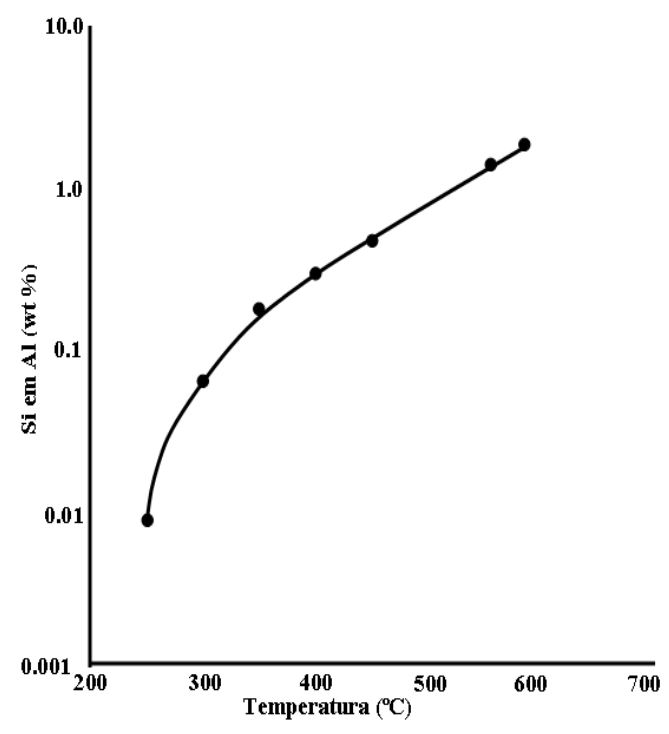

(b)

Figura 4.13. (a) Diagrama de fase do sistema Si-Al [162], e (b) solubilidade do Si em Al [165].

Espera-se que para um maior tempo de recozimento, maior seja a quantidade de silício consumido. Na realidade isto não é o que acontece devido ao fato de a máxima quantidade de Si que pode ser consumido pelo $\mathrm{Al}$ ser limitada ( $1 \%$ para $500^{\circ} \mathrm{C}$ ), portanto se espera que 0 incremento da taxa em função do tempo de recozimento siga uma tendência a saturar-se, como observado nas Figuras 4.5 e 4.8. Então, um incremento no consumo do Si do substrato passa a incrementar a quantidade de Al disponível [96,135-138,144].

Os resultados observados mostram que a deposição do Al e posterior recozimento a $500^{\circ} \mathrm{C}$ modifica tanto a morfologia dos poros quanto a taxa de corrosão das camadas macroporosas, promovendo maiores 
espessuras naquelas com maior tempo de recozimento. Estas estruturas serão usadas como material base para fabricar os microtubos de silício mediante corrosão eletroquímica. Os resultados e as discussões sobre essas estruturas são apresentadas nas seções a seguir.

\subsection{Formação das estruturas tubulares de silício a partir do silício poroso}

Estruturas tubulares com diâmetro médio interno entre $60 \mathrm{~nm}$ e 1,0 $\mu \mathrm{m}$, e paredes com espessura media entre $10 \mathrm{~nm}$ e $200 \mathrm{~nm}$, respectivamente, foram obtidas mediante corrosão eletroquímica sobre substrato de silício meso e macroporoso, respectivamente. As dimensões e forma dependem da morfologia dos poros da camada macroporosa usada como material de partida, segundo o detalhado na seção do procedimento experimental. Assim, dois tipos de estruturas foram fabricados, que classificaremos em micro (MTS) e nanotubos de silício (NTS). As primeiras são obtidas a partir de estruturas macroporosas, enquanto as outras foram obtidas em estruturas mesoporosas. Tanto os materiais empregados, quanto os detalhes dos procedimentos experimentais seguidos para a obtenção dessas estruturas são detalhados no capítulo III. Nesta seção, são apresentados os resultados sobre a obtenção das estruturas de MTS e, também, são discutidos os possíveis mecanismos de formação. Escolheuse trabalhar com MTS, devido a que seu tamanho relativamente grande permite um melhor estudo sobre os mecanismos envolvidos na sua formação. Para tanto, diversos parâmetros tem sido considerado tais como $\mathrm{pH}$, tipo e concentração dos oxidantes, características do substrato bem como o tempo de imersão, sobre a formação dos MTS.

\subsubsection{Efeito do pH na formação de microtubos de silício.}

A formação dos MTS em função do $\mathrm{pH}$ foi estudada mergulhando diferentes amostras em solução de fluoreto de amônia $\left(\mathrm{NH}_{4} \mathrm{~F}\right)$ misturada com diferentes tipos de oxidantes e clivando uma amostra em quatro 
partes que, subseqüentemente, foram imersas em $\mathrm{pH} 4,5$ a 7,5. Um estudo detalhado tem se realizado usando as amostras P77, B33, B36, B89, B99, B100 imersas em $5 \times 10^{-2} \mathrm{M} \mathrm{Na}_{2} \mathrm{SO}_{4}+0,25 \mathrm{M} \mathrm{NH}_{4} \mathrm{~F}$ durante aproximadamente 120 horas. O emprego de várias amostras de SMP formadas usando os mesmos parâmetros eletroquímicos, permitiu ampliar a faixa de $\mathrm{pH}$ estudada (de 4,5 a 9,5) com o intuito de determinar a melhor região de $\mathrm{pH}$ para formar as estruturas tubulares.

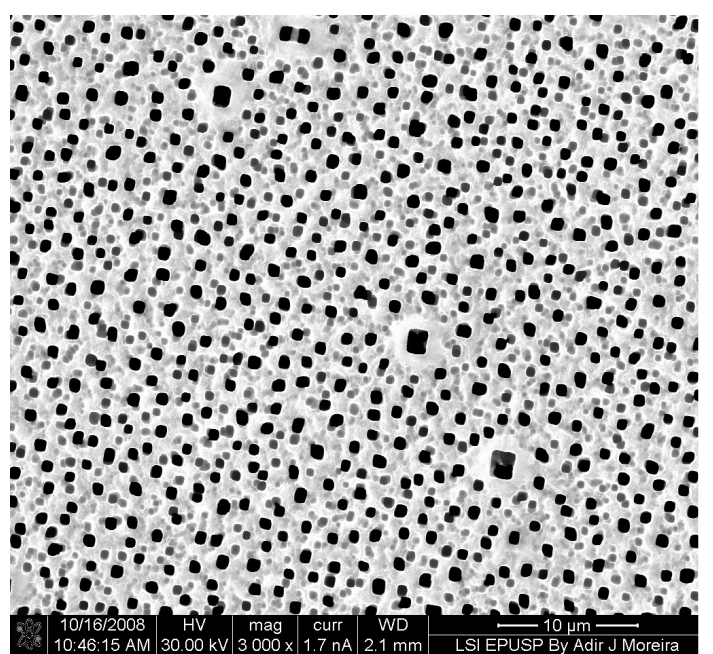

(a)

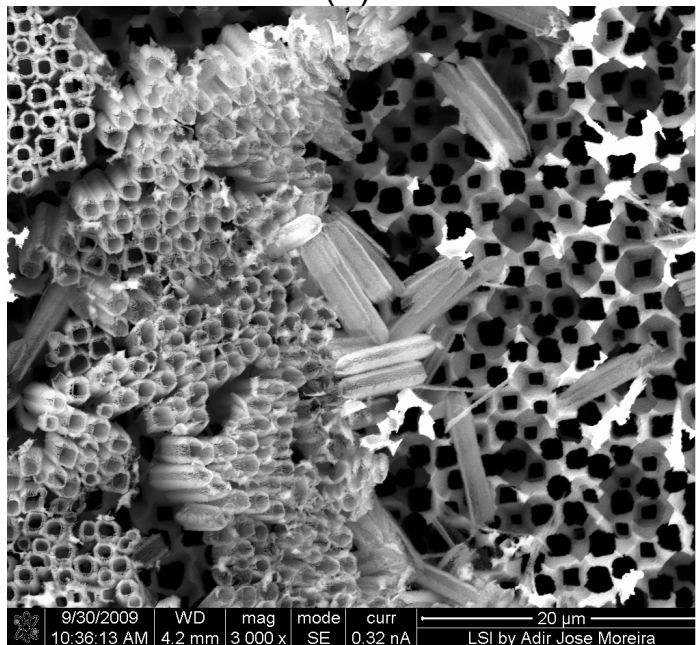

(c)

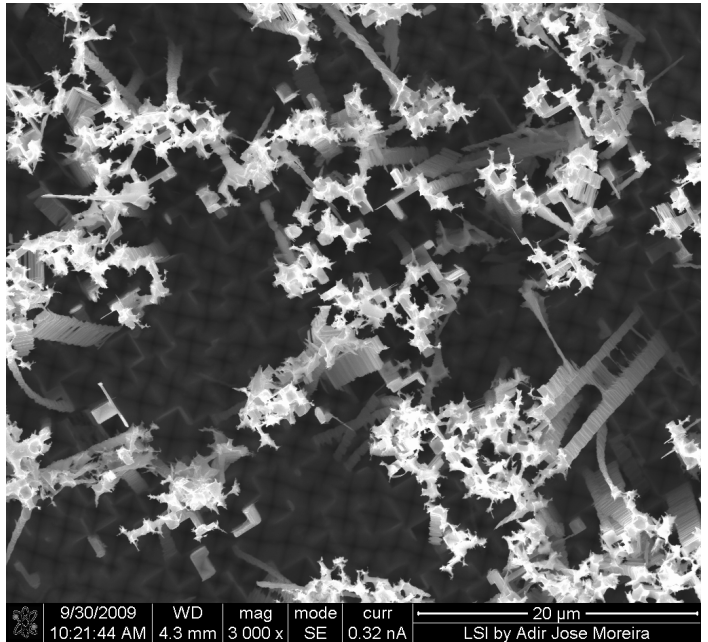

(b)

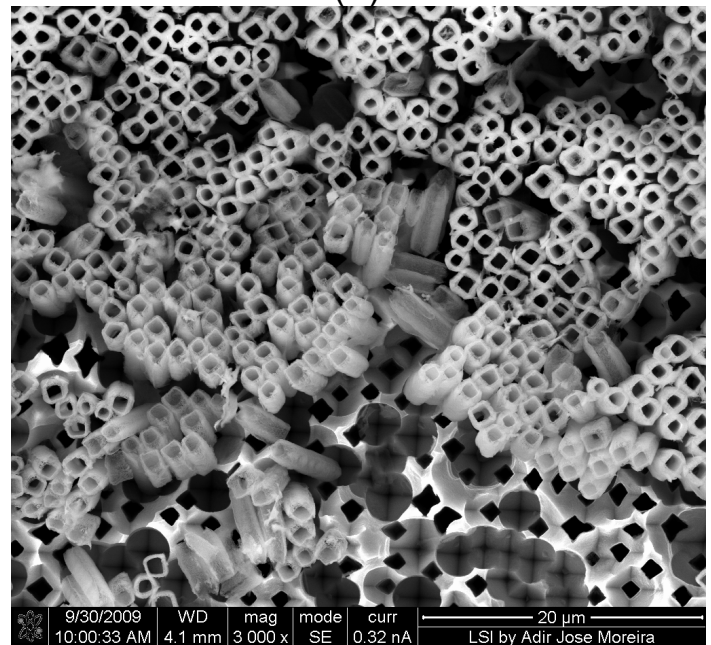

(d)

Figura 4.14. Imagens MEV das amostras P77 imersas durante quatro dias e oito horas em $5 \times 10^{-2} \mathrm{M} \mathrm{Na}_{2} \mathrm{SO}_{4}+0,25 \mathrm{M} \mathrm{NH}_{4} \mathrm{~F}$ com pH: (a) 4,5, (b) 5,5, (c) 6,5, e (d) 7,5

Os resultados da análise estrutural das amostras P77 e B89 são apresentados nas Figuras 4.14 e 4.15, respectivamente. Após 120 horas de imersão das amostras B77A (pH 4,5), B77B (pH 5,5), B77C (pH 6,5) e B77D ( $\mathrm{pH} 7,5)$; observa-se, na Figura 4.14a, que em $\mathrm{pH} 4,5$ a estrutura 
porosa não é corroída significativamente e permanece praticamente inalterada. No entanto, em pH 5,5, observa-se uma corrosão dramática da camada porosa deixando algumas poucas partes em pé, com aparência de um bosque de colunas parcialmente corroídas (Figura 4.14b), e não existindo evidencias da formação das estruturas tubulares. Quando $0 \mathrm{pH}$ é incrementando a 6,5, observa-se a formação das estruturas de MTS (Figura 4.14c) completamente definidos, muitos dos quais aparecem separados uns dos outros, enquanto outros aparecem aglomerados entre si. As paredes dos tubos apresentam uma espessura media de 260 $\mathrm{nm}$ aproximadamente. Semelhante comportamento é, também, observado quando o pH é fixado em 7,5, como mostrado na Figura 4.14d, mas diferente dos tubos formados em $\mathrm{pH} 6,5$, estes mostram-se melhor definidos e com paredes grossas (aproximadamente $700 \mathrm{~nm}$ ).

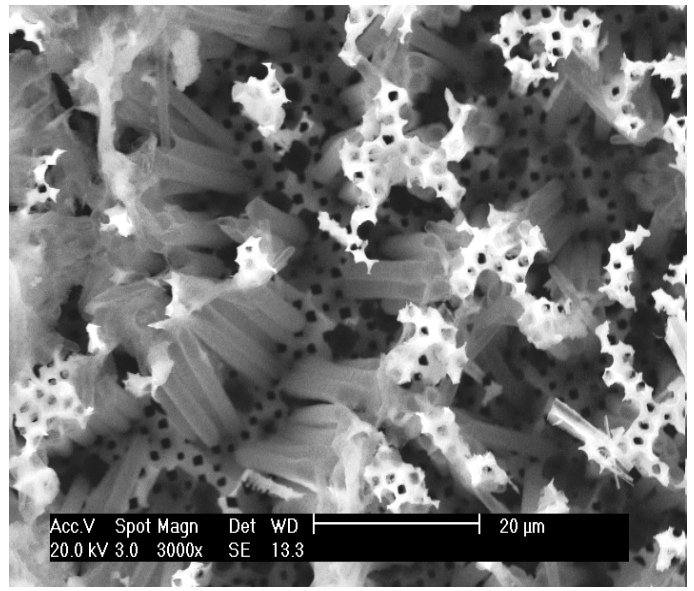

(a)

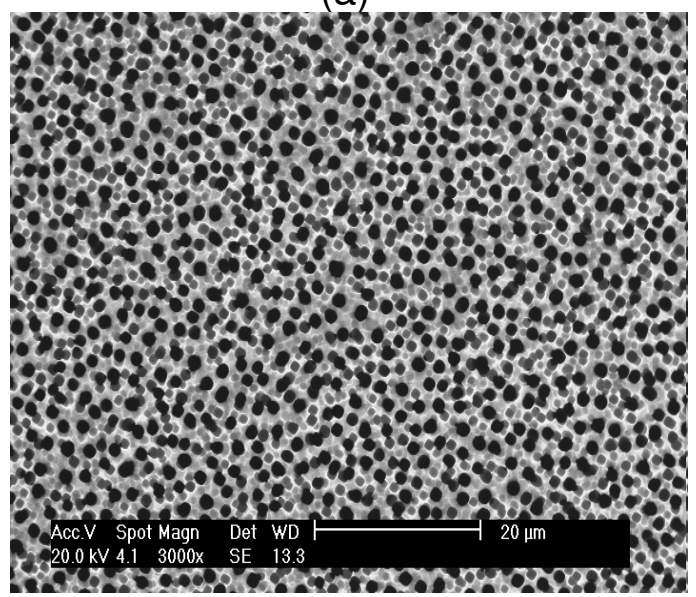

(c)

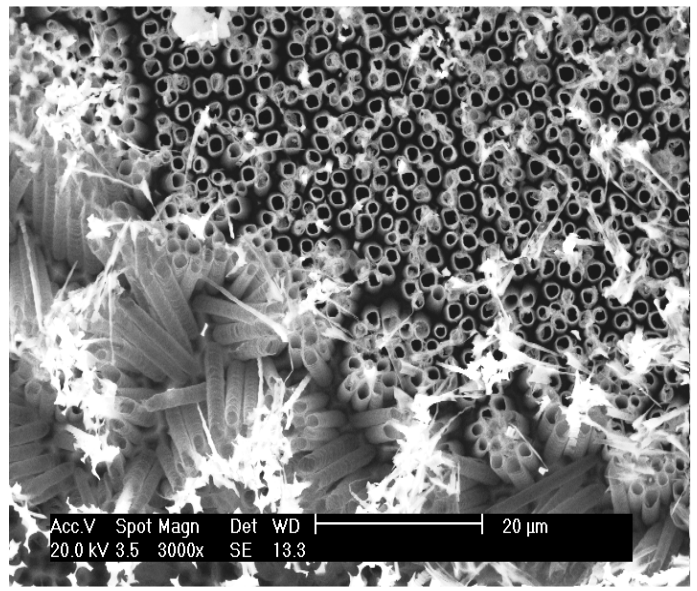

(b)

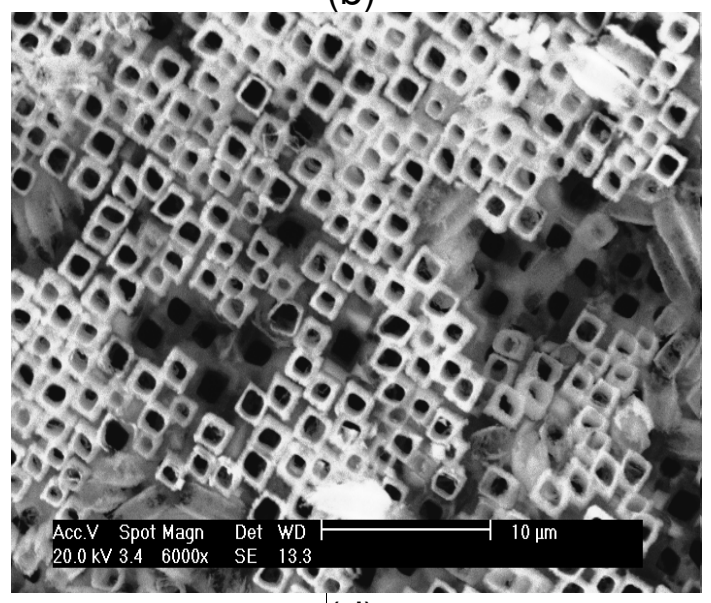

(d)

Figura 4.15. Imagens MEV da amostra B89 imerso em $5 \times 10^{-2} \mathrm{M} \mathrm{Na}_{2} \mathrm{SO}_{4}+0,25 \mathrm{M} \mathrm{NH}_{4} \mathrm{~F}$ com pH: (a) 6,5, (b) 7,5, (c) 8,5, e (d) 9,5 
Considerando que todas as amostras foram mergulhadas simultaneamente e pelo mesmo período de tempo, esses resultados mostram que as paredes dos tubos são sensíveis ao $\mathrm{pH}$ e dissolvem-se com maior taxa de corrosão em pH 6,5. Adicionalmente, as aberturas dos tubos apresentam formas irregulares determinados pela morfologia dos poros, isto é, existem tubos com abertura retangular e semicircular, predominando esta última. Resultados semelhantes são observados nas imagens do MEV da amostra B89 imersa em pH 6,5 (Figura 4.15a) e 7,5 (Figura 4.15b), enquanto que em pH 8,5 e 9,5 a formação dos MTS é inibida, porém existe marcadas diferenças entres estas duas últimas amostras. Em pH 8,5 (Figura 4.15c) a superfície da estrutura macroporosa aparece inalterada, decorrente da passivação, enquanto em pH 9,5 (Figura 4.15d) existe uma tendência à formação dos MTS, porém isso não chega a acontecer, possivelmente, por causa dos efeitos da dissolução química. Assim as Figuras 4.14 e 4.15 mostram claramente que a formação dos tubos esta limitado a uma estreita faixa de $\mathrm{pH}(6,5-7,5)$ e, para valores diferentes, a superfície porosa resulta passivada ou sofre forte corrosão que destrói a estrutura.

Uma vez que as amostras apresentam comportamento eletroquímico diferente em função do $\mathrm{pH}$, o estudo desse comportamento tem sido realizado através da análise das curvas voltamétricas, monitoramento do potencial de eletrodo a circuito aberto (PECA), bem como via a determinação do potencial de banda plana $\left(\mathrm{V}_{\mathrm{FB}}\right)$, usando para esse propósito, a amostra B99 que apresenta as mesmas características físicas da amostra B89. As curvas voltamétricas foram levantadas para todos os níveis de $\mathrm{pH}$ empregados e para todas as amostras, usando $300 \mathrm{mV} / \mathrm{seg}$ como velocidade de varredura começando pela região catódica. Ainda com o intuito de garantir a reprodutibilidade das condições da formação dos MTS, as condições do eletrólito também forma reproduzidas. É importante indicar que os parâmetros obtidos das curvas voltamétricas não representam o comportamento eletroquímico ao longo do tempo de formação dos MTS, apenas descrevem esse comportamento em um 
instante de tempo, podendo este mudar ao longo do tempo de formação dos MTS. As curvas voltamétricas para cada nível de $\mathrm{pH}$ bem como os valores de corrente de corrosão $\left(i_{\text {corr }}\right)$ e potencial de corrosão $\left(E_{\text {corr }}\right)$ obtidos a partir das curvas voltamétricas da amostra B90 são apresentados na Tabela 4.3 e Figura 4.16.

A Figura 4.16a mostram o comportamento da corrente para diferentes valores de $\mathrm{pH}$ quando o eletrodo de SMP é polarizado com uma tensão que varia entre $(-1,0$ a 1,0$) \mathrm{V}_{\mathrm{Ag} / \mathrm{AgCl}}$. A corrente total que cruza a interface SMP/eletrólito, quando polarizado externamente e imerso em uma solução fluorada, descreve-se pela relação (4.3). Nesse sistema, a espécie determinante da taxa de corrosão é o hidrogênio $[147,148]$ :

$$
\begin{gathered}
I(E)=\frac{i_{o a} \mathrm{e}^{\frac{\beta_{a}\left(E-E_{s i}\right)}{\phi}}-i_{B_{c}} \mathrm{e}^{-\frac{\beta_{c}\left(E-E_{H}\right)}{\phi}}}{1-\frac{i_{o c}}{i_{s a t}^{n}} \mathrm{e}^{-\frac{B_{c}\left(E-E_{H}\right)}{\phi}}} \\
i_{s a t}^{n}=\frac{e D_{n} n_{o}}{L}
\end{gathered}
$$

A equação (4.4) descreve a corrente de saturação do sistema, onde $n_{o}$ é a concentração de elétrons em equilíbrio, $D_{n}$ é o coeficiente de difusão do elétron, e $L$ é o comprimento de difusão dos elétrons $[64,148]$.

No sistema que estamos a analisar, a corrente de saturação ocorre na região catódica uma vez que as amostras de SMP foram formadas em substrato tipo $\mathrm{p}$. A variação da corrente catódica em função do $\mathrm{pH}$ para a amostra B99 é mostrada na Figura $4.16 \mathrm{~b}$, e foi obtida no ponto $-1,0$ $\mathrm{V}_{\mathrm{Ag} / \mathrm{AgCl} \text {. }}$ 
Tabela 4.3- Valores obtidos a partir da curva voltametrica da amostra B99.

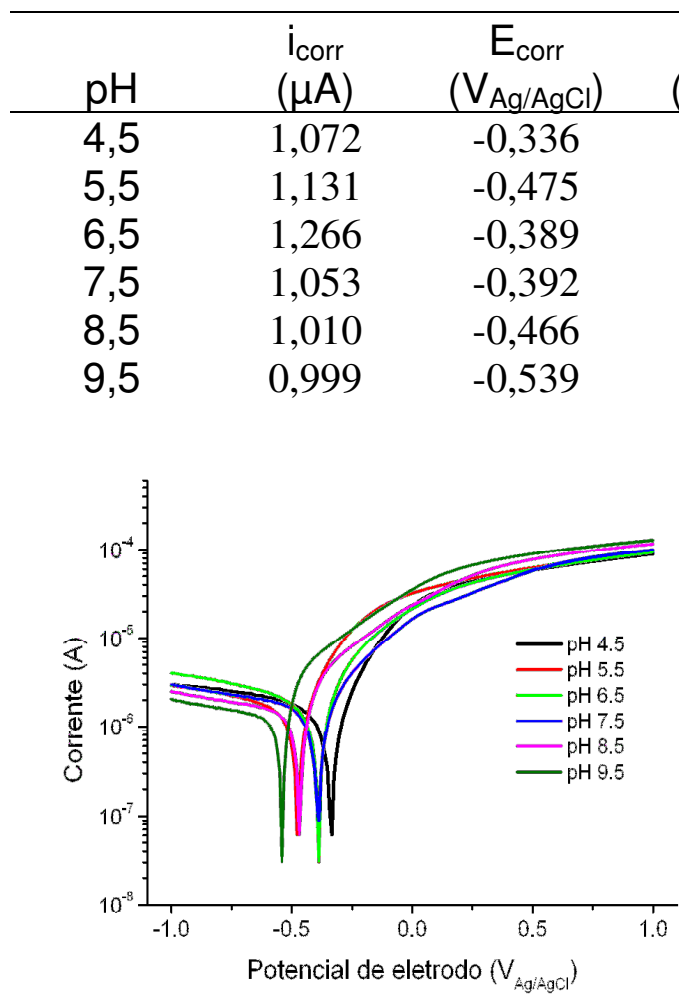

(a)

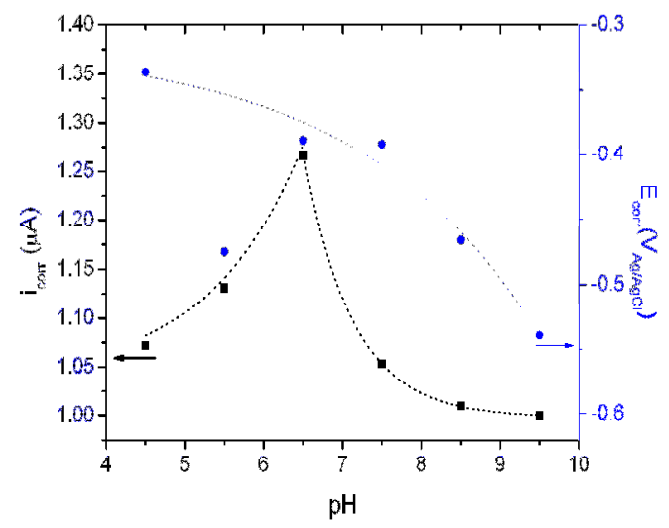

(c)

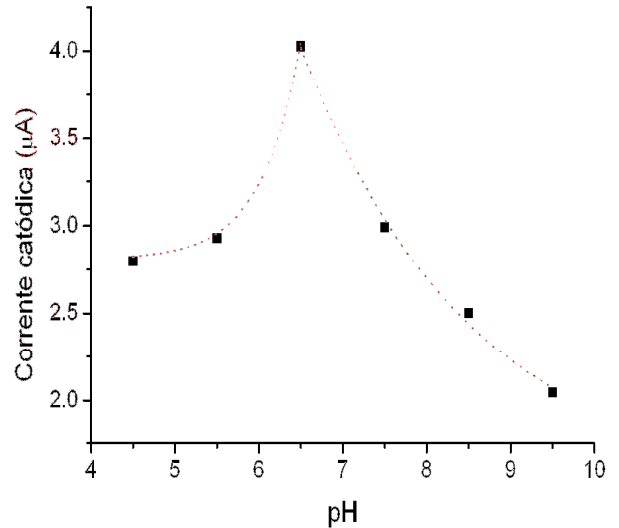

(b)

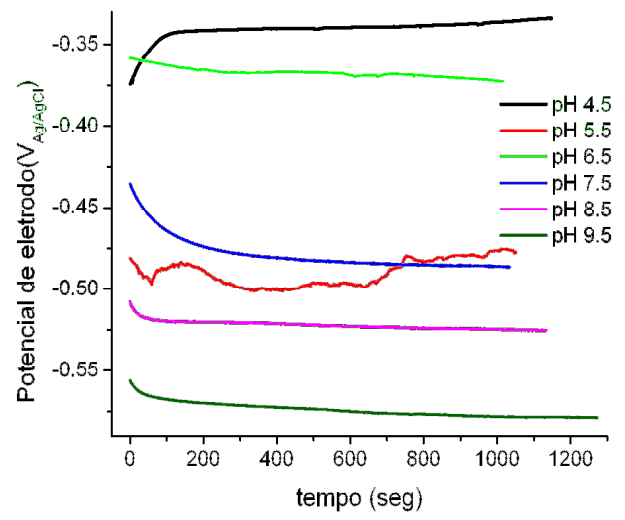

(d)

Figura 4.16. (a) Curvas voltamétricas, (b) corrente catódica, (c) corrente de corrosão e potencial de corrosão, e (d) PECA em função do tempo das imersas em $5 \times 10^{-2} \mathrm{M}$ $\mathrm{Na}_{2} \mathrm{SO}_{4}+0,25 \mathrm{M} \mathrm{NH}_{4} \mathrm{~F}$ em função do $\mathrm{pH}$

No caso do silício tipo p, quando polarizado catodicamente (braço esquerdo na Figura 4.16a), a corrente catódica atinge seu valor limite ou de saturação, devido à baixa concentração de elétrons existente no semicondutor. A analise da corrente catódica é de particular importância, 
devido a que esta é proporcional à corrente de corrosão [64,66,149], logo uma estimativa da corrente de corrosão pode ser obtida da variação da corrente catódica $[66,149]$. Nesse sentido, a partir do perfil da corrente catódica, mostrada na Figura 4.6b, observa-se que inicialmente esta cresce até atingir seu valor máximo em pH 6,5 e diminui exponencialmente para valores de $\mathrm{pH}$ maiores. Uma vez que o eletrodo de SMP é polarizado com a mesma tensão externa, a variação na corrente catódica pode ser atribuída à variação do potencial de barreira associada à camada de depleção $[64,66]$. Uma discussão mais apurada é apresentada mais adiante.

A partir das curvas voltamétricas da Figura 4.16a, extraiu-se os valores da $i_{c o r r}$ e $E_{c o r r}$ em função do pH (Tabela 4.3 e Figura 4.16c). Apesar de que o comportamento da curva de polarização do eletrodo em estudo mostra um comportamento não-reversível, podemos associar a intensidade da corrente de corrosão com a taxa de corrosão de Si. Neste sentido a partir do comportamento de $i_{\text {corr }}$ em função de $\mathrm{pH}$ mostrado na Figura $4.16 \mathrm{c}$ podemos afirmar que a taxa de corrosão é máxima em pH 6,5 e, este resultado, é bem correlacionado com a existência de uma maior concentração de espécies fluoradas $H F_{2}^{-}$nesta região de $\mathrm{pH}[69,70]$. Acima deste nível de $\mathrm{pH}$ a corrente de corrosão decresce exponencialmente em função do $\mathrm{pH}$, como se observa na Figura 4.16c. Já na região entre $4,5 \leq \mathrm{pH} \leq 6,5$ a $i_{\text {corr }}$ cresce exponencialmente, enquanto que $\circ E_{c o r r}$ decresce também exponencialmente ao longo de toda região de $\mathrm{pH}$ em estudo, embora que em $\mathrm{pH} 5,5$ sai fora da curva. Este comportamento associa-se ao efeito do oxidante $\left(\mathrm{Na}_{2} \mathrm{SO}_{4}\right)$, fato que é notório no perfil do monitoramento do PECA (Figura 4.16d), onde se observa, claramente, o deslocamento a valores mais negativos. Assim, o efeito do oxidante manifesta-se, mais notoriamente, na corrente anódica e no PECA, associado à corrosão anisotrópica $[64,65]$. Diferente dos outros $\mathrm{pH}$, o comportamento em $\mathrm{pH}$ 5,5 é completamente aleatório que poderia 
ser atribuído a efeitos da corrosão anisotrópica do substrato [64,65]. Isto explicaria a estrutura em forma de bosque de estacas observado na Figura 4.14b.

O comportamento eletroquímico observado serve de auxilio para elucidar um possível mecanismo da corrosão durante a formação dos MTS. Assim, em um primeiro estágio, analisaremos os diferentes processos de corrosão envolvidos, enquanto que, no segundo estágio, faremos as considerações necessárias para a formação dos MTS que, como veremos mais adiante, a camada de depleção da estrutura macroporosa apresenta uma participação significativa na formação das estruturas tubulares de silício.

O primeiro item a considerar-se será a corrente de corrosão e para tanto é necessário considerar as espécies envolvidas no processo. O eletrólito empregado é uma solução aquosa de $\mathrm{NH}_{4} \mathrm{~F}$ misturada com $\mathrm{Na}_{2} \mathrm{SO}_{4}$, estes passaram a dissociar-se nas suas formas iônicas primárias descritos pelas equações (4.5) e (4.6) e outras formas secundárias, cujas espécies predominantes dependem unicamente do $\mathrm{pH}$ e modificam 0 comportamento eletroquímico da interação SMP/eletrólito [64-66,150], mediante os processo de oxirredução que envolvem essas espécies. Isto dará lugar às reações catódicas que contribuem à corrente catódica em função do $\mathrm{pH}$, como mostrado no diagrama de Pourbaix do enxofre, na Figura A2 do apêndice. Estas reações são expressas pelas equações (4.7) a (4.9) [150]:

$$
\begin{array}{cc}
\mathrm{Na}_{2} \mathrm{SO}_{4} \longrightarrow 2 \mathrm{Na}^{+}+\mathrm{SO}_{4}^{2-} & \\
\mathrm{NH}_{4} \mathrm{~F} \longrightarrow \mathrm{NH}_{4}^{+}+\mathrm{F}^{-} & \\
\mathrm{SO}_{4}^{2-}+10 \mathrm{H}^{+}+8 e \longrightarrow \mathrm{H}_{2} \mathrm{~S}+4 \mathrm{H}_{2} \mathrm{O} & E_{0}=0,303 V_{S H E} \\
\mathrm{SO}_{4}^{2-}+8 \mathrm{H}^{+}+6 e \longrightarrow \mathrm{S}_{2} \mathrm{O} \mathrm{H}_{2} \mathrm{O} & E_{0}=0,357 V_{S H E} \\
\mathrm{SO}_{4}^{2-}+4 \mathrm{H}^{+}+2 e \longrightarrow \mathrm{H}_{2} \mathrm{SO}_{3}+\mathrm{H}_{2} \mathrm{O} & E_{0}=0,172 V_{S H E}
\end{array}
$$


Uma vez que silício é um elemento completamente instável em meio aquoso, sobre a superfície do SMP forma-se uma camada de óxido de silício [64-66]. Em baixas concentrações de HF (meio neutro a alcalino), a superfície do eletrodo considera-se estar constituído, principalmente, por ligações $\mathrm{Si}-\mathrm{OH}$ que dão lugar à rápida formação do oxido de silício mediante as reações $(4.10)$, e $(4.11)[64,65]$ :

$$
\begin{aligned}
& \mathrm{Si}+2 \mathrm{H}_{2} \mathrm{O}+m h^{+} \longrightarrow \mathrm{SiO}_{2}+4 \mathrm{H}^{+}+(4-m) e \\
& \mathrm{Si}+4 \mathrm{OH}^{-}+m h^{+} \longrightarrow \mathrm{SiO}_{2}+2 \mathrm{H}_{2} \mathrm{O}+(4-m) e \quad(m<4)
\end{aligned}
$$

Enquanto que em soluções concentradas de HF ou pH baixo, o processo de oxidação ocorre lentamente mediante a substituição das ligações $\mathrm{Si}-\mathrm{H}$ por $\mathrm{Si}-\mathrm{OH}[64,65,151]$

$$
\mathrm{SiH}_{x}+2 \mathrm{H}_{2} \mathrm{O} \longrightarrow \mathrm{SiO}_{2}+(4+x) \mathrm{H}^{+}+(4+x) e
$$

Após formação da camada de $\mathrm{SiO}_{2}$, esta é removida continuamente pelas espécies fluoradas presentes no eletrólito e, que por sua vez, contribuem à corrente anódica. As reações (4.13) a (4.14) descrevem a remoção do $\mathrm{SiO}_{2}[64-66,78]:$

$$
\begin{aligned}
& \mathrm{SiO}_{2}+6 \mathrm{HF} \longrightarrow \mathrm{SiF}_{6}^{2-}+2 \mathrm{H}_{2} \mathrm{O}+2 \mathrm{H}^{+} \\
& \mathrm{SiO}_{2}+3 \mathrm{HF}_{2}^{-} \longrightarrow \mathrm{SiF}_{6}^{2-}+2 \mathrm{H}_{2} \mathrm{O}+\mathrm{OH}^{-}
\end{aligned}
$$

Por outro lado, as condições termodinâmicas do sistema em equilíbrio, representado no diagrama de Pourbaix do sódio (Figura A1 do apêndice) [150], indicam que não existe condições para a redução dos cátions $\mathrm{Na}^{+}$para qualquer $\mathrm{pH}$, logo este permanecera na sua forma iônica expressa pela equação (4.5). Assim, a dissolução do substrato restringese apenas aos sulfatos, amônia e flúor. 
Uma vez dissociado o fluoreto de amônia, a espécie $\mathrm{NH}_{4}^{+}$terá participação pouco relevante no processo eletroquímico, já que nas condições de $\mathrm{pH}$ e potencial de eletrodo do sistema encontra-se na sua forma mais estável. No entanto, no caso das espécies fluoradas, após a dissociação do fluoreto de amônia coexistiram diferentes espécies tais como $\mathrm{F}^{-}, \mathrm{F}_{2}^{-} \mathrm{HF}, \mathrm{HF}_{2}^{-}, \mathrm{F}^{-},(\mathrm{HF})_{2}, \mathrm{H}_{2} \mathrm{~F}_{3}$ e outras possíveis espécies fluoradas $[64,66,69,70,73,150]$. A predominância de uma espécie sobre outra depende da concentração da solução fluorada, bem com do $\mathrm{pH}$, como mostrado na Figura 4.17 [73]. Sendo que o eletrólito é uma solução aquosa, outra espécie que competirá na dissolução do silício é o $O H^{-}[64,65,68]$. Esta ultima, será favorecida especialmente em $\mathrm{pH}$ alcalino $[69,70]$.

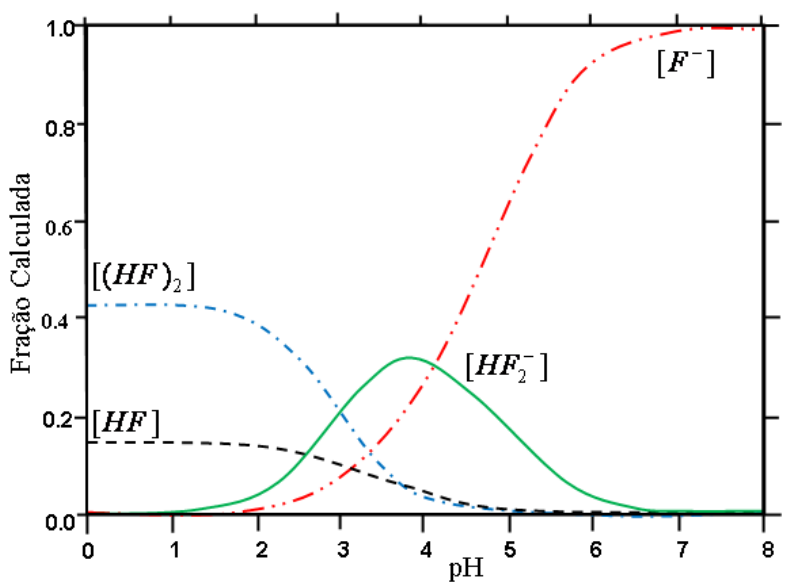

Figura 4.17. Valores teóricos da concentração das espécies fluoradas em função do pH [73].

Nas Figura 4.16b e Figura 4.16c foram mostrados o perfil da corrente de catódica e corrente de corrosão, respectivamente, onde foi possível observar que o pico máximo foi atingido quando o $\mathrm{pH}$ da solução foi de 6,5 , este resultado esta bem correlacionado com a maior concentração de espécies do tipo $\mathrm{HF}_{2}^{-}$nessa região, segundo o reportado em $[69,70,74]$, embora os valores teóricos mostrados na Figura 4.17 indicam o contrário $[64,69,70]$, Para baixos valores de $\mathrm{pH}$, menores do que constante de dissociação (aproximadamente 3,2 [64,65,147,152]), na Figura 4.17, 
observa-se que predomina a presença de $H F$, enquanto que para $\mathrm{pH}$ elevado a predominância é a da espécie $F^{-}$, porém ela não esta envolvida ativamente na dissolução do $\mathrm{SiO}_{2}[64,152,153]$. Para $\mathrm{pH}>3,2$ abunda os íons de hidrogênio que, rapidamente, formam ligações $\mathrm{Si}-\mathrm{H}$ com os átomos de $\mathrm{Si}$ da superfície do substrato, devido à alta afinidade eletrônica entre eles [64,65,154], formando uma camada passivadora que evita a corrosão da estrutura, como mostrado na Figura 4.14a.

A corrente de corrosão, como anteriormente comentado, atinge seu máximo valor em pH 6,5 (Figura 4.16c). Uma vez que a corrente de corrosão origina-se da interação SMP/eletrólito, este é um indicador da taxa de corrosão em circuito aberto em virtude da reação espontânea dos reagentes, logo, esperava-se que valores semelhantes de $\mathrm{i}_{\text {corr }}$ deveriam de produzir estruturas similares, a menos que as condições eletroquímicas sejam diferentes. Assim, se somente $\mathrm{i}_{\text {corr }}$ for considerado para analisar o comportamento do eletrodo, então se esperava que as estruturas resultantes após o mergulho dos filmes de MPS em pH 4,5 e 7,5 fossem semelhantes, já que a corrente de corrosão nestes dois meios ( $\mathrm{pH} 4,5$ e $\mathrm{pH} 7,5)$ apresentam valores muito próximos (Figura 4.16b). Porém, os resultados mostrado na Figura 4.14, indicam que a formação dos MTS apenas acontece em pH 7,5, enquanto que em $\mathrm{pH} \mathrm{4,5} \mathrm{a}$ superfície resulta passivada, isto revela que o processo químico e eletroquímico na superfície do filme de MPS é complexo e que apenas a monitoração de um parâmetro não resulta suficiente para explicar 0 resultado final. Adicionalmente, a Figura 4.16b mostra que, embora as correntes de corrosão sejam semelhantes, o $E_{\text {corr }}$ dessas duas amostras são diferentes, sendo menos negativo em $\mathrm{pH}$ 4,5. Portanto, 0 comportamento eletroquímico na interfase SMP/eletrólito, sugere a existência de processos diferentes para cada nível de $\mathrm{pH}$ da solução. Isto pode ser reafirmado, se observamos o comportamento do PECA nas soluções com os valores de pH acima citados (Figura 4.16c). Em pH 4,5, 
observa-se um perfil totalmente oposta àquele observado em $\mathrm{pH} 7,5$, com uma tendência a atingir seu estado estacionário em valores menos negativos, que descrevem o efeito da passivação da superfície devido à formação de ligações $S i-H$, principalmente, seguindo a reação descrita pela equação (4.15), já que, em soluções ácidas, sabe-se que predominam os íons $H^{+}[64-66,97,98]$. Assim, as possíveis reações catódicas decorrentes da abundância dos íons de hidrogênio na solução serão [64-66,83,151]:

$$
\begin{aligned}
& H^{+}+S i+e \longrightarrow S i-H \quad E_{H}=-0,06 p H\left(V_{\text {SHE }}\right) \\
& 2 H^{+}+2 e \longrightarrow H_{2} \uparrow
\end{aligned}
$$

Uma melhor elucidação das possíveis espécies envolvidas na dissolução do silício nos diferentes valores de $\mathrm{pH}$ pode ser obtida mediante a comparação do potencial de circuito aberto (PECA) com o potencial redox de cada uma das espécies presentes no eletrólito (Figura 4.18)

Em condições de circuito aberto, o potencial de eletrodo medido em $\mathrm{pH}$ 4,5 é igual a $-0.344 \mathrm{~V}_{\mathrm{Ag} / \mathrm{AgCl}}$ (Figura 4.18a)e, sendo este menos negativo do que 0 potencial redox do hidrogênio $\left(-0,266 \mathrm{~V}_{\mathrm{SHE}}\right.$ ou $\left.-0,471 \mathrm{~V}_{\mathrm{Ag} / \mathrm{AgCl}}\right)$ $[64,65,150]$, não favorece a reação (4.16), logo não haverá evolução do $H_{2}$. Este é o típico comportamento eletroquímico da dissolução tetravalente que dá lugar a processo de dissolução total ou eletropolimento do substrato, onde não há evolução do hidrogênio $[64,65]$. Ainda nessas condições, a reação da equação (4.15), também, não é favorecida. Porém, esta ocorre mediante as ligações livres dos átomos de silício superficiais (dangling Bond) que são altamente reativos. Os dangling bonds originam estados de superfície situados na região da banda proibida do silício, facilitando a transferência de carga e sendo, por esta razão, ligações altamente reativas [64-66]. 


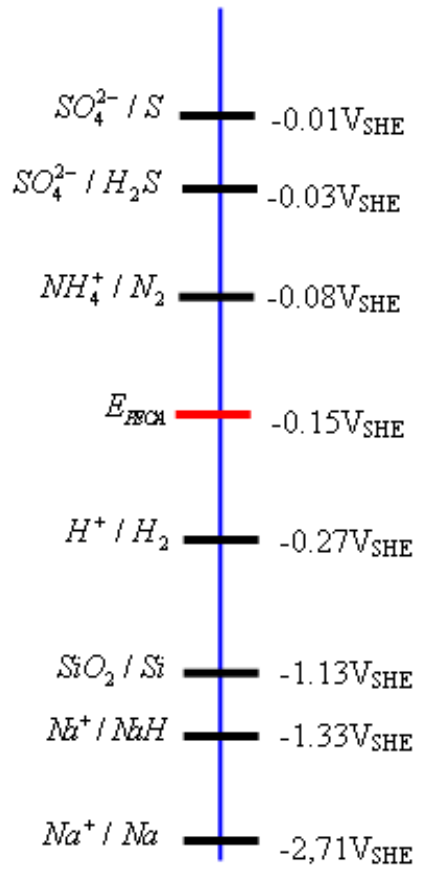

(a)

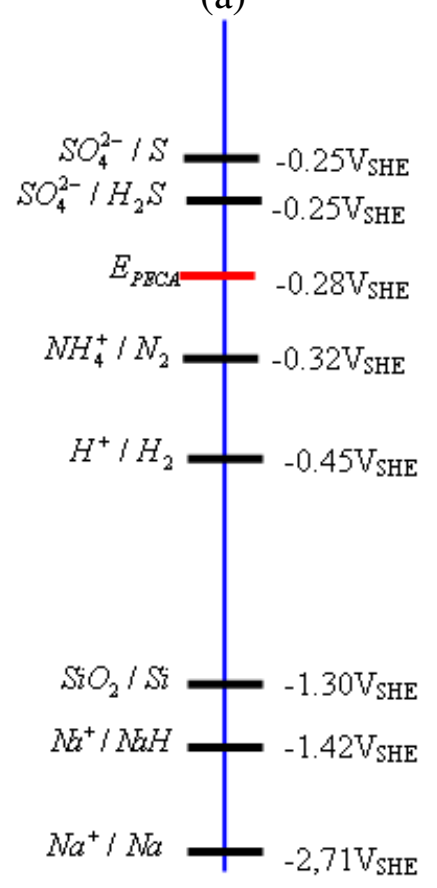

(d)

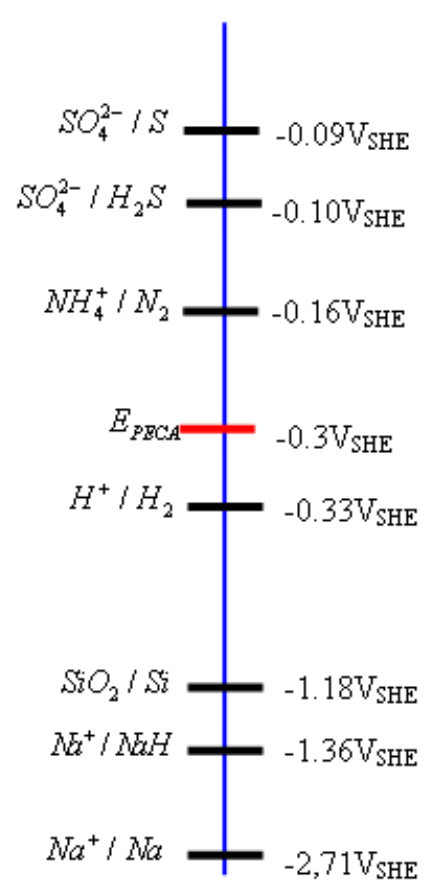

(b)

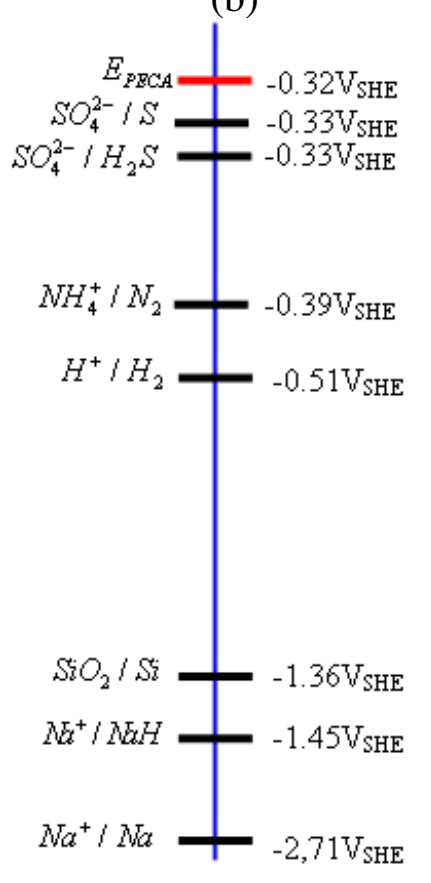

(e)

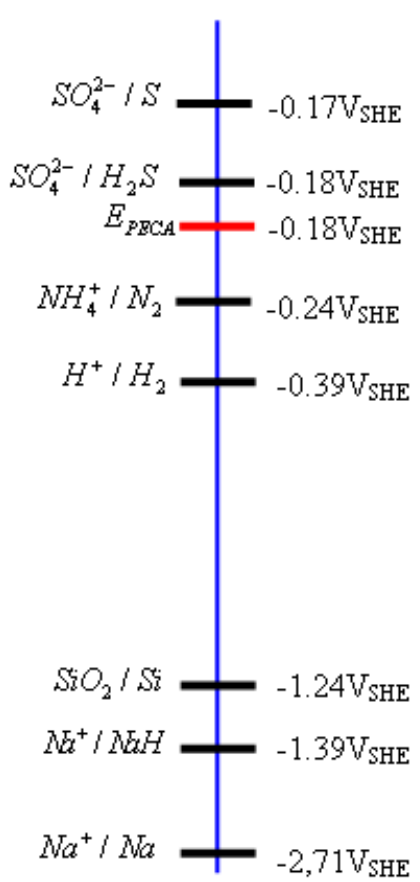

(c)

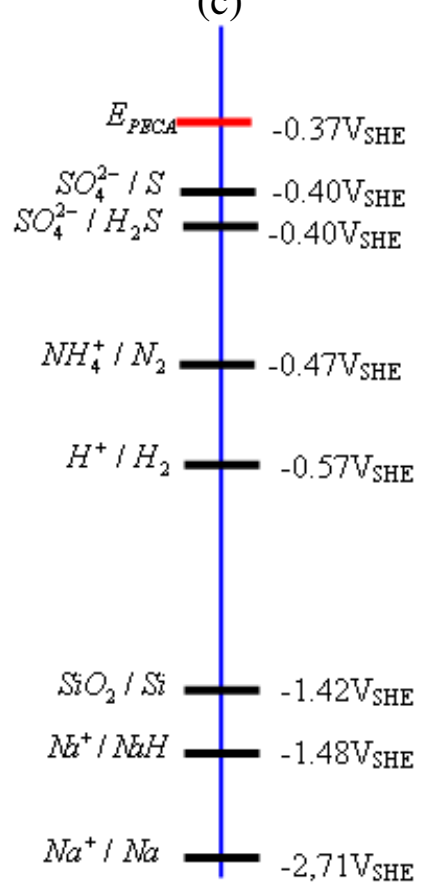

(f)

Figura 4.18. Comparação do potencial de circuito aberto (PECA) com o potencial redox das possíveis reações favorecidas das espécies presentes no eletrólito de $5 \times 10^{-2} \mathrm{M}$ $\mathrm{Na}_{2} \mathrm{SO}_{4}+0,25 \mathrm{M} \mathrm{NH}_{4} \mathrm{~F}$ em pH 4,5 (a); 5,5 (b); 6,5 (c); 7,5 (d); 8,5 (e) e 9,5 (f). A linha em vermelho representa o PECA medido para cada caso. 
Uma melhor compreensão dos processos de óxido-redução, a partir do PECA, pode ser obtida mediante a relação $(4.17)[66,147,148]$, onde é possível descrever mais claramente o comportamento do PECA em função dos potenciais redox do $\mathrm{Si}\left(E_{S i}\right)$, do hidrogênio $\left(E_{H}\right)$ e das correntes de troca catódica $\left(i_{o c}\right)$ e corrente de troca anódica $\left(i_{o a}\right)$ no eletrodo, respectivamente.

$$
E_{P E C A}=\frac{\beta_{a} E_{S i}+\beta_{c} E_{H}}{\beta_{c}+\beta_{a}}+\frac{k T}{e\left(\beta_{c}+\beta_{a}\right)} \ln \left(\frac{i_{o c}}{i_{o a}}\right)
$$

$\mathrm{Na}$ equação (4.17), $\beta_{a}$ e $\beta_{c}$ são os coeficientes de transferência anódica do silício e catódica do hidrogênio, respectivamente.

De acordo com a equação (4.17), o PECA incrementa seu valor nos processo onde predomina a corrente de troca catódica (processos de redução), como é o caso da redução do $\mathrm{Si} / \mathrm{H}^{+}$para formar as ligações $\mathrm{Si}-\mathrm{H}$ (equação 4.15) [64-66,83,151], enquanto que o deslocamento a valores mais negativos acontece naqueles processos onde predomina a corrente anódica, isto é, nos processos que promovem a dissolução do substrato, como acontece no caso do silício imerso em solução fluorada [64-66]. Turner [86] tem reportado o comportamento do PECA em função do $\mathrm{pH}$ em uma solução de $1 \mathrm{M} \mathrm{NaCl}$ e observou-se que este segue um deslocamento a valores negativos em forma suave na medida em que 0 $\mathrm{pH}$ é incrementado. Esse resultado é semelhante àquele observado no presente trabalho (Figura 4.16c e 4.16d), exceto em pH 5,5, onde 0 potencial é mais negativo e atribui-se aos efeitos das espécies oxidantes presentes no eletrólito, em particular devido à atividade catalítica da espécie $\mathrm{SO}_{4}^{2-}$ na formação do óxido visto que as condições termodinâmicas são favoráveis para a redução desta espécie (Figura 4.18b). Considerando a equação (4.17), observa-se que este comportamento apenas é possível se a razão $i_{o c} / i_{o a}$ torna-se menor do que a unidade, e acontecerá quando $i_{o c}<i_{o a}$, portanto, incrementado a $i_{o a}$ 
ou diminuindo $i_{o c}$, ou através da variação simultânea de ambos. Em virtude de que o Si é um material instável em solução aquosa, forma uma camada de $\mathrm{SiO}_{2}$ que é dissolvido em presença de espécies fluoradas [6466]. Assim, o deslocamento do PECA a valores mais negativos indica a dissolução do substrato, e corresponde a um incremento em $i_{o a}$. No entanto, um incremento do PECA no sentido positivo é sinal da passivação da superfície do eletrodo associado às reações catódicas governadas pela relação (4.15) que conduzem à formação das ligações $S i-H$, como acontece na solução em pH 4,5 (Figura 4.16c). A reação (4.15) predomina sobre as reações catódicas da espécie $S_{4}^{2-}$, devido a que estas são altamente estáveis do que qualquer outra possível ligação com o silício, uma vez que as ligações $S i-H$ apresentam baixa polarização [154].

O incremento do $\mathrm{pH}$ a 5,5 diminui as ligações $\mathrm{Si}-H$ favorecendo a interação com as espécies $\mathrm{OH}^{-}, \mathrm{H}_{2} \mathrm{O}$ e $\mathrm{SO}_{4}^{2-}$, segundo as equações (4.11) e (4.12), que produzem um incremento na corrente de corrosão e um deslocamento abrupto no PECA. Isto evidencia, também, um incremento na $i_{o a}$, devido às reações nas equações (4.10) a (4.14), nessa ordem. Decorrente do deslocamento do PECA a valores mais negativos (0,503 $\mathrm{V}_{\mathrm{Ag} / \mathrm{AgCl}}$ ou $-0,298 \mathrm{~V}_{\mathrm{SHE}}$ ), em pH 5,5, as condições termodinâmicas passam a favorecer as reações catódicas (4.7) a (4.9) que promoveram o incremento na taxa de crescimento do $\mathrm{SiO}_{2}$, devido ao efeito catalítico, via redução do $\mathrm{SO}_{4}^{2-}$ nos seus diferentes estados, que injetam lacunas na banda de valência (BV). Estas são necessárias para a formação de $\mathrm{SiO}_{2}$ que, subseqüentemente, é dissolvido pelas espécies fluoradas mediante rápidos processos de oxidação e dissolução predominantemente isotrópica [64,65], seguindo o mecanismo explicado na seção 2.4.2, resultando em um perfil irregular do PECA (Figura 4.16d) que promove a formação das estruturas mostrada na Figura 4.14b. Este processo conduz a um incremento na corrente de corrosão já que um incremento nas 
reações catódicas produzem um incremento na corrente de corrosão $[64,66,149]$

Se considerarmos que em pH 5,5 coexistem as espécies $H F_{2}^{-}$e $H F$, e as condições são favoráveis para as reações descritas pelas equações (4.7) e (4.9), a reações totais envolvida serão:

$$
\begin{aligned}
& 2 \mathrm{Si}+12 \mathrm{HF}+\mathrm{SO}_{4}^{2-} \longrightarrow 2 \mathrm{SiF}_{6}^{2-}+\mathrm{H}_{2} \mathrm{~S}+4 \mathrm{H}_{2} \mathrm{O}+2 \mathrm{H}^{+}+2(4-m) e+2(4-m) h^{+} \\
& \mathrm{Si}+6 \mathrm{HF}+2 \mathrm{SO}_{4}^{2-}+2 \mathrm{H}^{+} \longrightarrow 2 \mathrm{SiF}_{6}^{2-}+2 \mathrm{H}_{2} \mathrm{SO}_{3}+2 \mathrm{H}_{2} \mathrm{O}+(4-m) e+(4-m) h^{+} \\
& 2 \mathrm{Si}^{+} 6 \mathrm{HF}_{2}^{-}+\mathrm{SO}_{4}^{2-}+2 \mathrm{H}^{+} \longrightarrow 2 \mathrm{SiF}_{6}^{2-}+\mathrm{H}_{2} \mathrm{~S}+2 \mathrm{OH}^{-}+2 \mathrm{H}_{2} \mathrm{O}+2(4-m) e+2(4-m) h^{+} \\
& \mathrm{Si}+3 \mathrm{HF}_{2}^{-}+2 \mathrm{SO}_{4}^{2-}+4 \mathrm{H}^{+} \longrightarrow \mathrm{SiF}_{6}^{2-}+2 \mathrm{H}_{2} \mathrm{SO}_{3}+\mathrm{OH}^{-}+\mathrm{H}_{2} \mathrm{O}+(4-m) e+(4-m) h^{+}
\end{aligned}
$$

Apesar do incremento na corrente de corrosão decorrente das reações catalíticas na formação do $\mathrm{SiO}_{2}$, esta ainda resulta sendo menor do que a corrente de corrosão na solução com pH 6,5. Isto poderia ser atribuído à predominância da espécie $H F$ devido a que esta apresenta uma taxa de corrosão quatro vezes menor do que a espécie $\mathrm{HF}_{2}^{-}$, como tem sido reportado por H. Kikuyama et. al [155] e J. S. Judge [71]. Adicionalmente, C. Serre et al. [81] reportou que em quanto menor é o valor do $\mathrm{pH}$ a espécie $\mathrm{HF}_{2}^{-}$torna-se menos ativa na dissolução do $\mathrm{SiO}_{2}$, logo, em $\mathrm{pH}$ 5,5 as reações que predominam serão aquelas descritas nas equações (4.18) e/ou (4.19).

Em pH 6,5, as Figuras 4.16b e 4.16c mostram um incremento da taxa de corrosão e do PECA, respectivamente, associado ao incremento tanto da atividade da espécie $H F_{2}^{-}[69-71,81,155]$, quanto ao incremento das ligações $\mathrm{Si}-\mathrm{OH}$ que catalisam a formação do $\mathrm{SiO}_{2}$ de acordo com as equações (4.10) e/ou (4.11). Estas reações injetam lacunas na BV $[64,65,80]$, e contribuem à dissolução do Si em forma predominantemente 
anisotrópica [66,98,115-118], permitindo a formação dos MTS, como mostrado nas Figuras $4.14 \mathrm{c}$ e $4.15 \mathrm{a}$. Neste $\mathrm{pH}$, o incremento da $i_{\text {corr }}$ (Figura 4.16c) relaciona-se tanto ao incremento da taxa de crescimento do $\mathrm{SiO}_{2}$ quanto a sua rápida dissolução pelas espécies $\mathrm{HF}_{2}^{-}$cuja concentração é maior neste $\mathrm{pH}[69,70]$ e é quatro vezes mais ativa na dissolução do $\mathrm{SiO}_{2}$ [71,155]. Quando comparamos o PECA com o potencial redox das espécies oxidantes (Figura 4.18c), observamos que embora o PECA tenha sido deslocado a valores menos negativos, como se vê na Figura $4.16 \mathrm{~d}\left(-0.371 \mathrm{~V}_{\mathrm{Ag} / \mathrm{AgCl}}\right.$ ou $\left.-0.166 \mathrm{~V}_{\mathrm{SHE}}\right)$, ele ainda é suficientemente menor para promover as reações (4.7) a (4.9) que injetam lacunas na $\mathrm{BV}$ do $\mathrm{Si}$ que promovem um incremento na taxa de crescimento do $\mathrm{SiO}_{2}$. Adicionalmente, sendo que a solução também esta composta por íons $\mathrm{NH}_{4}^{+}$, as condições do PECA em pH 6,5 favorecem a reação anódica $\mathrm{NH}_{4}^{+} / \mathrm{N}_{2}$ devido a que o potencial redox dessa reação é mais negativo do que o PECA e cujo valor é -0,188 $V_{\text {SHE }}$ aproximadamente, segundo o digrama de Pourbaix para 0 nitrogênio (Figura A3 do apêndice [150]:

$$
2 \mathrm{NH}_{4}^{+} \longrightarrow \mathrm{N}_{2} \uparrow+8 \mathrm{H}^{+}+6 e \quad E_{0}=0,275 V_{S H E}
$$

Em adição à reação eletroquímica (4.22), as condições termodinâmicas neste $\mathrm{pH}$ também favorecem as reações químicas que leva à formação de gás de amônia e incrementa a concentração do $H F$, como mostra a equação $(4.23)[83,150]$ :

$$
\mathrm{NH}_{4}^{+}+\mathrm{F}^{-} \longrightarrow \mathrm{NH}_{3}+\mathrm{HF}
$$

Porém devido a abundância da espécie $F^{-}$(veja Figura 4.17)[73] e as condições não favoráveis para a existência do $H F$ rapidamente reagira juntando-se com outro $F^{-}$para formar a espécie $H F_{2}^{-}[65,147,150]$, fato que tem sido confirmado via analise XPS que detecto maior concentração de ligações $S i-F_{2}$ em pH 6,5, como tem sido reportado em [70,74], e 
detalhado amplamente na seção 2.4. Assim, as condições termodinâmicas são favoráveis para que em $\mathrm{pH}$ 6,5 exista uma maior concentração de $\mathrm{HF}_{2}^{-}$que é fortemente ativa na dissolução do $\mathrm{SiO}_{2}$ promovendo uma dissolução quatro vezes maior daquele promovido pelo $H F[71,81,155]$. Adicionalmente, o incremento do $\mathrm{pH}$ torna o processo de corrosão mais anisotrópico e menos caótico do que em pH 5,5, como se mostra no perfil do PECA (Figura 4.16c).

$\mathrm{Em} \mathrm{pH} \mathrm{7,5} \mathrm{o} \mathrm{PECA} \mathrm{desloca-se} \mathrm{novamente} \mathrm{a} \mathrm{valores} \mathrm{mais} \mathrm{negativos}$ próximos daquele observado em $\mathrm{pH} 5,5$, porém com um perfil mais suave que indica que o processo de corrosão que esteja acontecendo no substrato é bem mais controlado. A Figura 4.16b mostra que sob estas condições a corrente de corrosão cai notavelmente a valores próximos daquele observado em $\mathrm{pH}$ 4,5. Isto pode ser atribuído à queda na concentração da espécie $H F_{2}^{-}$[69-71,81,155], que é a encarregada da dissolução eletroquímica, predominando desta vez a dissolução química por ação das espécies $\mathrm{OH}^{-}$e $\mathrm{H}_{2} \mathrm{O}[64,65,92,94]$, e cujo mecanismo tem sido explanado amplamente na seção 2.4.3.

$$
\mathrm{Si}+2 \mathrm{H}_{2} \mathrm{O}+2 \mathrm{OH}^{-} \longrightarrow \mathrm{Si}(\mathrm{OH})_{2} \mathrm{O}_{2}^{2-}+2 \mathrm{H}_{2}
$$

Os resultados mostrados nas Figuras $4.14 \mathrm{~d}$ e $4.15 \mathrm{~b}$ mostram a importância dessas espécies na formação dos MTS já que incrementa a anisotropia a corrosão permitindo a formação de MTS melhor definidos do que em pH 6,5. Segundo o diagrama de Pourbaix do enxofre (Figura A2) [150], para condições de pH e PECA observados, as condições termodinâmicas ainda favorecem tanto à reação catódica (4.8), quanto às reações anódicas (4.10) e (4.22), bem como à reação química (4.23), logo a baixa corrente de corrosão apenas pode ser atribuído ao decremento da espécie $\mathrm{HF}_{2}^{-}[99,105]$, pois sob as atuais condições de $\mathrm{pH}$ predomina a espécie $F^{-}$que não tem participação ativa na dissolução do $\mathrm{SiO}_{2}$ $[71,81,155]$. Essas reações são mais bem visualizadas quando comparadas o potencial redox das espécies no eletrólito com PECA (Figura 4.18d). Por outro lado, os resultados da análise estrutural das 
amostras imersas em pH 5,5 a 7,5, sugerem que a espécie $H F$ determina a corrosão isotrópica, enquanto que a espécie $H F_{2}^{-}$incrementa a taxa de corrosão seguindo o perfil anisotrópico determinado pelas espécies $\mathrm{OH}^{-} \mathrm{e}$ $\mathrm{H}_{2} \mathrm{O}$.

Em pH 8,5 observa-se, na Figura 4.15c, que a superfície não sofre maior corrosão aparecendo semelhante à amostra imersa em pH 4,5. Adicionalmente, na Figura 4.16c vê-se que a corrente de corrosão atinge valores muito pequenos ainda menores daquele observado em $\mathrm{pH} 4,5$. Similar comportamento observa-se na Figura $4.16 \mathrm{~b}$, enquanto que 0 PECA (Figura 4.16c) é deslocado a valores mais negativos ainda, seguindo o comportamento observado na literatura em função do $\mathrm{pH}$ $[64,86]$. Como comentado antes, o deslocamento do PECA a valores menos negativos, também pode acontecer por conta de uma queda no corrente $i_{o c}$ decorrente da não disponibilidade de elétrons na interface SMP/eletrólito devido ao efeito da passivação. De acordo com o reportado previamente no diagrama de Pourbaix do nitrogênio (Figura A3) [150], sugere-se que a superfície teria sido passivada por um incremento nas ligações $\mathrm{Si}-\mathrm{H}$ decorrentes da reação eletroquímica e química dos íons $\mathrm{NH}_{4}^{+}$que dão lugar à evolução dos gases $\mathrm{N}_{2}$ e $\mathrm{NH}_{3}$, respectivamente, e liberam íons $H^{+}$, de acordo com as equações (4.22) e (4.25) [150]:

$$
\mathrm{NH}_{4}^{+} \longrightarrow \mathrm{NH}_{3} \uparrow+\mathrm{H}^{+}
$$

Adicionalmente, as condições termodinâmicas não mais favorecem a atividade catalítica da espécie $\mathrm{SO}_{4}^{2-}$ visto que o PECA $\left(-0,32 \mathrm{~V}_{\mathrm{SHE}}\right)$ é menos negativa do que os potenciais redox da espécie $S_{4}^{2-}\left(-0.33 \mathrm{~V}_{\mathrm{SHE}}\right)$, como se mostra na Figura 4.18e.

Em pH 9,5, também não se observa formação dos MTS, porém aparecem os contornos dos possíveis tubos que sugere uma tentativa de se formar os MTS (Figura 4.15d). Considerando que nessa região de $\mathrm{pH}$ as 
espécies predominantes são $\mathrm{NH}_{4} \mathrm{OH}, \mathrm{OH}^{-}, \mathrm{H}_{2} \mathrm{O}$ e $\mathrm{F}^{-}$[150], já que a reação das espécies oxidantes é inibida (Figura 4.18f), a dissolução do substrato é basicamente devido à participação ativa das espécies $\mathrm{OH}^{-}$e $\mathrm{H}_{2} \mathrm{O}$ de acordo com as equações (4.10) e (4.11) [64,65,92,93], enquanto que a espécie $F^{-}$não participa ativamente embora exista em grande abundância devido a que a camada de $\mathrm{SiO}_{2}$ formada não pode ser removida pela espécie $F^{-}[69-71,81,155]$, portanto a dissolução do Si é um processo totalmente químico. Isto explica a baixa corrente de corrosão e corrente catódica observada nas Figuras 4.16c e 4.16b, respectivamente, apenas atribuída à contribuição das reações que não envolvem a dissolução do substrato, mas sim as reações no eletrólito tais como a reação anódica (4.22) que também é a encarregada de incrementar a corrente anódica tanto em $\mathrm{pH} \mathrm{8,5}$ quanto em 9,5. Por outro lado, a analise estrutural (Figura 4.15d) da amostras imersas em pH 9,5 mostra a formação de tubos com abertura quadrada. Isto mostra que a corrosão anisotrópica é a encarregada de determinar a formação da parede dos MTS a partir da camada de depleção. A presença de tubos em processo de formação indica que é necessária a presença do agente oxidante com intuito de injetar lacunas e acelerar a taxa de corrosão que permitirá formar tubos de maior comprimento através da dissolução pela espécie fluorada, preferentemente $H F_{2}^{-}$para evitar destruir os MTS por efeito da corrosão isotrópica.

Os resultados dos espectros EDS (Figura 4.19) das estruturas em discussão confirmam a tendência do comportamento químico e eletroquímico discutido acima como veremos a seguir. É importante indicar que no caso das amostras que foram passivadas o EDS foi obtida sobre toda a superfície, enquanto no caso das amostras que sofreram corrosão estas foram obtidas nas estruturas resultantes, isto é, nas paredes dos tubos ou estacas. 


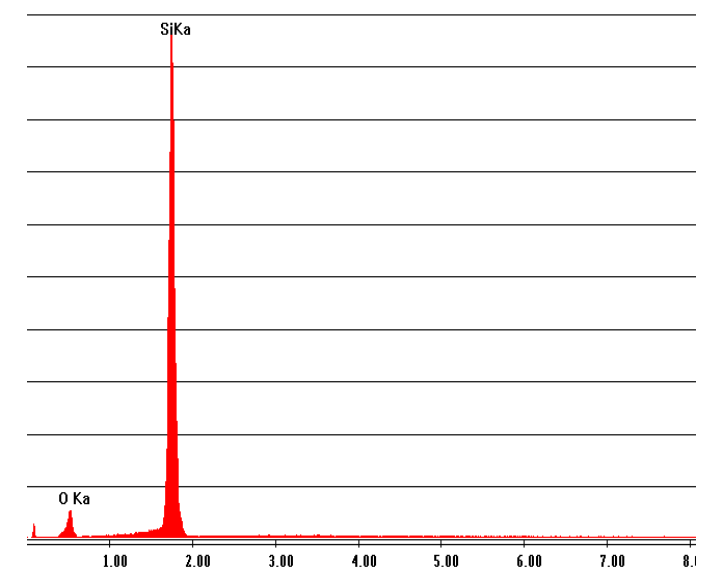

(a)

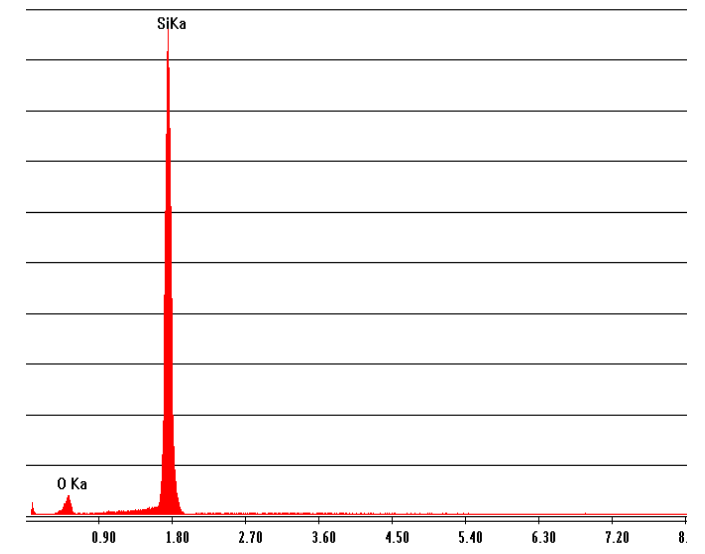

(c)

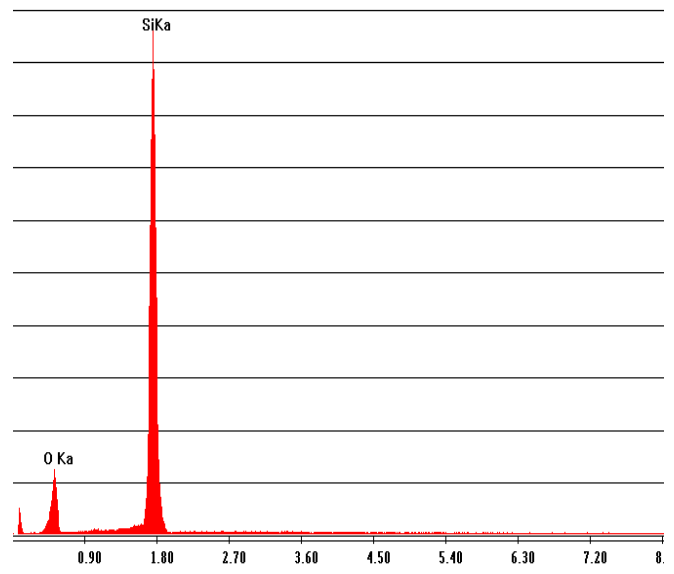

(e)

Figura 4.19. Espectro EDS da analise química das

(c) 7,5; (d) 8,5; (e) 9,5, e (f) elementos presentes na amostras.

A composição química das diferentes amostras para cada valor de $\mathrm{pH}$ são resumidas na Tabela 4.3 e Figura 4.19f, onde se observa claramente que a concentração de oxigênio segue o mesmo perfil da corrente de corrosão (Figura 4.16c) , exceto em $\mathrm{pH} 9,5$, e apresenta o pico máximo em $\mathrm{pH}$ 6,5,

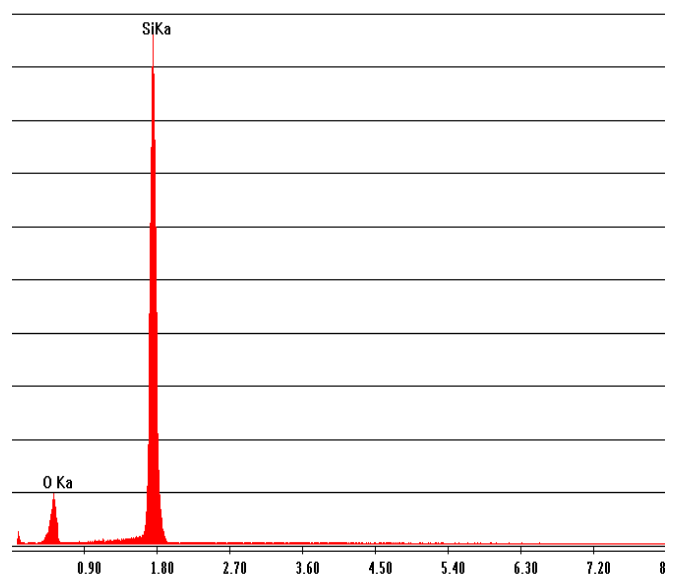

(b)

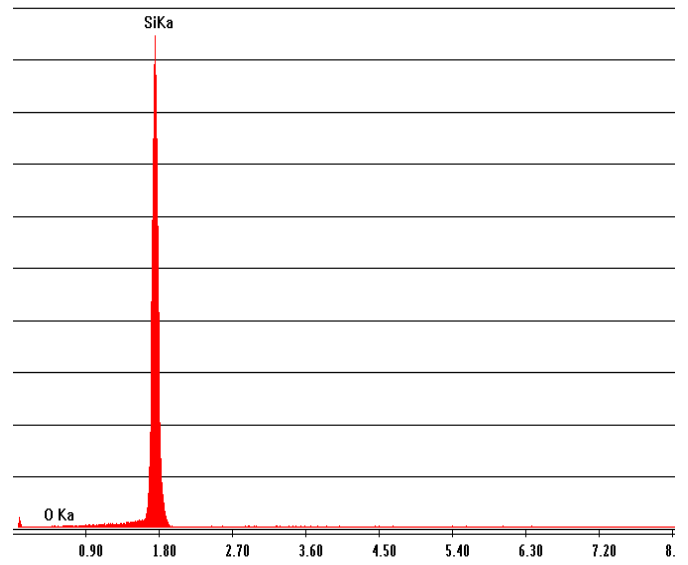

(d)

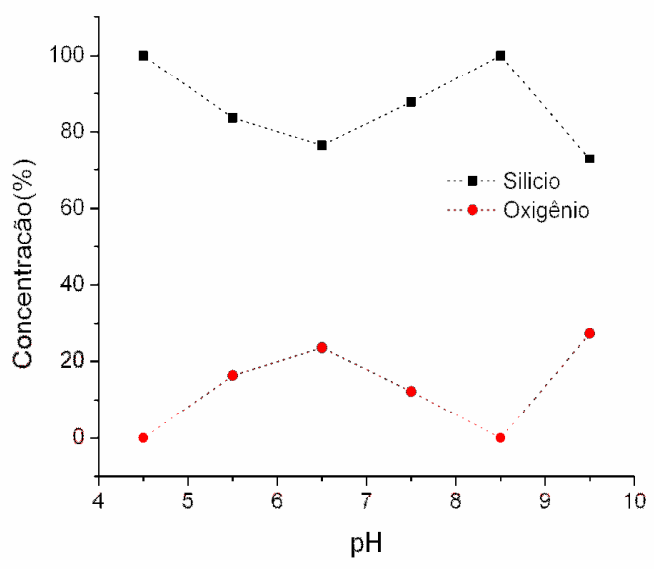

f)

(a) 5,5; (b) 6,5; 
enquanto que em pH 4,5 e 8,5 a presença do oxigênio é nula, resultados que estão bem correlacionados com a passivação da superfície da amostra (Figura 4.14a e 4.15c) De acordo com a analise previa apresentada nesta seção, na faixa de pH 5,5 a 7,5 as condições termodinâmicas são favoráveis a redução do $\mathrm{SO}_{4}^{2-}$ nas formas descritas pelas equações (4.7) a (4.9) e injetam lacunas na BV necessárias para a formação do $\mathrm{SiO}_{2}$ de acordo as equações (4.26) e (4.27).

$$
\begin{aligned}
& 2 \mathrm{Si}+\mathrm{SO}_{4}^{2-}+2 \mathrm{H}^{+} \longrightarrow 2 \mathrm{SiO}_{2}+\mathrm{H}_{2} \mathrm{~S}+2(4-m) e+2(4-m) h^{+} \\
& \mathrm{Si}+2 \mathrm{SO}_{4}^{2-}+4 \mathrm{H}^{+} \longrightarrow \mathrm{SiO}_{2}+2 \mathrm{H}_{2} \mathrm{SO}_{3}+(4-m) e+(4-m) h^{+}
\end{aligned}
$$

A equação (4.8) não foi levada em consideração devido a que a EDS não detectou a presença de enxofre nas amostras, como visto na Figura 4.19, porém tampouco pode deixar de ser considerada como uma reação intermediaria que conduz à formação do $\mathrm{H}_{2} \mathrm{SO}_{3}$ [150]. No entanto, como antes comentado em pH 8,5 a superfície é passivada pelas reações (4.22) e (4.25), enquanto a alta concentração de oxigênio em pH 9,5 é decorrente da formação de óxidos por ação ativa das espécies $\mathrm{OH}^{-} \mathrm{e}$ $\mathrm{H}_{2} \mathrm{O}$, como mostrado nas equações (4.10) e (4.11), devido às elevadas concentrações de ligações $\mathrm{Si}-\mathrm{OH}$ [64,65,92,93]. As reações que catalisam a formação do $\mathrm{SiO}_{2}$ (equações 4.25 e 4.26) estão restritas apenas à faixa de $\mathrm{pH} 5,5$ a 7,5 cuja maior taxa ocorre em pH 6,5 .

A ativação das diferentes reações descritas e discutidas acima depende da transferência de carga na interface Si/eletrólito, do lado do silício o parâmetro importante que participa na troca é a região de depleção que atua como barreira, então a modulação desta barreira permitirá que as reações aconteçam. O procedimento experimental que nos permitira ter informação sobre as características desta barreira está relacionada com a determinação da banda plana $\left(\mathrm{V}_{\mathrm{FB}}\right)$ do substrato de MPS nas soluções em estudo. $O$ calculo de $V_{F B}$ foi realizado através da extrapolação da 
relação de Mott-Schottky em baixa freqüência, utilizando a equação (4.28) $[64,156]$. $\mathrm{O} \mathrm{V}_{\mathrm{FB}}$ é o potencial necessário para que as bandas de energia estejam paralelas $[64,65]$.

$$
\frac{1}{C^{2}}=\frac{2}{e \varepsilon_{S i} \varepsilon_{o} A^{2} N_{a}}\left(V-V_{F B}-\frac{k T}{e}\right)
$$

Os resultados apresentados na Figura 4.20a, obtidos em $10 \mathrm{kHz}$, mostram um comportamento linear para todos os valores de $\mathrm{pH}$, evidenciando baixa atividade dos estados de interface, já que o afastamento da linearidade é atribuído a efeitos dos estados superficiais $[64,66]$. Assim, a determinação de $V_{F B}$ fornecera a informação sobre a curvatura dos níveis energéticos do Si. A queda de tensão na camada de depleção $\left(\mathrm{V}_{\mathrm{s}}\right)$, está relacionado com o PECA $\left(V_{P E C A}=V_{m}\right)$ e $0 \quad \mathrm{~V}_{\mathrm{FB}}$ mediante a relação (4.29). Os resultados obtidos a partir da curva MottSchottky e a tensão PECA são resumidos na Tabela 4.4 e representados na Figura 4.20 respectivamente.

$$
V_{s}=V_{P E C A}-V_{F B}
$$

Os resultados na Tabela 4.4 mostram que, $\mathrm{V}_{\mathrm{FB}}$ é sensível à variação do $\mathrm{pH}$ e tende a decrescer na medida que o nível de $\mathrm{pH}$ solução se incrementa. Adicionalmente, observa-se que a largura da camada de depleção também diminui com o pH (Figura 4.20c), e o sistema apresenta uma largura mais estreita em $\mathrm{pH}$ 6,5 região na qual se atinge a máxima corrente de corrosão, que pode estar associado não apenas ao incremento na concentração da espécie $\mathrm{HF}_{2}^{-}$, mas também à diminuição da largura da camada de depleção e abaixamento do barreira energética $V_{s}$, como se vê nas Figuras 4.20b e 4.20c. Contudo, o incremento da corrente de corrosão não apenas depende da diminuição da barreira $V_{s}$ no substrato, mas também da concentração de espécie ativas na dissolução do $\mathrm{SiO}_{2}$, como já tem sido comentado. Isto é evidente na 
Figura 4.20, onde se vê que em $\mathrm{pH} 7,5 V_{s}$ torna-se ainda mais negativa do que em pH 6,5 mostrando que em pH 7,5 a camada de depleção é mais pronunciada resultado que esta bem correlacionado com a menor corrente de corrosão (Figura 4.16c) e a menor concentração de $H F_{2}^{-}$ $[69,70]$.

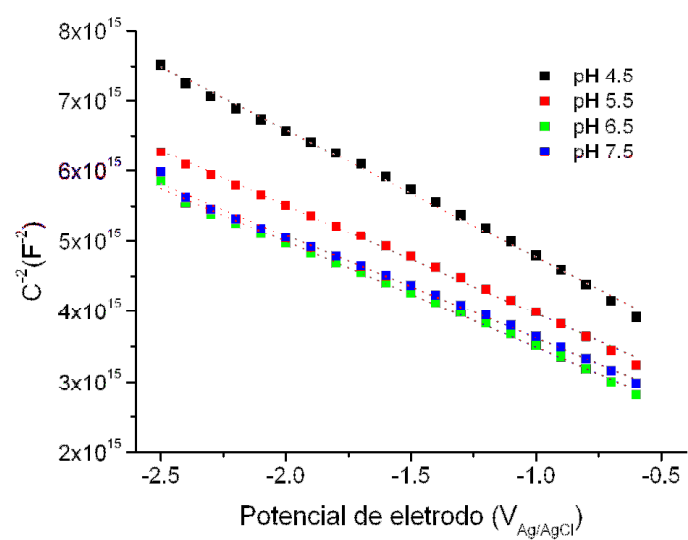

(a)

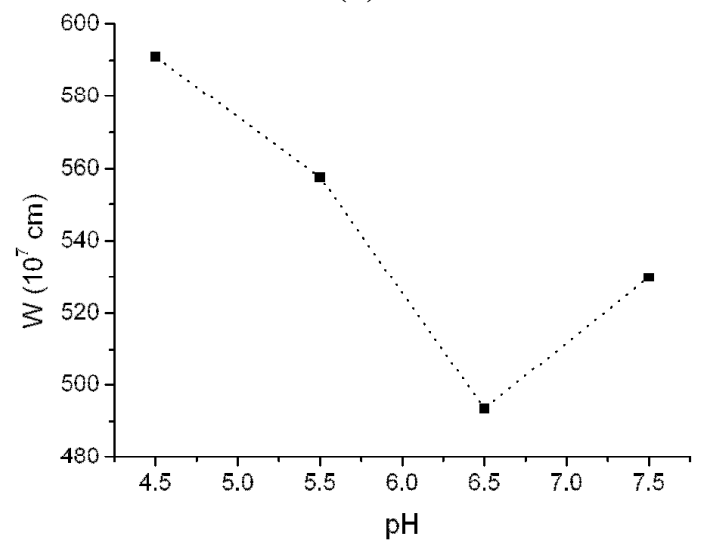

(c)

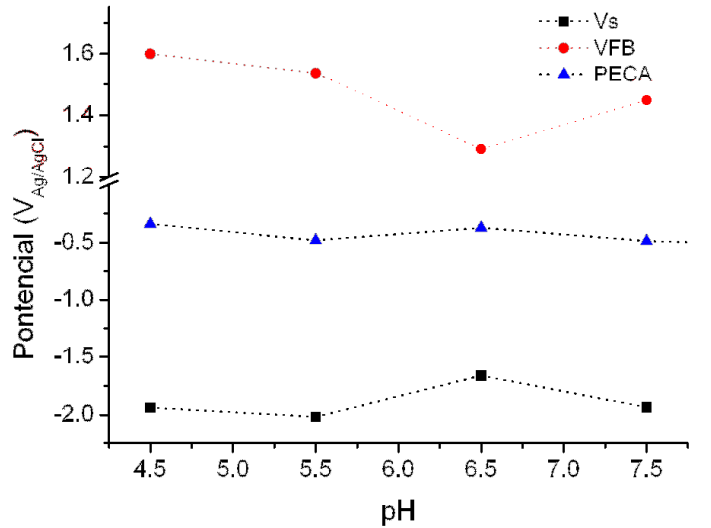

(b)

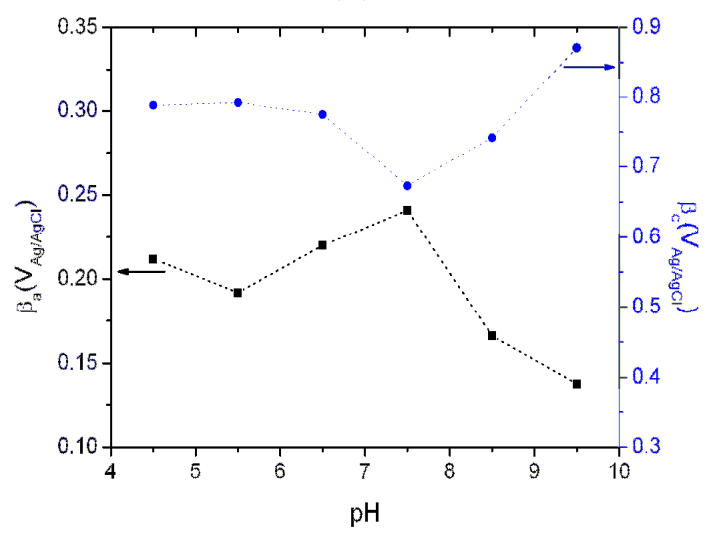

(d)

Figura 4.20. (a) Curvas Mott-Schottky; (b) $\mathrm{V}_{\mathrm{FB}}$, PECA, e $\mathrm{V}_{\mathrm{s}}$; (c) largura de depleção; e (d) Coeficiente de transferência em função do $\mathrm{pH}$.

Tabela 4.4- Parâmetros extraídos da analise C-V da amostra B90.

\begin{tabular}{ccccccc}
\hline $\mathrm{pH}$ & $\begin{array}{c}\mathrm{PECA} \\
\left(\mathrm{V}_{\mathrm{Ag} / \mathrm{AgCl}}\right)\end{array}$ & $\begin{array}{c}\mathrm{i}_{\text {corr }} \\
(\mathrm{uA})\end{array}$ & $\begin{array}{c}\mathrm{V}_{\mathrm{FB}} \\
\left(\mathrm{V}_{\mathrm{Ag} / \mathrm{AgCl}}\right)\end{array}$ & $\begin{array}{c}\mathrm{V}_{\mathrm{FB}} \\
\left(\mathrm{V}_{\mathrm{SHE}}\right)\end{array}$ & $\begin{array}{c}\mathrm{V}_{\mathrm{s}} \\
\left(\mathrm{V}_{\mathrm{Ag} / \mathrm{AgCl}}\right)\end{array}$ & $\begin{array}{c}\mathrm{W}_{\perp} \\
(\mathrm{nm})\end{array}$ \\
\hline 4,5 & $-0,3376$ & 1,07 & 1,60 & 1,81 & $-1,94$ & 591,0 \\
5,5 & $-0,4793$ & 1,13 & 1,54 & 1,74 & $-2,02$ & 557,6 \\
6,5 & $-0,3706$ & 1,27 & 1,29 & 1,50 & $-1,66$ & 493,5 \\
7,5 & $-0,4854$ & 1,05 & 1,45 & 1,65 & $-1,93$ & 530,0 \\
8,5 & $-0,5243$ & 1,01 & - & - & - & \\
9,5 & $-0,5774$ & 1,00 & - & - & - & \\
\hline
\end{tabular}


Adicionalmente, é conhecido que nos elétrodos semicondutores a corrente não apenas depende da concentração lacunas (ou elétrons) na interface e da queda de tensão na camada de depleção $V_{s}$, mas também da energia de ativação e do coeficiente de transferência das espécies no eletrólito [17,64,66,156-158].

Analisando o comportamento dos coeficientes de transferência anódica e catódica (Figura 4.20d) e a equação (4.3), podemos interpretar que quanto maior é a coeficiente de transferência catódico $\left(\beta_{c}\right)$ menor é a corrente catódica, enquanto que a corrente anódica incrementa-se na medida em que o coeficiente de transferência anódico cresce $\left(\beta_{a}\right)$. Assim em $\mathrm{pH} 4,5$ a $i_{c o r r}$ é pequena devido a que $\beta_{c}$ e grande decorrente das reações catódicas (4.15) que passivam a superfície. A Figura $4.20 \mathrm{~d}$ mostra que $\beta_{c}$ permanece quase constante entre $\mathrm{pH} 4,5$ a 5,5 , enquanto que em pH 6,5 ० $\beta_{c}$ diminui. Este comportamento sugere que em pH 4,5 a redução ocorre via os estados de interface, enquanto que em pH 5,5 e 6,5 a redução da espécie oxidante $\mathrm{SO}_{4}^{2-}$ ocorre inicialmente via os estados de interface $[64,65]$, já que apesar que existem as condições termodinâmicas ainda não existe a fonte de elétrons necessária para a redução do $\mathrm{SO}_{4}^{2-}$ que por sua vez catalisara a formação de $\mathrm{SiO}_{2}$. Uma vez que a amostra encontra-se em meio fluorado, $\mathrm{O} \mathrm{SiO}_{2}$ é removido rapidamente e incrementa $\circ \beta_{a}$, que pode ser observado através do incremento da $i_{\text {corr }}$ nessa região de $\mathrm{pH}$.

Por outro lado, em pH 7,5, a baixa $i_{\text {corr }}$ comparada com aquela observada em pH 6,5, e as condições termodinâmicas favoráveis para as reações catódicas (4.7) a (4.9) e (4.22) sugerem que a diminuição da $i_{\text {corr }}$ não apenas estaria atribuída ao decréscimo na concentração da espécie $H_{2}^{-}$, mas também à diminuição da atividade catalítica da espécie $\mathrm{SO}_{4}^{2-}$ na 
formação do $\mathrm{SiO}_{2}$, uma vez que os elétrons necessários para a redução do $\mathrm{SO}_{4}^{2-}$ desta vez são fornecidos pela reação (4.22) e pelo substrato, é por essa razão que $i_{c o r r}$ é menor.

Em pH 8,5 ocorre uma queda nos coeficientes de transferência que poderia ser atribuído ao efeitos da passivação local da superfície pelas ligações $S i-H$ uma vez que as reações (4.22) e (4.25) que liberam íons $\mathrm{H}^{+}$que rapidamente se ligam com o $\mathrm{Si}$ via os estados de interface $[64,65]$ devido a sua alta afinidade eletrônica, e forma semelhante aquele que ocorre em pH 4,5. Assim, a passivação da superfície inibe a transferência de carga entre o SMP e o eletrólito evitando a formação de $\mathrm{SiO}_{2}$ na superfície. Contudo, não podemos descartar a formação de uma camada de $\mathrm{SiO}_{2}$ suficientemente fina como para não poder ser detectada pelo EDS (Figura 4.19d) e passivar a superfície já que amostra encontra-se em meio aquoso fluorado, onde a espécie predominante é $F^{-}$que não participa ativamente da dissolução do $\mathrm{SiO}_{2}[64,152,153]$. Já em pH 9,5, embora que a transferência de carga seja menor, ocorre a formação do $\mathrm{SiO}_{2}$ decorrente da atividade da espécie $\mathrm{OH}^{-}$, segundo mostrado pela reação (4.10), porém esta não é removida pelas espécies $F^{-}$(Figura 4.19f)[ 64,152,153]. É importante indicar que apesar da dissolução envolver a transferência de carga na interface SMP/eletrólito, os coeficientes mostrados na Tabela 4.3 apenas podem ser usados para uma análise qualitativa do sistema pois estes parâmetros mudam com 0 tempo.

O diagrama de bandas de energia permite identificar os possíveis mecanismos de transferência de carga nos processos de oxido-redução. A Figura 4.21 mostra esquematicamente os diferentes potencias de redução das espécies presentes no eletrólito, bem como o a mudança da altura da barreira para cada $\mathrm{pH}$. Em pH 4,5 observa-se que as condições energéticas não favorecem evolução do $H_{2}$ (equação 4.5), já que a altura 
da barreira $V_{s}$ é grande e o PECA (-0.133 $\left.\mathrm{V}_{\mathrm{SHE}}\right)$ é menos negativo do que o potencial redox do hidrogênio $\left(-0.266 V_{\mathrm{SHE}}\right)$, porém isto favorece a redução do $\mathrm{SO}_{4}^{2-}$, apesar que na pratica isto não acontece devido à formação de ligações Si-H mediante a reação catódica (4.15) via os estados de superfície $[83,148]$.

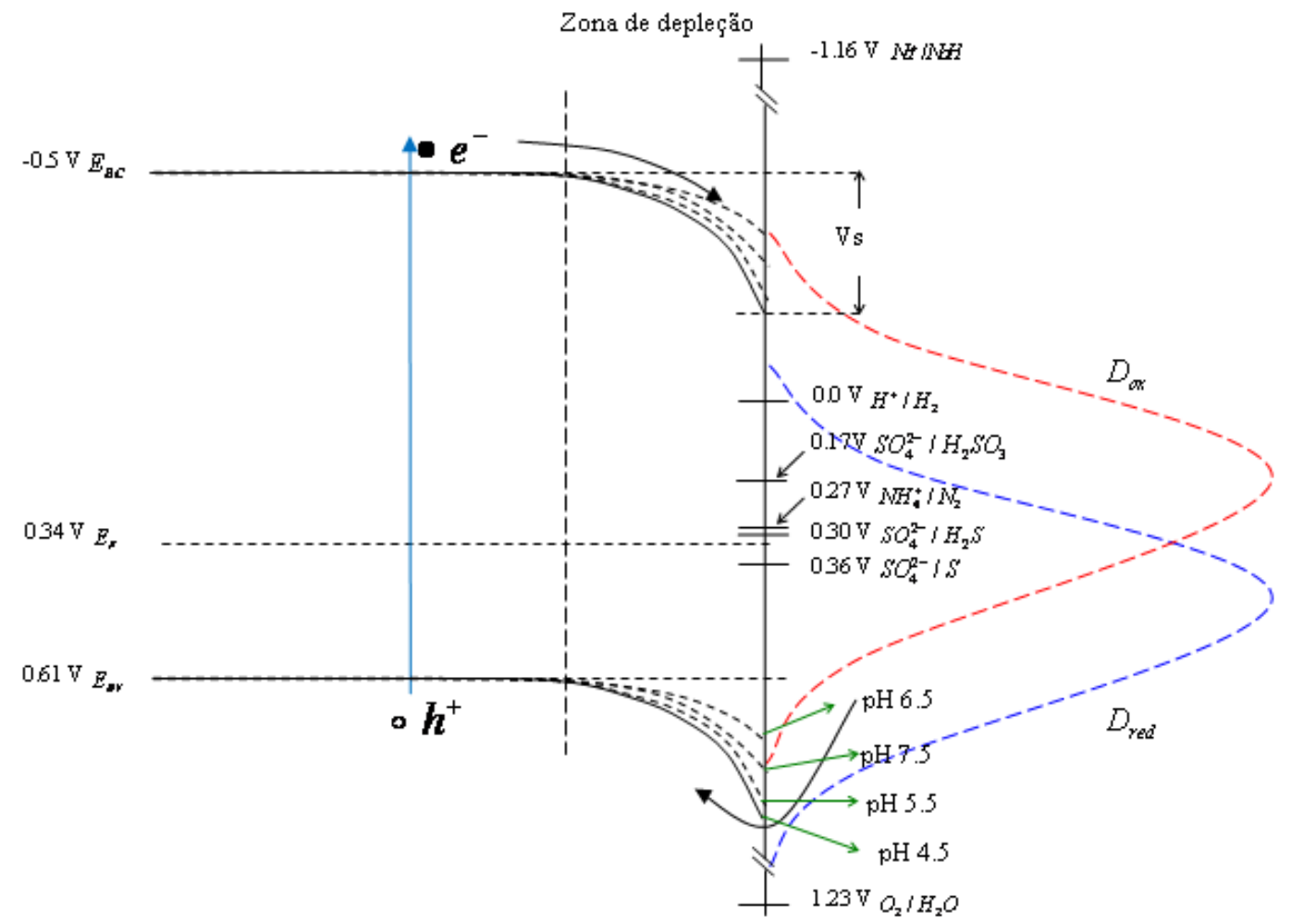

Figura 4.21. Diagrama esquemático qualitativo da transferência de elétrons e lacunas durante a corrosão do $\mathrm{Si}$.

No entanto, em pH 5,5, a barreira diminui levemente e facilita transferência de carga. Contudo, devido às condições termodinâmicas e cinéticas a redução do $\mathrm{SO}_{4}^{2-}$ catalisa a formação de $\mathrm{SiO}_{2}$ mediante a injeção de lacunas na BV, (Figura 4.19f), embora o $V_{s}$ tenha-se incrementado, já que o incremento de $i_{\text {corr }}$ esta condicionado ao incremento na taxa de formação e dissolução da camada $\mathrm{SiO}_{2}$ pelas espécies $\mathrm{HF}$ e $\mathrm{HF}_{2}^{-}$, como antes comentado. 
Já em $\mathrm{pH}$ 6,5 tanto a barreira $V_{s}$ quanto $0 \mathrm{~W}$ diminuem (Figuras 4.20b e 4.20c), o que permite maior injeção de lacunas por conta da redução do $\mathrm{SO}_{4}^{2-}$. Isto somado à predominância da espécie $\mathrm{HF}_{2}^{-}[69,70]$ conduzem a um incremento na taxa de corrosão. Assim, em pH 6,5 observa-se as melhores condições termodinâmicas e cinéticas para a dissolução do Si. Isto também indica-nos que o incremento na taxa de dissolução do Si reportado por M. Matsumura et. al [69] e Kikuyama et. al [155] não é apenas decorrente do incremento na concentração do $H F_{2}^{-}$, mas também na diminuição de $V_{s}$ e da largura da camada de depleção que permite maior concentração de lacunas na interface.

$\mathrm{Em} \mathrm{pH} \mathrm{7,5,} \mathrm{as} \mathrm{condições} \mathrm{termodinâmicas} \mathrm{e} \mathrm{cinéticas} \mathrm{tornam-se} \mathrm{as} \mathrm{menos}$ favoráveis para injeção de lacunas na BV e transferência de elétrons para o eletrólito mediante a reação de redução do $\mathrm{SO}_{4}^{2-}$ devido a que houve um incremento tanto na largura da camada de depleção quanto no potencial barreira, e isto somado ao decremento na concentração das espécies $H F_{2}^{-}$conduzem à diminuição da corrente de corrosão $[69,70,74]$. Adicionalmente, o decremento nas rações catalíticas do $\mathrm{SO}_{4}^{2-}$ pode observar-se também na diminuição da concentração de oxigênio na amostra em relação à concentração em pH 5,5 (Tabela 4.3).

Os resultados mostrados e analisados acima mostram que a formação dos MTS esta restrita à faixa de $\mathrm{pH}$ 6,5-7,5 devido a que nessas faixas existe a condição termodinâmica e cinética para uma transferência de carga controlada mediante as reações que promovem uma corrosão predominantemente anisotrópica. No entanto, a análise do efeito do $\mathrm{pH}$ sob o ponto de vista termodinâmico e cinético apenas fornece informação sobre os mecanismos envolvidos na dissolução do silício, mas não oferece nenhuma informação sobre qual o mecanismo de formação dos MTS. Para tanto é necessário considerar as características estruturais do eletrodo. A seção a seguir detalha outro aspecto completar na formação 
dos MTS baseado na contribuição da camada de depleção na formação das paredes dos tubos.

\subsubsection{Mecanismo de formação dos microtubos de silício.}

Os resultados experimentais acima apresentados e discutidos sobre os mecanismos de formação dos microtubos de silício envolvem processo de transferência de carga e como conseqüência dependem também do comportamento da camada de depleção na camada de silício poroso.

Quando o substrato é colocado em contato intimo com uma solução eletrolítica, aparece uma camada de depleção entorno da superfície da amostra decorrente da diferença de energia entre a energia de Fermi do Si e o potencial de redox do eletrólito $[64,65,97,98]$, que dará lugar à transferência de elétrons do substrato para o eletrólito (no caso do Si tipo n) ou do eletrólito para o substrato ( no caso do Si tipo p), o que conduz a processos de oxidação e redução dos íons do eletrólito até atingir o estado estacionário $[64,65,97,98]$. Sendo que o silício é instável em meio aquoso este continuamente oxida-se formando uma camada de $\mathrm{SiO}_{2}[64,65,150]$, que em meio aquoso fluorado é removido em forma isotrópica e/ou anisotrópica dependendo no $\mathrm{pH}$ e composição química do eletrólito [64-66], logo se dissolve continuamente desde que é colocado em contato com o eletrólito. No caso do fluoreto de amônia, isto acontece em forma anisotrópica sendo a direção $<100>$ aquela com maior taxa de corrosão [75-78].

Decorrente da interação SMP/eletrólito, entre dois poros adjacentes formam-se ao menos duas regiões: uma com camada depleção sobre a superfície $(100)\left(W_{\perp}=W\right)$ com campo elétrico $\left(E_{\|}\right)$paralelo à direção $<100>$; e outra adjunta à superfície da parede do poro $\left(W_{\|}\right)$com campo elétrico $\left(E_{\perp}\right)$ perpendicular a dita superfície, como mostrado na Figura 4.22a. A primeira região expande-se ao longo da superfície entre a borda das camadas de depleção verticais dos poros adjuntos (Figura 4.22a), 
enquanto que a segunda expande-se ao longo das paredes dos poros e muda de direção na ponta dos poros devido ao encurvamento da superfície interna dos poros.

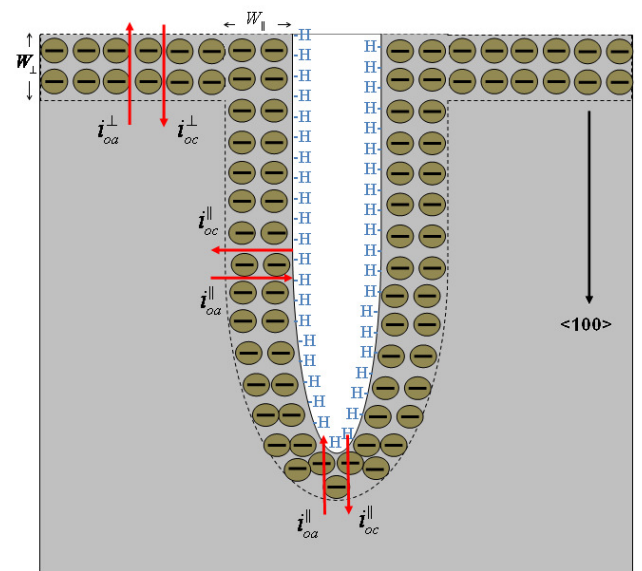

(a)

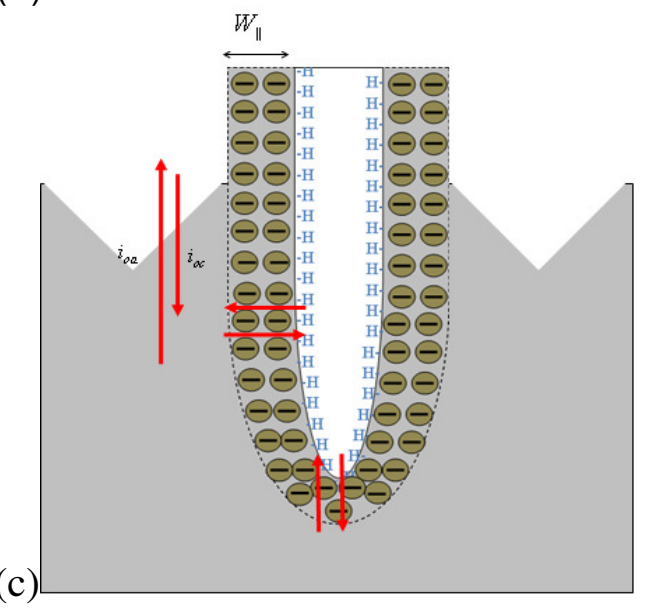

(b)

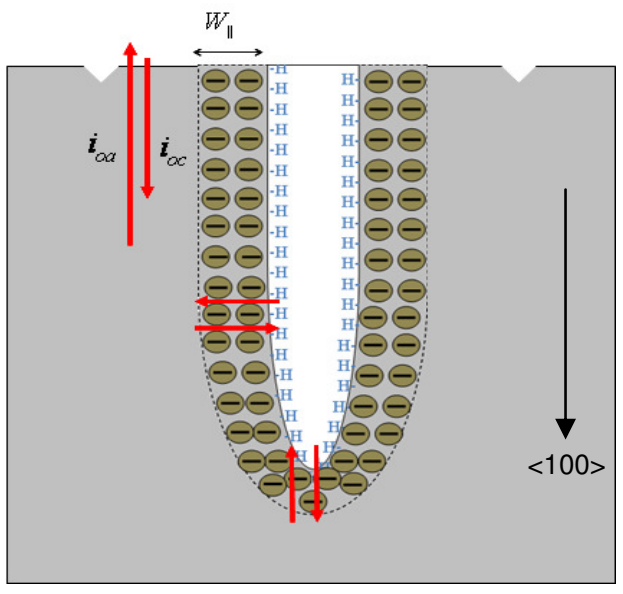

(d)

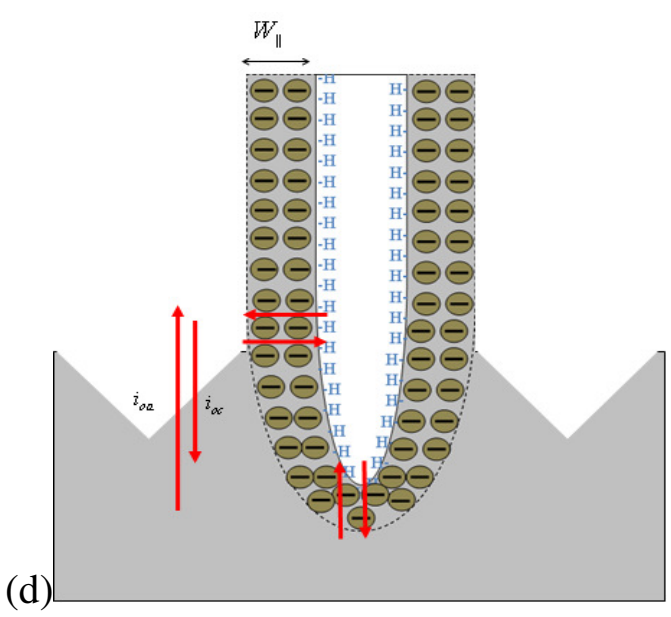

Figura 4.22. (a) Diagrama esquemático da formação da camada de depleção no SMP imerso em solução ácida; e em (b) solução fluorada levemente acida a alcalina. Formação dos MTS por dissolução do silício para diferentes tempos de imersão (b,c,d).

É importante indicar que, em uma situação real, a camada de depleção $W_{\perp}$ apenas forma-se quando o SMP é imerso em uma solução ácida (fluorada ou não) em que a superfície possa ser passivada (Figura 4.22a), enquanto que em uma solução alcalina (fluorada ou não) esta camada não chega se formar plenamente, já que esta é constantemente dissolvida ao longo do tempo (Figura 4.22b), enquanto que a camada $W_{\|}$, dissolvese a uma taxa muito menor devido a que as paredes dos poros estão constituídos por um conjunto de planos onde a taxa de corrosão é menor 
em relação ao plano (100) [93,159]. Assim, em uma primeira aproximação podemos considerar esta camada sendo ideal com comprimento $W_{\|}$à qual esta associada um campo elétrico máximo na interface MPS/eletrólito:

$$
\begin{aligned}
& W_{\|}=\sqrt{\frac{2 \varepsilon_{S i} \varepsilon_{o}\left(V_{F B}-V-k T / e\right)}{e N_{a}}} \\
& E_{\perp \max }=\sqrt{\frac{2 e N_{a}\left(V_{F B}-V-k T / e\right)}{\varepsilon}}
\end{aligned}
$$

Adicionalmente, a espessura $W_{\|}$não apenas muda de direção, mas também se torna mais estreita, enquanto que o campo elétrico associado $E_{\perp}$ torna-se mais intenso na ponta dos poros $[64,65,97,98]$.

Como já descrito nas seções 2.4 .3 e 2.4.4, a corrosão em meios alcalinos é predominantemente anisotrópica e atribui-se à participação ativa do $\mathrm{OH}^{-}$que produz maior taxa e corrosão na direção <100> e menor na direção <111> [17,64,65,75,78,92,94], porém diminui sua característica anisotrópica adicionando algum oxidante na solução, tais como o HF[64,65]. Assim, sob esse ponto de vista entende-se que o HF age como catalisador da dissolução do $\mathrm{Si}$, mediante a permanente remoção do $\mathrm{SiO}_{2}$ e possibilita a continua dissolução do Si $[64,65,85,148]$. No entanto, sendo que a remoção do Si está condicionada à formação do $\mathrm{SiO}_{2}$ é necessário que ela seja formada previamente e para tanto é necessário a injeção de lacunas na BV, isto é, elétrons sejam arrancados da BV o que implica vencer a barreira energética da camada de depleção [64-66], ou equivalentemente diminuir a energia de ativação da superfície a dissolver [82,85,115,148]. Isto é possível adicionando no eletrólito agentes oxidantes cujo potencial redox esteja localizado na região da BV ou próximo dela, e estas injetaram lacunas na BV permitindo a formação de $\mathrm{SiO}_{2}$, que em soluções fluoradas ácidas produzem uma forte corrosão 
isotrópica que poderia eletropolir o substrato $[17,64,65,86]$, mas em soluções fluoradas alcalinas apenas aceleram a taxa de corrosão preservando o comportamento anisotrópico [83,160]; porém desde que a solução tem presença de espécies fluoradas sempre coexistiram os dois tipos de corrosão [115-118]. Assim, para a formação dos MTS é necessário que a corrosão isotrópica seja menor do que a corrosão anisotrópica.

Por outro lado, sendo que a corrosão anisotrópica é de natureza química, portanto não precisa de elétrons para iniciar a corrosão do Si [64,65,75$77,92,94]$, e sua taxa de corrosão é maior quanto menor é a concentração de dopantes do substrato $[17,64,65]$, logo segue-se que isto conduziria a uma rápida corrosão do substrato, atacando principalmente à camada de depleção, inibindo a formação dos MTS. Logo, a formação dos MTS esta condicionada à coexistência da corrosão anisotrópica e isotrópica, sendo a primeira a encarregada de demarcar a rota a seguir para a formação dos MTS, enquanto a segunda acelera o processo de dissolução do substrato seguindo o caminho demarcado pela corrosão anisotrópica. Esta condição pode conseguir-se adicionando espécies oxidantes na solução aquosa de $\mathrm{NH}_{4} \mathrm{~F}$ e/ou modulando $\mathrm{o} \mathrm{pH}$ adequadamente de forma que predomine uma sobre a outra segundo nossas necessidades .

Para a formação dos MTS, em um primeiro momento, após a imersão do substrato, forma-se uma camada fina de $\mathrm{SiO}_{2}$ devido à ação dos oxidantes ou as espécies $\mathrm{OH}^{-}, \mathrm{H}_{2} \mathrm{O}[77,78,92,161,162]$ cuja espessura é maior nas regiões $W_{\perp}$ devido a ser essa a direção preferencial de corrosão [64,65], enquanto que nas regiões $W_{\|}$supõe-se ser mais fina devido à dificuldade de injetar lacuna nessa região o que conduz a regiões localmente diferentes que promovera processos eletroquímicos localmente diferentes [64-66].

Em uma situação de depleção ideal não deveria ocorrer formação da fina camada de $\mathrm{SiO}_{2}$ devido à falta de elétrons na camada de depleção 
(estado disponíveis para injetar lacunas) especialmente na região de intersecção entre as camadas $W_{\|}$e $W_{\perp}$, que dá lugar à formação das paredes dos tubos. Contudo, sendo que em uma situação real sempre existem portadores minoritários em movimento, que podem ultrapassar a barreira energética e formar uma fina camada de $\mathrm{SiO}_{2}$, que subseqüentemente é removida eletroquimicamente pelas espécies fluoradas $[64,65]$. Adicionalmente, a formação dos tubos é também favorecida pelo fato que as espécies $\mathrm{OH}^{-}$e $\mathrm{H}_{2} \mathrm{O}$ apresentam uma baixa taxa de corrosão ao $\mathrm{SiO}_{2}[64,65]$. Como resultado a taxa de dissolução do Si na interseção das camadas de depleção é muito menor em relação à taxa dentro da camada $W_{\perp}$. É importante mencionar que durante a corrosão a camada $W_{\perp}$ deixa de ser paralela à superfície e segue o perfil da corrosão anisotrópica em forma de "V", como mostrado nas Figuras $4.22 \mathrm{~b}$ a $4.22 \mathrm{~d}$. Inicialmente a corrosão avançará em todas as direções com diferentes taxas crescendo em forma de "V" até atingir as bordas da camada de depleção $W_{\|}$e depois continua a crescer principalmente na direção (100) ainda preservando a forma "V" (Figura 4.22d).

O raciocínio anterior consegue explicar a dissolução preferencial na direção (100) dentro do Si e a preservação das paredes dos tubos são considerados, porém não explica porque essas paredes não são atacadas pelo eletrólito na direção perpendicular $<100>$ (ou mesmo na ponta dos poros) desde o interior dos poros sendo que a amostra toda esta imersa na mesma solução. O campo elétrico é mais intenso nas superfícies curvas da interface SMP/eletrólito [64,65], como é o caso da superfície das paredes dos poros e essa curvatura promoverá a intensificação do campo $E_{\perp}$ em relação ao campo $E_{\|}$o que subseqüentemente provocará um estreitamento na camada de depleção $W_{\|}[64,65]$. Apesar desse estreitamento, a corrosão no sentido perpendicular à superfície do poro não ocorre, possivelmente por duas razões: (1) incremento da barreira 
energética devido ao campo elétrico $E_{\perp}$ que é máximo na interface Si/eletrólito e age como uma camada passivadora [64,65,163,164], e/ou (2) paredes estão constituídas por um arranjo de planos onde a taxa de corrosão é pequena [93,165]. Nesse sentido, as paredes dos MTS seguem um padrão perpendicular, que unicamente muda nas regiões próximas da ponta, estas estão formadas por um arranjo de planos cristalinos tais como os planos (331), (221), (111), (110), entre outros, que apresentam uma baixa taxa de corrosão em relação ao plano (100) e inibe a corrosão no sentido perpendicular à direção $<100>[93,165]$. Lysko [165] tem sugerido que os planos cristalinos dissolvem-se em sentido perpendicular ao plano (hkl) em forma exponencial à densidade de ligações, que pela sua vez é à proporcional à atividade química dos átomos, enquanto que na direção paralela à superfície esta segue uma relação senoidal ao ângulo entre os planos (hkl) e (111). A baixa taxa de corrosão também pode interpretar-se como um incremento na energia de ativação desses planos decorrente do incremento na energia de ativação da dissolução do $\mathrm{Si}$ nessas direções, por tanto sua dissolução é desprezível frente aquele observado na direção <100> [64,93,165,166]. Adicionalmente, na medida em que se formam os MTS, tanto as paredes internas quanto as paredes externas dos MTS estarão em contato direto com o eletrólito, logo em ambas as paredes o campo elétrico $E_{\perp}$ será máximo nas interfaces e agirá como uma camada passivadora em ambas as faces da parede dos tubos $[64,65,163,164]$, porém devido a que o campo elétrico associado à camada de depleção é mais intenso em uma superfície com maior raio de curvatura [64,65], a superfície interna do tubo será melhor passivada do que superfície externa $[65,97,98,151]$.

As estruturas apresentadas na Figura 4.23 mostram claramente a característica anisotrópica do processo de corrosão durante a formação das estruturas tubulares de silício, resultado que é explicado pelo mecanismo da formação sugerido neste trabalho e cuja representação esquemática é mostrada na Figura 4.22b a 4.22d. A espessura medida 
diretamente da imagem, na Figura 4.23, é da ordem de $278 \mathrm{~nm}$ aproximadamente, e é da mesma ordem daquele observado na amostra P77C (aproximadamente $260 \mathrm{~nm}$ ). Estes valores de espessura são aproximadamente três vezes menores daquele esperado para a largura da camada de depleção do silício tipo p com concentração de dopantes na ordem de $10^{15} \mathrm{~cm}^{-3}(10 \Omega \mathrm{cm})$, mesmo na interface ainda não-corroída. As espessuras dos tubos acima indicados corresponderiam à espessura da camada de depleção de um substrato com dopagem de $10^{16} \mathrm{~cm}^{-3}$ aproximadamente, isto é, uma ordem de grandeza maior daquele usado. Este resultado sugere a influência de outros fatores não considerados na análise até aqui e que será feita mais adiante. A Figura 4.23b mostra 0 perfil dos tubos formados onde se vê que os tubos não estão mais ligados ao substrato mostrando que a corrosão seguiu o perfil dos poros, isto é, os tubos são fechados por baixo e o substrato mostra o perfil em "V" típico da corrosão anisotrópica.

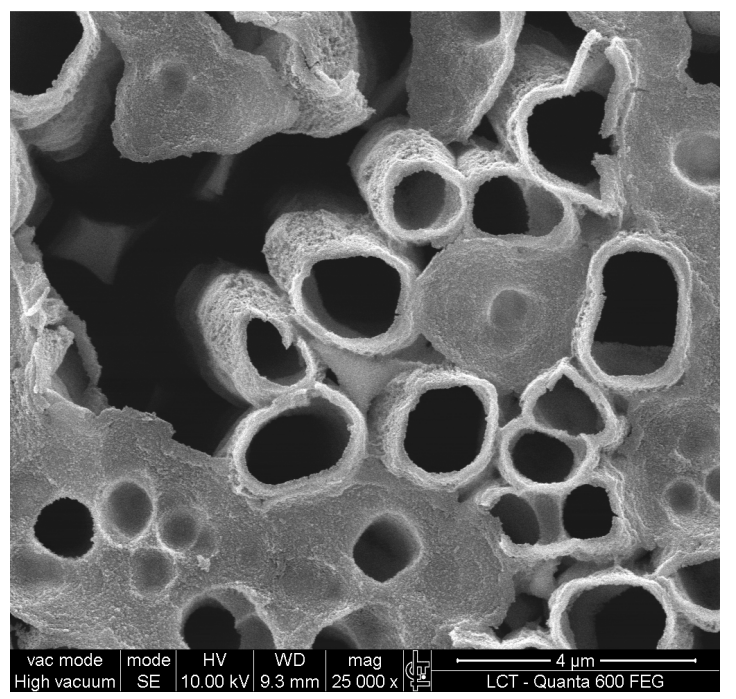

(a)

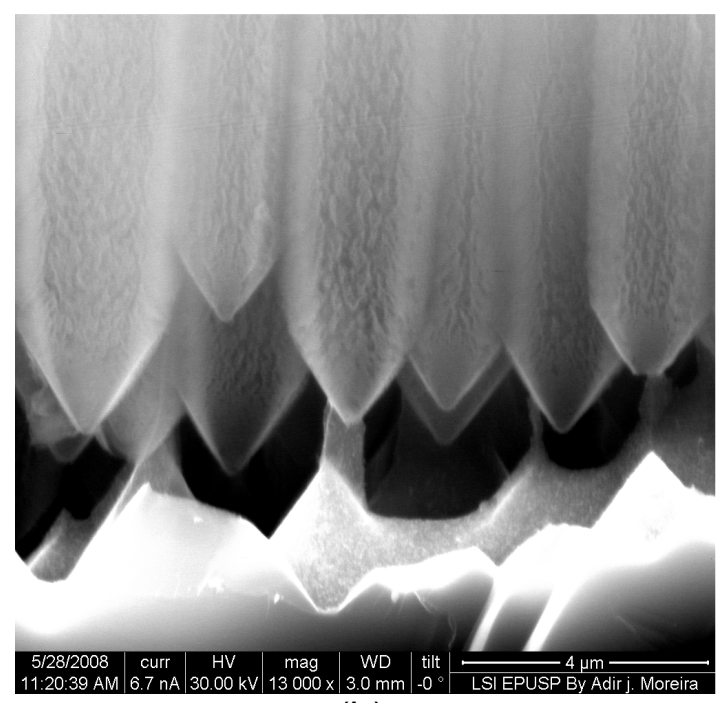

(b)

Figura 4.23. (a) Vista de topo da formação dos MTS onde se vê o contorno das camadas de depleção (paredes) formadas na amostra P64, e (b) do perfil dos microtubos formados sobe amostra (P44). Ambas as amostras forma imersas em $5 \times 10^{-2} \mathrm{M} \mathrm{NiSO}_{4}+0,25 \mathrm{M} \mathrm{NH}_{4} \mathrm{~F}$.

Como foi mencionada antes, em uma situação real a camada de depleção não esta totalmente isenta de lacunas, portanto, dissolve-se ao longo do 
tempo com taxa menor na camada $W_{\|}$, porém não desprezível em relação daquela observada na camada $W_{\perp}$. A diferença na taxa de corrosão é modulada não apenas através da variação do $\mathrm{pH}$, mas também pela presença do oxidante no eletrólito $[64,65,92,161,162]$. Sendo que em $\mathrm{pH}$ ácido predomina a corrosão isotrópica, ambas as camadas depleção são atacadas pelas espécies fluoradas quase com a mesma taxa de corrosão $[64,65]$.

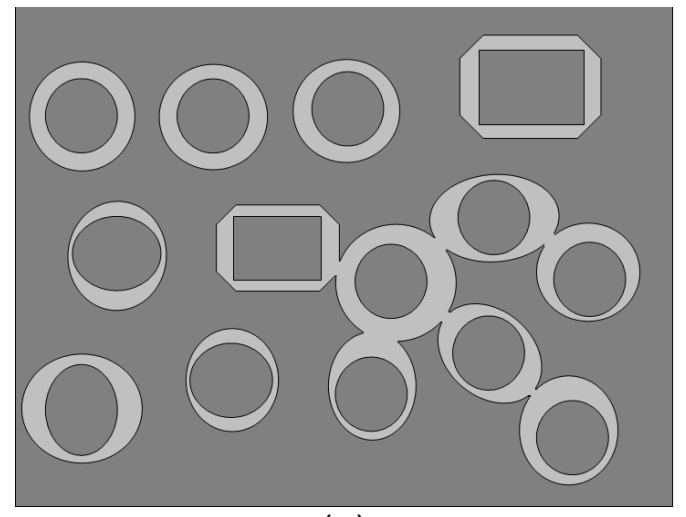

(a)

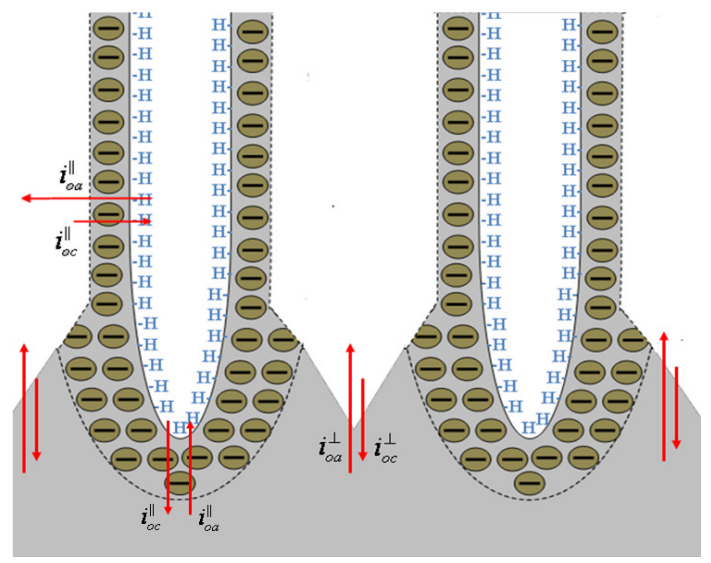

(c)

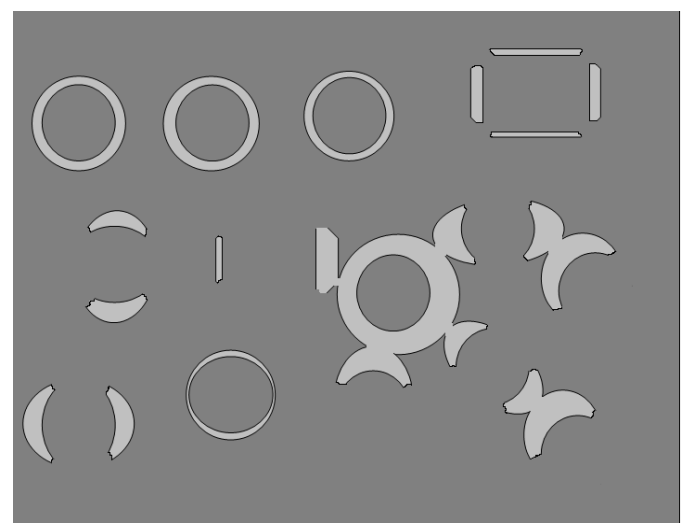

(b)

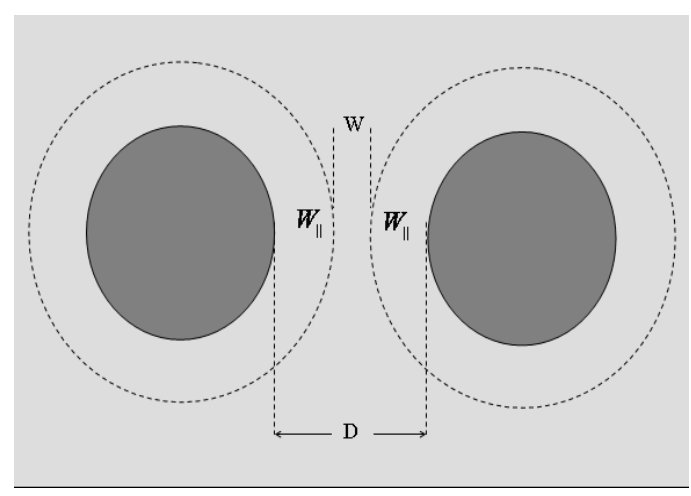

(d)

Figura 4.24. Diagrama esquemático da vista de topo $(a, b)$ e do perfil (c) da formação e dissolução das paredes dos tubos ao longo do tempo; e condições geométricas para a formação dos microtubos de silício (d).

$\mathrm{Na}$ medida em que o pH diminui a corrosão isotrópica passa a ser importante e dissolve a camada $W_{\|}$com maior rapidez, e em razão disso, em pH 5,5 o eletrólito ataca o substrato também na direção perpendicular à direção <100> com uma taxa de corrosão não-desprezível. Sob essas condições os poros são dissolvidos em forma diferente de acordo com o 
comprimento de $W_{\|}$, que é menor nas áreas curvadas, como observado esquematicamente na Figura 4.24a, portanto dissolvem-se mais rapidamente do que aquelas regiões menos curvadas [64,65]. Assim, segundo seja a geometria do poro podem formar-se ao longo do tempo MTS com paredes muito finas ou estruturas com aparência de estacas irregulares (Figuras 4.24a e 4.24b), porém devido à predominância da corrosão isotrópica e o longo tempo de imersão geralmente a estrutura tem aparência de estacas irregulares e desorganizadas, como mostrado na Figura 4.14b. Em pH 6,5 a taxa de corrosão lateral diminui, devido à queda na corrosão isotrópica, logo é possível a formação dos MTS, porém se o tempo de imersão for muito longo os tubos podem também ser dissolvidos. No entanto em $\mathrm{pH} 7,5$ as paredes dos tubos formados apresentam maior espessura devido a que sofrem menor corrosão.

A verificação experimental do mecanismo de dissolução das paredes dos tubos em função do tempo de imersão tem sido realizada mediante 0 controle do tempo de imersão de amostras durante um dia, três dias e cinco dias, em uma solução baseada em $0,25 \mathrm{M}$ de $\mathrm{NH}_{4} \mathrm{~F}$, misturada com $5 \times 10^{-2} \mathrm{M} \mathrm{CoSO}_{4}$. Os resultados observados via o MEV são apresentados na Figura 4.25. O diâmetro médio dos tubos é 1,2 $\mu \mathrm{m}$, e é semelhante àqueles formados em solução com $\mathrm{Na}_{2} \mathrm{SO}_{4}$. A determinação estatística da espessura das paredes dos tubos mostra que após um dia de imersão os tubos estão em processo de formação (Figura 4.25a) e apresentam espessura media de $308 \mathrm{~nm}$, enquanto que após três dias observam-se tubos bem definido com espessura media $242 \mathrm{~nm}$ (Figura 4.25b), e tornase mais fina ainda após 5 dias de imersão $(228 \mathrm{~nm}$ ) com tendência a dissolver-se (Figura 4.25c). A gráfica da espessura em função do tempo de imersão mostra que as espessuras dos tubos diminuem em forma exponencial com o tempo de imersão:

$$
d(n m)=224,23+83,77 e^{-(t-1) / 1,29}
$$




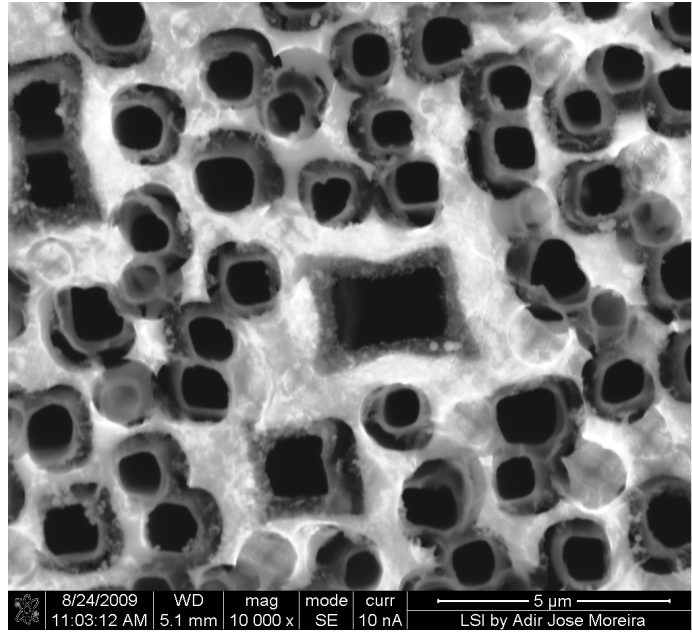

(a)

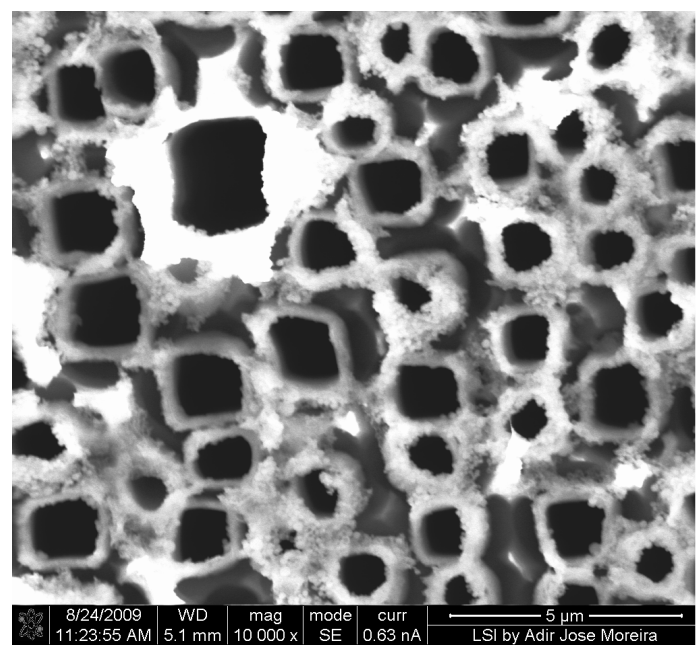

(c)

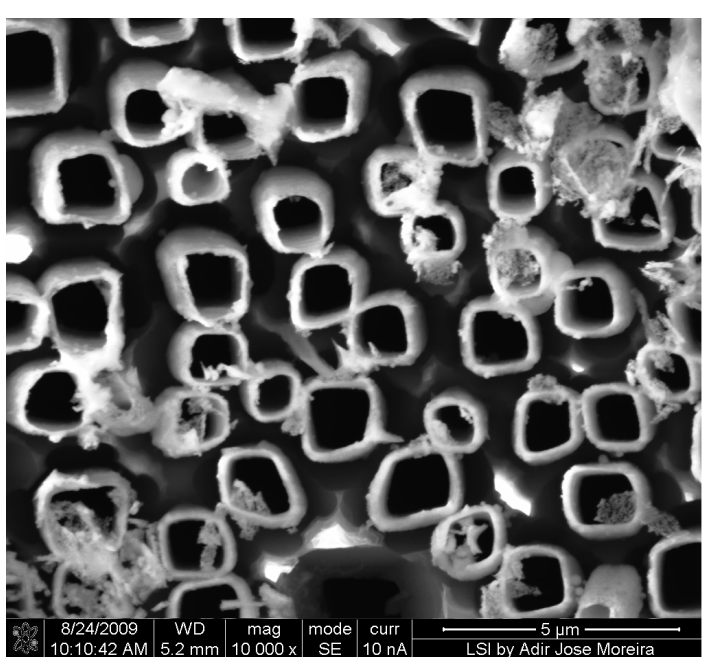

(b)

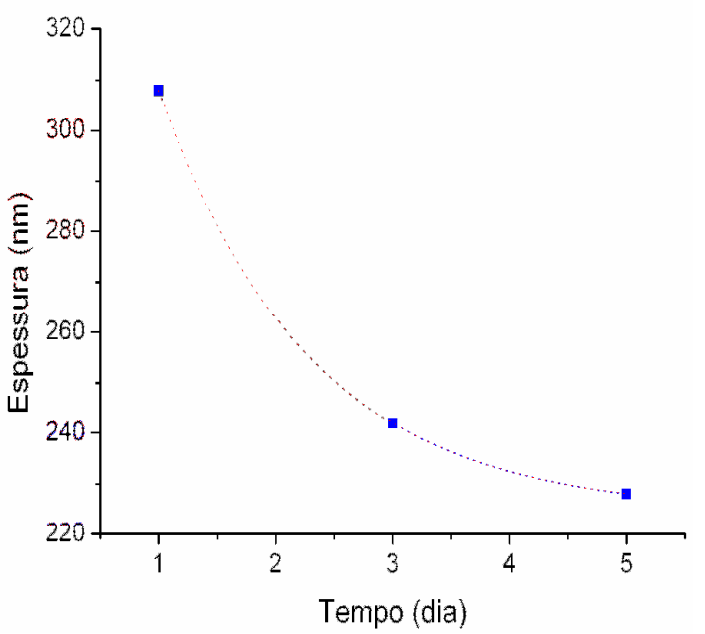

(d)

Figura 4.25. Evolução da formação dos tubos em uma solução de $5 \times 10^{-2} \mathrm{M} \mathrm{CoSO}_{4}+$ $0,25 \mathrm{M} \mathrm{NH}_{4} \mathrm{~F}$ durante (a) um dia; (b) três dias (c) cinco dias; e (d) gráfico do comportamento do estreitamento da parede dos tubos em função do tempo de mergulho das amostras de MPS.

Outra forma de visualizar os resultados acima apresentados é levando em consideração que em circuito aberto, as reações eletroquímicas ocorrem devido à troca de elétrons por conta da diferença entre o nível de Fermi do silício e o potencial redox do eletrólito que dão lugar a uma corrente de troca de carga ou simplesmente corrente de troca $[64,66,167]$. Em situações onde predomina a corrente de troca catódica $\left(i_{o c}\right)$ (troca de lacunas) ocorre a dissolução do substrato $[64,66,167]$. Esta sempre predomina em substrato de silício imerso em solução fluorada, portanto, sempre teremos uma corrente de corrosão $[64,66,167]$. Sendo que para 
tanto é necessária a formação e remoção do $\mathrm{SiO}_{2}$ resulta importante a reações catódicas que catalisam a formação $\mathrm{SiO}_{2}$ e incrementam a corrente catódica de troca $\left(i_{o c}\right)[64,149]$. A relação entre a corrente de corrosão e as correntes de troca é expressa pela equação (4.36) e (4.37) $[64,149]$ :

$$
\begin{aligned}
& i_{c o r r}=i_{o c}-i_{o a} \\
& i_{o c}=A z e k_{o} n_{s} c_{o x} \mathrm{e}^{-E_{a} / k T}
\end{aligned}
$$

Onde $z, k_{o}, n_{s}, c_{o x}, E_{a}$ são: o número de elétrons transferidos, a constante de transferência, a densidade de elétrons na superfície, a concentração de oxidante na interface, e a energia de ativação, respectivamente. Se considerarmos que aproximadamente o valor de $c_{o x}$ não varia ao longo de toda interface então os parâmetros que modificam a corrente catódica está ligada à atividade catalítica dos oxidantes que abaixam a $E_{a}$ $[64,65,85,115,148]$, e concentração $n_{s}$ [66-70], sendo que o primeiro parâmetro é uma característica que depende do eletrólito e do substrato, enquanto que a segunda depende unicamente do substrato. $\mathrm{O}$ valor de $n_{s}$ depende da transferência de carga na interface, e sendo que este processo resulta mais difícil nas nos planos que compõem as paredes dos tubos, isto é, os planos (111), (331), (221), (110) devido a sua baixa taxa de corrosão $[64,65,93,165,166]$ então podermos ter valores pequenos de $n_{s}$ na interface o que poderia explicar a baixa taxa de corrosão nestas direções.

Seguindo o raciocínio proposto por Lysko [165] para a dissolução anisotrópica do silício, e considerando que na solução coexiste a corrosão isotrópica e anisotrópica, podemos supor que a corrente catódica total esta composta por uma paralela $\left(i_{o c}^{\|}\right)$e outra perpendicular $\left(i_{o c}^{\perp}\right)$ à direção $<100>$ que agem sobre as camadas $W_{\|}$e $W_{\perp}$, respectivamente cuja 
representação esquemática é mostrada na Figura 4.23 (a), assim a corrente catódica total será:

$$
i_{o c}=i_{o c}^{\perp}+i_{o c}^{\|}=A z e k_{o} c_{o x}\left(n_{s}^{\perp} \mathrm{e}^{-E_{a}^{\perp} / k T}+n_{s}^{\|} \mathrm{e}^{-E_{a}^{\|} / k T}\right)
$$

Onde os termos $E_{a}^{\perp}, E_{a}^{\|}, n_{s}^{\perp}$, e $n_{s}^{\|}$são as energias de ativação e concentração de elétrons na direção na paralela e perpendicular à direção $<100>$, respectivamente.

A literatura tem reportado $[64,93,165,166]$ que a energia de ativação na direção $<100>$ do silício imerso em solução alcalina é muito menor daqueles nas direções que compõem as paredes dos poros, portanto, a energia de ativação nas paredes será menor do que a energia de ativação na direção $<100>\left(E_{\perp}^{a}<E_{\|}^{a}\right)[93,165,166]$. Os resultados obtidos na formação dos MTS em diferentes pHs mostraram-nos que $E_{\|}^{a}$ diminui mais rapidamente quando se adiciona oxidantes e se diminui o $\mathrm{pH}$, isto é, a corrente $i_{o c}^{\|}$torna-se importante e devido a essa razão que a corrosão torna-se menos anisotrópico em $\mathrm{pH}$ ácido dando lugar à destruição da estrutura macroporosa (Figura 4.14b).

As discussões apresentadas nesta seção indicam o porquê os MTS apresentam paredes mais finas daquelas esperadas considerando a concentração de Si. Esta diferença atribui-se pelo menos a dois fatores: (1) efeito da taxa de corrosão, devido ao longo do tempo de imersão por conta da injeção de lacunas na camada $W_{\|}$[83,148]; (2) Redução da camada $W_{\|}$por efeito da curvatura da parede dos poros $[64,65]$. Assim, longos períodos de imersão ou soluções ácidas, sempre que não ocorra a passivação da superfície via ligações $S i-H$, podem levar a dissolução total dos MTS.

Por outro lado, embora as condições termodinâmicas e cinéticas sejam dadas, a formação dos tubos está inda condicionada às condições 
geométricas. Formam-se MTS em amostras cuja distância entre poros (D) é maior à soma das camadas de depleção dos poros vizinhos (Figura 4.24d), isto é:

$$
D=2 W_{\|}+w
$$

Sendo que os poros encontram-se no mesmo substrato e imersos no mesmo eletrólito, então terão a mesma largura da camada de depleção. Se $w \leq 0$, então a formação dos poros é inibida devido a que, idealmente, a camada de depleção é imune à corrosão eletroquímica, portanto serão atacados pela corrosão química o que promovera a destruição do substrato. No entanto, se o substrato é composto por regiões com $w \leq 0 \mathrm{e}$ $w>0$, então naquelas primeiras formaram-se aglomerados de MTS, enquanto nas regiões com $w>0$ tubos isolados um dos outros, como se mostra esquematicamente na Figura 4.24a.

\subsubsection{Efeito do oxidante na formação dos microtubos de silício}

O comportamento eletroquímico da interface SMP/eletrólito depende da natureza tanto do eletrodo quanto da composição química do eletrólito $[64,64,97,98,167]$. Portanto, espera-se que mudando as condições da interface SMP/eletrólito consiga-se estruturas diferentes. Adicionalmente, na seção 4.2.1, mediante a descrição do mecanismo de formação dos MTS, mostrou-se a importância dos oxidantes na formação dos MTS omitindo o efeito dos cátions metálicos sobre a formação dos MTS. Por outro lado, sabe-se que os elementos de transição são excelentes catalisadores para os processos eletroquímicos em razão de terem elétrons de valência no nível "d" incompleto ou que podem formar cátions com um sub-nível d incompleto [168]. Nesse sentido, nesta seção apresentaram-se os resultados sobre o efeito dos sais com metais de transição, tais como o níquel, cobalto e manganês. 


\subsubsection{Microtubos formados em $5 \times 10^{-2} \mathrm{M} \mathrm{NiSO}_{4}+0,25 \mathrm{M} \mathrm{NH}_{4} \mathrm{~F}$.}

Quatro diferentes tipos de amostras (B20, B24, B25 e B50) foram imersas simultaneamente em uma solução de $5 \times 10^{-2} \mathrm{NiSO}_{4}$, misturado com $0,25 \mathrm{M} \mathrm{NH}_{4} \mathrm{~F}$ durante 120 horas em diferentes valores de $\mathrm{pH}$. Todas as amostras foram metalizadas com $0,5 \mu \mathrm{m}$ de $\mathrm{Al}$ e recozidas durante meia hora antes da formação da camada de silício macroporoso. A formação da camada macroporosa das amostras B20, B24 e B50 foi obtida em solução de HF:DMF, enquanto que a amostra B25 foi anodizada em solução de HF:etanol (1:1). Todas essas amostras foram polarizadas de acordo com os parâmetros especificados no capítulo III. Após 120 horas de imersão, idênticos resultados observaram-se nas amostras B20, B24, e B50; porém, os resultados observados na amostra B25 diferem completamente daquelas três primeiras. Os resultados das amostras B20 e B25 serão apresentados e discutidos a seguir. A Figura 4.25 mostra as diferentes estruturas e composições químicas da amostra B20 para diferentes valores de $\mathrm{pH}$.

Os resultados estruturais das amostras imersas em $\mathrm{pH} \quad 4,5$ (B20A) e 5,5 (B20B) (Figuras 4.26a e 4.26b), não diferem, estruturalmente, daquelas obtidas nos mesmos $\mathrm{pH}$ em presença de cátions $\mathrm{Na}^{+}$, discutidas anteriormente (Figuras 4.14a e 4.14b). Estes resultados sugerem o mesmo mecanismo da dissolução eletroquímica para ambos os casos. Já no caso da amostra imersa em pH 6,5 (B20C) observa-se a formação de estruturas tubulares constituída principalmente por níquel, como revela a análise EDS (Figura 4.26g). A imagem aumentada mostra maiores detalhes da estrutura dos microtubos de níquel (MTN) e, estas, são mostradas na Figura 4.27, onde se observam claramente a presença de tubos bem definidos constituídos por paredes rugosas, devido ás paredes estarem formadas por um arranjo de nanopartículas de níquel aproximadamente esféricos com diâmetro médio de $100 \mathrm{~nm}$, enquanto que, o diâmetro interno, apresenta as dimensões do diâmetro interno dos poros do substrato macroporoso $(\approx 1.1 \mu \mathrm{m})$. 
(a)

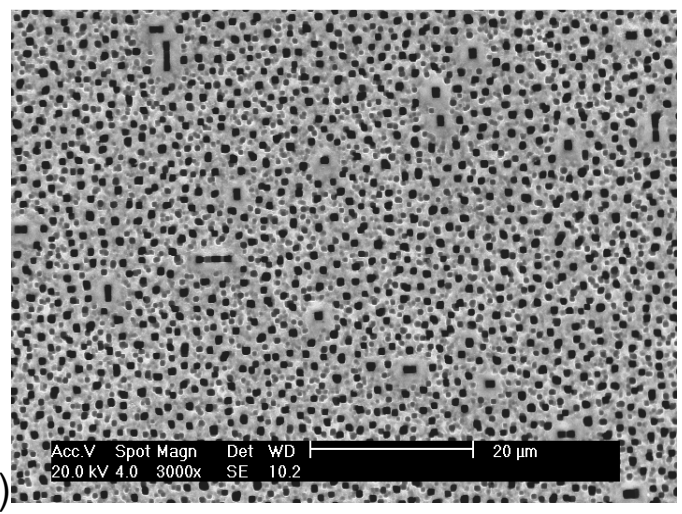

(b)

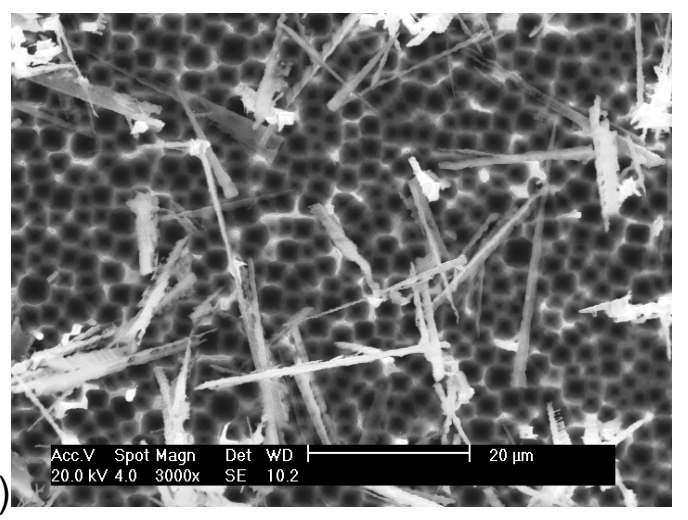

(c)
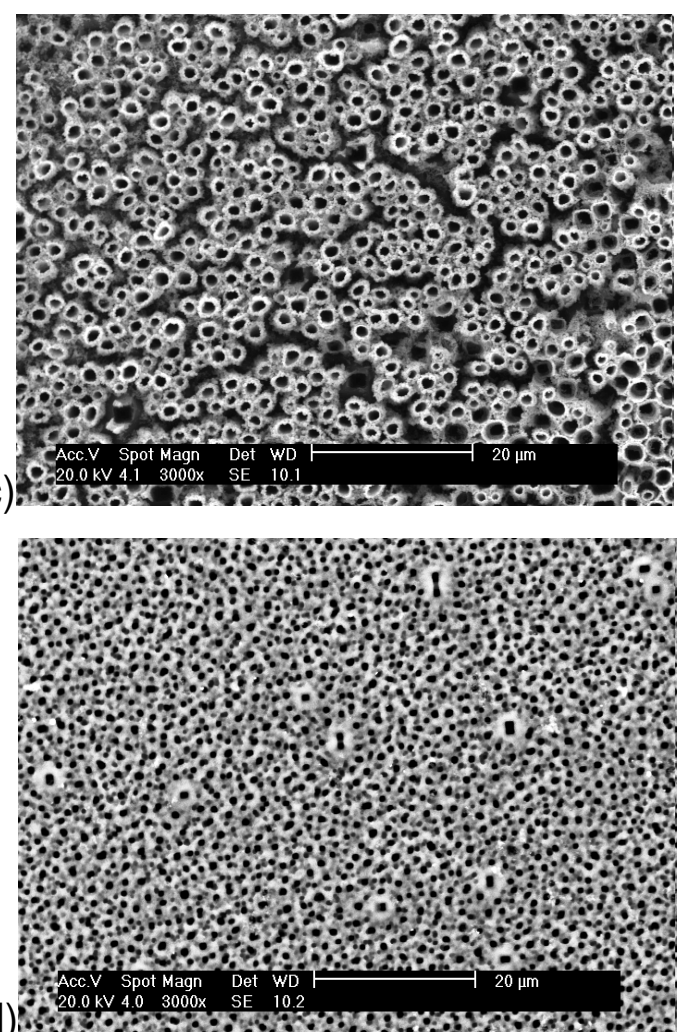

(d)
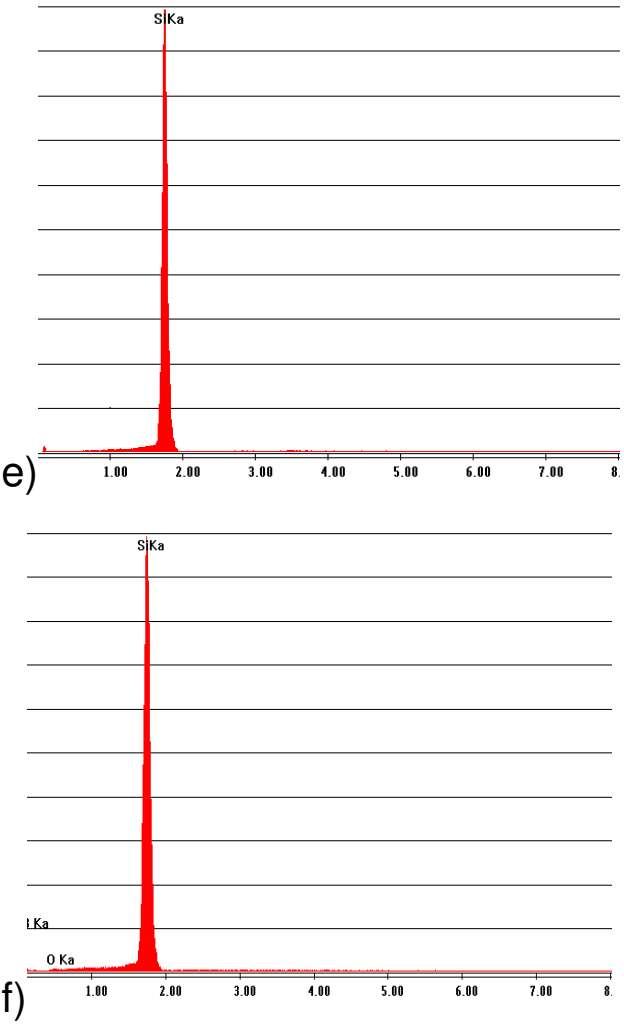

(f)

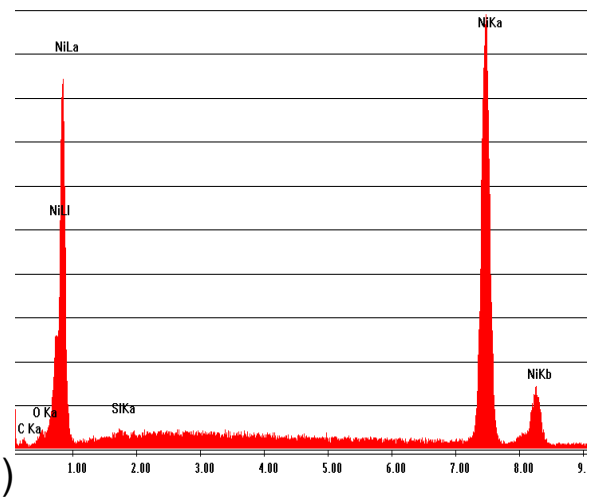

(g)

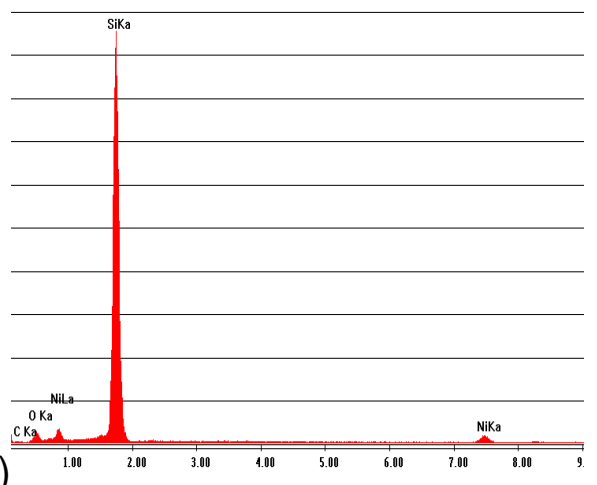

Figura 4.26. Estrutura superficial e espectro EDS da amostra imersa em pH: 4,5 (a,e), 5,5(b,f), 6,5 (c,g); e 7,5 (d,h). 


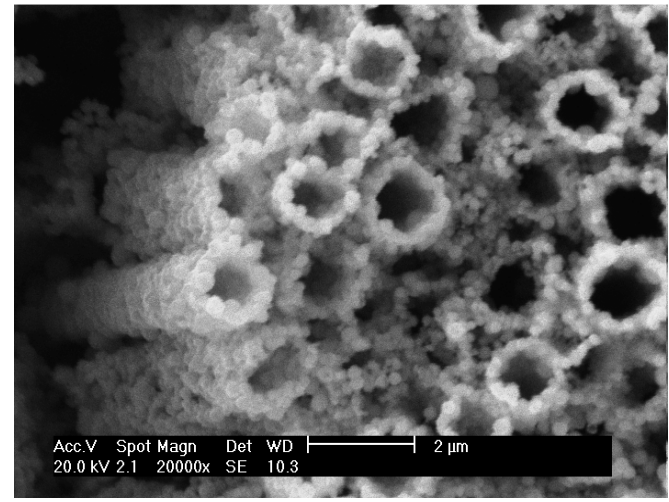

(a)

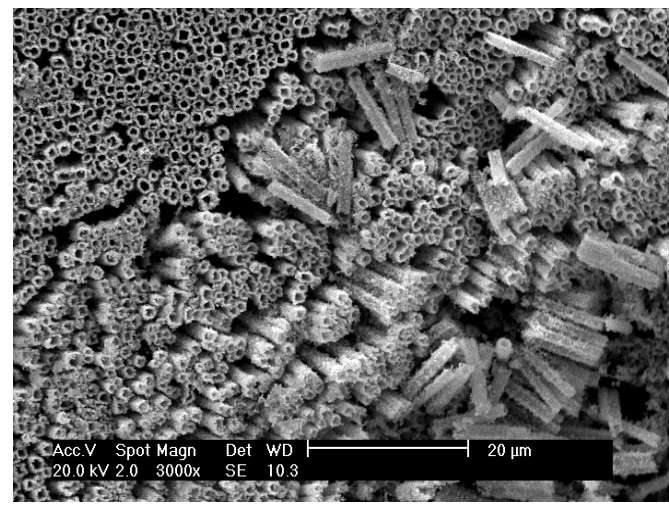

(c)

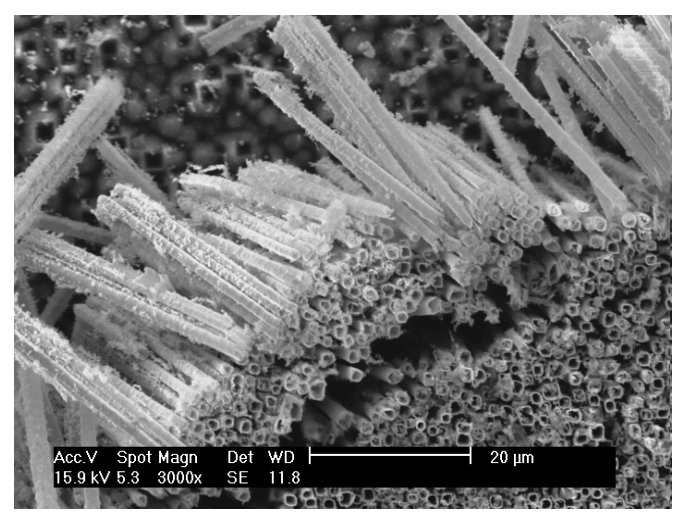

(e)

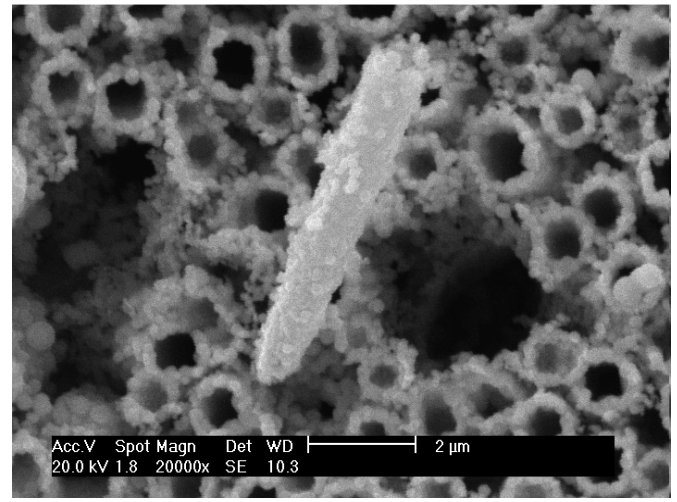

(b)

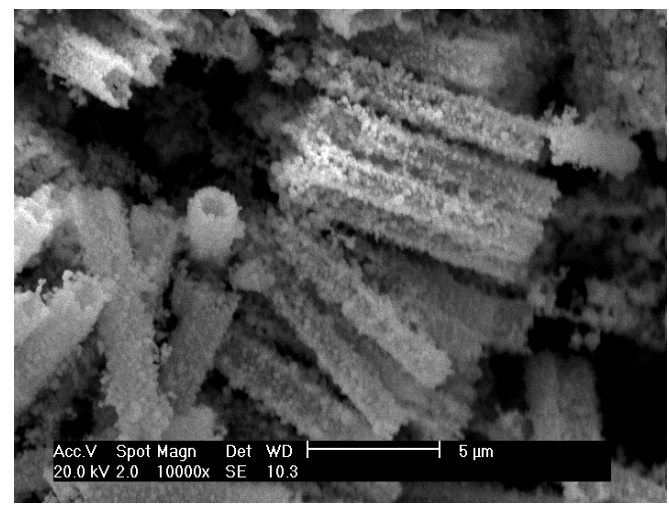

(d)

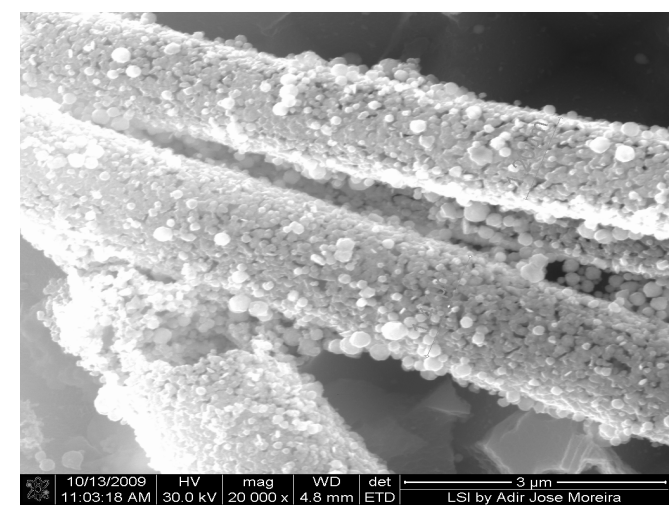

(f)

Figura 4.27. Microtubos de níquel obtidos na amostra B20C (a,b); B24C (c,d); e B50 (e,f) imersos em pH 6,5.

Nanopartículas com diâmetros similares têm sido reportadas por Harraz et al [126,169] e Zhang et al [129] durante a deposição de Ni em silício poroso e replicação da estrutura de SMP, respectivamente. É importante indicar que sobre as paredes dos MTN também se observa a formação de aglomerados com diâmetros na faixa de 100 a 300 nm, aproximadamente 
(Figura 4.27f). Quando o pH é incrementado a 7,5, a superfície apresenta uma aparência estrutural similar àquela imersa em pH 4,5. Assim, estruturalmente, apenas em pH 6,5 observa-se uma diferença marcante em relação às estruturas obtidas na solução de $\mathrm{NH}_{4} \mathrm{~F}$ misturado com $\mathrm{Na}_{2} \mathrm{SO}_{4}$.

A quantificação da composição química via EDS para os diferentes valores de $\mathrm{pH}$ são resumidos na Tabela 4.5 e Figura 4.28. Observa-se que as estruturas estão compostas basicamente de $\mathrm{Si}, \mathrm{Ni}, \mathrm{O}, \mathrm{C}, \mathrm{Cr}, \mathrm{Fe}, \mathrm{e}$ $\mathrm{Cu}$ em concentrações que dependem do $\mathrm{pH}$. A presença de elementos não considerados na solução $(\mathrm{Cr}, \mathrm{Fe}, \mathrm{C}, \mathrm{Cu})$ origina-se nas impurezas do sal de níquel $\left(\mathrm{NiSO}_{4}\right)$ usado no eletrólito. A alta concentração de $\mathrm{Ni}$ em pH 6,5 indica que as estruturas tubulares são de níquel, enquanto que o oxigênio parece estar em forma de $\mathrm{SiO}_{2}$ devido à dissolução da camada porosa e redução dos metais presentes. Adicionalmente, a presença de $\mathrm{Ni}$ na amostra em pH 7,5 indica que a estrutura original da amostra foi preservada devido à ação passivadora da camada de níquel depositada sobre a superfície em forma de hidróxido de níquel $\mathrm{Ni}(\mathrm{OH})_{2}$ em função das condições de pH que são adequadas para sua formação [150]. Isto explicaria o incremento na concentração de oxigêno nessa amostra.

Tabela 4.5- Concentração de elementos presentes nas amostras B20.

\begin{tabular}{cccccccc}
\hline $\mathrm{pH}$ & $\mathrm{Si}$ & $\mathrm{O}$ & $\mathrm{Cr}$ & $\mathrm{Fe}$ & $\mathrm{Ni}$ & $\mathrm{C}$ & $\mathrm{Cu}$ \\
\hline 4,5 & 99,66 & - & - & - & - & - & 0,34 \\
5,5 & 83,79 & 1,72 & 3,09 & 10,21 & 1,19 & - & - \\
6,5 & 1,09 & 1,77 & - & - & 86,72 & 3,79 & 6,63 \\
7,5 & 77,05 & 3,02 & - & - & 17,13 & 2,00 & 0,80 \\
\hline
\end{tabular}

Os resultados do MEV (Figura 4.26) mostram-nos que não há maior diferença estrutural em pH 4,5 e 5,5, em relação às amostras imersas na solução com $\mathrm{Na}_{2} \mathrm{SO}_{4}$, a não ser na presença de depósitos de Fe e Cr. No entanto, a principal diferença encontra-se nas amostras imersas em $\mathrm{pH}$ 6,5 e 7,5 . 


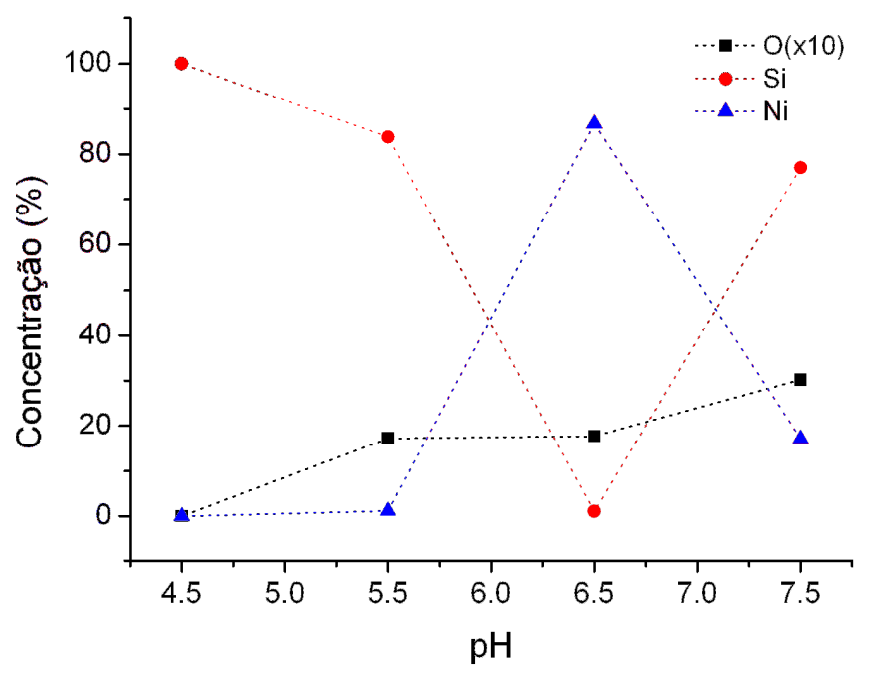

Figura 4.28. Concentração de Si, O e Ni detectado nas amostras B20 após a formação dos MTN.

Quando o substrato MPS é imerso no eletrólito, acontecem simultaneamente varias reações de oxirredução. As reações anódicas envolvidas são aquelas descritas pelas equações (4.10) e (4.11) encarregadas da formação do $\mathrm{SiO}_{2}$ decorrente da instabilidade do Si em meio aquoso [64,150,152], e é dissolvida imediatamente pelas espécies fluoradas $H F_{2}^{-}$e $H F$, de acordo com as reações (4.13) e/ou (4.14) $[64,125,153]$. Simultaneamente, as reações catódicas sobre a estrutura macroporosa serão [129,150,170]

$$
\mathrm{Ni}^{2+}+2 e \longrightarrow \mathrm{Ni} \quad E_{\mathrm{Ni}^{2+} / \mathrm{Ni}}=-0,296 V_{\mathrm{SHE}}
$$

Uma vez que em pH 6,5 coexistem diferentes espécies fluoradas, tais como as espécies $H F$ e $H F_{2}^{-}$, as reações totais para essas duas espécies serão:

$$
\begin{aligned}
& 2 \mathrm{Ni}^{2+}+\mathrm{Si}+6 \mathrm{HF} \longrightarrow \mathrm{SiF}_{6}^{2-}+2 \mathrm{Ni}+6 \mathrm{H}^{+} \\
& 2 \mathrm{Ni}^{2+}+\mathrm{Si}+3 \mathrm{HF}_{2}^{-} \longrightarrow \mathrm{SiF}_{6}^{2-}+2 \mathrm{Ni}+3 \mathrm{H}^{+}+\mathrm{H}_{2} \mathrm{O}
\end{aligned}
$$

Porém, entre elas, a reação dada pela equação (4.39) será a predominante, decorrente da abundância da espécie $H_{2}^{-}$nesse $\mathrm{pH}$ 
[69,70]. De acordo com essas equações, a superfície macroporosa é constantemente dissolvida dando lugar à deposição do níquel via deslocamento galvânico [105,126,129,169]. As equações (4.38) e/ou (4.39) expressam o processo de deslocamento galvânico mediante a qual átomos de silício são deslocados do substrato e substituídos por átomos de Ni. Decorrente desse processo, a estrutura final é uma replica da estrutura original [105,129], portanto, para a formação de MTN foi necessário previamente a formação dos MTS. O espectro EDS da amostra em questão mostra que, efetivamente, a estrutura final resultante são os MTN, que são uma replica dos MTS, cujas paredes estão constituídas por nanopartículas de níquel.

Para a deposição do níquel não é apenas suficiente que as condições termodinâmicas sejam favoráveis, também é necessário que exista uma fonte de elétrons. Nesse sentido, os agentes redutores podem participar como fonte de elétrons [171-173], ou mesmo o substrato $[137,154,157,184]$. Assim, o substrato de SMP pode ser usado como fonte de elétrons desde que ocorra a corrosão do substrato, como ocorre nas soluções fluoradas [105,127,129,167,169]. A literatura [105,169] tem reportado que em soluções fluoradas ácidas não é possível a deposição do $\mathrm{Ni}$, mesmo que as condições termodinâmicas sejam favoráveis. Porém, em soluções levemente ácidas a levemente alcalinas sua deposição é possível. Isto ocorre devido ao níquel ser um metal com potencial redox mais negativo $\left(-0.296 \mathrm{~V}_{\text {SHE }}\right.$ para $\left.5 \times 10^{-2} \mathrm{M}\right)$ comparado ao potencial redox do hidrogênio (-0.24 $\mathrm{V}_{\mathrm{SHE}}$ para $\mathrm{pH} 4$, por exemplo). Portanto, em soluções ácidas, a redução do hidrogênio predomina sobre a redução do $\mathrm{Ni}$, promovendo a passivação da superfície pelas ligações $S i-H$. Em soluções ácidas, estas reações são favorecidas tanto pela sua natureza estável $[97,98,169]$, quanto pela abundância dos íons $H^{+}$no eletrólito [64,65,97,151], apesar que as condições termodinâmicas podem, também, ser favoráveis para a deposição do níquel $[126,169]$. Em soluções fluoradas com valores de $\mathrm{pH}$ entre levemente ácido a levemente alcalino, a concentração das espécies $\mathrm{OH}^{-}$é maior e deslocam o PECA a 
valores mais negativos [64,65]. Estas espécies são rapidamente absorvidas pelo substrato e catalisam a formação $\mathrm{SiO}_{2}$ que, subseqüentemente, será dissolvida pelas espécies fluoradas [105,129], liberando os elétrons necessários para a redução $\mathrm{Ni}^{2+} / \mathrm{Ni}$ via deslocamento galvânico, como expresso pelas equações (4.38) e/ou (4.39).

Como comentado anteriormente, sob condições de pH 7,5 não foram observadas alterações significativas nas estruturas, somente constatou-se a presença de uma camada de $\mathrm{Ni}$ e oxigênio (Figura $4.25 \mathrm{~d}$ e $4.25 \mathrm{~h}$ ). Sob condições de $\mathrm{pH}$ e concentração de íons $\mathrm{Ni}^{2+}$ em torno de $5 \times 10^{-2} \mathrm{M}$, aqui usadas, o diagrama de Pourbaix do níquel aponta a que (Figura A4 do apêndice) esses elementos estariam depositadas em forma de uma camada de hidróxido de níquel $\mathrm{Ni}(\mathrm{OH})_{2}$ decorrente da reação química (4.40) [150,174], isto é, não precisa de elétrons para se depositar sobre a superfície do substrato[150]. Portanto, nessas condições, o substrato permanece praticamente inalterado em relação à estrutura original, já que o $\mathrm{Ni}(\mathrm{OH})_{2}$ é um material estável e insolúvel em soluções aquosas [150].

$$
\mathrm{Ni}^{2+}+2 \mathrm{H}_{2} \mathrm{O} \longrightarrow \mathrm{Ni}(\mathrm{OH})_{2} \downarrow+2 \mathrm{H}^{+}
$$

A análise voltamétrica (Figura 4.29a) mostra-nos que o comportamento eletroquímico das amostras B20, B24 e B50, são diferentes daqueles observados nas amostras imersas em solução fluoreto de amônia com $\mathrm{Na}_{2} \mathrm{SO}_{4}$, principalmente na região anódica em $\mathrm{pH} 7,5$, onde se observa tanto um decréscimo da corrente, quanto um comportamento ondulado da mesma, enquanto que, na região catódica, as correntes tendem a crescer, sendo este comportamento totalmente diferente daquele indicado pela teoria que prevê a tendência à saturação, segundo a equação (4.4).

Em pH 4,5, pode-se observar que a corrente anódica é maior do que em outros valores, enquanto que a corrente catódica é semelhante aqueles observados nos outros $\mathrm{pH}$, exceto em $\mathrm{pH} 5,5$, e sugere que seja devido às reações (4.15) que dariam lugar à passivação da superfície, como 
mostrado na Figura 4.26a. Já em pH 5,5 observa-se um leve incremento na corrente catódica, que pode ser atribuída à redução $H^{+} / H_{2}$ e aos efeitos catalisadores da redução do $S_{4}^{2-} / H_{2} S$ [150], uma vez que as condições termodinâmicas são favoráveis para a redução dessa espécie mediante reações intermediarias expressas pelas equações (4.7) a (4.9) ou outras que poderiam ocorrer na interface SMP/eletrólito.

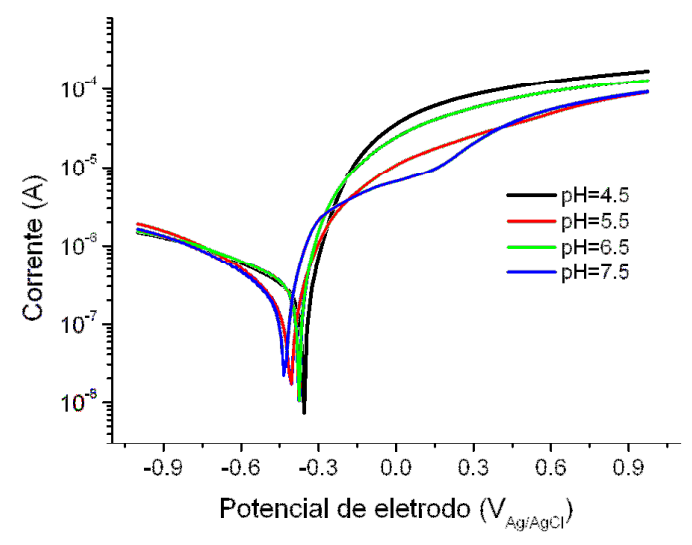

(a)

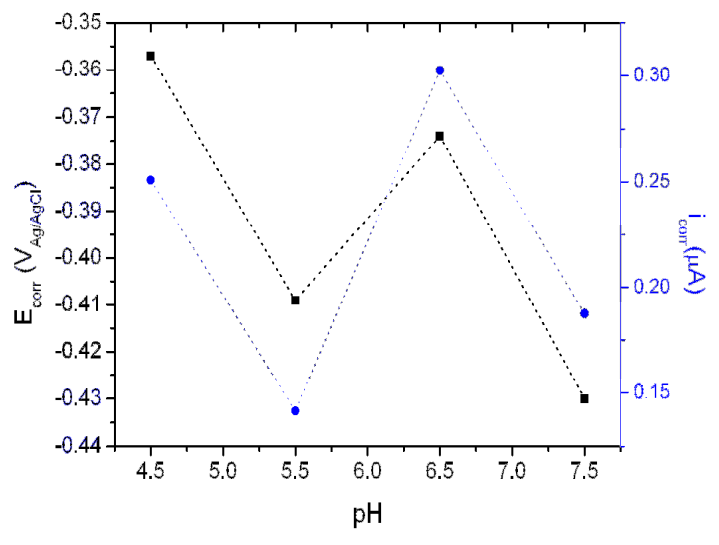

(b)

Figura 4.29. (a) Curvas voltamétricas, e (b) Potencial e corrente de corrosão das amostras imersas em $5 \times 10^{-2} \mathrm{M} \mathrm{NiSO}_{4}+0,25 \mathrm{M} \mathrm{NH}_{4} \mathrm{~F}$

No caso do $\mathrm{pH}$ 6,5, a Figura 4.29a mostra um incremento na corrente anódica, em relação àqueles observados em $\mathrm{pH} 5,5$, que poderia ser atribuído, de acordo ao correspondente diagrama de Pourbaix do nitrogênio (Figura A3)[150], à redução do $\mathrm{NH}_{4}^{+}$nas suas diferentes formas, tais como às descritas pelas equações (4.22), (4.41) a (4.44) [150,174], uma vez que o potencial de eletrodo na região anódica é superior a $-0.374 \mathrm{~V}_{\mathrm{Ag} / \mathrm{AgCl}}\left(-170 \mathrm{~V}_{\mathrm{SHE}}\right)$ e nesta região, de acordo com o diagrama de Pourbaix do enxofre e do níquel (Figura A2 e A4, respectivamente), tanto 0 sulfato quanto 0 níquel permanecem na sua forma iônica [150].

$$
\mathrm{NH}_{4}^{+}+2 \mathrm{H}_{2} \mathrm{O} \rightleftarrows \mathrm{NO}_{2}^{-}+8 \mathrm{H}^{+}+6 e \quad E_{o}=0,897 V_{\text {SHE }}
$$




$$
\begin{array}{ll}
\mathrm{NO}_{2}^{-}+\mathrm{H}_{2} \mathrm{O} \rightleftarrows \mathrm{NO}_{3}^{-}+2 \mathrm{H}^{+}+e & E_{o}=0,835 V_{S H E} \\
\mathrm{~N}_{2} \mathrm{O} \uparrow+5 \mathrm{H}_{2} \mathrm{O} \rightleftarrows 2 \mathrm{NO}_{3}^{-}+10 \mathrm{H}^{+}+8 e & E_{o}=1,116 V_{S H E} \\
\mathrm{~N}_{2} \uparrow+6 \mathrm{H}_{2} \mathrm{O} \rightleftarrows 2 \mathrm{NO}_{3}^{-}+12 \mathrm{H}^{+}+10 e & E_{o}=1,246 V_{S H E}
\end{array}
$$

Apesar do incremento na corrente anódica poder ser atribuído ao efeito das reações (4.41) a (4.44), o baixo valor de $\beta_{a}$ em pH 6,5 (Tabela 4.6) sugere que o incremento na corrente anódica, também poderia ser atribuído ao decréscimo na altura da barreira na camada. Isto permitiria maior transferência de elétrons do eletrólito para o substrato.

Em pH 7,5 a análise voltamétrica (Figura 4.28a) mostra inicialmente uma queda na corrente anódica na região entre $-0,250 \mathrm{~V}_{\mathrm{Ag} / \mathrm{AgCl}}$ a $0,15 \mathrm{~V}_{\mathrm{Ag} / \mathrm{AgCl}}$ ($0,45 \mathrm{~V}_{\mathrm{SHE}} \mathrm{a} 0,355 \mathrm{~V}_{\mathrm{SHE}}$ ) em relação àquelas observadas nos outros pHs empregados, atribuída a efeitos da passivaçaõ da superfície do eletrodo devido à formação de $\mathrm{Ni}(\mathrm{OH})_{2}$, porém, a partir de $0,15 \mathrm{~V}_{\mathrm{Ag} / \mathrm{AgCl}}$, observase um incremento que pode ser atribuído às reações (4.22), (4.33) a (4.37), em forma semelhante àquele observado em $\mathrm{pH}$ 6,5. A contribuição dos íons de níquel sobre a corrente anódica observa-se mediante as reações (4.45) a (4.47), enquanto que a espécie $S_{4}^{2-}$ não apresenta contribuição nenhuma, nas condições atuais de PECA e pH, devido a permanecer na sua forma iônica, como apontado pelo diagrama de Pourbaix do níquel [150].

$$
\begin{array}{ll}
3 \mathrm{Ni}^{2+}+6 \mathrm{H}_{2} \mathrm{O} \rightleftarrows \mathrm{Ni}_{3} \mathrm{O}_{4}+8 \mathrm{H}^{+}+2 e & E^{0}=1.977 V_{S H E} \\
3 \mathrm{NiO}+\mathrm{H}_{2} \mathrm{O} \rightleftarrows \mathrm{Ni}_{3} \mathrm{O}_{4}+2 \mathrm{H}^{+}+2 e & E^{0}=0.897 V_{S H E} \\
2 \mathrm{Ni}_{3} \mathrm{O}_{4}+\mathrm{H}_{2} \mathrm{O} \rightleftarrows 3 \mathrm{Ni}_{2} \mathrm{O}_{3}+2 \mathrm{H}^{+}+2 e & E^{0}=1.305 V_{S H E}
\end{array}
$$


A Figura 4.29b mostra o perfil da corrente de corrosão, onde em $\mathrm{pH} 4,5$, a $i_{c o r r}$ apresenta um maior valor associado à reação (4.15) que dá lugar à passivação da superfície $[66,67,97,108]$. Em pH 5,5, $i_{c o r r}$ apresenta menor valor devido a decréscimo em $i_{o c}$, e leve incremento em $i_{o a}$ associado à variação nos coeficientes de transferência de carga correspondentes, como resumido na Tabela 4.6 e Figura 4.30a, decorrentes das reações catódicas (4.18) e (4.19), que produzem uma corrosão predominantemente isotrópica e destrói a camada porosa, como descrito na seção 4.2.1. Adicionalmente, as variações de $i_{o c} \mathrm{e} i_{o a}$ produzem um deslocamento abrupto do PECA (ver equação 4.17), como observado na Figura 4.29b.

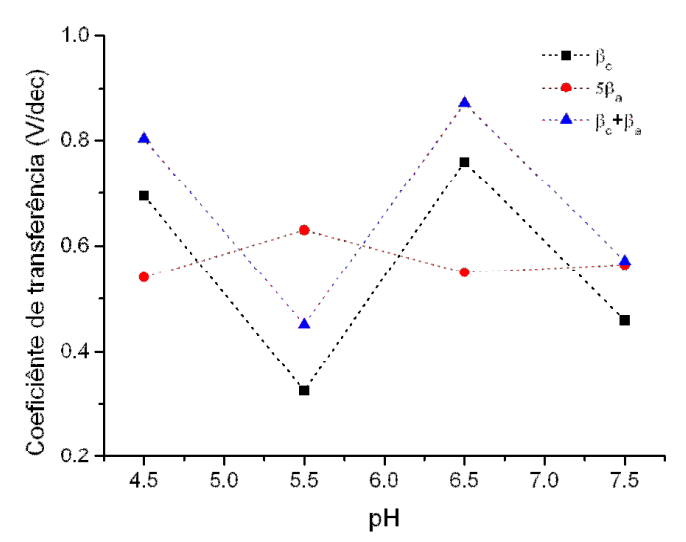

(a)

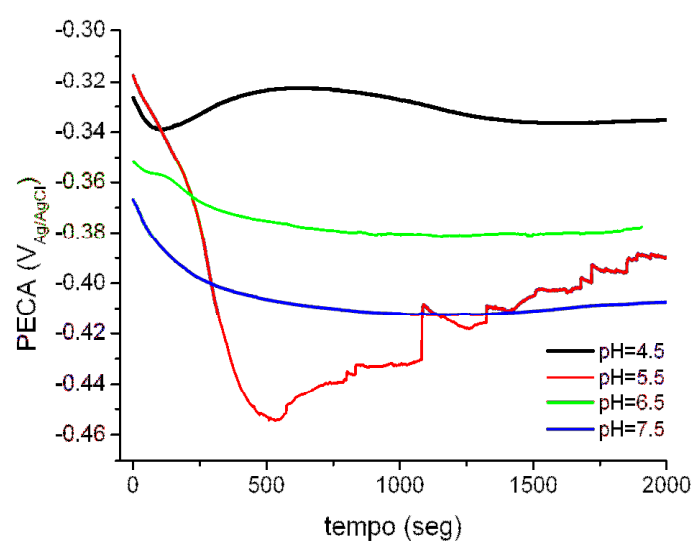

(b)

Figura 4.30. (a) Coeficientes de transferência, e (b) Potencial de eletrodo a circuito aberto em solução de $5 \times 10^{-2} \mathrm{M} \mathrm{NiSO}_{4}+0,25 \mathrm{M} \mathrm{NH}_{4} \mathrm{~F}$.

Tabela 4.6- Coeficientes de transferência, potencial e corrente de corrosão obtidos em $5 \times 10^{-2} \mathrm{M} \mathrm{NiSO}_{4}+0,25 \mathrm{M} \mathrm{NH}_{4} \mathrm{~F}$.

\begin{tabular}{ccccc}
\hline $\mathrm{pH}$ & $\begin{array}{c}\beta_{c} \\
(\mathrm{~V} / \mathrm{dec})\end{array}$ & $\begin{array}{c}\beta_{a} \\
(\mathrm{~V} / \mathrm{dec})\end{array}$ & $\begin{array}{c}\mathrm{E}_{\text {corr }} \\
\left(\mathrm{V}_{\text {Ag/Agcl }}\right.\end{array}$ & $\begin{array}{c}\mathrm{i}_{\text {corr }} \\
(\mathrm{UA})\end{array}$ \\
\hline 4,5 & 0,695 & 0,108 & $-0,357$ & 0,251 \\
5,5 & 0,325 & 0,126 & $-0,409$ & 0,142 \\
6,5 & 0,760 & 0,110 & $-0,374$ & 0,303 \\
7,5 & 0,459 & 0,113 & $-0,430$ & 0,188 \\
\hline
\end{tabular}


O perfil irregular do PECA sugere rápidos processos de oxidação e dissolução do substrato que conduzem a uma corrosão predominantemente isotrópica [64,65]. Embora a disponibilidade de elétrons na interface SMP/eletrólito, decorrente da dissolução do substrato, a probabilidade de deposição do $\mathrm{Ni}$ é pequena, devido às condições termodinâmicas não favoráveis, já que o PECA atingido é aproximadamente $-0.460 \mathrm{~V}_{\mathrm{Ag} / \mathrm{AgCl}}$ ( ou $-0.255 \mathrm{~V}_{\mathrm{SHE}}$ ) que é menos negativo do que o potencial redox do $\mathrm{Ni}\left(-0.296 \mathrm{~V}_{\mathrm{SHE}}\right)$. Adicionalmente, após um breve tempo, o PECA passa a incrementar, anulando as condições para a redução do $\mathrm{Ni}$. Assim, as concentrações de $\mathrm{Ni}$ detectadas pelo EDS (Tabela 4.5 e 4.28) poderiam estar em forma de complexos [157] ou em forma metálica, depositados via deslocamento galvânico $[105,126,129,169]$. No entanto, a literatura mostra que os complexos metálicos formam-se em potenciais redox muito menor daquele necessário para a redução metálica que segue a equação (4.37) [157]. Assim, a concentração de níquel detectado teria que estar, necessariamente, na sua forma metálica. Isto sugere que ao longo do tempo de imersão (120 horas) o PECA sofre deslocamento a valores suficientemente negativos para gerar as condições termodinâmicas para 0 deslocamento galvânico [126,169]. Este deslocamento do PECA é induzido devido aos efeitos da corrosão do substrato $[64,65]$.

Por outro lado, em $\mathrm{pH}$ 6,5, o incremento em $i_{\text {corr }}$ parece ser devido ao incremento em $i_{o c}$ e decréscimo em $i_{o a}$, já que o PECA desloca-se no sentido positivo a $-0,381 \mathrm{~V}_{\text {Ag/AgCl }}$ (ou $-0,176 \mathrm{~V}_{\mathrm{SHE}}$ ) em relação ao $\mathrm{pH}$ de 5,5 , e este valor permanece quase constante durante os 1000 segundos monitorados, como se tem observado na Figura 4.30b. Nessas condições, tanto $\circ \mathrm{Ni}$, quanto o sulfato, permanecem na sua forma iônica, apenas sendo possíveis as reações (4.23) e (4.25), bem como a dissolução do Si, que dará lugar á formação dos MTS. Isto sugere que, inicialmente, formam-se as estruturas tubulares de $\mathrm{Si}$ e, posteriormente, acontece o deslocamento galvânico $[153,184]$, seguindo o comportamento descrito 
pela equação (4.39), já que em pH 6,5 predomina a concentração de $\mathrm{HF}_{2}^{-}[69,70]$, permitindo a formação dos MTN (Figura 4.26c). Assim, os MTN formam-se via deslocamento galvânico, usando como molde os MTS previamente formados. Esses resultados mostram que ao longo do tempo de imersão, o PECA desloca-se a valores mais negativos do potencial redox do Ni devido ao efeito da corrosão do substrato [64]. Para verificar este argumento, foram realizados ensaios para diferentes tempos de mergulho. As amostras B71 e B88 foram imersas durante três dias na mesma solução eletrolítica da amostra em discussão (Figura 4.31 (a) e 4.31(b)). Na amostra B88 observam-se as paredes com pequenas aglomerações de $\mathrm{Ni}$ sugerindo que o processo de deslocamento galvânico encontra-se na sua fase inicial, enquanto que na amostra B71 mostram-se claramente alguns MTN (dentro do circulo vermelho) em fase de formação, mostrando claramente que os MTN formam-se a partir dos MTS e começam preferencialmente pela parte mais exposta ao eletrólito, que neste caso é a parte superior, devido aos MTS formarem-se começando pela parte superior dos tubos. Portanto, esses ficam expostos ao eletrólito mais tempo.

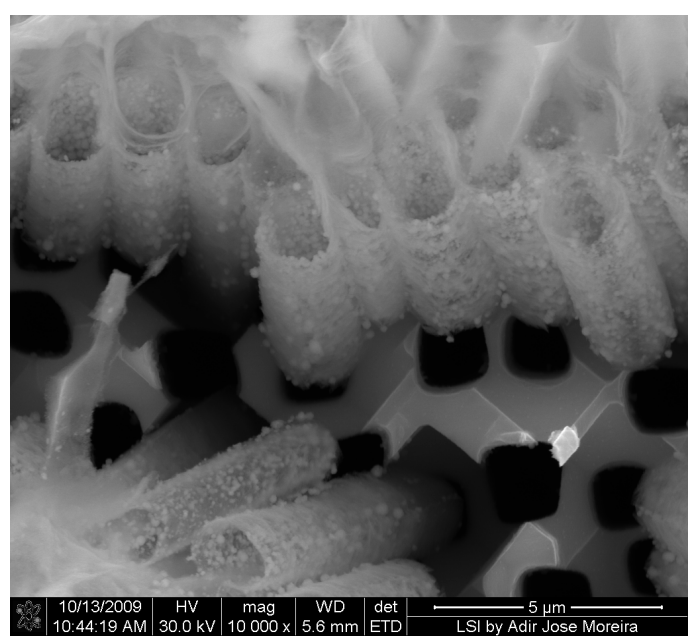

(a)

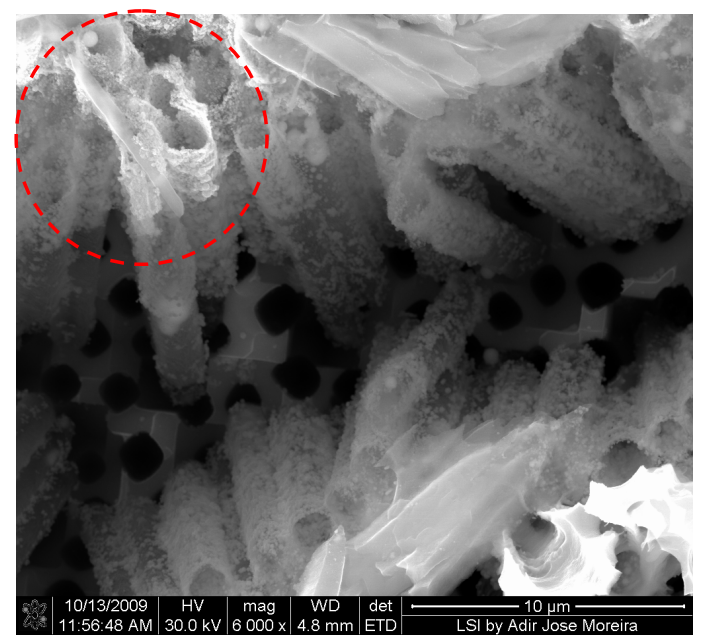

(b)

Figura 4.31. Formação parcial dos MTN via deslocamento galvânico dos microtubos de silício (a) B71, e (b) B88.

Por outro lado, em pH 7,5, o valor de $i_{c o r r}$ é menor do que nos outros casos devido à inibição da transferência de elétrons do substrato para o eletrólito (ou equivalentemente injeção de lacunas) decorrente da possível 
passivação da superfície (Figura 4.26d) pela camada de $\mathrm{Ni}(\mathrm{OH})_{2}[150,174]$. Adicionalmente, o monitoramento do PECA ao longo do tempo em $\mathrm{pH}$ 7,5 mostra deslocamento no sentido negativo (aproximadamente $-0,405 \quad \mathrm{~V}_{\mathrm{Ag} / \mathrm{AgCl}}$ ) (Figura $4.30 \mathrm{~b}$ ) e mostra que inicialmente o substrato é atacado e pausadamente é passivada até atingir um comportamento estável após 15 minutos aproximadamente. Segundo o diagrama de Pourbaix do sistema (Figura A4) [150], nestas condições, o potencial termodinâmico apenas favorece a reação eletroquímica (4.22), e a reação química (4.40). Esta última conduz à passivação da superfície mediante a formação de uma camada de $\mathrm{Ni}(\mathrm{OH})_{2}$, como mostrado na Figura 4.25d, motivo pelo qual, inibe-se a corrosão do MPS, sendo este resultado diferente daquelas amostras imersas em $\mathrm{NH}_{4} \mathrm{~F}+\mathrm{Na}_{2} \mathrm{SO}_{4}$ (Figuras 4.14 e 4.15b). Uma vez que a concentração de oxigênio, detectado via EDS, não é condizente com a concentração de $\mathrm{Ni}$, sugere-se que o oxigênio não apenas estaria na forma $\mathrm{Ni}(\mathrm{OH})_{2}$, mas também na forma $\mathrm{SiO}_{2}$.

\subsubsection{Microtubos formados em $5 \times 10^{-2} \mathrm{M} \mathrm{CoSO}_{4}+0,25 \mathrm{M} \mathrm{NH}_{4} \mathrm{~F}$.}

Outro elemento de transição utilizado no presente trabalho foi o cobalto, cujo potencial redox $\mathrm{Co}^{2+} / \mathrm{Co}$ para uma concentração de $5 \times 10^{-2} \mathrm{M}$ é igual a $-0.318 \mathrm{~V}_{\text {SHE }}$ e é próximo do potencial redox do $\mathrm{Ni}^{2+} / \mathrm{Ni}$, sugerindo o mesmo comportamento catalisador daquele mostrado pelo $\mathrm{Ni}$. A morfologia estrutural das amostras obtidas após imersão do substrato de MPS em $5 \times 10^{-2} \mathrm{M} \mathrm{CoSO}_{4}+0,25 \mathrm{M} \mathrm{NH}_{4} \mathrm{~F}$ em pH de 4,5 e 5,5 respectivamente, foi semelhante às das amostras mergulhadas em eletrólito, contendo cátions de $\mathrm{Na}^{+}$e $\mathrm{Ni}^{2+}$ em $\mathrm{pH} 4,5$ e 5,5, respectivamente (Figura 4.32a 4.32c, 4.26a e 4.26b). Adicionalmente, a composição química destas amostras também apresentou o mesmo perfil químico como apontado pelos espectros EDS nas Figuras 4.32e e 4.32f, respectivamente, quando comparados com os resultados das amostras obtidas em soluções contendo $\mathrm{Na}^{+}$e $\mathrm{Ni}^{2+}$. 
(a)

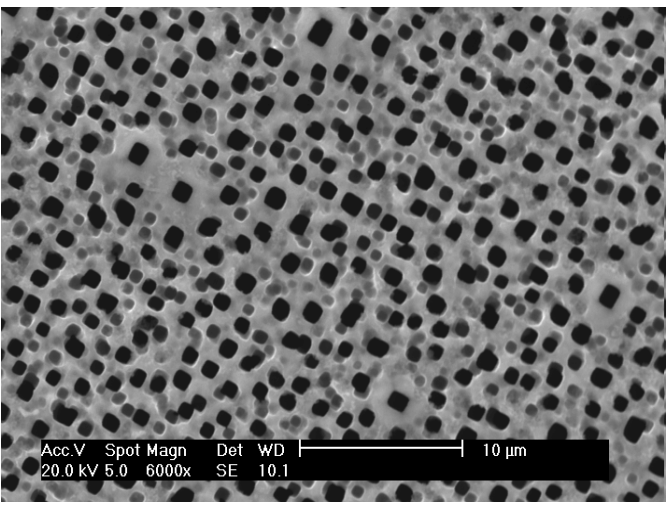

(b)

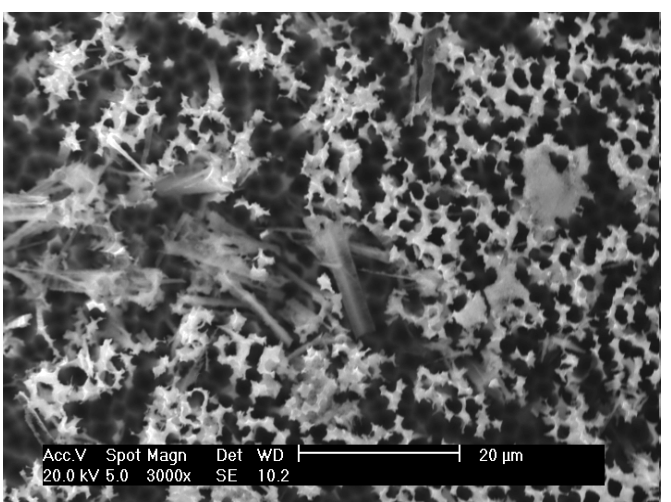

(c)

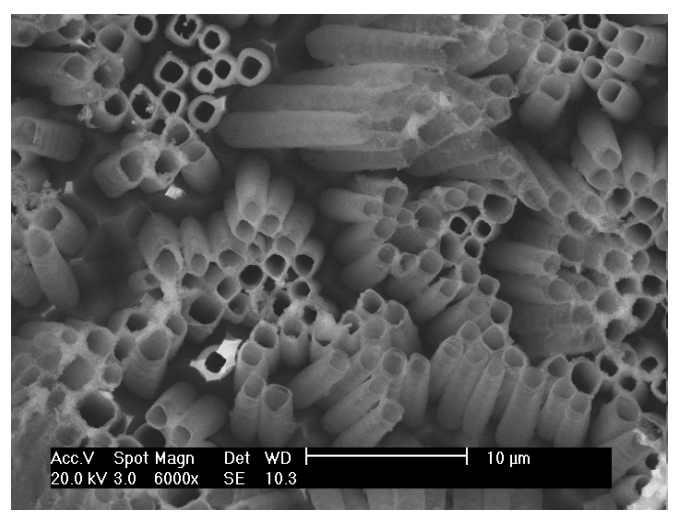

(d)

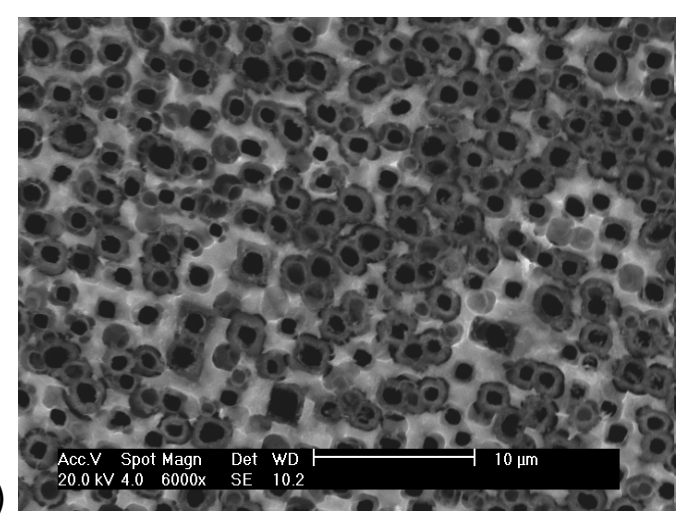

(e)

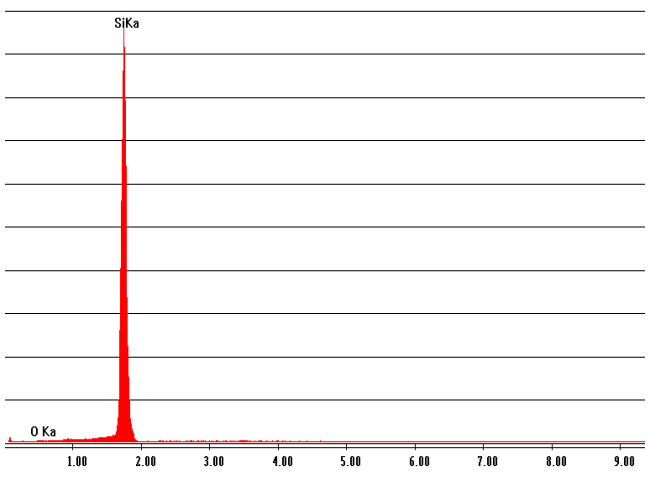

$(\mathrm{f})$

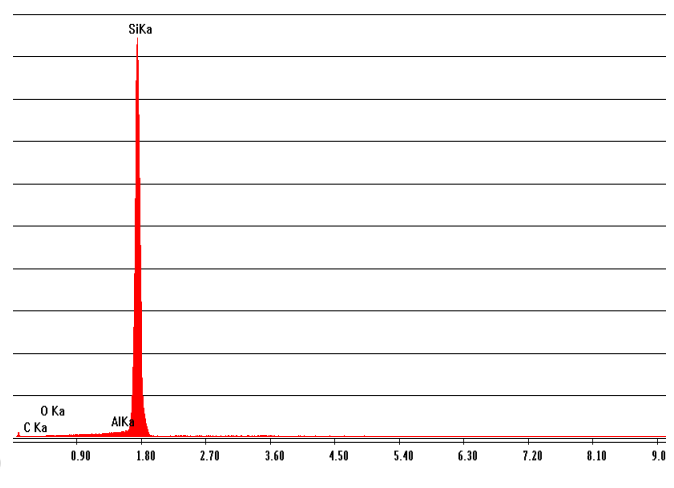

(g)

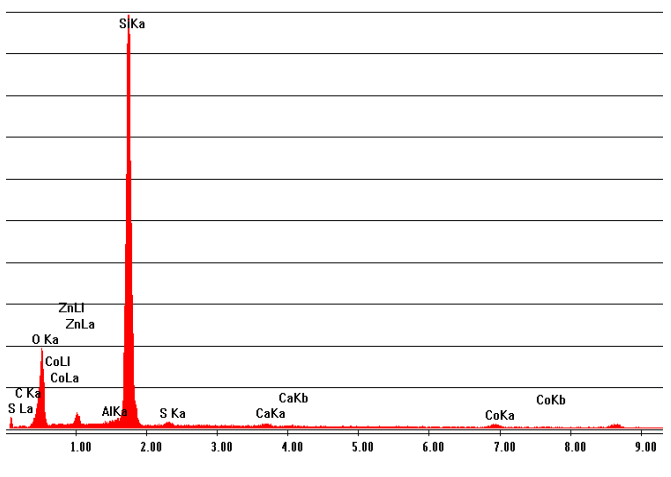

(h)

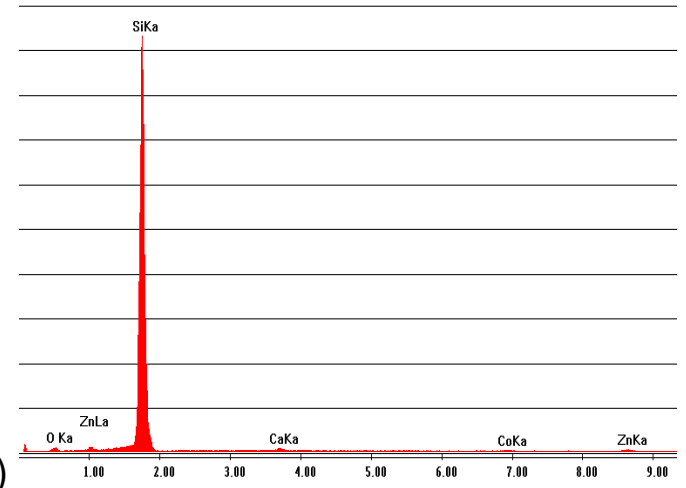

Figura 4.32. Imagens MEV e espectro EDS da amostra B27 imersa em $5 \times 10^{-2} \mathrm{CoSO}_{4}+0,25 \mathrm{M}$ $\mathrm{NH}_{4} \mathrm{~F}$ com pH 4,5 (a,e); 5,5 (b,f); 6,5 (c,g) e 7,5 (d,h) 
Estes resultados sugerem que, mesmo com a solução contendo íons de Co, os mecanismo de passivação e corrosão nestes níveis de pH são os mesmos daqueles nas soluções contendo íons de $\mathrm{Na}^{+}$e $\mathrm{Ni}^{2+}$, anteriormente discutidas (Seção 4.2.1).

No entanto, em pH 6,5, diferente da estruturas obtidas no eletrólito com cátions $\mathrm{Ni}^{2+}$, na solução com íons de Co, observa-se que os microtubos de silício (MTS) são bem definidos (Figura 4.31c) e estes apresentam pequenas quantidades de Co sobre sua superfície exterior, como mostrado nos espectro EDS da amostra, resumidos na Tabela $4.7 \mathrm{e}$ Figura $4.32 \mathrm{~g}$ e 4.33 , respectivamente. Adicionalmente, também se observa a presença de oxigênio, zinco, enxofre, cálcio e cobalto em porcentagens pequenas, como mostra a Tabela 4.7. Em uma solução de $\mathrm{pH} 7,5$, a imagem MEV (Figura 4.32d) da morfologia superficial da amostra apresenta estruturas cujas características sugerem um possível estágio inicial da formação dos MTS, pois observa-se claramente a formação de anéis que posteriormente podem tornar-se tubos de silício (Figura 4.31d). Este resultado mostra que a formação dos MTSs em uma solução de $\mathrm{pH} 7,5$ contendo íons de $\mathrm{Co}^{2+}$ é um processo lento, atribuído à baixa concentração de espécies $H F_{2}^{-}$, neste nível de $\mathrm{pH}[64,69,70]$, como também foi sugerido na formação das estruturas em soluções contendo íons de $\mathrm{Na}^{+}$e $\mathrm{Ni}^{2+}$, discutido em seções anteriores.

Tabela 4.7- Resumo dos elementos presentes nas amostras mergulhadas na solução $\mathrm{CoSO}_{4}+\mathrm{NH}_{4} \mathrm{~F}$

\begin{tabular}{ccccccccc}
\hline $\mathrm{pH}$ & $\mathrm{Si}(\%)$ & $\mathrm{O}(\%)$ & $\mathrm{Zn}(\%)$ & $\mathrm{Ca}(\%)$ & $\mathrm{S}(\%)$ & $\mathrm{Co}(\%)$ & $\mathrm{Cu}(\%)$ & $\mathrm{C}(\%)$ \\
\hline 4,5 & 98,52 & 0,00 & 0,00 & 0,00 & 0,24 & 0,33 & 0,91 & 0,00 \\
5,5 & 99,31 & 0,69 & 0,00 & 0,00 & 0,00 & 0,00 & 0,00 & 0,00 \\
6,5 & 59,02 & 30,88 & 4,31 & 0,00 & 1,14 & 2,30 & 0,00 & 1,55 \\
7,5 & 89,93 & 2,83 & 4,41 & 1,14 & 0,00 & 1,68 & 0,00 & 0,00 \\
\hline
\end{tabular}

No entanto, a análise química mostra baixa presença de Co sobre a estrutura, sendo esta na mesma ordem do Ca e menor do que o Zn (veja Tabela 4.7). Os microtubos de silício bem definidos e estruturados obtidos em solução contendo íons de $\mathrm{Co}^{2+}$ sugerem que estes íons modulam de 
forma controlada a corrosão de silício, evitando processos rápidos que normalmente originam estruturas muito rugosas. Assim, os cátions $\mathrm{Co}^{2+}$ são melhores catalisadores do que os cátions $\mathrm{Ni}^{2+}$ na dissolução do $\mathrm{Si}$ permitindo a formação de estruturas melhor definidas em relação àquelas observadas na presença de $\mathrm{Ni}^{2+}$.

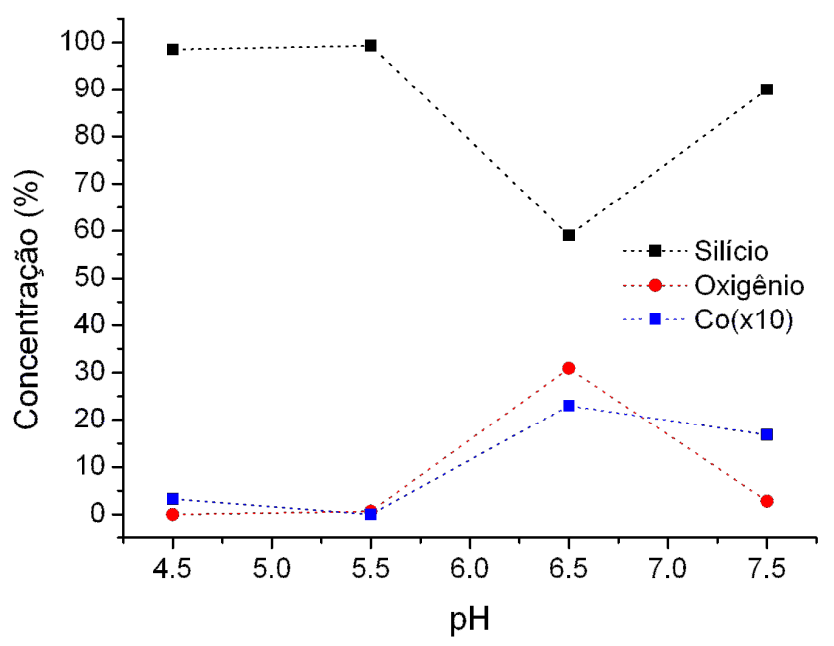

Figura 4.33. Concentração de elementos detectados via EDS após terem sido mergulhados no eletrólito fluorado com cátions $\mathrm{Co}^{2+}$.

A análise do comportamento eletroquímico foi realizada utilizando-se uma amostra processada sob as mesmas condições de pré-tratamento e do eletrólito (amostra B102). As curvas voltamétricas e os parâmetros obtidos a partir delas são apresentados na Figura 4.33a e na Tabela 4.8, respectivamente, e mostram um comportamento levemente diferente em relação daquela apresentada pela amostra imersa na solução misturada com $\mathrm{NiSO}_{4}$ (Tabela 4.6). Porém, existem alguns elementos em comum entre o comportamento eletroquímico das amostras imersas em solução com $\mathrm{NiSO}_{4}$ e $\mathrm{CoSO}_{4}$, citados a seguir:

- Em ambos os casos a corrente anódica é da ordem de $10^{-4} \mathrm{~A}$, enquanto que a corrente catódica difere em uma ordem de grandeza, aproximadamente, sendo maior na presença de $\mathrm{CoSO}_{4}$. Isto sugere 
também uma maior corrente de corrosão, já que a corrente catódica é proporcional à corrente de corrosão.

- A corrente anódica é maior em pH 4,5 e tem menor valor ao longo de todo o perfil em $\mathrm{pH} 7,5$.

- No caso da amostra imersa em $\mathrm{CoSO}_{4}$, a corrente catódica satura-se em valores próximos uma da outra, enquanto que naquela imersa em $\mathrm{NiSO}_{4}$ a corrente catódica não mostra evidências de saturação.

- A corrente de corrosão, $i_{c o r r}$, é máxima em pH 6,5 e é mínima em pH 7,5 (Figura 4.33b).

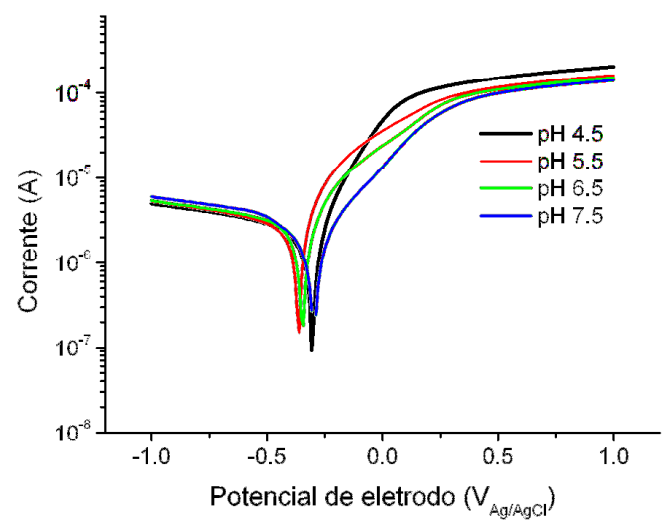

(a)

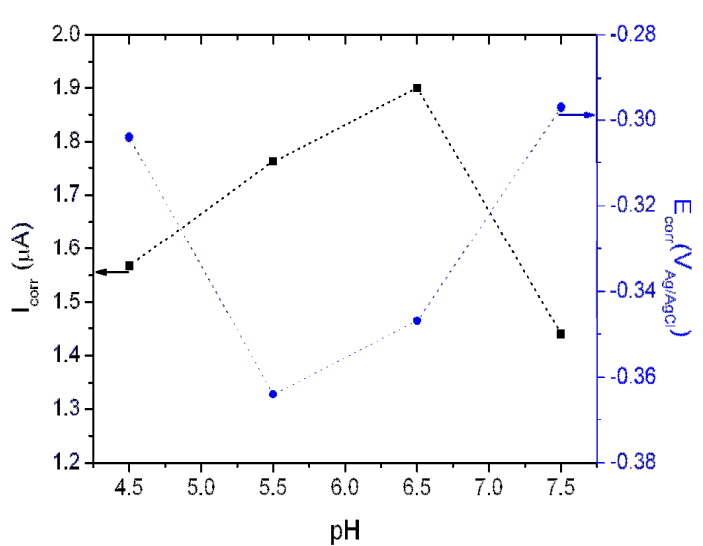

(b)

Figura 4.34. Curvas voltamétricas, e PECA e corrente de corrosão da amostra B102.

Tabela 4.8. Parâmetros eletroquímicos extraídos da amostra B102 usando o eletrodo de referência $\mathrm{Ag} / \mathrm{AgCl}$.

\begin{tabular}{cccccccc}
$\mathrm{pH}$ & $\begin{array}{c}\beta_{c} \\
(\mathrm{~V} / \mathrm{dec})\end{array}$ & $\begin{array}{c}\beta_{a} \\
(\mathrm{~V} / \mathrm{dec})\end{array}$ & $\begin{array}{c}\mathrm{E}_{\text {corr }} \\
(\mathrm{V})\end{array}$ & $\begin{array}{c}\mathrm{i}_{\text {corr }} \\
(\mathrm{UA})\end{array}$ & $\begin{array}{c}\mathrm{V}_{\mathrm{FB}} \\
(\mathrm{V})\end{array}$ & $\begin{array}{c}\mathrm{W} \\
(\mathrm{nm})\end{array}$ & $\begin{array}{c}\mathrm{V}_{\mathrm{s}} \\
(\mathrm{V})\end{array}$ \\
\hline 4,5 & 0,797 & 0,178 & $-0,304$ & 1,568 & 1,506 & 2579 & $-1,81$ \\
5,5 & 0,690 & 0,170 & $-0,364$ & 1,762 & 1,459 & 2501 & $-1,82$ \\
6,5 & 0,759 & 0,230 & $-0,347$ & 1,900 & 1,365 & 2382 & $-1,71$ \\
7,5 & 0,567 & 0,287 & $-0,297$ & 1,440 & 1,696 & 2539 & $-1,99$ \\
\hline
\end{tabular}

Nas curvas voltamétricas, acima de $0,0 \mathrm{~V}_{\mathrm{Ag} / \mathrm{AgCl}}\left(0,205 \mathrm{~V}_{\mathrm{SHE}}\right)$, observa-se incremento na corrente anódica, e esta é atribuída ao efeito da polarização anódica externa que diminui a altura da barreira da camada 
de depleção $[64,66,156,157]$. Desta forma, o potencial aplicado e a diminuição da altura da barreira, sugerem que as reações que envolvem as espécies de nitrogênio, descritas pelas equações (4.22) e (4.41) a (4.44), seriam termodinamicamente favorecidas devido ao incremento do potencial de eletrodo para todos os $\mathrm{pH}$, como sugere o diagrama de Purbaix do nitrogênio (Figura A3), enquanto que nestas condições, segundo o diagrama de Pourbaix do enxofre (Figura A2) [150], a espécie $\mathrm{SO}_{4}^{2-}$ permanece na sua forma iônica, não contribuindo à corrente anódica.

Em condições de circuito aberto, a formação de $\mathrm{Co}(\mathrm{OH})_{2}$ ocorre em pH levemente maior em relação à formação do $\mathrm{Ni}(\mathrm{OH})_{2}$ [150]. Para $5 \times 10^{-2} \mathrm{M}$ de cations $\mathrm{Ni}^{2+}$ o pH limiar para a precipitação de $\mathrm{Ni}(\mathrm{OH})_{2}$ é 6,75 (Figura A4), enquanto que, para a mesma concentração de $\mathrm{Co}^{2+}$, este é de aproximadamente 6,95 (Figura A5) [150]. Assim, para valores superiores a 6,75 e 6,95, tanto o níquel, quanto o cobalto, respectivamente, precipitaram-se. Por outro lado, em pH 7,5 as condições termodinâmicas são favoráveis para a reação (4.24) e libera íons $H^{+}$promovendo o deslocamento local do $\mathrm{pH}$ para a região ácida e, de acordo com os resultados observados na Figura 4.32h e 4.33, este deslocamento poderia ter atingido, localmente, valores de $\mathrm{pH}$ menores do que 6,95. Adicionalmente, o deslocamento do PECA a valores menos negativos do que o potencial redox do Co (aproximadamente $-0,320 \mathrm{~V}_{\mathrm{Ag} / \mathrm{AgCl}}$ ou -0,115 $\mathrm{V}_{\mathrm{SHE}}$ ), poderia explicar a razão pela qual a superfície da amostra imersa em $\mathrm{pH} 7,5$ (B27D) não apresenta depósitos de cobalto (Figura 4.32h e 4.33).

Comportamento análogo àquele observado em presença do $\mathrm{NiSO}_{4}$ observa-se no PECA do MPS imerso em solução misturada com $\mathrm{CoSO}_{4}$. O monitoramento do PECA durante 1000 segundos (Figura 4.35), mostranos que em $\mathrm{pH} 4,5$ ocorre um leve deslocamento do PECA a valores mais negativos tendendo ao estado estacionario em torno de -0,36 
$\mathrm{V}_{\mathrm{Ag} / \mathrm{AgCl}}$. Como indicado na secção 4.2.2, esse comportamento é típico de um processo de dissolução do substrato decorrente do incremento em $i_{o a}$, segundo apontado pela equação (4.17), atingindo logo o estado estacionário em razão do incremento das ligações $S i-H[64,65,83,148]$. $\mathrm{Em}$ pH 5,5 observa-se uma queda abrupta do PECA, decorrente das correções isotrópicas[64] que dominam o processo cujos mecanismos já foram discutidos amplamente na secção 4.2.2. No entanto, após 200 segundos aproximadamente, o PECA começa a deslocar-se em sentido positivo incrementando seu valor vagarosamente e com um perfil menos irregular em relação às curvas da solução contendo $\mathrm{Ni}^{2+}$, sugerindo que esta corrosão é um processo menos agressivo daquele observado na presença de $\mathrm{Ni}^{2+}$. Importante apontar que, a estrutura morfológica desta amostra apresentou um perfil semelhante daquele obtido em solução de $\mathrm{Na}_{2} \mathrm{SO}_{4}$.

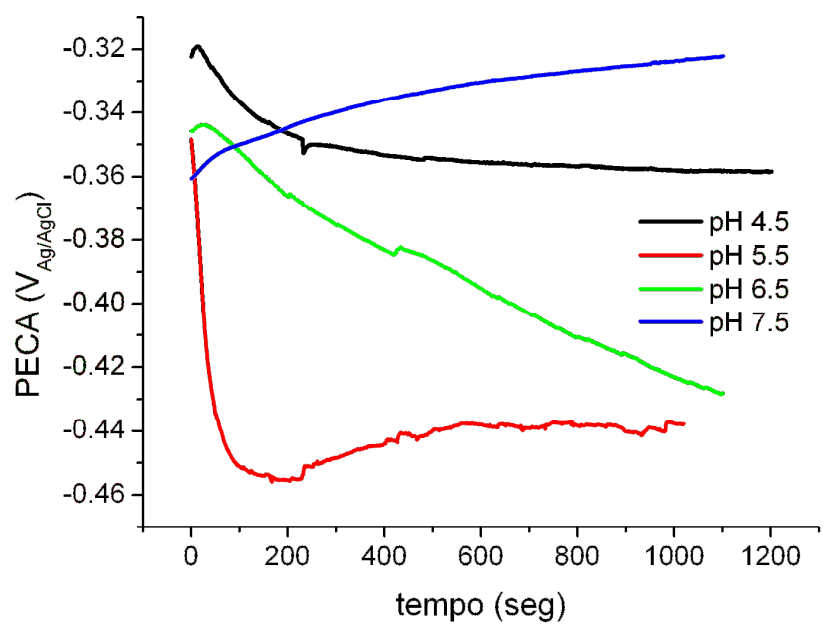

Figura 4.35 monitoramento do potencial de eletrodo ao longo do tempo para amostra B102 imersa em $5 \times 10^{-2} \mathrm{M} \mathrm{CoSO}_{4}+0,25 \mathrm{M} \mathrm{NH}_{4} \mathrm{~F}$.

No entanto, o comportamento do PECA em pH 6,5 (Figura 4.35), apresenta um deslocamento no sentido negativo de forma quase linear no tempo, atingindo o valor de $-0.420 \mathrm{~V}_{\mathrm{Ag} / \mathrm{AgCl}}$ após 1100 segundos. Porém, a tendência da curva mostra que o PECA ainda pode continuar seu decrescimento e, eventualmente, atingir potenciais da mesma magnitude, 
ou menores do que o potencial redox do cobalto, que para uma concentração de $50 \times 10^{-3} \mathrm{M}$ é igual a $-0,523 \mathrm{~V}_{\mathrm{Ag} / \mathrm{AgCl}}$ (ou $-0.318 \mathrm{~V}_{\mathrm{SHE}}$ ). $\mathrm{E}$, em virtude desse decréscimo, geraram-se as condições termodinâmicas necessárias para a redução do $\mathrm{Co}^{2+}$ via deslocamento galvânico.

Adicionalmente, no espectro EDS observa-se a presença do $\mathrm{Zn}$ nas amostras imersas em pH 6,5 e 7,5. Este elemento, de acordo com as especificações do fabricante, constitui parte das impurezas presentes no sal empregado como oxidante e sua presença na superfície da amostra, sugere que ao longo do tempo de imersão o PECA tem atingido valores abaixo do potencial redox do $\mathrm{Zn}\left(-0.7618 \mathrm{~V}_{\mathrm{SHE}}\right)[93,185]$. No entanto, a baixa concentração de Co no espectro EDS (2.3\%) é inesperada, já que as condições termodinâmicas e cinéticas desse sistema favorecem à redução do Co. Essa baixa concentração pode ser entendido se considerarmos que, em pH 6,5, as condições termodinâmicas e cinéticas também são favoráveis para a redução do Zn e S [150,170], e competem com o Co pelos elétrons disponíveis para sua redução. $\mathrm{Em} \mathrm{pH} \mathrm{7,5,} \mathrm{०}$ perfil do PECA descreve a passivação da superfície, como resultado da formação de uma camada fina de $\mathrm{Co}(\mathrm{OH})_{2}$ e , possivelmente, $\mathrm{Zn}(\mathrm{OH})_{2}$. Esta camada forma-se mediante reação química, análoga à formação do $\mathrm{Ni}(\mathrm{OH})_{2}$ [150], já comentado na seção 4.2.3.1.

Os parâmetros extraídos do levantamento da curva de Mott-Schottky (Figura 4.36a) sugerem que todos os processos de oxirredução na interface SMP/eletrólito, ocorrem mediante a injeção de lacunas à BV por elementos oxidantes, no caso $\mathrm{SO}_{4}^{2-}$ [64], favorecida pelas condições termodinâmicas e cinéticas, bem como o decréscimo do potencial de barreira em função do $\mathrm{pH}$. 


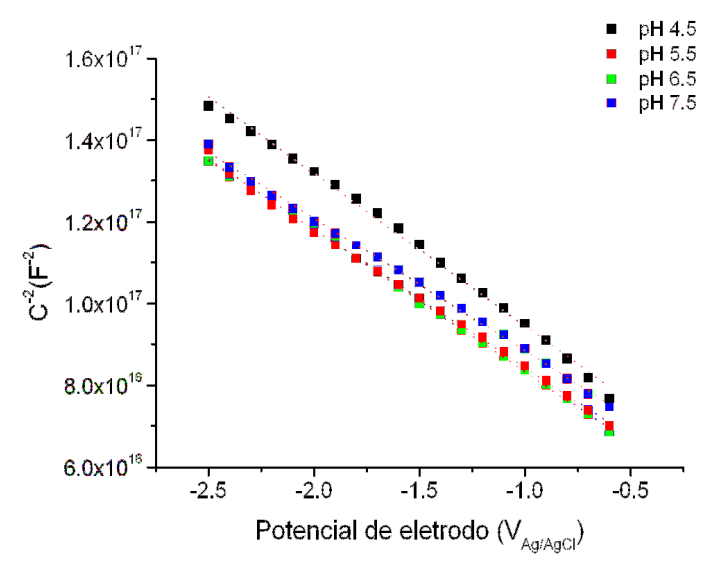

(a)

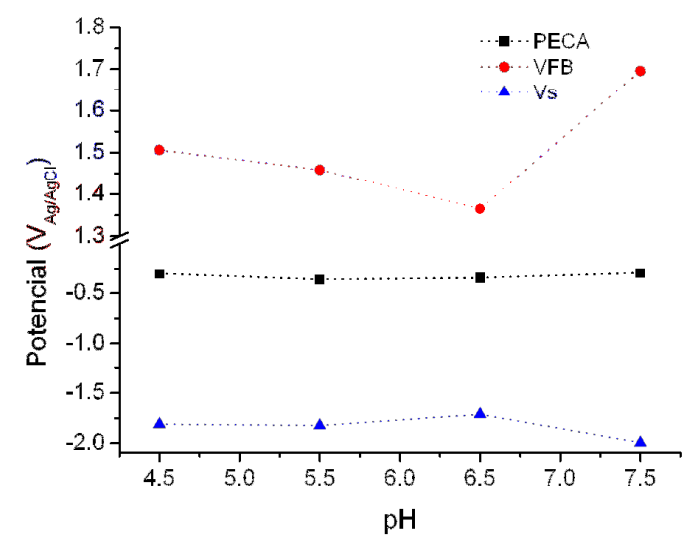

(c)

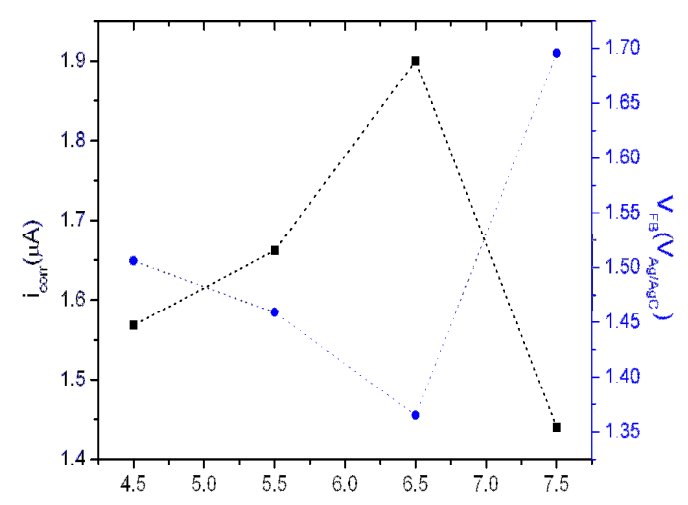

$\mathrm{pH}$

(b)

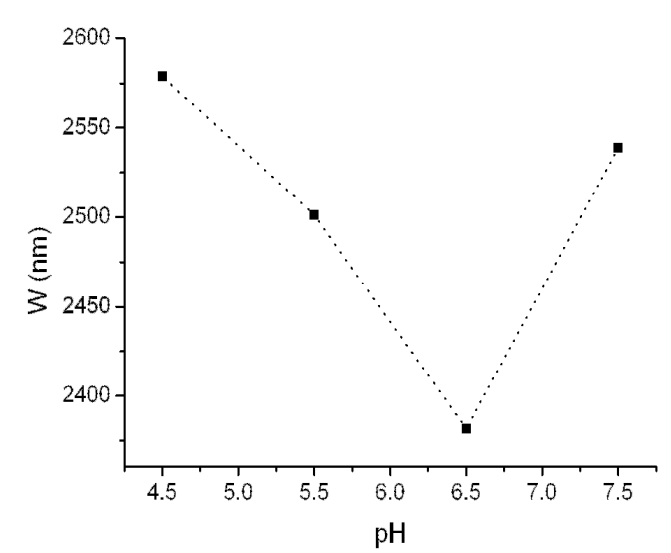

(d)

Figura 4.36. (a) Curvas Mott-Schottky, (b) $V_{F B}$ e corrente de corrosão, (c) PECA, $V_{s}, V_{F B}, e$ (d) camada de depleção em função do pH.

O perfil do potencial de barreira mostra-nos uma variação em forma oposta à largura da camada de depleção $\mathrm{W}=W_{\perp}$ (Figura 4.36b), apresentando menor altura em $\mathrm{pH}$ 6,5, região na qual ocorre um incremento na corrente de corrosão, decorrente de uma maior transferência de carga [64,65,97,98], favorecida pelo decréscimo da altura da barreira e estreitamento da largura da camada de depleção (Figuras 4.36b e 4.36d). Analogamente, a baixa corrente de corrosão nos outros valores de $\mathrm{pH}$, atribui-se ao incremento da altura da barreira e largura da camada de depleção que inibe a transferência de elétrons do substrato para o eletrólito. 
Quando comparado as Tabelas 4.4 e 4.8, observa-se que os valores da largura da camada de depleção são maiores quando o SMP é imerso no eletrólito com $\mathrm{CoSO}_{4}$, sugerindo que, nesta solução, as taxas de corrosão deveriam ser menores, já que a transferência de carga no sistema semicondutor/eletrólito é controlada pela largura da camada de depleção e pelo potencial de barreira $V_{s}[64,83,148,156,157]$. Porém, os resultados mostram que a corrente de corrosão é maior na solução com $\mathrm{CoSO}_{4}$, que poderia ser atribuído à menor altura do potencial de barreira, sugerindo que a transferência de carga é mais sensível à potencial de barreira do que à largura da camada de depleção. Contudo, uma vez que o EDS da amostras revela a presença de outros elementos (Tabela 4.7), além do Co, não se descarta a possibilidade de que o incremento na corrente de corrosão também tenha sido devido ao efeito catalisador desses outros elementos presentes no eletrólito, principalmente, em pH 6,5.

\subsubsection{Microtubos formados em $5 \times 10^{-2} \mathrm{M} \mathrm{Mn}\left(\mathrm{NO}_{3}\right)_{2}+0,25 \mathrm{M} \mathrm{NH}_{4} \mathrm{~F}$.}

Resultados anteriormente discutidos neste trabalho mostraram que em $\mathrm{pH}$ 4,5 a superfície da camada porosa permanece passivada, principalmente, pelas ligações $\mathrm{Si}-\mathrm{H}$, sempre que o potencial redox dos cátions metálicos presentes no eletrólito sejam mais negativos do que o potencial redox do hidrogênio de modo que não aconteça sua deposição na superfície macroporosa $[137,156,158]$. Considerando que tanto o Co, quanto o $\mathrm{Ni}$ têm potencial redox relativamente baixo, esta última se deposita em $\mathrm{pH}$ 6,5 ou maior, devido às reações eletroquímicas (4.38) e/ou (4.39). Por outro lado em soluções muito básicas podemos ter a formação de hidróxidos metálicos (equação 4.42) e óxidos metálicos que podem passivar a superfície e não permitir formação dos MTS, o que efetivamente foi discutido na secção 4.2.2, onde se mostrou que em $\mathrm{pH}$ 8,5 a superfície passiva-se, enquanto que, em solução misturada com $\mathrm{Na}_{2} \mathrm{SO}_{4}$, em pH 8,5, a superfície passiva-se e, em pH 9,5, aparecem alguns indícios de formação dos MTS. Assim, para enriquecer a 
discussão do efeito catalisador dos metais de transição, também foi utilizado o sal de $\mathrm{Mn}\left(\mathrm{NO}_{3}\right)_{2}$ na mesma concentração do sal $\mathrm{CoSO}_{4}$ e para os mesmos níveis de $\mathrm{pH}$ utilizados anteriormente, devido ao $\mathrm{Mn}^{2+} / \mathrm{Mn}$ ter um potencial redox muito negativo $\left(-1,223 \mathrm{~V}_{\text {SHE }}\right.$ para $\left.5 \times 10^{-2} \mathrm{M}\right)$. Para tal fim foi empregada a amostra B101, cuja superfície polida foi metalizada e recozida por meia hora em $\mathrm{N}_{2}$ a $550{ }^{\circ} \mathrm{C}$. Após 120 horas de imersão, a amostra foi caracterizada por MEV, cujas imagens são mostradas na Figura 4.37.

Diferente das amostras imersas no eletrólito misturado com $\mathrm{Na}_{2} \mathrm{SO}_{4}$, ou $\mathrm{NiSO}_{4}$, ou $\mathrm{CoSO}_{4}$, nestas amostras observa-se que a formação dos MTS ocorre em uma maior região de $\mathrm{pH}$, entre 5,5 a 7,5, em relação àqueles obtidos em sulfatos. A análise estrutural da amostra B101 via MEV mostra que os tubos apresentam diferenças significativas, cujo estudo apurado ajudara-nos a entender a importância do $\mathrm{Mn}\left(\mathrm{NO}_{3}\right)_{2}$ na formação dos MTS. Os tubos formados em diferentes pHs apresentam diferenças significativas, resultado que está diretamente relacionado com as características particulares do sal de $\mathrm{Mn}\left(\mathrm{NO}_{3}\right)_{2}$ na formação dos MTS. Em pH 5,5, diferente dos outros oxidantes, ocorre a formação dos MTS e aparecem aglomerados entre si, possivelmente devido à distância entre os poros ser menor do que $2 W_{\|}$, portanto, as camadas de depleção de dois poros adjuntos sobrepõem-se e formam tubos colados um com outro. As condições geométricas para a formação dos MTS já são discutidas na seção 4.2.2.

$\mathrm{Em} \mathrm{pH} \mathrm{6,5,} \mathrm{o} \mathrm{comportamento} \mathrm{também} \mathrm{difere} \mathrm{daqueles} \mathrm{antes} \mathrm{já} \mathrm{vistos}$ nesta região de $\mathrm{pH}$ (Figuras 4.14c, 4.15a, 4.27c e 4.32c), onde normalmente observa-se a formação de tubos bem definidos ou a formação de MTN. Neste caso, os tubos aparecem não tão bem definidos, deixando uma aparência de estar se dissolvendo, possivelmente devido ao longo tempo de imersão no eletrólito. 
(a)

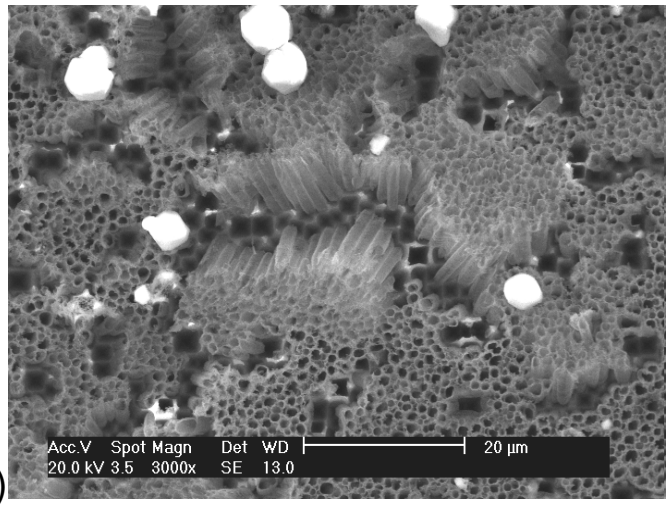

(b)

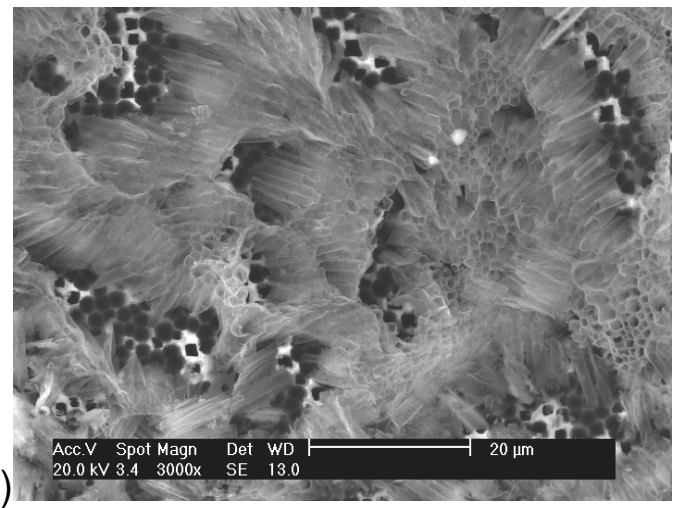

(c)

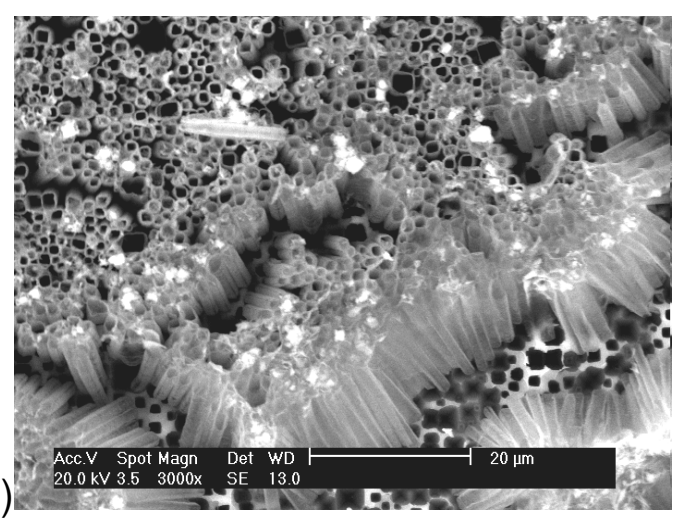

(d)

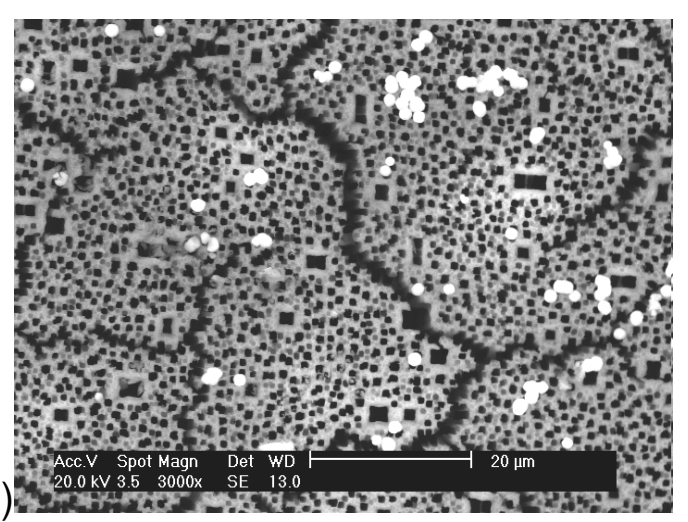

(e)

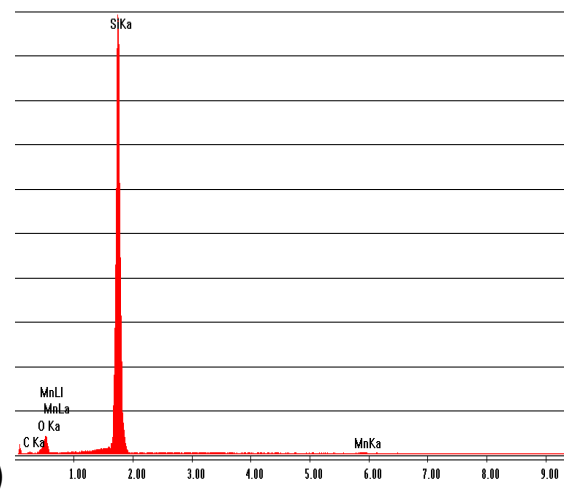

(f)

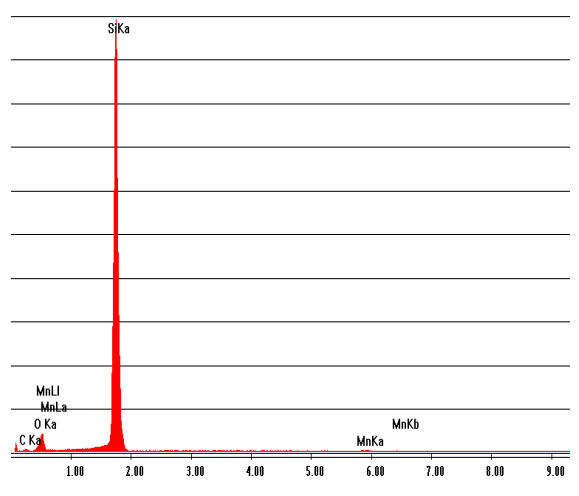

(g)

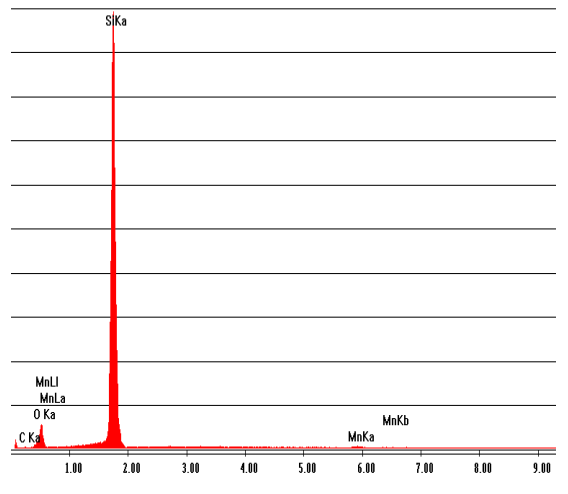

(h)

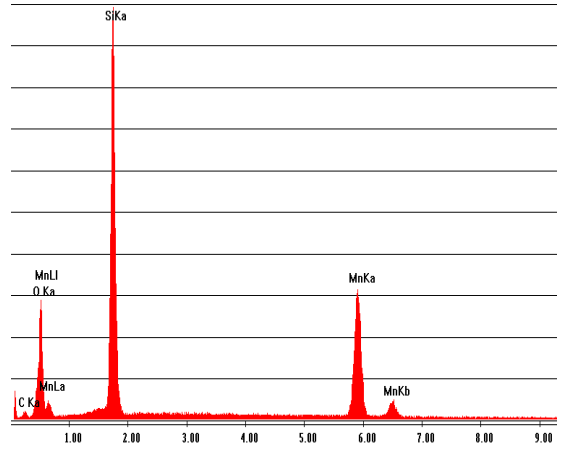

Figura 4.37. Imagens MEV e espectro EDS da amostra B101 imersa em $5 \times 10^{-2} \mathrm{M}$ $\mathrm{Mn}\left(\mathrm{NO}_{3}\right)_{2}+0,25 \mathrm{M} \mathrm{NH}_{4} \mathrm{~F}$ com pH 5,5 (a,e); 6,5 (b,f); 7,5 (c,g) e 8,5 (d,h) 
Já no caso da amostra imersa em pH 7,5, observa-se a formação de tubos melhor definidos (Figura 4.37c). Este resultado é completamente diferente aos obtidos em soluções contendo íons de $\mathrm{Ni}$ e Co, onde para o nível de pH 7,5 a formação de estruturas tubulares foi inibida pela passivação da superfície, como observadas nas Figuras $4.26 \mathrm{~d}$ e $4.32 \mathrm{~d}$, respectivamente. Adicionalmente, dependendo da região de formação, esses tubos podem aparecer também aglomerados ou soltos, como se mostra na Figura 4.38, onde é mostrada a estrutura morfológica dos tubos nas regiões mais exteriores ao centro da amostra. Assim, a forma final dos tubos depende não apenas do $\mathrm{pH}$, mas também da região de formação, sendo aquelas formadas em regiões mais afastadas do centro da amostra mais suscetíveis à aglomeração.

(a)

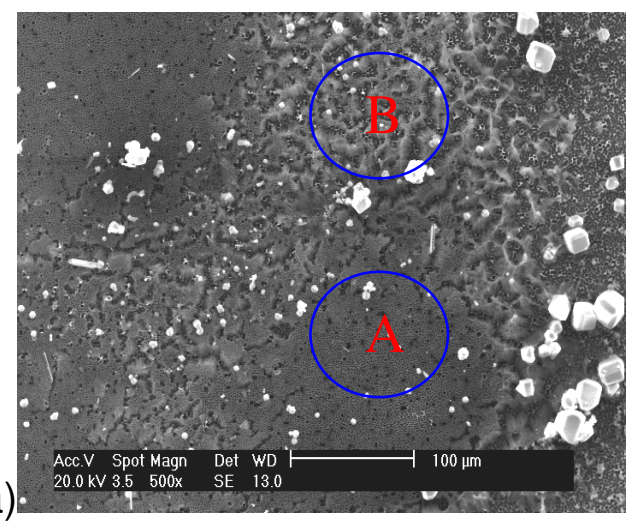

(b)

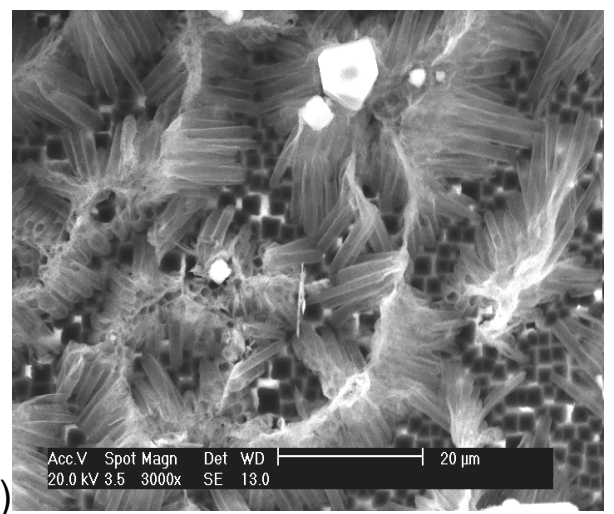

Figura 4.38. (a) Visão panorâmica da amostra B101; e (b) estrutura obtida da região "B" em pH 5,5.

O resultado final da estrutura obtida em solução de $\mathrm{pH}$ 8,5, com o oxidante de Mn (Figura 4.37d), mostra uma superfície passivada com alguns indícios de tubos em estágio de formação inicial, apresentando um aspecto diferente daqueles observados previamente nas Figuras $4.26 \mathrm{~d} e$ 4.32d, onde, a superfície da camada de MPS resulta sem alteração significativa. A inibição da formação completa das estruturas tubulares nesta solução pode ser devido à passivação da superfície por algum óxido de manganês, já que o espectro EDS desta amostra revela a existência de uma concentração significativa de $\mathrm{Mn}$ e O, respectivamente 
(Figura 4.37h e 4.40a). Isto sugere que a passivação da superfície é um processo lento e acontece simultaneamente com a formação dos MTS.

É importante mencionar que, dependendo do lugar, a estrutura pode resultar com aparência diferente, como se vê nas Figuras 4.38 e 4.39. A estrutura na Figura 4.36a difere daquelas formadas em lugares não tão próximos da parte central da amostra (Figura 4.37b). Esta última estrutura foi observada na região "A", indicada na Figura 4.37a, enquanto que aquelas mostradas na Figura 4.36a, foram obtidas região "B". Nessa região os tubos aparecem mais definidos, embora estas, também se mostram aglomerados entre si e unidas pela parte superior das mesmas, que, somado aos efeitos da dissolução, fazem que os tubos apareçam com as aberturas superiores fechadas.

(a)

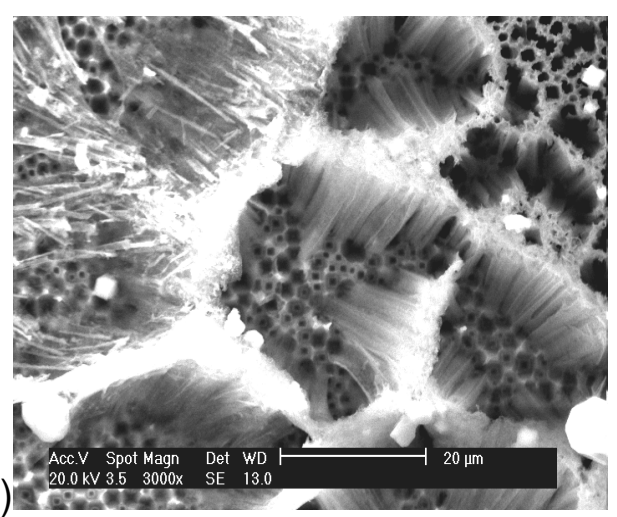

(b)

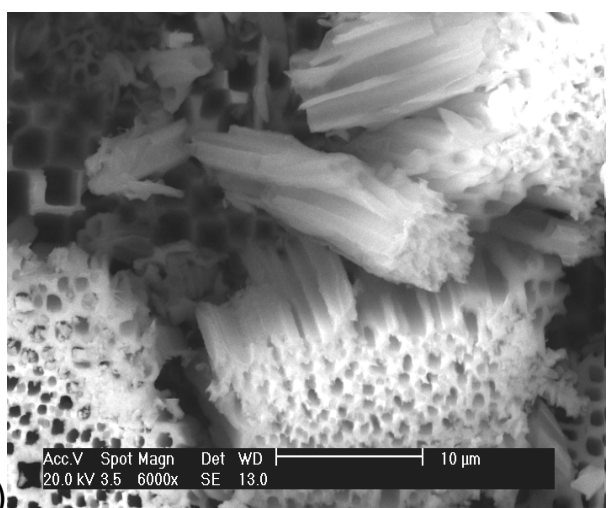

Figura 4.39 (a)Microtubos de silício formados em regiões longe do centro da amostra, e (b) Estrutura formada em $\mathrm{pH} 8,5$

$\mathrm{Na}$ Figura 4.40a observa-se que, diferente das amostras imersas em eletrólito com cátions $\mathrm{Na}^{+}, \mathrm{Ni}^{2+}$ ou $\mathrm{Co}^{2+}$, onde a maior presença de oxigênio ocorria em $\mathrm{pH} 6,5$, na presença de cátion $\mathrm{Mn}^{2+}$ este fato acontece em pH 8,5 ,situação na qual também acontece a maior presença de Mn depositado na superfície. A análise de EDS correspondente a regiões com aspecto de aglomerados metálicos observados nas Figuras 4.37 e 4.38 mostram efetivamente serem aglomerados de manganês, já que o espectro EDS destes aglomerados apresenta uma elevada concentração de Mn passando a ser o átomo dominante nestas estruturas (Figura 4.39c). 


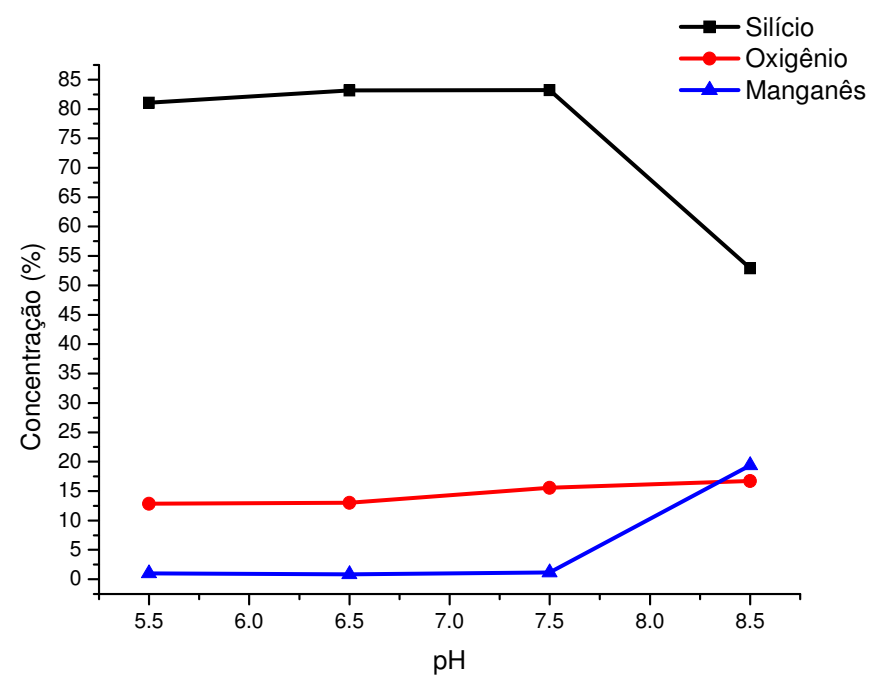

(a)

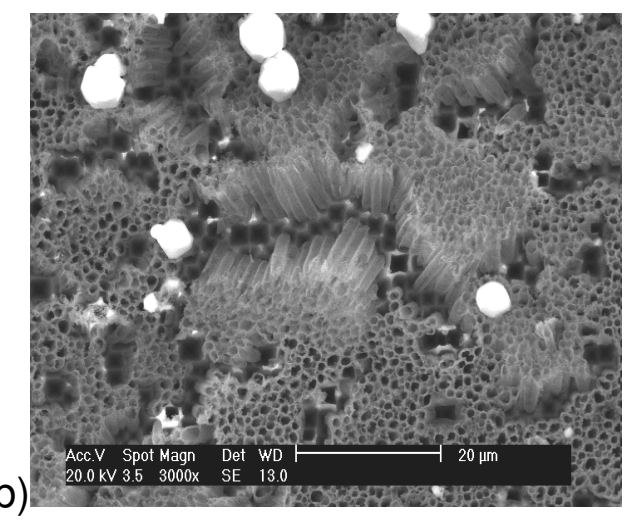

(c)

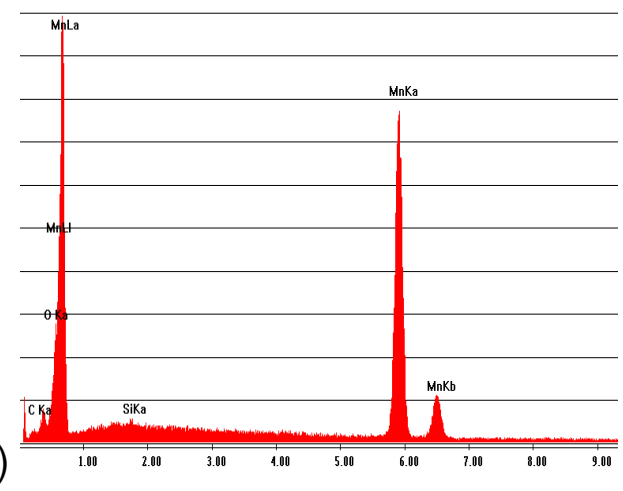

Figura 4.40. (a) Concentração de elementos em função do $\mathrm{pH}$; (b) formação de aglomerados de Mn sobre os MTSs da amostra B101; e (c) EDS dos aglomerados.

A quantificação da análise química é resumida na Tabela 4.9 e na Figura 4.40a, e mostram que os elementos detectados pelo EDS estão constituídos por silício, oxigênio, manganês e carbono, provenientes principalmente das impurezas intrínsecas do sal oxidante. É importante mencionar que os espectros EDS foram obtidos na parede dos tubos.

Tabela 4.9- Composição química dos MTS da amostra B101

\begin{tabular}{ccccc}
\hline $\mathrm{pH}$ & $\mathrm{Si}(\%)$ & $\mathrm{O}(\%)$ & $\mathrm{Mn}(\%)$ & $\mathrm{C}(\%)$ \\
\hline 5,5 & 81,10 & 12,88 & 1,01 & 5,01 \\
6,5 & 83,17 & 13,03 & 0,85 & 2,96 \\
7,5 & 83,24 & 15,58 & 1,17 & - \\
8,5 & 52,93 & 16,71 & 19,40 & 10,97 \\
\hline
\end{tabular}


O comportamento eletroquímico da interação entre a amostra B101 e o eletrólito, foi estudado através de curvas voltamétricas, apresentadas na Figura 4.41a, de onde foram obtidas as respectivas correntes de corrosão e potenciais de corrosão, que são resumidos na Figura 4.41b e Tabela 4.10 , onde, adicionalmente, também foram resumidos os coeficientes de transferência anódica e catódica para cada $\mathrm{pH}$. Contrário àquilo que acontece na presença dos oxidantes baseados em $\mathrm{XSO}_{4}\left(\mathrm{X}=\mathrm{Na} a_{2}, \mathrm{Ni}, \mathrm{Co}\right)$, neste caso observa-se um incremento na corrente anódica em função do $\mathrm{pH}$ que poderia estar associado às reações intermediárias, decorrentes da polarização externa.

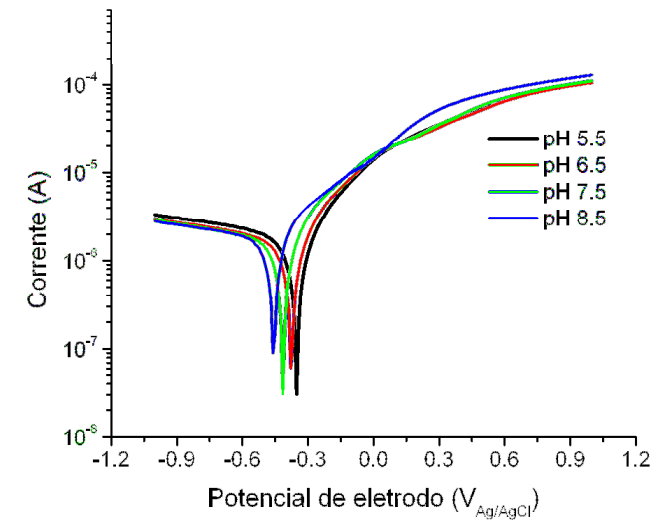

(a)

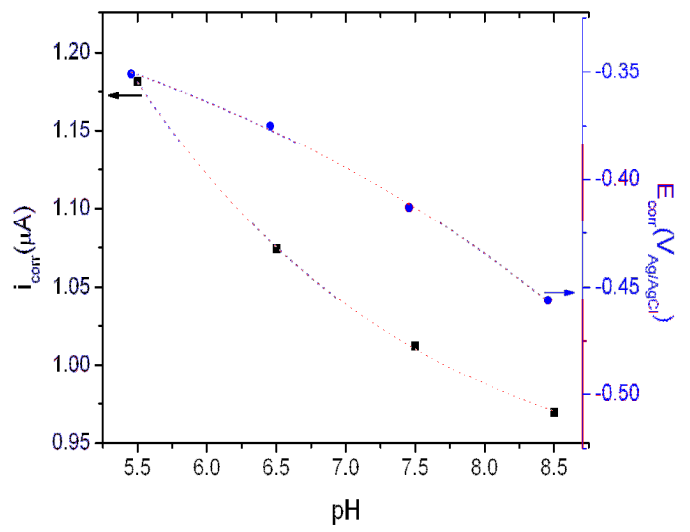

(b)

Figura 4.41. (a) Curvas voltamétrica e (b) variação do potencial e corrente de corrosão

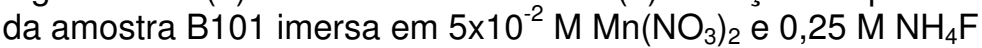

Tabela 4.10. Coeficiente de transferência, potencial e corrente de corrosão da amostra B101 imersa em solução com $\mathrm{Mn}\left(\mathrm{NO}_{3}\right)_{2}$

\begin{tabular}{|c|c|c|c|c|}
\hline $\mathrm{pH}$ & $\beta_{c}(\mathrm{~V} / \mathrm{dec})$ & $\beta_{a}(\mathrm{~V} / \mathrm{dec})$ & $\mathrm{E}_{\mathrm{corr}}\left(\mathrm{V}_{\mathrm{Ag} / \mathrm{AgCl}}\right)$ & $\mathrm{i}_{\text {corr }}(\mathrm{uA})$ \\
\hline 5,5 & 0,728 & 0,281 & $-0,351$ & 1,181 \\
\hline 6,5 & 0,733 & 0,261 & $-0,375$ & 1,074 \\
\hline 7,5 & 0,583 & 0,239 & $-0,413$ & 1,012 \\
\hline 8,5 & 0,467 & 0,213 & $-0,456$ & 0,969 \\
\hline
\end{tabular}

$\mathrm{Na}$ solução aquosa fluorada, o nitrato de manganês dissocia-se na sua forma iônica primária:

$$
\mathrm{Mn}\left(\mathrm{NO}_{3}\right)_{2} \longrightarrow \mathrm{Mn}^{2+}+2 \mathrm{NO}_{3}^{-}
$$


Como anteriormente comentado, devido à polarização externa, ocorre a diminuição da altura da barreira, promovendo uma maior taxa de transferência de portadores de carga, geram as condições termodinâmicas e cinéticas para que ocorram as reações anódicas (4.25) e (4.49) a (4.51), participando, desta forma, nos processos de transferência de carga na interface.

$$
\begin{aligned}
& 2 \mathrm{NH}_{4}^{+}+\mathrm{H}_{2} \mathrm{O} \rightleftarrows \mathrm{N}_{2} \mathrm{O} \uparrow+10 \mathrm{H}^{+}+8 e \quad E^{0}=0.647 V_{\text {SHE }} \\
& \mathrm{NO} \uparrow+2 \mathrm{H}_{2} \mathrm{O} \rightleftarrows \mathrm{NO}_{3}^{-}+4 \mathrm{H}^{+}+3 e \quad E^{0}=0.957 V_{\text {SHE }} \\
& \mathrm{HNO}_{2}+\mathrm{H}_{2} \mathrm{O} \rightleftarrows \mathrm{NO}_{3}^{-}+3 \mathrm{H}^{+}+2 e \quad E^{0}=0.934 V_{\text {SHE }}
\end{aligned}
$$

$\mathrm{O}$ incremento na corrente anódica em $\mathrm{pH} 7,5$, poderia atribuir-se à reação (4.39), que, segundo o diagrama de Pourbaix do nitrogênio (Figura A3) [150], começa a reagir nesse $\mathrm{pH}$, enquanto que a contribuição dos cátions $\mathrm{Mn}^{2+}$ sobre a corrente anódica, pode-se dar mediante a formação de óxidos metálicos de Mn com reações análogas às descritas nas equações (4.45) a (4.47), respectivamente, como apontado pelo diagrama de Pourbaix do manganês (Figura A6 do apêndice) [150].

Por outro lado, o perfil da curva de $i_{\text {corr }}$ em função do pH (Figura 4.41b) mostra, também, um comportamento totalmente diferente àquele observado nas amostras imersas na solução fluorada com $\mathrm{XSO}_{4}$ ( $\mathrm{X}=\mathrm{Na} a_{2}, \mathrm{Ni}, \mathrm{Co}$ ). Neste caso, a corrente $i_{\text {corr }}$ apresenta um valor elevado que vai diminuindo à medida que o $\mathrm{pH}$ da solução aumenta. Ao mesmo tempo, o potencial de corrosão, $E_{\text {corr }}$, começa com um valor elevado, em $\mathrm{pH} 5,5$, e decresce para valores mais negativos à medida que o $\mathrm{pH}$ é incrementado. Esta mudança é mais lenta do que a da corrente $i_{\text {corr }}$. Apesar de $i_{\text {corr }}$ ser maior em pH 5,5, os tubos formados são menos definidos em comparação aos formados em pH 7,5. A aparência 
dissolvida dos tubos em $\mathrm{pH}$ 6,5 atribui-se à atividade do $H F_{2}^{-}$na dissolução do $\mathrm{SiO}_{2}$. Já em pH 7,5, a concentração da espécie $\mathrm{HF}_{2}^{-}$ mínima, enquanto abunda a espécie $F^{-}[69,70]$. Assim, a presença de tubos melhores definidos (Figura 4.37c) pode ser atribuída a alguma dessas espécies ou à espécie $O H^{-}$. Os resultados sugerem que a espécie que participa ativamente na dissolução do silício, continua a ser o $H F_{2}^{-}$, uma vez que a espécie $F^{-}$não participa de forma ativa na dissolução do $\mathrm{SiO}_{2}$ [71,73,81], enquanto que a espécie $\mathrm{OH}^{-}$, em condições de temperatura ambiente, apresenta uma taxa de corrosão desprezível do $\mathrm{SiO}_{2}[64,65]$

Sob o ponto de vista do comportamento eletroquímico, a diferença mais significativa aparece no comportamento do PECA ao longo do tempo. Diferente do comportamento do PECA no eletrólito misturado com sulfatos metálicos, não se observa o deslocamento abrupto em pH 5,5. De acordo com o perfil do PECA, em função do tempo, observa-se que os valores iniciais do PECA são deslocados a potenciais mais negativos em comparação com as outras soluções já discutidas, e este comportamento apresenta-se para todos os níveis de $\mathrm{pH}$ (Figura 4.41), sendo mais elevado no $\mathrm{pH} 8,5$. Como já foi comentada antes, em condições de circuito aberto, uma queda do PECA é ocasionada por um incremento na corrente anódica de troca (equação 4.17) decorrente da transferência de elétrons do substrato para o eletrólito ou, em forma equivalente, injeção de lacunas do eletrólito para a BV do silício [64,83,148], que irá produzir a dissolução do silício nas regiões interporos que estão situadas fora da área de depleção correspondente às paredes dos poros.

Como anteriormente discutido na secção 4.2.1, a dissolução ocorre segundo o mecanismo descrito pelas equações (4.10) e (4.11) seguido da reação (4.13) e/ou (4.14), dependendo em qual seja a espécie ativa dominante [64,65,153], e para tanto é necessário a injeção de lacunas por algum elemento oxidante $[64,65]$. Diferente dos sulfatos, o potencial redox 
da redução da espécie $\mathrm{NH}_{3}^{-}$localiza-se dentro da BV, especialmente das reações catódicas expressas por (4.41) a (4.44), e (4.49) a (4.51) já que seus respectivos potenciais redox localizam-se acima da BV $[150,170]$. Possivelmente, estas reações geram a evolução de gases que envolvem o nitrogênio, durante o processo de formação dos tubos, já que foi possível observar um comportamento efervescente que procedia da superfície das amostras imersas. Assim, considerando as reações parciais (4.11), (4.13), (4.14), (4.43) e (4.50), as reações totais podem ser expressas por:

$$
\begin{aligned}
& 10 \mathrm{Si}+60 \mathrm{HF}+8 \mathrm{NO}_{3}^{-} \longrightarrow 10 \mathrm{SiF}_{6}^{2-}+4 \mathrm{~N}_{2} \uparrow+24 \mathrm{H}_{2} \mathrm{O}+12 \mathrm{H}^{+}+10(4-m) h^{+}+10(4-m) e \\
& 10 \mathrm{Si}+30 \mathrm{HF}_{2}^{-}+8 \mathrm{NO}_{3}^{-}+8 \mathrm{H}^{+} \longrightarrow 10 \mathrm{SiF}_{6}^{2-}+4 \mathrm{~N}_{2} \uparrow+10 \mathrm{OH}^{-}+14 \mathrm{H}_{2} \mathrm{O}+10(4-m) h^{+}+10(4-m) e \\
& 3 \mathrm{Si}+18 \mathrm{HF}+4 \mathrm{NO}_{3}^{-} \longrightarrow 3 \mathrm{SiF}_{6}^{2-}+4 \mathrm{NO} \uparrow+8 \mathrm{H}_{2} \mathrm{O}+2 \mathrm{H}^{+}+3(4-m) h^{+}+3(4-m) e( \\
& 3 \mathrm{Si}+9 \mathrm{HF}_{2}^{-}+4 \mathrm{NO}_{3}^{-}+4 \mathrm{H}^{+} \longrightarrow 3 \mathrm{SiF}_{6}^{2-}+4 \mathrm{NO}+3 \mathrm{OH}^{-}+5 \mathrm{H}_{2} \mathrm{O}+3(4-m) h^{+}+3(4-m) e
\end{aligned}
$$

De onde se vê que as reações decorrentes da espécie $H F$ liberam hidrogênio, enquanto aquelas que envolvem a espécie $H_{2}^{-}$consomem hidrogênio. Isto significa que o pH da solução muda localmente, tornandose mais ácida se a dissolução ocorre via $H F$, enquanto que se esta acontece mediante a espécie $\mathrm{HF}_{2}^{-}, \mathrm{O} \mathrm{pH}$ na interface torna-se menos ácido. Assim, uma vez que em $\mathrm{pH} 6,5$, a concentração de $H F_{2}^{-}$na interface é maior $[69,71,81]$, sugere-se que a dissolução torna-se mais anisotrópica ao longo do tempo, enquanto que, em pH 5,5, a dissolução torna-se menos anisotrópica ao longo do tempo de imersão.

Na Figura 4.42 observa-se que o PECA, em pH 5,5 e 6,5, após atingir seu valor mínimo tende a incrementar levemente. Este comportamento sugere que o processo de corrosão apresenta períodos de formação e dissolução do $\mathrm{SiO}_{2}$, cuja freqüência depende do $\mathrm{pH}$ e, de acordo com a Figura 4.41, 
este período é maior na medida em que o $\mathrm{pH}$ incrementa-se. Considerando que, em pH 5,5, para a solução contendo íons de $\mathrm{Mn}$, temos formação de estruturas de tubos de silício, então podemos assumir que o processo de corrosão é anisotrópico e, este processo, conduz a comportamento do PECA seguindo uma curva suave. Já no caso dos processos onde a corrosão foi mais violenta (utilizando sal de $\mathrm{Ni}$, por exemplo), a curva do PECA mostrou oscilações rápidas de característica randômica (Figura 4.30) e, conseqüentemente, descrevem um processo predominantemente isotrópico.

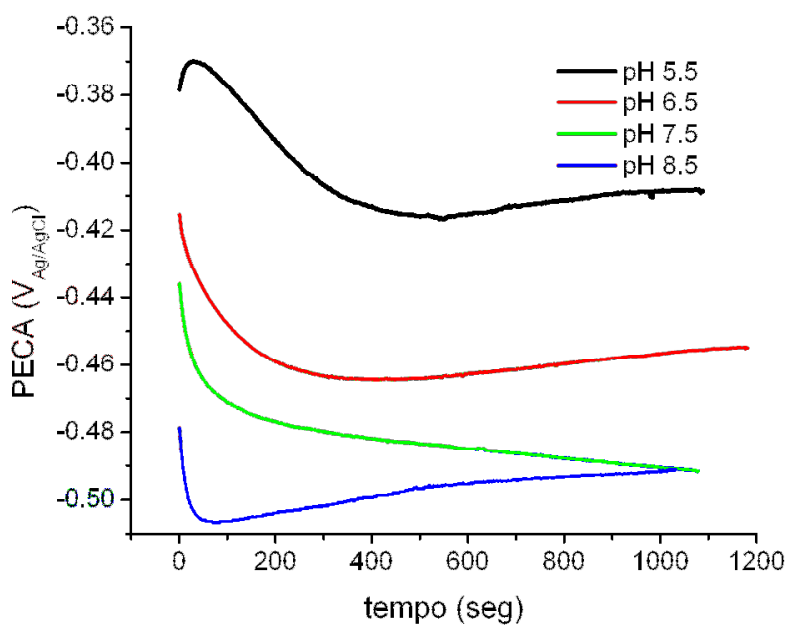

Figura 4.42. Perfil da variação do potencial de eletrodo em circuito aberto sobre a amostra B102.

Por outro lado, os resultados do EDS (Figura 4.40a e Tabela 4.9) e análise voltamétrica (Figura 4.41b e Tabela 4.10), sugerem que o processo de dissolução, em pH 7,5, acontece mais lentamente, pois nesta região de $\mathrm{pH}$, as espécies $H F$ e $H_{2}^{-}$apresentam uma baixa concentração (Figura 4.17) [64,65,73], predominando a espécie $F^{-}$que não esta envolvida ativamente na dissolução do $\mathrm{SiO}_{2}[99,112,120,175]$. Este resultado é bem correlacionado com o baixo valor da corrente de corrosão (Figura 4.41b) neste nível de $\mathrm{pH}$. Assim, isto explicaria o porquê os MTS formados em pH 7,5 mostram-se melhores definidos em relação àqueles obtidos em outros valores de $\mathrm{pH}$, sendo mais notório isto se 
comparado com aqueles MTS obtidos em pH 6,5, onde a atividade da espécie $H F_{2}^{-}$é maior $[69,70]$.

No caso do $\mathrm{pH}$ 8,5 o perfil do PECA sugere que inicialmente acontece um processo de corrosão com elevada taxa, em relação aos casos anteriores, principalmente devido à corrosão química. Após este comportamento inicial, a curva começa a crescer com uma inclinação maior que as outras de tal forma a atingir o estado estacionário a uma velocidade maior do que no caso do $\mathrm{pH}$ 5,5 e 6,5. Este comportamento sugere que a superfície é passivada, devido a qual se inibem possíveis processos de corrosão. Esta camada passivadora pode estar constituída de $\mathrm{Mn}(\mathrm{OH})_{2} \mathrm{e}$ $\mathrm{SiO}_{2}$, já que o espectro EDS aponta a presença significativa de $\mathrm{Mn}, \mathrm{O}$ e $\mathrm{Si}$, respectivamente (Figuras $4.37 \mathrm{~h}$ e $4.40 \mathrm{a}$ ).

O diagrama de bandas, na Figura 4.43, mostra qualitativamente que a redução dos cátions $\mathrm{Mn}^{2+}$ na forma metálica acontece apenas mediante o consumo de elétrons de $\mathrm{BC}$, isto é, o $\mathrm{Mn}$ poderia depositar-se no substrato via deslocamento galvânico, já que nesse processo os elétrons de BC são consumidos pelos cátions [105,167,169]. Uma vez que o potencial redox da espécie $\mathrm{NO}_{3}^{-}$localiza-se na $\mathrm{BV}$ do $\mathrm{Si}$, sua redução nas suas diferentes formas injeta lacunas na BV [64,65,86,124,147]. Porém, para manter o equilíbrio de cargas, é necessário que elétrons da BV sejam ejetados à $B C[64-66,153]$, isto é, estarão disponíveis para a redução $\mathrm{Mn}^{2+} / \mathrm{Mn}$. O mecanismo de redução do $\mathrm{Mn}^{2+}$, acima citado, sugere a possibilidade de preencher os MTSs com Mn através da modulação do PECA, que é responsável pela curvatura dos níveis de energia do Si na superfície da interface. No presente trabalho foi possível obter este tipo de estruturas a partir de um substrato MPS (amostra B106) que foi formado sem necessidade de metalizar com Al a fase polida do Si. As estruturas de MTSs preenchidas com Mn podem ser observadas na Figura 4.44. As estruturas assumem formas de barras, algumas das quais estão parcialmente preenchidas. Esses resultados mostram que é 
possível formar tanto MTS, quanto barras de Mn apenas modulando o potencial de eletrodo.

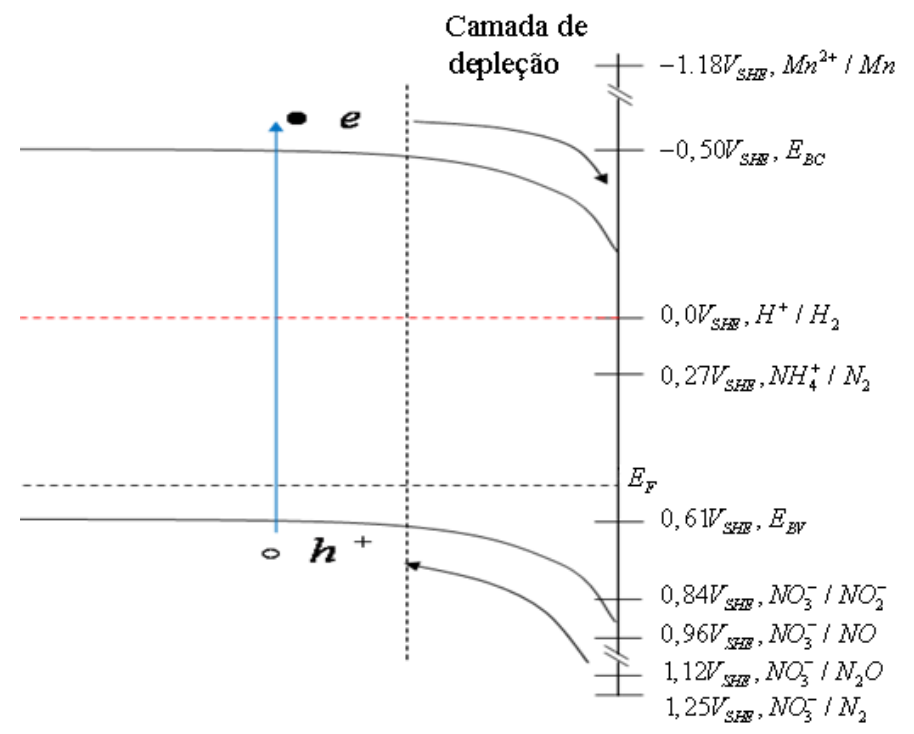

Figura 4.43. Diagrama esquemático da localização qualitativa dos potencias redox das reações do $\mathrm{NO}_{3}^{-}$em relação às bandas do Si tipo p. Adaptado de [115]

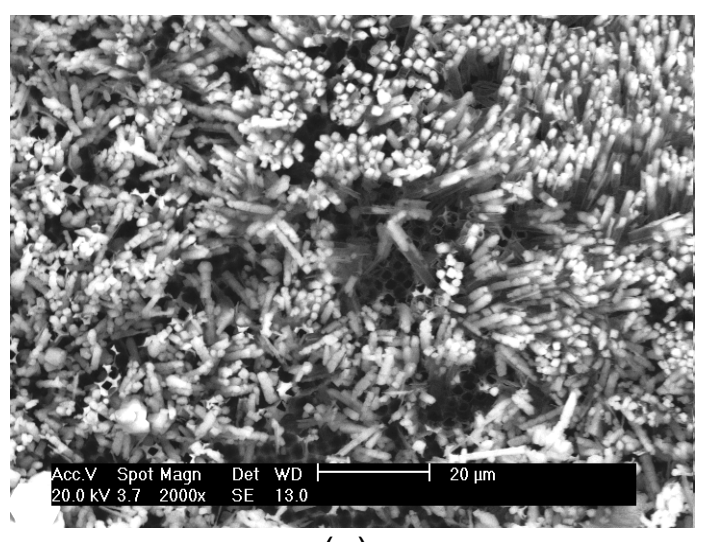

(a)

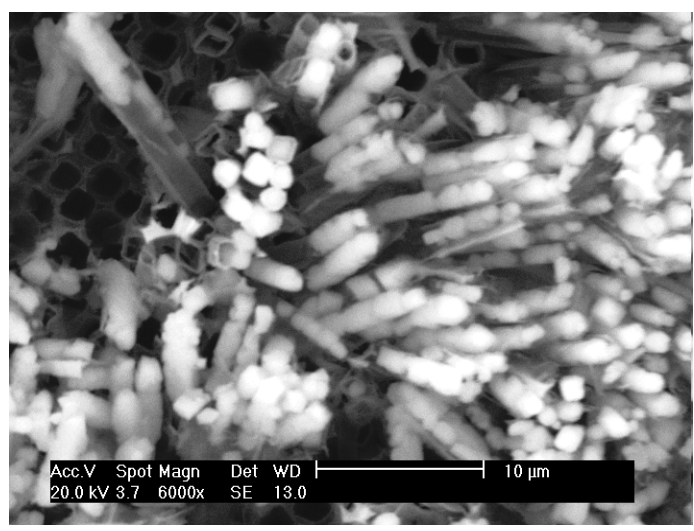

(b)

Figura 4.44 Formação das barras de manganês dentro dos MTS da amostra imersa em $\mathrm{pH} 6,5$

\subsubsection{Microtubos formados em 0,25 $\mathrm{M} \mathrm{NH}_{4} \mathrm{~F}$.}

Como já foi visto, a importância dos oxidantes é injetar lacunas para catalisar a dissolução do silício. Adicionalmente, também se observou que os cátions de metais de transição participam na dissolução do substrato catalisando o crescimento e dissolução do óxido de silício [176,177]. Por 
outro lado, em meio alcalino fluorado a dissolução do substrato acontece via eletroquímica e química, devido à participação ativa das espécies fluoradas, e às espécies $\mathrm{OH}^{-}$e $\mathrm{H}_{2} \mathrm{O}$ [75-78], respectivamente. Sabe-se que a taxa de corrosão do Si é aumentada adicionando-se agentes oxidantes nas soluções ácidas fluoradas, quer estes sejam metálicos ou não, como descrito na seção 2.7 .2 [17,64,85,124,16,177]. No entanto, poucos trabalhos reportam sobre a dissolução do Si em solução fluorada alcalina misturada com agentes oxidantes [178]. Assim, para saber qual é a função dos oxidantes sobre a formação dos MTS mergulhou-se amostras B36 em 0,25 M NH $4 \mathrm{~F}_{4}$ com diferentes valores de $\mathrm{pH}$ durante seis dias (144 horas). É importante mencionar que a amostra foi metalizada na face polida e recozida durante meia hora a $500{ }^{\circ} \mathrm{C}$ em ambiente de nitrogênio e só após este processo foi formada a camada de MPS utilizada posteriormente na formação dos MTSs.

Estruturalmente, o resultado observado em pH 4,5 (Figura 4.45a), não difere daqueles já discutidos e analisados anteriormente, para o mesmo valor de $\mathrm{pH}$, nas soluções contendo eletrólitos com presença de cátions. Este resultado deve-se à formação de ligações $\mathrm{Si}-\mathrm{H}$ na superfície do $\mathrm{Si}$ que a passivam contra qualquer processo de corrosão (Seção 4.2.2). No entanto, em pH 5,5, embora existam áreas sobre a qual a corrosão não permitiu a formação dos MTS (Figura 4.46a), também existem outras, onde houve a formação dessas estruturas (Figura 4.45b), mesmo que com comprimento menor. A espessura média da parede dos tubos melhores definidos é entorno de $471 \mathrm{~nm}$, que corresponde, aproximadamente, à largura da camada de depleção do $\mathrm{Si}$ com concentração $N_{a}=3.85 \times 10^{15} \mathrm{~cm}^{-3}$ que é da mesma ordem de grandeza do substrato de $\mathrm{Si}$ utilizado na formação das camadas macroporosas. Isto mostra, mais uma vez, que a redução das paredes dos MTS está associada ao incremento na taxa de corrosão, decorrente da injeção de lacunas pelos oxidantes no eletrólito, que é unicamente controlada pela camada de depleção e o nível de pH. Este incremento ocorre tanto 
perpendicularmente, quanto paralelamente ao plano (100), como mostrado na Figura 4.24c na secção 4.2.2 e

a)

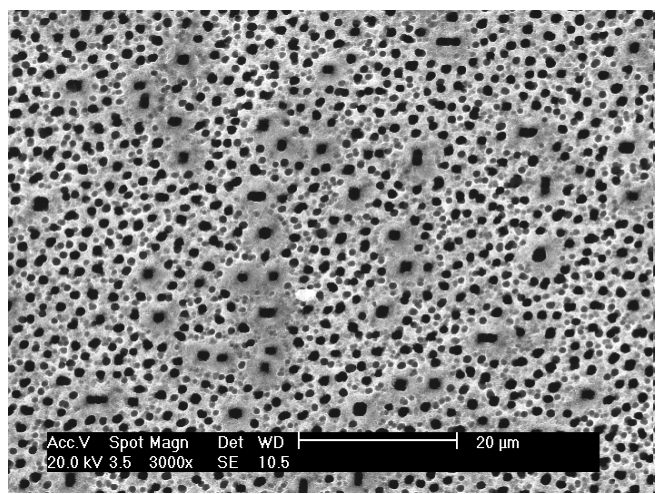

(b)

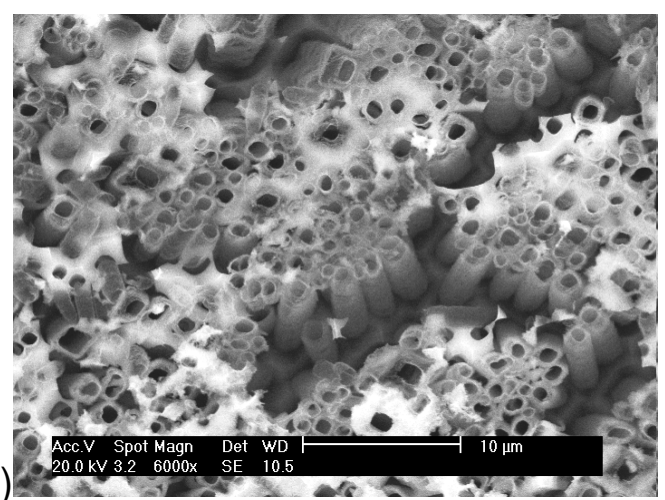

(c)

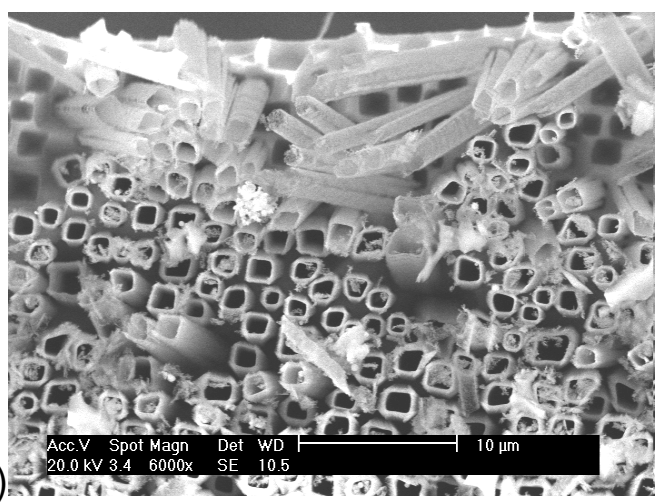

(d)

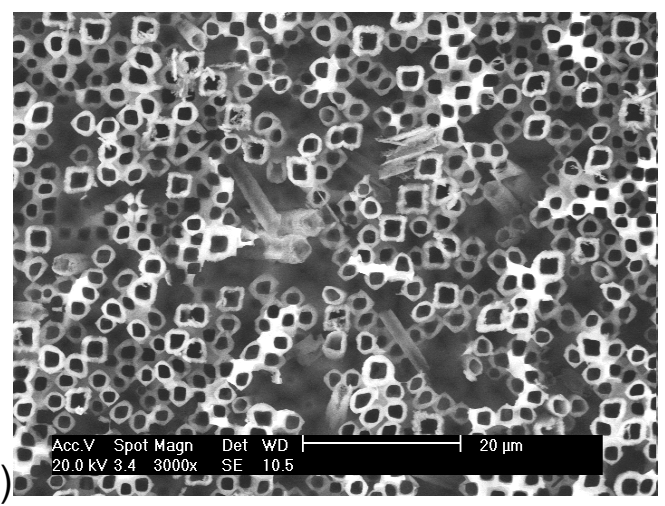

(e)

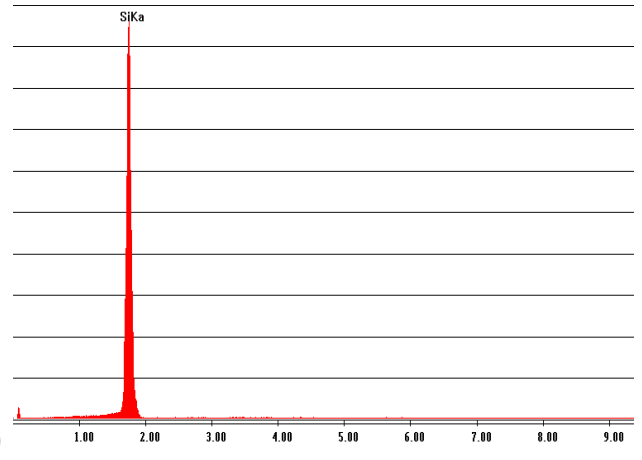

(f)

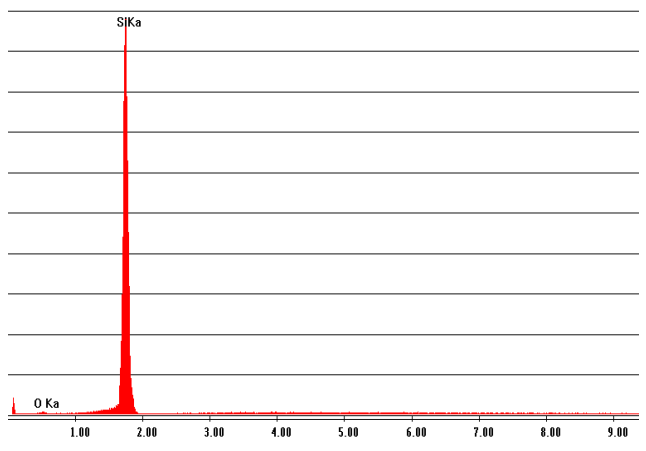

(g)

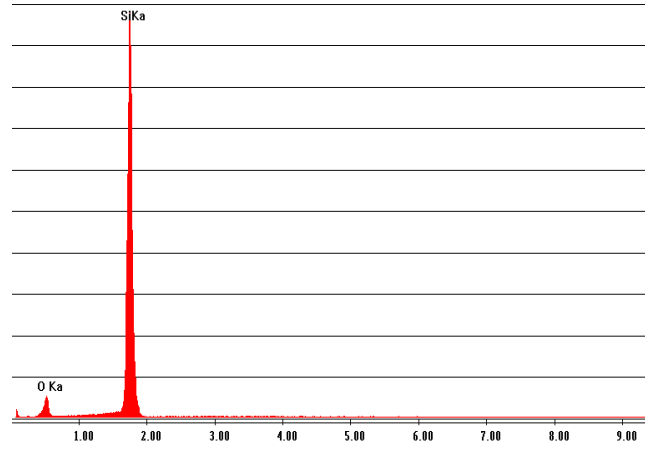

(h)

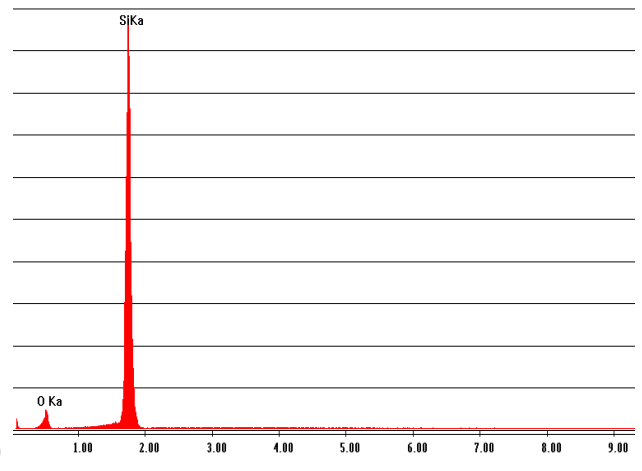

Figura 4.45. Imagens MEV e espectro EDS da amostra B36 imersa em 0,25 M NH $\mathrm{H}_{4} \mathrm{~F}$ com pH $4,5(\mathrm{a}, \mathrm{e}) ; 5,5(\mathrm{~b}, \mathrm{f}) ; 6,5(\mathrm{c}, \mathrm{g})$ e $7,5(\mathrm{~d}, \mathrm{~h})$ 
Em $\mathrm{pH}$ 6,5, tubos melhores definidos são formados, especialmente nas regiões próximas às bordas do substrato (Figura 4.45c) onde a interação SMP/eletrólito é maior, enquanto nas regiões mais próximas do meio da amostra a formação é mais lenta e, portanto, nesta região os tubos encontram-se em processo de formação (Figura 4.46b). Isto pode ocorrer devido a que nas regiões próximas do centro, a corrosão começa pela parte superior dos poros, enquanto que nas bordas o processo de corrosão pode simultaneamente começar pela parte superior e pelos lados, o que promoverá uma rápida formação dos MTS nessas regiões. A espessura média das paredes dos tubos melhores definidos, formadas na região de $\mathrm{pH}$ 6,5, é igual a $472 \mathrm{~nm}$ e corresponderiam a uma concentração de dopantes $N_{a}=3.85 \times 10^{15} \mathrm{~cm}^{-3}$.

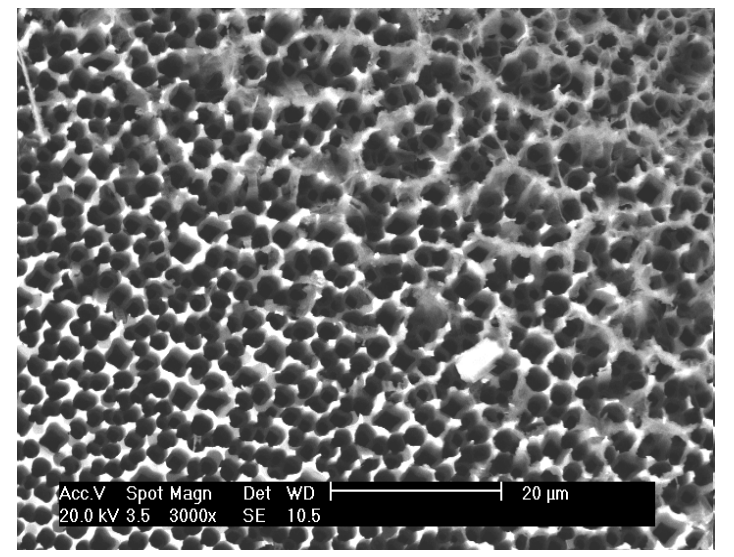

(a)

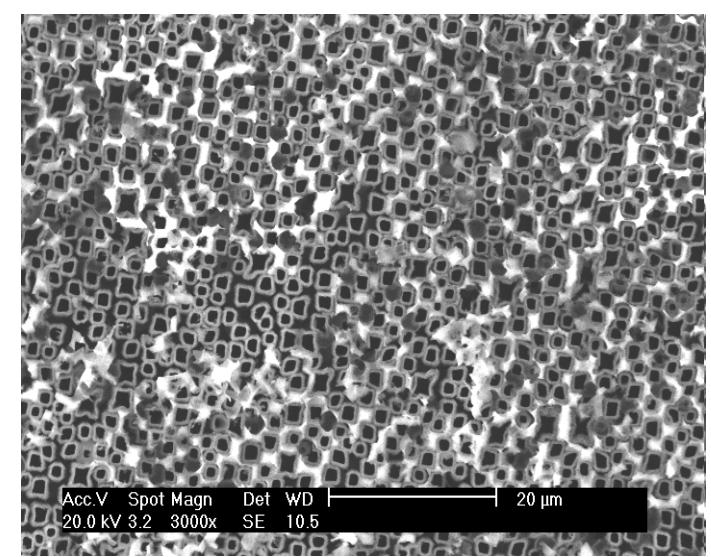

(b)

Figura 4.46. (a) região dissolvida correspondente à amostra B36 em pH 5,5; (b) região central, onde a formação dos MTS é mais lenta em pH 6,5

Em pH 7,5 a estrutura final (Figura 4.44d) mostra os MTSs com um aspecto de formação incompleta, porém bem definidos na parte superior. Isto sugere que a taxa de corrosão é baixa neste nível de $\mathrm{pH}$, e que pode ser atribuído à maior predominância da espécie $F^{-}$que não participa ativamente na dissolução do $\mathrm{SiO}_{2}$ [69,71,81]. Assim, a corrosão acontece, unicamente, devido às espécies $\mathrm{OH}^{-}, \mathrm{H}_{2} \mathrm{O}[75,78]$ e $\mathrm{HF}_{2}^{-}$, respectivamente, apesar da concentração desta última espécie ser muito baixa [64,65,73]. Como conseqüência, a corrosão é totalmente anisotrópica, e podem ser observadas na Figura 4.44d. Adicionalmente, 
as estruturas de MTSs desta amostra são diferentes das amostras que foram imersas em pH 5,5 e 6,5, respectivamente. Nestas amostras, os MTS são predominantemente retangulares com dimensões maiores que $2.1 \mu \mathrm{m}$ e, cujas paredes apresentam espessuras médias de $830 \mathrm{~nm}$ aproximadamente.

A análise química, através dos espectros EDS, revela uma maior presença de oxigênio nas estruturas obtidas em soluções de pH 6,5 e 7,5, respectivamente (Figura 4.47 e Tabela 4.11). Uma vez que a solução eletrolítica é isenta de agentes oxidantes, a não ser $0 \mathrm{OH}^{-}$e uma baixa concentração de $\mathrm{SO}_{4}^{2-}$, devido ao $\mathrm{H}_{2} \mathrm{SO}_{4}$ usado para deslocar o $\mathrm{pH}$ a regiões ácidas, então o oxigênio detectado atribui-se à formação de $\mathrm{SiO}_{2}$ e $\mathrm{Si}-\mathrm{OH}$ sobre toda a camada macroporosa, decorrente da elevada reatividade do $\mathrm{Si}$ e elevada concentração dessas espécies no eletrólito [75,78]. A baixa quantidade de oxigênio em pH 5,5 atribui-se à baixa concentração das ligações $\mathrm{Si}-\mathrm{OH}$ e à maior dissolução do $\mathrm{SiO}_{2}$ por conta do $H F$.

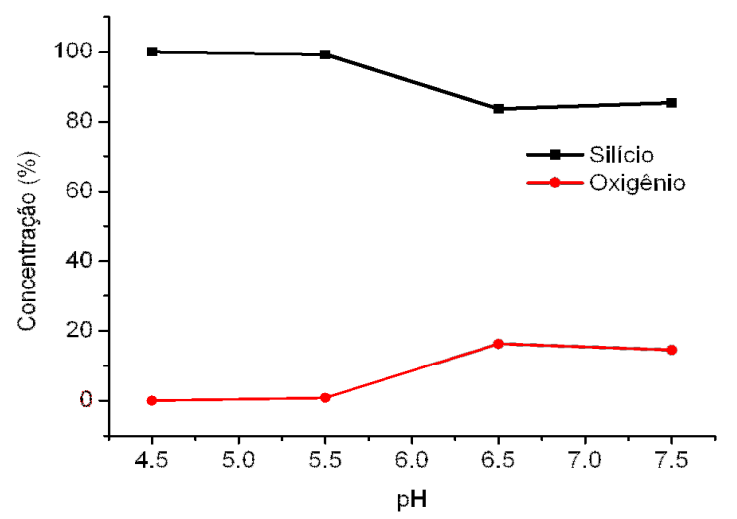

Figura 4.47. Concentração de elementos químicos detectados na superfície da amostra B36

O comportamento eletroquímico da interação entre o substrato e o eletrólito, neste caso, mostra-se não ser diferente daquele observado nas amostras imersas em eletrólito com sais metálicos. As curvas voltamétricas (Figura 4.48a) mostram que, tanto as correntes anódicas, 
quanto as correntes catódicas estão na mesma ordem de magnitude dos observados nos casos anteriores. No entanto, a corrente de corrosão apresenta-se menor do que nos casos anteriores (Figura 4.48b), sugerindo menor taxa de corrosão neste processo, se comparado com as amostras imersas em eletrólito com oxidantes. Apesar de nesta solução não ter sido adicionado nenhum tipo de oxidante, a camada macroporosa dissolve-se mediante um processo predominantemente anisotrópico, não sendo descartada a contribuição da componente isotrópica, já que os processos de reação química na superfície apontam a uma oxidação por ação direta das espécies $\mathrm{OH}^{-}$e $\mathrm{H}_{2} \mathrm{O}$ [75,-78,92,93].

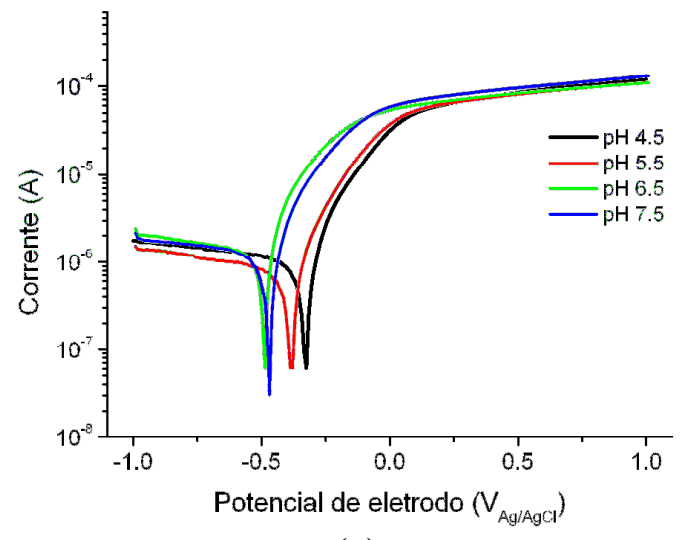

(a)

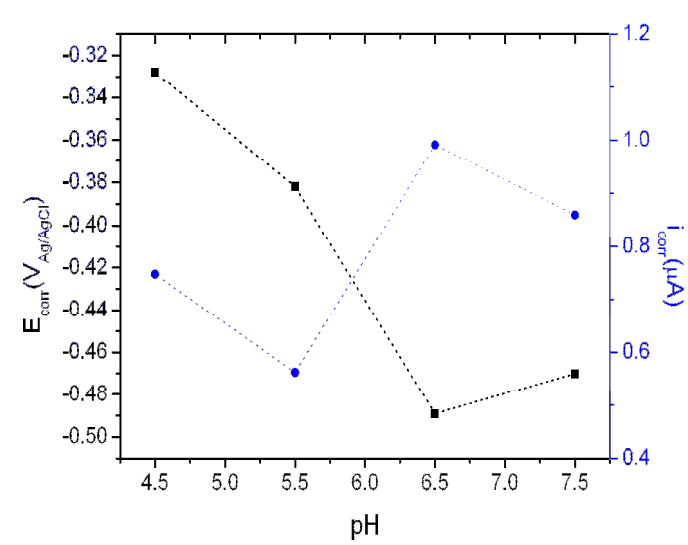

(b)

Figura 4.48. (a)Curvas voltamétricas da amostra B36, e (b) corrente de corrosão e potencial de corrosão em função do $\mathrm{pH}$.

Tabela 4.11- Parâmetros eletroquímicos e composição química extraídos da amostra B36 imersa em solução sem oxidantes.

\begin{tabular}{|c|c|c|c|c|c|}
\hline $\mathrm{pH}$ & $\beta_{c}(\mathrm{~V} / \mathrm{dec})$ & $\beta_{a}(\mathrm{~V} / \mathrm{dec}$ & $E_{\text {corr }}\left(V_{\mathrm{Ag} / \mathrm{AgCl}}\right)$ & $\mathrm{i}_{\text {corr }}(\mathrm{uA})$ & $\mathrm{Si}(\%) \mathrm{O}(\%)$ \\
\hline 4,5 & 0,888 & 0,142 & $-0,328$ & 0,748 & $100,000,00$ \\
\hline 5,5 & 0,820 & 0,148 & $-0,382$ & 0,562 & $\begin{array}{ll}99,19 & 0,81\end{array}$ \\
\hline 6,5 & 0,870 & 0,131 & $-0,489$ & 0,991 & $\begin{array}{llll}83,71 & 16,29\end{array}$ \\
\hline 7,5 & 0,796 & 0,138 & $-0,470$ & 0,860 & $85,44 \quad 14,56$ \\
\hline
\end{tabular}

Os perfis das curvas dos PECAs mostrados na Figura 4.49, revelam que, em $\mathrm{pH} 4,5$, o sistema atinge rapidamente o equilíbrio, após um processo de corrosão inicial, decorrente da passivação da superfície do substrato pelas ligações Si-H. Em pH 5,5, observa-se um deslocamento vagaroso 
com perfil suave, diferente às curvas PECAs daqueles observados nas amostras imersas no eletrólito fluorado com $\mathrm{XSO}_{4}\left(\mathrm{X}=\mathrm{Na}_{2}, \mathrm{Ni}, \mathrm{Co}\right)$, onde o deslocamento inicial é abrupto e atribui-se a efeitos da corrosão isotrópica predominante, devido ao efeito dos oxidantes $[64,65,83,147]$. Já em pH 6,5, a curva PECA apresenta um valor inicial de elevado valor negativo $\left(-0,42 \quad \mathrm{~V}_{\mathrm{Ag} / \mathrm{AgCl}}\right)$ mantendo-se estável ao longo do tempo. No entanto, este comportamento resulta ser diferente em $\mathrm{pH} 7,5$ onde observa-se um deslocamento a valores menos negativos, mas após atingir seu máximo observa-se um decréscimo para valores mais negativos de forma contínua. É importante salientar que a formação dos MTS em pH 5,5 acontece apenas naquelas soluções cujo PECA muda lentamente ao longo do tempo, fato que acontece nas soluções isentas de $\mathrm{XSO}_{4}\left(\mathrm{X}=\mathrm{Na} \mathrm{a}_{2}, \mathrm{Ni}, \mathrm{Co}\right)$. Isto sugere que adicionar agentes oxidantes na solução eletrolítica não necessariamente conduz a um incremento na isotropia da corrosão, como tem reportado a literatura $[66,67]$, já que isto não acontece quando se substitui $\mathrm{O}^{\mathrm{XSO}_{4}} \quad\left(\mathrm{X}=\mathrm{Na}_{2}, \mathrm{Ni}, \mathrm{Co}\right)$, por $\mathrm{Mn}\left(\mathrm{NO}_{3}\right)_{2}$.

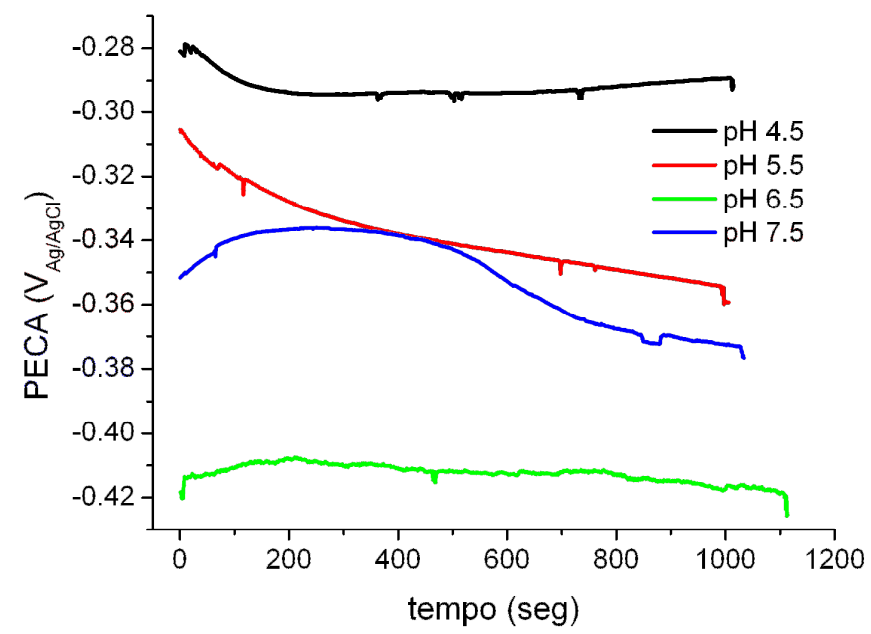

Figura 4.49. Monitoramento do PECA da amostra B36 ao longo do tempo. 


\subsubsection{Análise comparativa do comportamento eletroquímico da formação dos microtubos de silício.}

Apesar dos MTS obtidos em solução com $\mathrm{XSO}_{4} \quad\left(\mathrm{X}=\mathrm{Na}_{2}, \mathrm{Ni}, \mathrm{Co}\right)$, apresentarem semelhanças, o comportamento eletroquímico observado na análise das curvas voltamétricas mostra que a corrente catódica apresenta diferenças significativas entre elas (Figura 4.50a), especialmente na solução com $\mathrm{NiSO}_{4}$, que mostra um aumento da corrente catódica quando o potencial de polarização na região catódica é incrementado, diferente daquelas observadas nas outras amostras. Um comportamento desta natureza é indicativo de processo de redução [85,115,148], que de acordo com os resultados obtidos (Figura 4.26c), poderiam atribuir-se aos processos de deslocamento galvânico. $O$ baixo valor da corrente de corrosão (Figura 4.50b) sugere que as correntes de troca anódica e catódica são quase da mesma ordem de magnitude, uma vez que no deslocamento galvânico consome-se a mesma quantidade de elétrons perdidos pelo substrato.

Adicionalmente, de acordo com a Figura 4.51a, a amostra, obtida na solução contendo $\mathrm{NiSO}_{4}$, apresenta uma baixa concentração de oxigênio para todos os pHs, mesmo se comparado com o observado na amostra sem oxidantes, especialmente em pH 6,5 e 7,5, respectivamente. Esse resultado mostra-se contraditório àquele esperado por ação dos oxidantes, especialmente considerando que tanto o $\mathrm{Ni}$ quanto o Co são excelentes catalisadores para a formação de $\mathrm{SiO}_{2}$ [179]. No caso da amostra obtida em solução contendo $\mathrm{CoSO}_{4}$, a concentração de oxigênio apresenta valores maiores do que os observados na amostra obtida em solução com $\mathrm{NiSO}_{4}$, resultado não esperado desde que, tanto o níquel, quanto 0 cobalto apresentam propriedades catalíticas semelhantes $[168,179]$. 


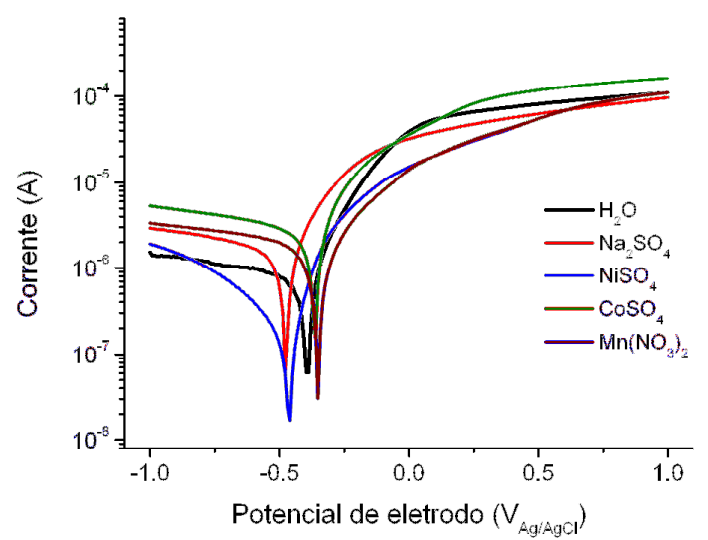

(a)

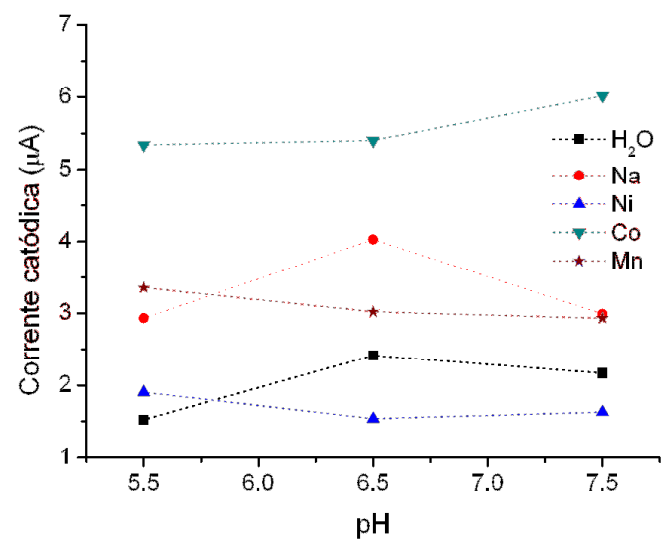

(c)

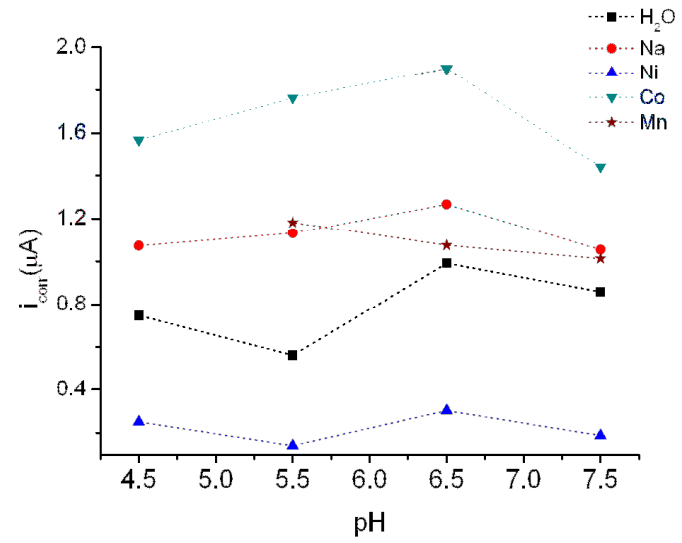

(b)

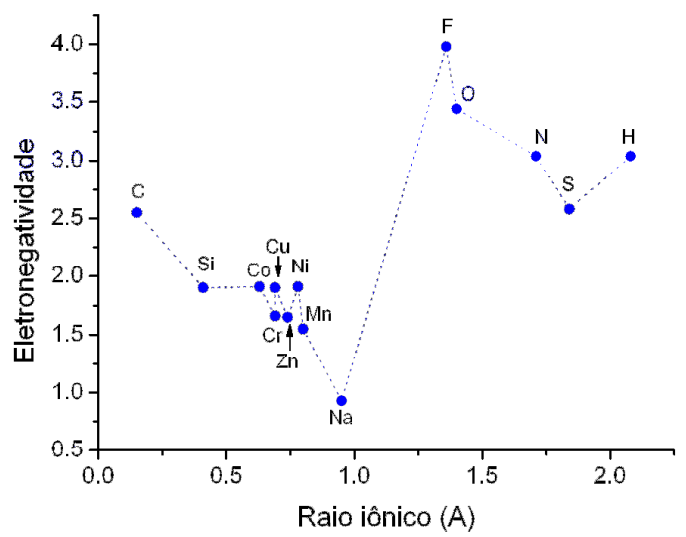

(d)

Figura 4.50. (a) comparação das curvas voltamétricas em $\mathrm{pH} 6,5$, (b) corrente de corrosão, e (c) corrente catódica em diferentes pHs; e (d) eletronegatividade versus raio iônico dos elementos presentes nas soluções.

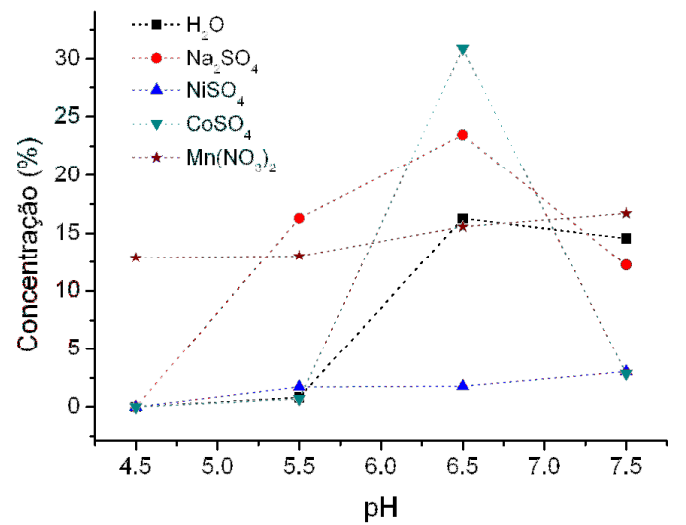

(a)

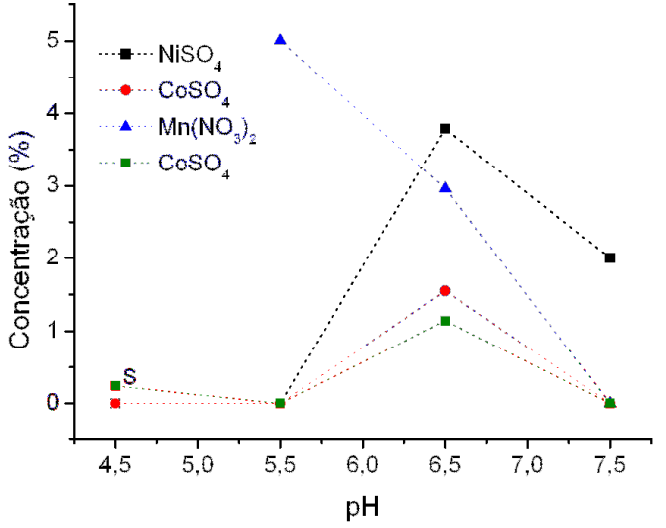

(b)

Figura 4.51. Concentração de (a) oxigênio, e (b) carbono na superfície das amostras imersas em soluções com diferentes oxidantes. A linha verde em (b) representa a concentração de enxofre na solução com $\mathrm{CoSO}_{4}$. 
A importância dos agentes oxidantes adicionados no eletrólito observa-se na Figura $4.50 \mathrm{~b}$, onde se mostra que a corrente de corrosão varia na presença dos diferentes tipos de oxidantes, e a concentração de oxigênio, detectado via EDS, apresentou uma correlação com a intensidade da corrente de corrosão (Figura 4.50a). Usando como referência o perfil do $i_{\text {corr }}$ obtida na solução isenta de oxidantes observa-se que em todos os casos onde foram adicionados agentes oxidantes houve um incremento no $i_{\text {corr }}$, exceto na solução contendo $\mathrm{NiSO}_{4}$ que apresenta valores menores de $\mathrm{i}_{\text {corr. }}$ R. Douani et al. [85] sugere que a dissolução do $\mathrm{Si}$ imerso em meio fluorado com oxidantes é catalisado pelos cátions metálicos com eletronegatividade e potencial redox maior do que a do $\mathrm{Si}$ devido aos agentes oxidantes preferirem capturar elétrons das partículas metálicas depositadas sobre o Si que agem como sítios catódicos locais [85,115,180]. De acordo com a literatura [82,115], cátions com eletronegatividade maior à $\mathrm{Si}$ podem agir como ótimos catalisadores para a dissolução do silício [82,115]. Uma vez que a elétronegatividade do $\mathrm{Ni}(1,91)$ é levemente maior ao do $\mathrm{Si}(1,90)$ e menor à da $\mathrm{Ag}(1,93)$ [181], está será menos catalítica na dissolução do silício em relação à Ag sobre o Si, por exemplo, o que resultará em um deslocamento galvânico com menor taxa de corrosão. Porém, este deveria ser maior, se comparado com o aquele esperado para o cobalto, devido à eletronegatividade do Co $(1,88)$ ser menor do que o Si[181]. Logo, este último não poderia ser melhor catalisador do que o níquel na corrosão do $\mathrm{Si}$, isto é, a corrente de corrosão das amostras imersas na solução com $\mathrm{CoSO}_{4}$ deveria ser menor ou da mesma ordem daquela observada no caso do Ni. No entanto, os resultados mostrados na Figura 4.50b, mostram maior corrente de corrosão quando as amostras são imersas na solução com $\mathrm{CoSO}_{4}$, sendo este resultado inesperado. Analogamente, a concentração de oxigênio em função do pH (Figura 4.51a), sendo este resultado bem correlacionado com a corrente de corrosão e atribuído à ação catalítica dos oxidantes, e sugere que na presença de $\mathrm{CoSO}_{4}$ a atividade catalítica da solução 
incrementa-se, possivelmente devido à contribuição da redução de outro elementos, tais como o $\mathrm{C}$ e $\mathrm{S}$, detectados pelo EDS em concentrações proporcionais ao oxigênio (Figura 4.51b). Assim, em adição á espécie $\mathrm{SO}_{4}^{2-}$ e $\mathrm{Co}^{2+}$, tanto $\circ \mathrm{S}$, quanto $\circ \mathrm{C}$, poderiam estar participando ativamente na catalise da dissolução do $\mathrm{Si}$, em razão de ter eletronegatividade maior a do silício como mostrado na Figura 4.50d (2,58 e 2,55, respectivamente), [181]. A presença do C sobre as amostras é detectada pelo EDS e poderia ter como origem as impurezas intrínsecas nos sais metálicos, uma vez que de acordo com as indicações do fabricante, o nível de impurezas é de aproximadamente $2 \%$ encontrandose entre elas o $\mathrm{C}, \mathrm{Zn}, \mathrm{Fe}, \mathrm{Cu}$, entre outros.

Assim, os metais de maior eletronegatividade atraem elétrons do silício e podem originar estados reduzidos solúveis ou insolúveis [85,115]. Nesse sentido, o óxido de silício, formado em torno das partículas metálicas, pode ser removida pela solução de HF $[85,125]$. No processo de deslocamento galvânico o mecanismo é semelhante, já que a deposição das partículas metálicas ocorre mediante a redução dos íons metálicos, que atuam como agentes oxidantes e oxidam o silício embaixo da camada metálica formada. Este processo continua enquanto que os elétrons consigam ser transferidos através da camada metálica [115].

No caso das amostras imersas em solução com $\mathrm{Na}_{2} \mathrm{SO}_{4}$, a análise química apenas revela a presença do oxigênio e silício na amostra para todos os valores de $\mathrm{pH}$. Isto sugere que a catálise da corrosão do silício está ligada à atividade iônica das espécies $\mathrm{SO}_{4}^{2-}$ e $\mathrm{Na}^{+}$, não precisando para tanto ser absorvido pela superfície do substrato, como tem sido sugerido por A. Belaidi et al. [111,182]. Estes autores têm reportado que a dissolução anódica do $\mathrm{Si}$, em meio aquoso fluorado, é sensível ao raio iônico dos cátions alcalino presentes na solução. 
Já no caso da solução com $M n\left(N O_{3}\right)_{2}, 0 \quad i_{\text {corr }}$ atribui-se plenamente à atividade do $\mathrm{NO}_{3}^{-}$e $\mathrm{C}$, devido a sua forte natureza oxidante $[64,124]$ e elevada eletronegatividade (2,55), respectivamente [181], apesar que a corrente aparece menor, possivelmente, devido aos efeitos da baixa eletronegatividade do manganês $(1,55)$ em relação ao do silício.

De acordo com a equação (4.34), a variação da corrente catódica originase na variação da concentração de oxidantes $\left(c_{o x}\right)$, e/ou da concentração de elétrons na interface SMP/eletrólito $\left(n_{s}\right)$ ou na energia de ativação do processo $\left(E_{a}\right)[64,149,183]$. Os resultados mostrados nos levam a concluir que, na formação dos MTS, o incremento da corrente catódica relaciona-se com o incremento da concentração de elétrons e redução da energia de ativação, decorrente da injeção de elétrons e o deslocamento do potencial de eletrodo.

Por outro lado, as curvas do comportamento do PECA (Figura 4.52), em $\mathrm{pH} 5,5$, para os diferentes oxidantes, mostra-nos que formação de tubos acontece quando o PECA diminui lentamente ao longo do tempo como acontece nas soluções com $\mathrm{Mn}\left(\mathrm{NO}_{3}\right)_{2}$ e sem oxidante, respectivamente. No caso de pH 7,5, como já foi comentado, a não formação dos MTS nas soluções com cátions $\mathrm{Co}^{2+}$ e $\mathrm{Ni}^{2+}$ é devida a efeitos de passivação por formação de óxidos metálicos. Contudo, de acordo com o perfil do PECA, as amostras imersas no eletrólito com $\mathrm{NiSO}_{4}$ sofrem uma corrosão inicial para logo serem passivadas, enquanto que as amostras imersas em eletrólito com $\mathrm{CoSO}_{4}$ passivam-se quase imediatamente. Adicionalmente, na ausência de cátions metálicos, a amostra sofre uma oxidação inicial para logo ser corroída. Já nos outros casos, todas são corroídas inicialmente e logo são passivadas, isto é, em todos os casos ocorre simultaneamente a redução eletroquímica do metal e a formação do hidróxido metálico. 


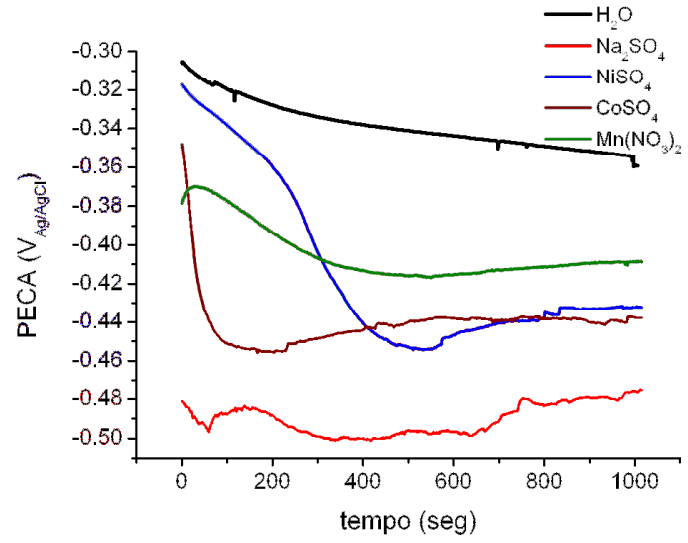

(a)

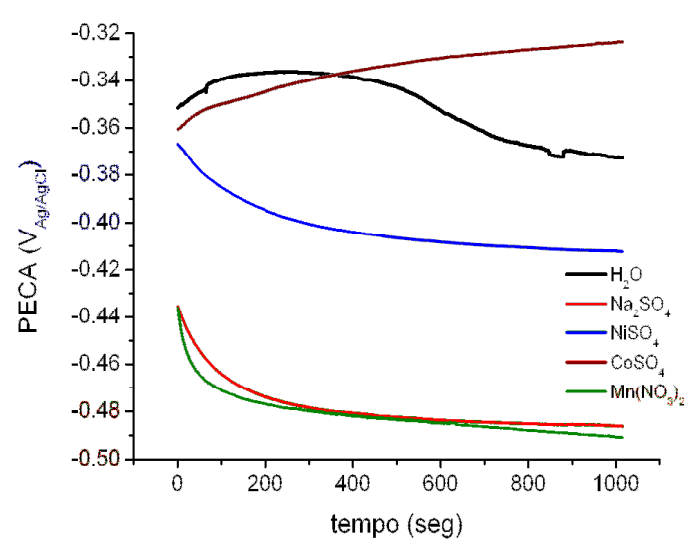

(b)

Figura 4.52. Evolução do PECA para os diferentes oxidantes em (a) pH 5,5; e (b) pH 7,5 .

\subsubsection{Efeito do substrato na formação de microtubos de silício}

Os resultados mostrados na seção 4.2.2 mostram a importância dos oxidantes na formação dos MTS, bem como a possibilidade de formar microtubos metálicos via deslocamento galvânico apenas trocando o tipo de oxidante. Nesse sentido, conseguiu-se formar microtubos de níquel. No entanto, esse comportamento não apenas depende da presença dos cátions $\mathrm{Ni}^{2+}$ na solução fluorada, mas também das condições do substrato. Embora neste trabalho não tenha sido apresentada a totalidade das amostras empregadas durante o estudo do mecanismo de formação dos MTS, os resultados observados mostram que as amostras com tratamento superficial prévio à formação da camada porosa mostram um comportamento eletroquímico diferente durante a formação das camadas porosas (Figura 4.9) e também quando mergulhadas no eletrólito para a formação dos MTS. Assim, diferentes comportamentos eletroquímicos têm sido observados quando modificadas as condições da interface SMP/eletrólito via metalização ou modificação na espessura da camada macroporosa. Nesta primeira parte serão mostrados os resultados em amostras não metalizadas. 


\subsubsection{Efeito da metalização do substrato sobre a formação dos microtubos de silício.}

Duas amostras (B101 e B106) foram metalizadas com 0,5 $\mu \mathrm{m}$ de Al e recozidas a $550{ }^{\circ} \mathrm{C}$ em ambiente de nitrogênio durante meia hora, seguindo os procedimentos explicados na seção 4.1.1, porém, uma delas foi metalizada na face polida (B101), enquanto que a outra (B106) na face rugosa (costas), apenas para melhorar o contato. Sob essas condições, as camadas porosas formadas com os mesmos parâmetros eletroquímicos desenvolvem espessuras semelhantes, porém com morfologia superficial diferente, como mostrado na seção 4.1 e na literatura [163,199], sugerindo que as propriedades químicas e físicas da superfície do SMP são modificadas por este pré-tratamento $[66,81,92,101,163]$. Ambas as amostras foram imersas em $5 \times 10^{-2} \mathrm{M}$ $\mathrm{Mn}\left(\mathrm{NO}_{3}\right)_{2}+0,25 \mathrm{M} \mathrm{NH}_{4} \mathrm{~F}$ de forma simultânea, portanto, ambos sujeitos às mesmas condições eletroquímicas.

Após 120 horas de imersão, observou-se que a amostra B106 apresenta resultados diferentes (Figura 4.53) daquele observado na amostra B101 (Figura 4.37), tanto estruturalmente quanto na composição química. $\mathrm{Na}$ Amostra B106, em pH 5,5, houve uma corrosão total da camada macroporosa e a formação de aglomerados de Mn sobre os quais ainda podem observar-se alguns MTS remanescentes. Em pH 6,5 observa-se estruturas de MTSs bem definidos, onde alguns MTSs apresentam sua parte interna totalmente preenchida com $\mathrm{Mn}$ e algumas outras parcialmente preenchidas. Existem grupos de MTSs que aparentemente estão fechados na parte superior e existem outros MTSs plenamente preenchidos dando-lhes uma aparência de barras de $\mathrm{Mn}$, como se observa nas Figuras 4.44 e 4.54b. Na solução com nível de pH 7,5 não é observada a presença de precipitados de Mn, em compensação observase estruturas de MTSs bem definidas. A amostra obtida em solução de $\mathrm{pH}$ 8,5 apresenta uma estrutura passivada pela formação de uma camada de 
$\mathrm{Mn}(\mathrm{OH})_{2}$ que inibe a corrosão da estrutura, em forma semelhante ao observado na amostra B101 (Figura 4.37d).

(a)

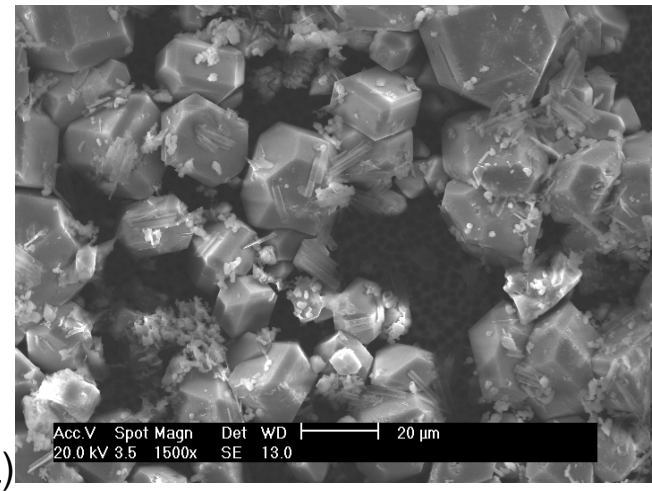

(b)

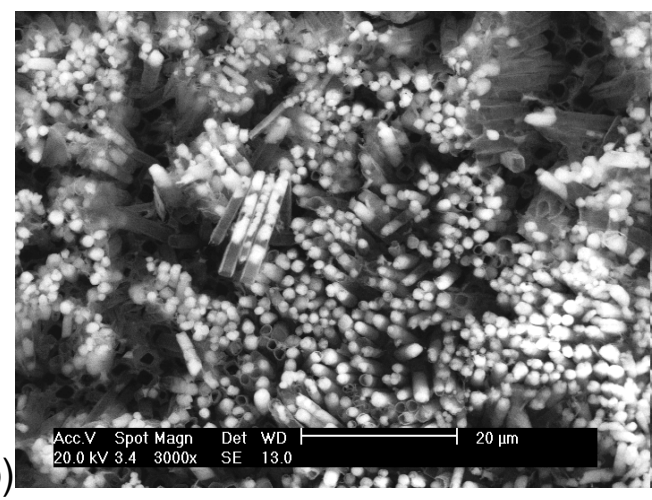

(c)

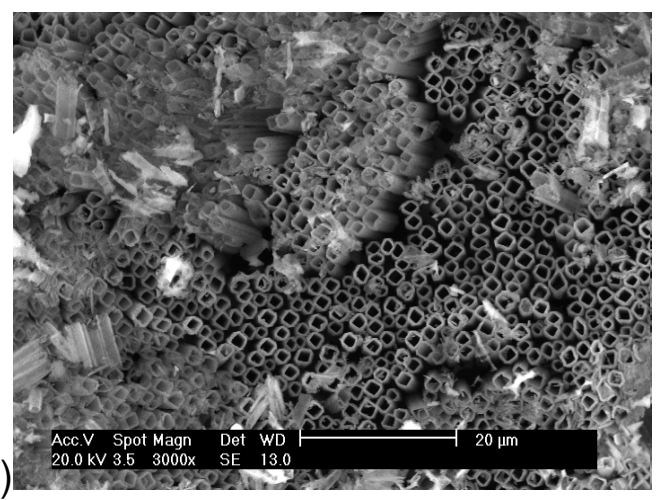

(d)

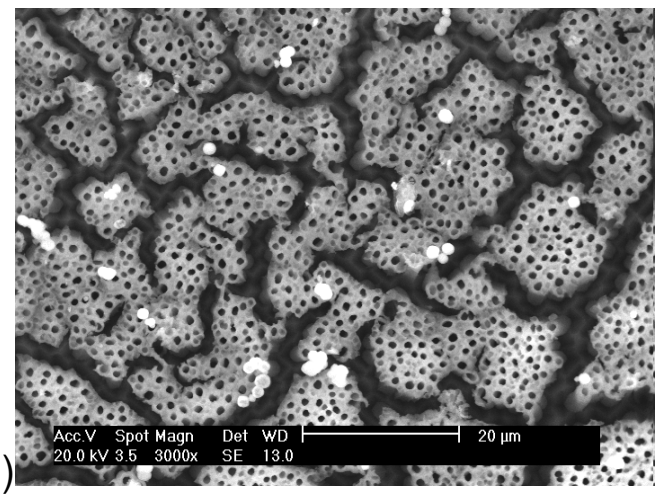

(e)

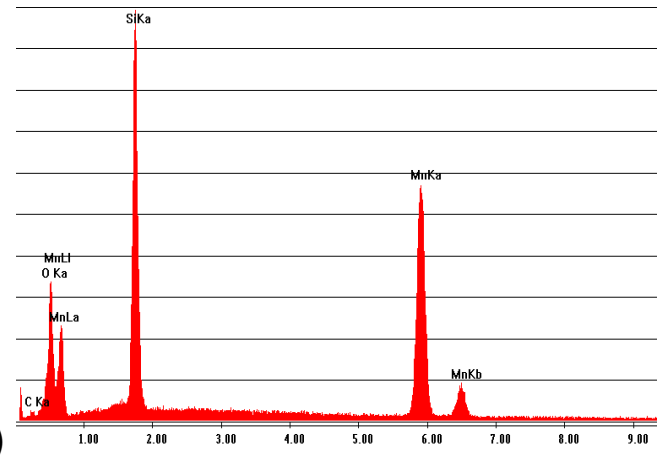

(f)

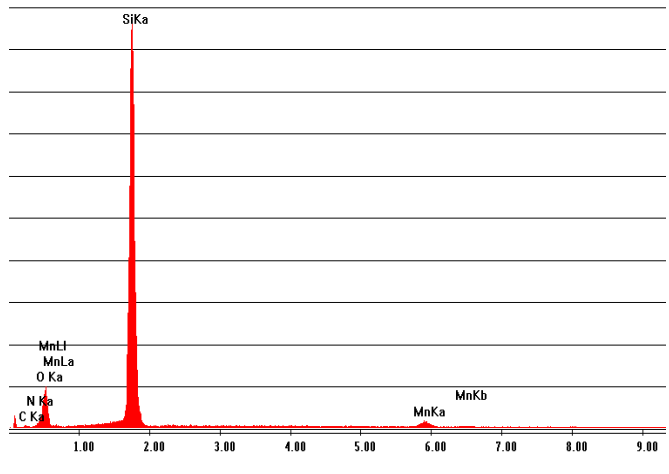

(g)

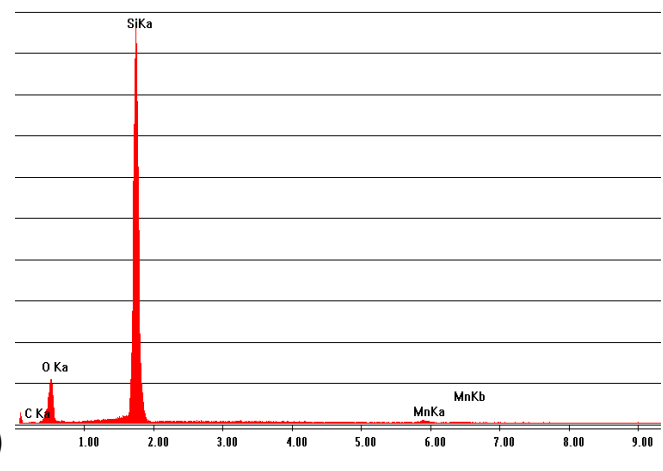

(h)

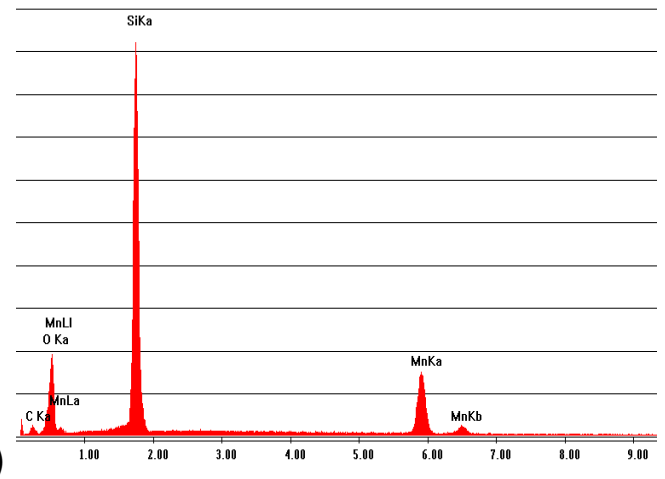

Figura 4.53. Análise estrutural e química da amostra B106 imersa em: pH 5,5 (a,e); pH 6,5 (b,f); $\mathrm{pH} 7,5$ (c, g); e pH 8,5 (d,h) 
A quantificação da concentração dos diferentes elementos químicos detectados por espectroscopia EDS sobre as amostras B101 e B106 é apresentada na Figura 4.54. A alta concentração do Mn sobre a amostra B106 em pH 4,5 é devido à presença de aglomerados de Mn (Figura 4.54a), enquanto um leve incremento deste elemento observa-se em $\mathrm{pH}$ 6,5 e 8,5 em relação à amostra B101.

Já em pH 7,5, a concentração de Mn é da mesma ordem. No entanto, a diferença mais significativa observa-se no perfil do oxigênio e do silício. $O$ primeiro elemento apresenta um crescimento aproximadamente linear em função do pH na amostra B101, enquanto que na amostra B106 este é máximo em pH 7,5. No entanto, a concentração de Si em ambas as amostras também apresenta diferenças e é maior em todos os pHs na amostra B101, enquanto que na amostra B106 apresenta seu pico máximo em $\mathrm{pH}$ 6,5, enquanto que é mínimo em $\mathrm{pH} 5,5$ devido à dissolução da camada macroporosa. Já em pH 8,5 esta é da mesma ordem de magnitude à concentração de $\mathrm{Mn}$.

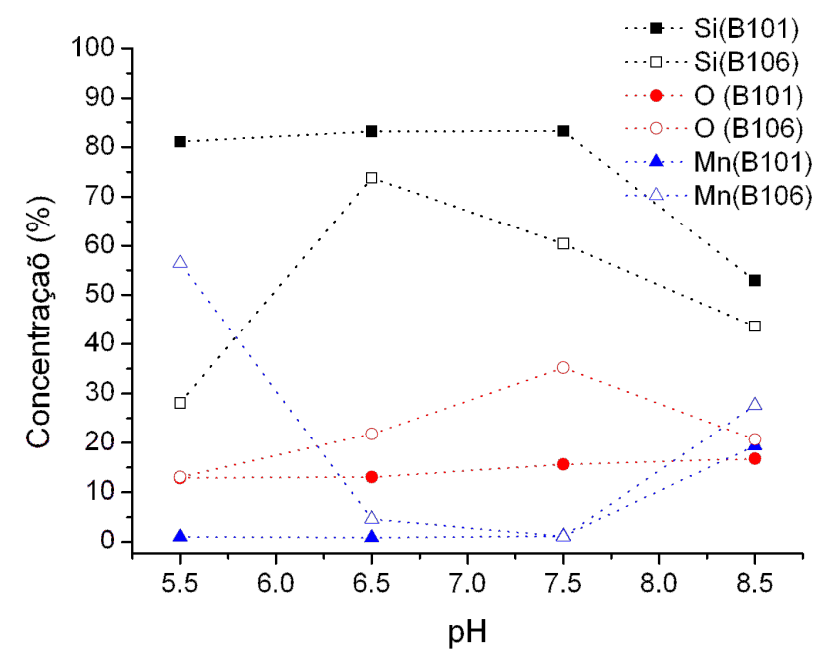

Figura 4.54 Comparação da composição química das amostras B101 e B106.

Um melhor entendimento do comportamento eletroquímico das duas amostras em questão pode ser obtido comparando-se as respectivas curvas voltamétricas (Figura 4.55). Independentemente das ondulações que aparecem na região anódica da amostra B106, nesta amostra 
observa-se um incremento nas correntes anódica e catódica em aproximadamente uma de ordem de grandeza em relação às observadas na amostra B101. O comportamento da corrente anódica na amostra B106 cresce de forma quase exponencial na medida em que o $\mathrm{pH}$ da solução aumenta, enquanto que no caso da amostra B101 também a corrente anódica cresce com o aumento do $\mathrm{pH}$ da solução, mas o crescimento é com menor rapidez (Figura 4.56a). No entanto, as correntes catódicas mostram comportamento totalmente oposto entre si.

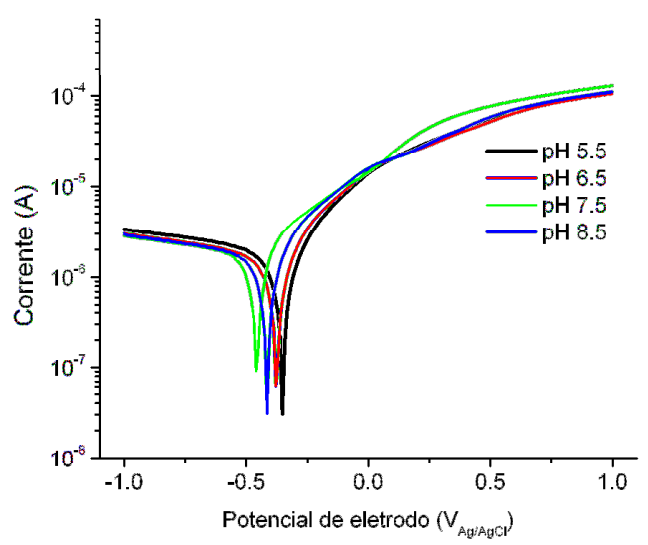

(a)

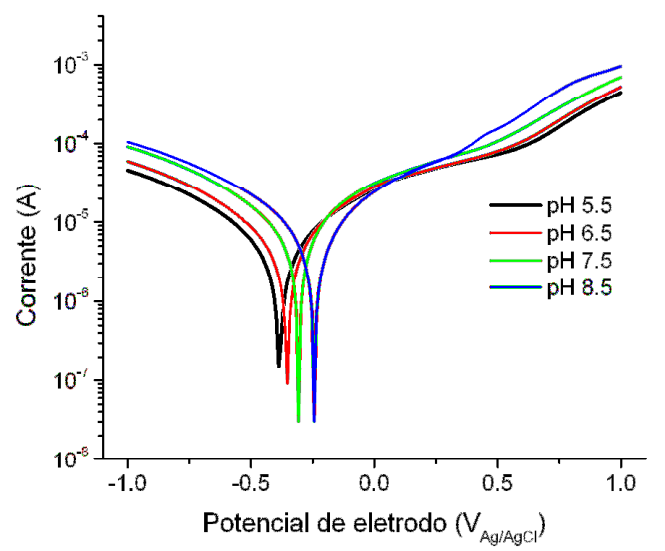

(b)

Figura 4.55 Curvas voltamétricas das amostras B101(a) e B106 (b) para diferentes níveis de pH.

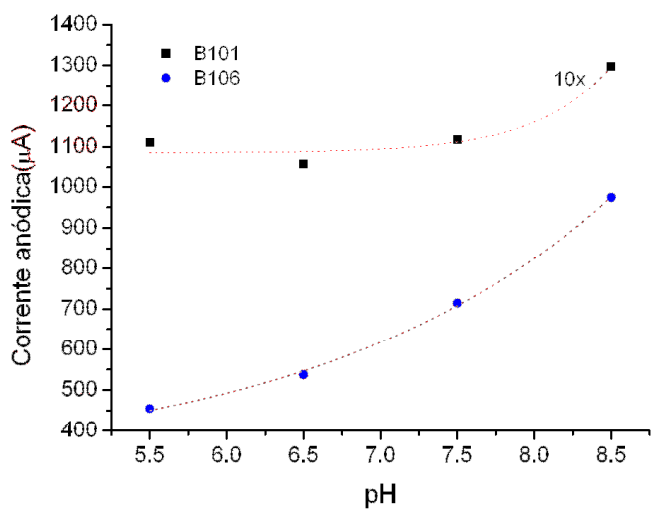

(a)

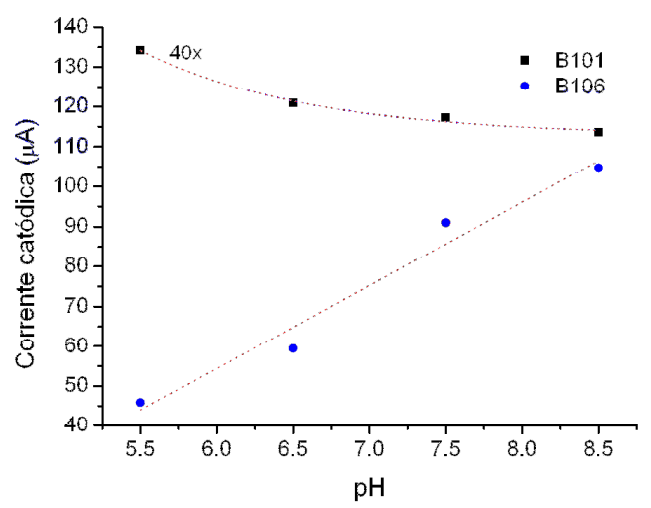

(b)

Figura 4.56 (a) comparação da variação da corrente anódica, e (b) catódica das amostras B101 e B106 em diferentes $\mathrm{pH}$. 
Sendo que ambas as amostras (B101 e B106) foram imersas simultaneamente na mesma solução eletrolítica, é claro que a mudança no comportamento eletroquímico da amostra B101 pode atribuir-se unicamente ao efeito do tratamento da superfície do substrato. Este tratamento produz a formação de uma camada resistiva, como foi discutido na secção 4.1. Apesar de que, durante a formação do SMP, as amostras tratadas com Al e recozidas durante meia hora apresentaram maior taxa de corrosão do que aquelas não-tratadas com Al (Figura 4.56). Em condições de circuito aberto, as amostras tratadas apresentaram uma taxa de corrosão muito menor, sendo esta entorno de $3 \mu \mathrm{m} / \mathrm{min}$, enquanto que as amostras não-tratadas apresentaram taxa de corrosão de aproximadamente $4 \mu \mathrm{m} / \mathrm{min}$ (Figura 4.57). Isto poderia explicar o porquê em pH 5,5, na amostra B101 tem se formado MTS, (Figura 4.34a), enquanto que na amostra B106 a estrutura é totalmente corroída com formação de depósitos granulados sobre a superfície (Figura 4.50a). É importante indicar que a determinação da taxa de corrosão em circuito abeto foi determinado mediante a imersão das amostras em $\mathrm{HF}: \mathrm{HNO}_{3}: \mathrm{CH}_{2} \mathrm{O}(1: 1: 1)$, durante 5 minutos.

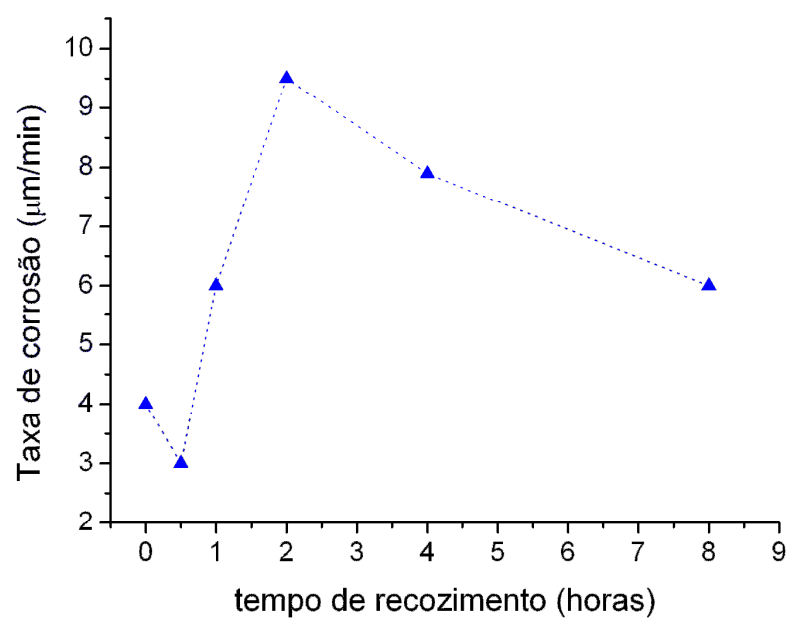

Figura 4.57. Dissolução do Si tipo p (100) não-metalizado e recozido em 1, 2, 4, e 8 horas pós metalização com Al e subseqüente remoção; imerso em solução de $\mathrm{HF}: \mathrm{NHO}_{3}: \mathrm{CH}_{2} \mathrm{O}(1: 1: 1)$ durante 5 minutos. 
A Figura 4.58a mostra o comportamento de $E_{c o r r}$ e $i_{c o r r}$ em função do nível de $\mathrm{pH}$ da solução, onde se observa que enquanto $E_{\text {corr }}$ cresce de forma exponencial, $i_{\text {corr }}$ cresce de forma linear. Este comportamento esta correlacionado com o comportamento da corrente anódica e catódica que também crescem na medida em que o nível de pH cresce (Figura 4.56a, $4.56 b)$.

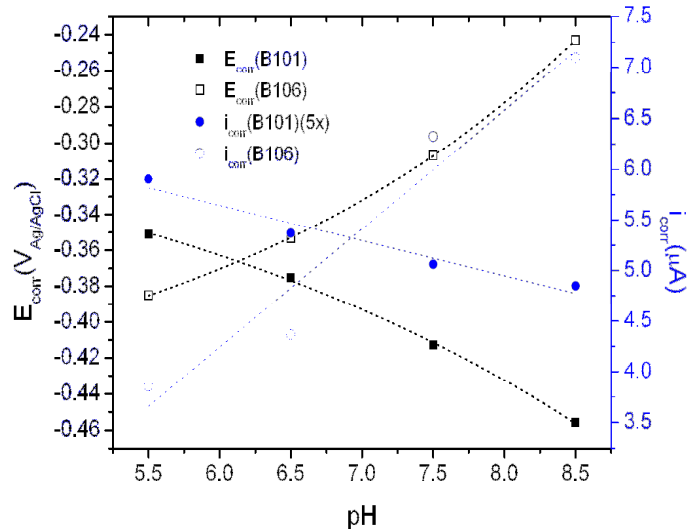

(a)

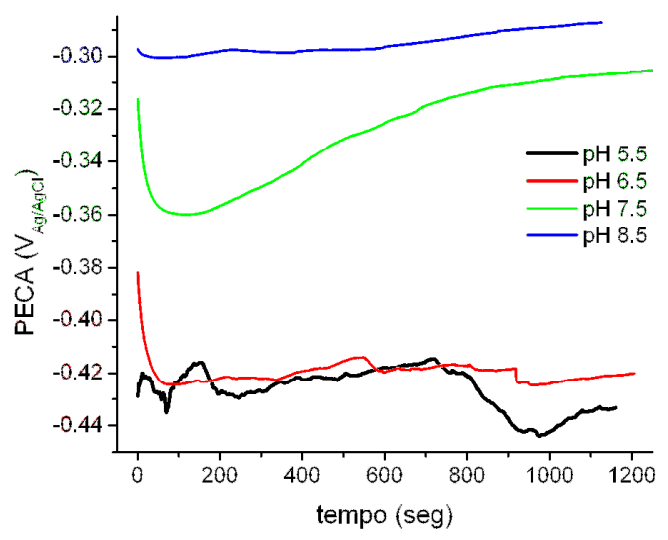

(b)

Figura 4.58. (a) comparação da variação do $E_{\text {corr }}$ e $i_{\text {corr }}$ das amostras B01 e B106; e (b) monitoramento do PECA da amostra B106.

Resultados análogos têm se observado em amostras macroporosas obtidas em substratos com superfícies não-tratadas que foram submersas em outras soluções. Isto se observa, por exemplo, na amostra B88 cuja estrutura foi mostrada na Figuras 4.31 e na amostra B71, mostradas na Figura 4.59. Ambas as amostras foram imersas em $5 \times 10^{-2} \mathrm{M} \mathrm{NiSO}$ misturado com 0,25 M NH${ }_{4} F$ durante 120 horas, respectivamente. Nestas amostras, em pH 5,5, as estruturas morfológicas das suas superfícies são completamente diferentes se comparadas com as das amostras tratadas com Al antes da formação da camada MPS (Figura 4.26b). Como já foi visto anteriormente, nesta amostra observa-se a formação de estacas de Si remanescente, enquanto que na amostra B71B (Figura 4.59a) observase que, aparentemente, houve dissolução de $\mathrm{Si}$ de tal forma que a estrutura apresenta uma característica esquelética de $\mathrm{Si}$ que, possivelmente, poderiam tornar-se estacas de Si se o tempo de imersão 
fosse maior. Já em pH 655, na amostra B71 observa-se a formação de MTS (Figura 4.59b), em cujas paredes externas depositaram-se nanopartículas de níquel via deslocamento galvânico (Figura 4.31) sendo este o estágio inicial para a formação do MTN, como explicado na seção 4.2.3.1, onde também foi apresentado a formação de MTN em amostras metalizadas na face polida (B20, B24 e B50) nesta mesma região de pH.

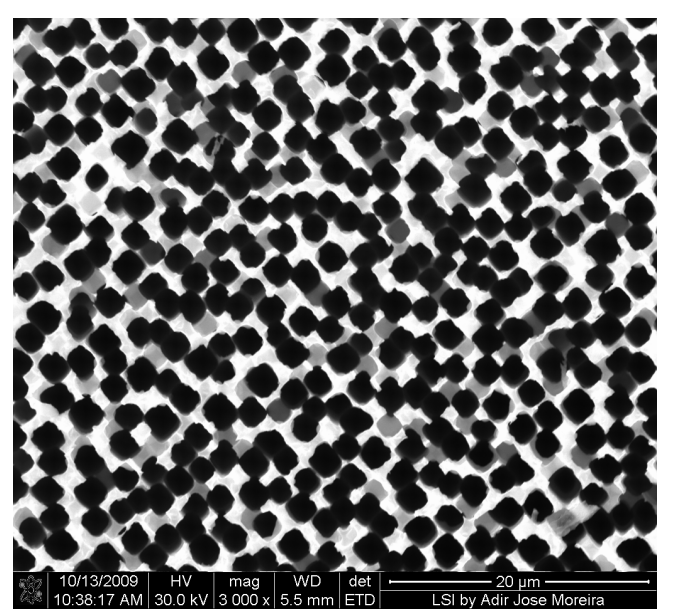

Figura 4.59. Estrutura superficial da amostra B71 imersa em (a) pH 5,5 e (b) $\mathrm{pH} 6,5$ imersas em $5 \times 10^{-2} \mathrm{M} \mathrm{NiSO}_{4}$ misturado com 0,25 $\mathrm{M} \mathrm{NH}_{4} \mathrm{~F}$

O levantamento das curvas voltamétricas (Figura 4.60a) mostra um comportamento similar àquele observado na Figura 4.55, tanto na corrente de corrosão, quanto no potencial de corrosão (Figura 4.60b), bem como no PECA (Figura 4.60c). As origens deste comportamento foram atribuídas ao incremento dos estados de interface, nas amostras não metalizadas, e já foram discutidas amplamente durante a análise do comportamento eletroquímico da amostra B106. Adicionalmente, o monitoramento do PECA ao longo do tempo mostra-nos que em pH 5,5 o PECA não apresenta um deslocamento abrupto e tende ao estado estacionário em forma regular, indicando um processo menos isotrópico daquele observado na amostra B20B (Figura 4.30b). Em pH 6,5 o PECA continua a deslocar-se vagarosamente a valores mais negativos, porém após 1000 segundos não tinha ainda atingido seu estado estacionário, 
diferente daquele observado em $\mathrm{pH}$ 7,5 que atingiu seu estado estacionário quase imediatamente.

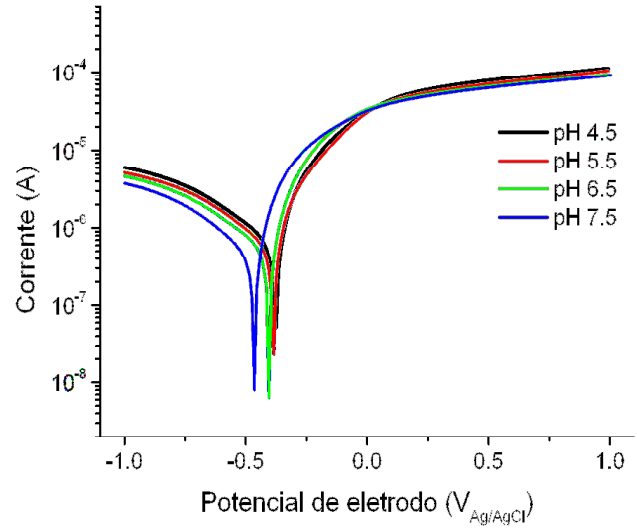

(a)

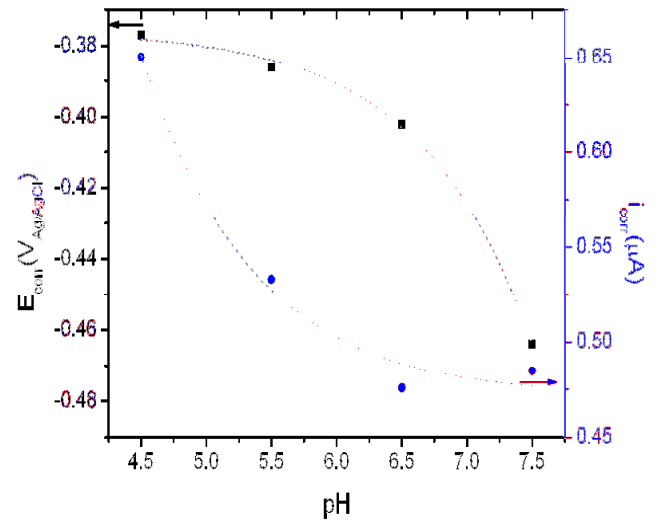

(b)

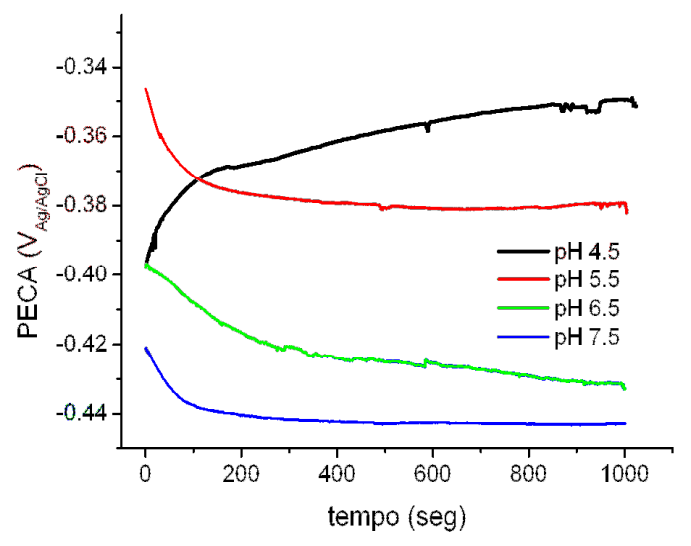

Figura 4.60. Curvas voltamétricas (a) ; corrente de corrosão e potencial de corrosão (b); e PECA (c) da amostra B71

Para as amostras metalizadas somente nas costas, esperavam-se resultados similares em relação às amostras sem nenhum processo de metalização, isto é, sem metalização nas costas nem na face polida. Porém, os resultados observados na amostra B58 (metalizada somente nas costas), imersa simultaneamente na mesma solução do que a amostra B71 (sem nenhuma metalização), apresenta marcadas diferenças. Assim, em pH 5,5 a superfície da amostra B58 (Figura 4.61a) apresenta-se destruída decorrente da corrosão. Para esta mesma amostra em pH 6,5 observa-se a formação de MTSs bem definidos não mostrando evidências de depósitos de Ni (Figura 4.61b), enquanto que 
em pH 7,5 a superfície aparentemente não mudou sua característica inicial sugerindo ausência ou uma taxa de corrosão insignificante (Figura 4.61c).

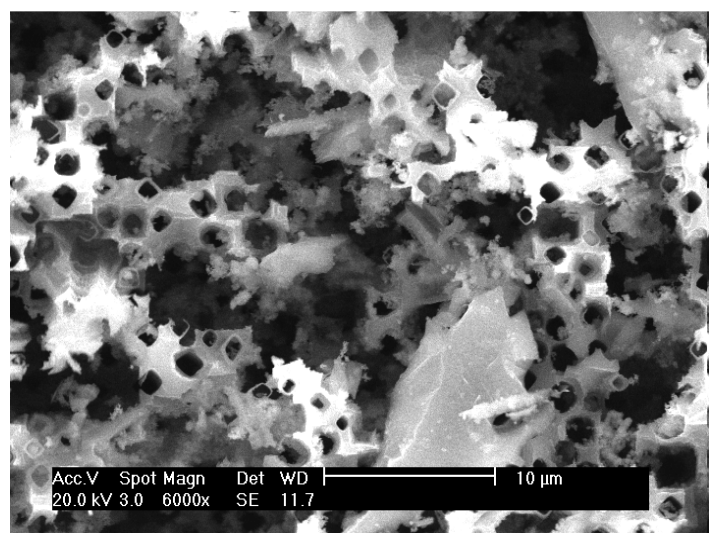

(a)

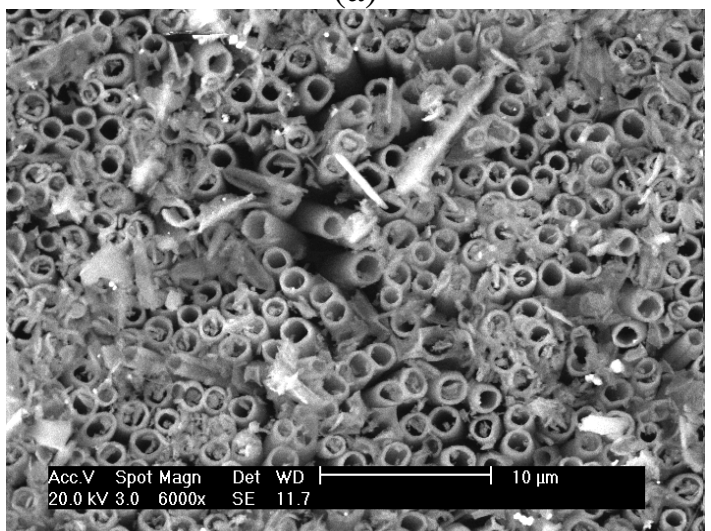

(b)

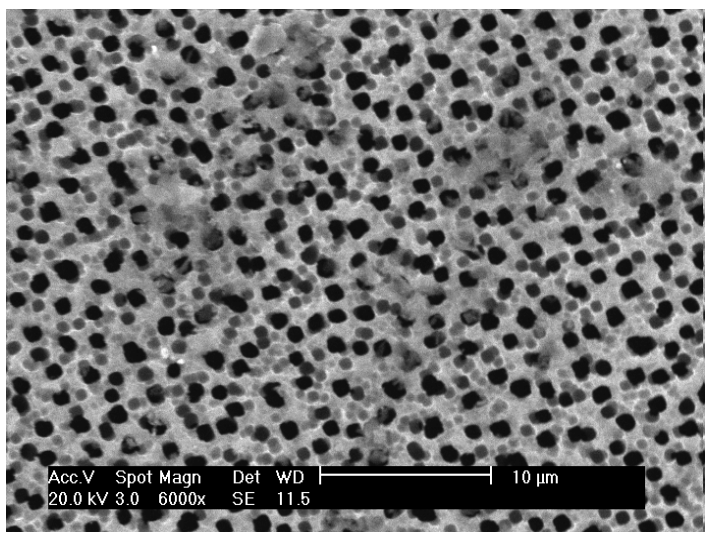

(c)

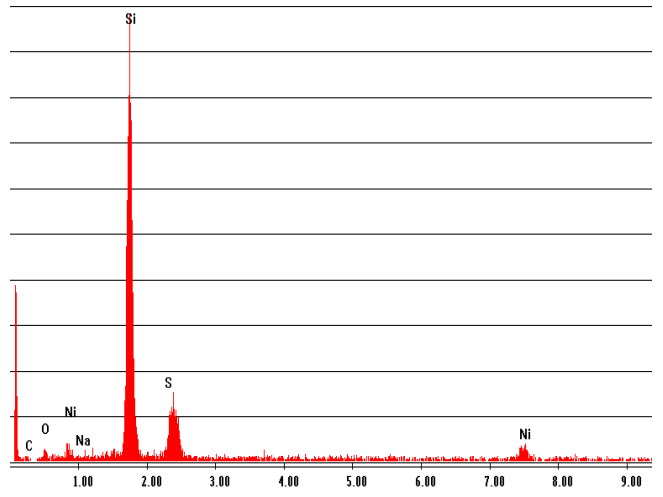

(d)

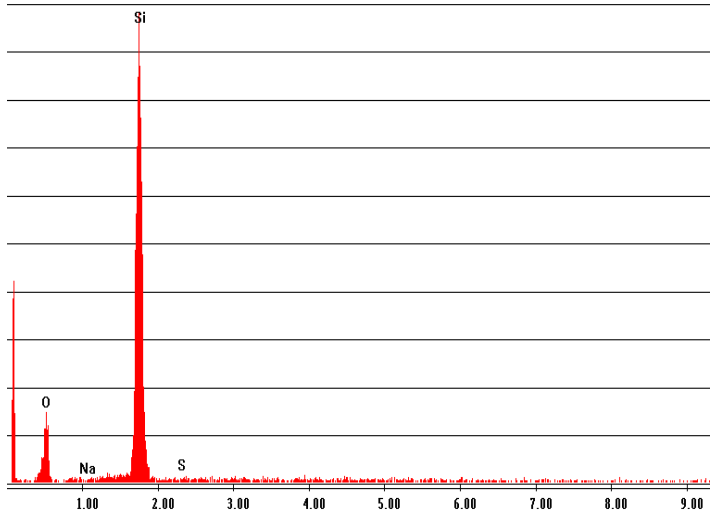

(e)

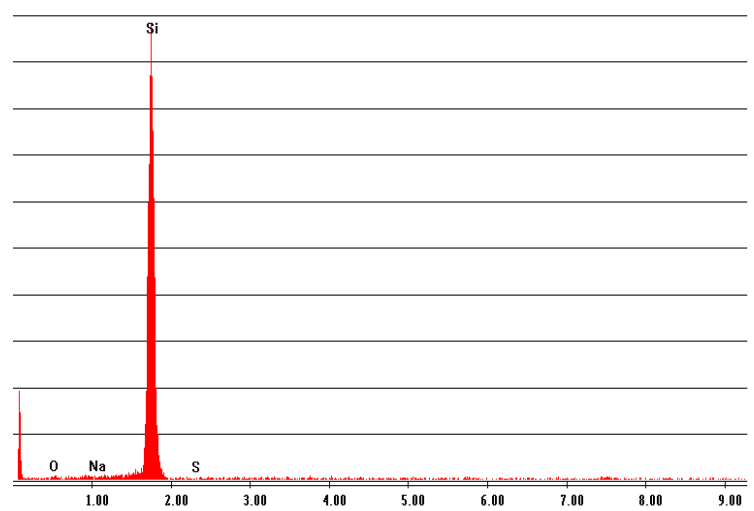

(f)

Figura 4.61 Estrutura superficial e analise química da amostra B58 imersa em $5 \times 10^{-2} \mathrm{M} \mathrm{NiSO}_{4}$ $+0,25 \mathrm{M} \mathrm{NH}_{4} \mathrm{~F}$ com pH entre 5,5 e 7,5.

Adicionalmente, os espectros EDS desta amostra não evidenciam a existência de $\mathrm{Ni}$ na superfície, aparecendo apenas indícios da presença de enxofre e oxigênio (Figura 4.61f). Considerando que ambas as 
amostras foram imersas na mesma solução durante o mesmo tempo de imersão, atribui-se que a diferença estrutural seja devida a efeitos da metalização nas costas. Porém essa face não participa ativamente na formação dos MTS descartando qualquer efeito de passivação da superfície por conta da metalização. No entanto, na secção 4.1 mostrouse que as amostras metalizadas e recozidas nas costas incrementam a espessura das camadas (Figura 4.5), que por sua vez modifica as condições químicas da interface SMP/eletrólito e promove uma variação no PECA em função do tempo de corrosão [136,184,185], e que finalmente determinará a estrutura resultante. Este efeito repete-se sem depender do eletrólito empregado para a formação dos MTS, como mostrado no caso das amostras B99 (MCe B100 (NM) que foram imersas simultaneamente em $0,25 \mathrm{M} \mathrm{NH} H_{4} \mathrm{~F}+50 \times 10^{-2} \mathrm{M} \mathrm{Na}_{2} \mathrm{SO}_{4}$ (Figura 4.62)

a)

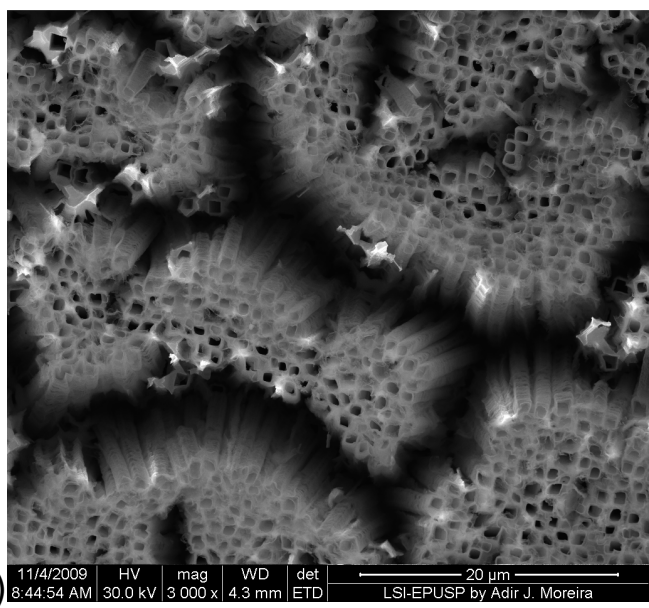

(b)

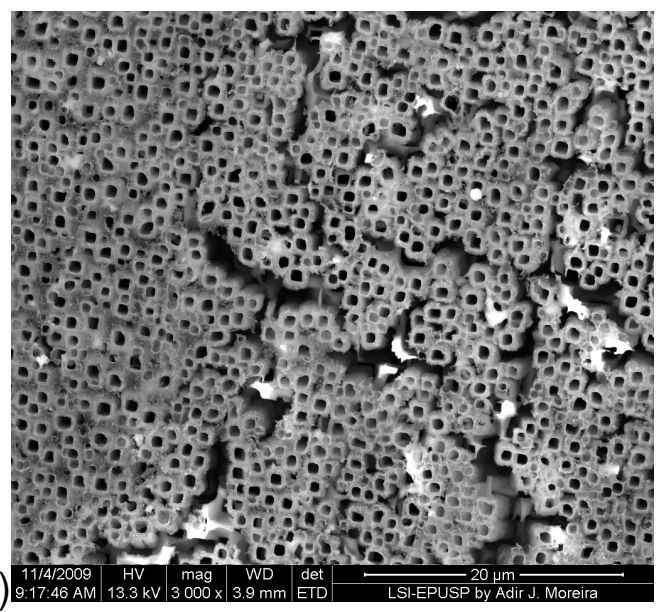

(c)

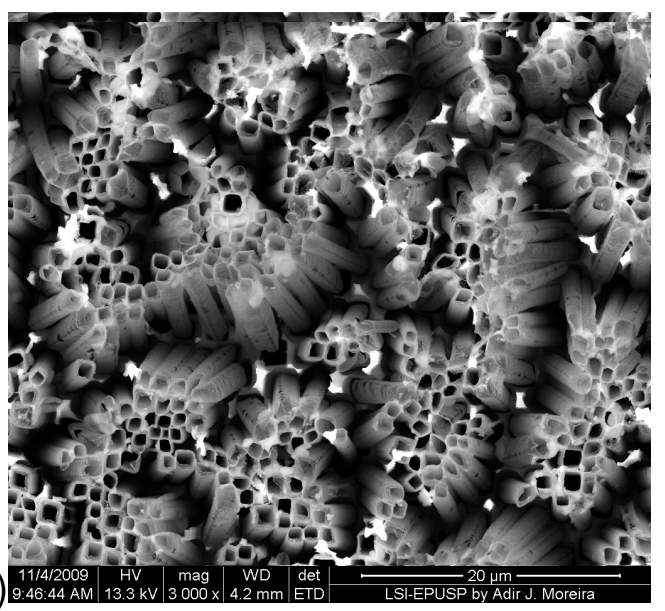

(d)

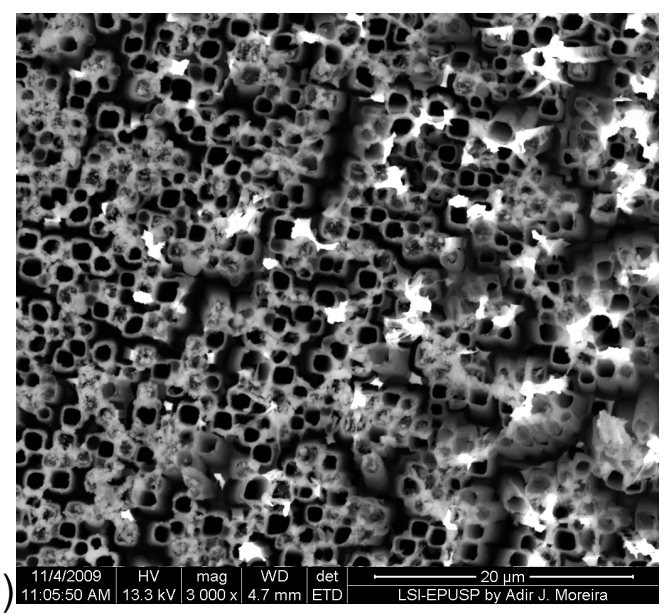

Figura 4.62. Formação dos MTS nas amostras B99 e B100 em pH 6,5 (a,c) e 7,5 (b,d), respectivamente, imersas em $0,25 \mathrm{M} \mathrm{NH}_{4} \mathrm{~F}+5 \times 10^{-2} \mathrm{M} \mathrm{Na}_{2} \mathrm{SO}_{4}$. 
O comportamento eletroquímico das curvas voltamétricas e do PECA em pH 6,5 e 7,5 de ambas as amostras são mostradas na Figura 4.63, onde se vê que no caso da amostra B99, o potencial $\mathrm{E}_{\text {corr }}$ é deslocado a valores menos negativos, mas a taxa de decrescimento é aproximadamente igual à amostra $\mathrm{B} 100$ até o nível de $\mathrm{pH} 8,5$, a partir deste ponto o potencial $\mathrm{E}_{\text {corr }}$ começa a deslocar-se em sentido positivo (Figura 4.63b). A diferença mais notável no comportamento eletroquímico de ambas as amostras é mais notável na curva do PECA em função do tempo (Figura 4.63c), onde se observa que para a amostra B100 os valores deste potencial são mais negativos do que os observados na amostra B99. De acordo com o diagrama de Pourbaix para o $\mathrm{SO}_{4}^{2-}$ e $\mathrm{NH}_{4}^{+}$(Figuras A2 e A3) [150] e considerando o nível do PECA na amostra B99 atingido após 1000 segundos para a condição de $\mathrm{pH} 6,5\left(-0.368 \mathrm{~V}_{\mathrm{Ag} / \mathrm{AgCl}}\right.$ ou $\left.-0.163 \mathrm{~V}_{\mathrm{SHE}}\right)$, sugerem uma condição eletroquímica desfavorável para a reação do $\mathrm{SO}_{4}^{2-}$ que permanecerá na sua forma iônica, enquanto estas condições de PECA são favoráveis para promover as reações (4.24) e (4.25) que dão lugar à formação de gás de nitrogênio e amônia, respectivamente, gerando íons de $\mathrm{H}^{+}$que poderão agir no sentido de modificar localmente $0 \mathrm{pH}$ e assim passivar parcialmente a superfície macroporosa, formando ligações Si-H. No entanto, as condições termodinâmicas (PECA -0,453 $\mathrm{V}_{\mathrm{Ag} / \mathrm{AgCl}}$ ou $\left.-0,248 \mathrm{~V}_{\text {SHEI }}\right)$ na amostra $\mathrm{B} 100$ favorecem as reações catódicas (4.8) a (4.10) e suprimem a (4.24). Este resultado mostra a importância da injeção de lacuna pelos agentes oxidantes. Na amostra B99 a injeção de lacunas na BV apenas pode ser atribuída às espécies $\mathrm{OH}^{-}$e $\mathrm{H}_{2} \mathrm{O}$ [64,65,187] que competiram com o $\mathrm{H}^{+}$no processo de corrosão, enquanto que na amostra B100 a injeção de lacunas será maior devido à participação ativa das espécies $\mathrm{OH}^{-}, \mathrm{H}_{2} \mathrm{O}$ e $\mathrm{SO}_{4}^{2-}$, portanto, permite a formação de MTS melhor definidos.

Em pH 7,5 as condições termodinâmicas do sistema promovem as mesmas reações tanto na amostra B99 quanto na B100, logo o comportamento eletroquímico será semelhante. No entanto, neste nível 
de $\mathrm{pH}$ a concentração da espécie $\mathrm{HF}_{2}^{-}$decresce significativamente promovendo uma baixa taxa de corrosão, desta forma os tubos não serão bem definidos (Figuras 4.62b e 4.62d).

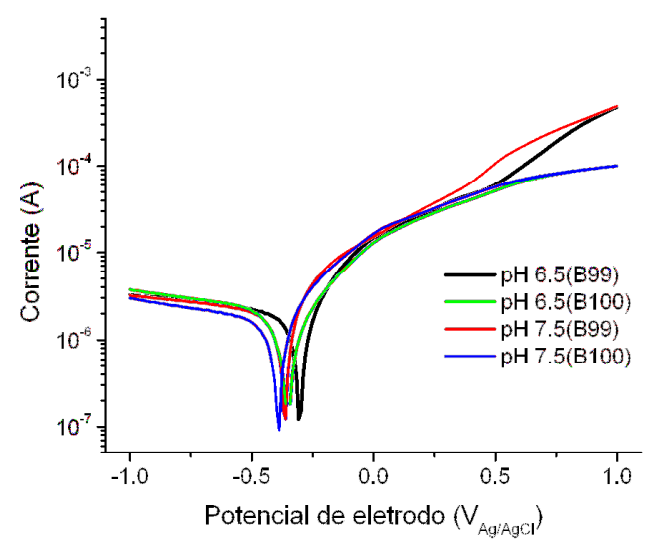

(a)

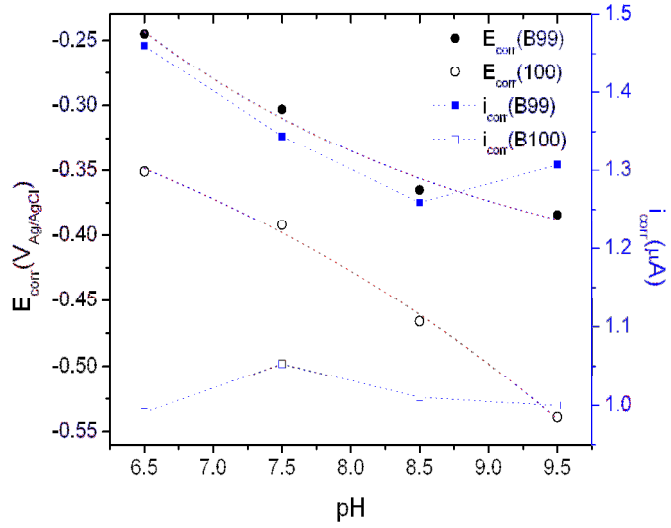

(b)

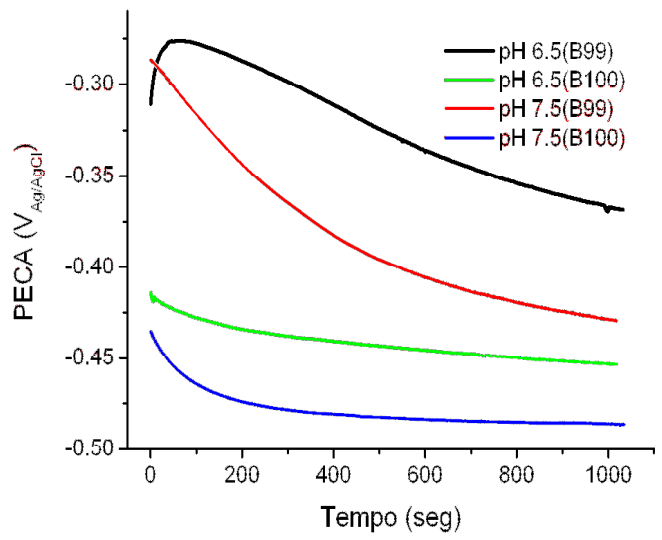

(c)

Figura 4.63. Comparação das curvas voltamétricas (a); corrente e potencial de corrosão (b); e PECA (c) das amostras B99 e B100.

\subsubsection{Efeito da porosidade das camadas MPS sobre a formação dos microtubos de silício.}

Até agora foi visto que a formação dos MTSs depende das condições termodinâmicas e cinéticas da dissolução do Si, sendo uma condição necessária para que o processo de corrosão do silício seja de característica predominantemente anisotrópica desde que processos de corrosão isotrópica conduzem a uma total destruição das estruturas 
porosas. Também foi visto que as propriedades químicas da interface SMP/eletrólito influem na formação dessas estruturas. No entanto, em alguns casos apesar das condições antes mencionadas serem satisfeitas não foi observada a formação de MTSs. Assim, com o intuito de estudar a influência da porosidade da camada inicial sobre a formação dos MTSs foi formado inicialmente uma camada de silício poroso em uma solução de HF:etanol (1:1), tendo sido previamente a superfície polida metalizada com Al (amostra B25). Convencionalmente as camadas de silício poroso obtidas no eletrólito HF:Etanol apresentam elevada porosidade se comparadas com camadas porosas obtidas em HF:DMF (amostras B20 e B24). Assim, estas três amostras foram mergulhadas numa solução de $5 \times 10^{-2} \mathrm{M} \mathrm{NiSO}_{4}+0,25 \mathrm{M} \mathrm{NH}_{4} \mathrm{~F}$. Os efeitos da imersão nesta solução para as amostras B20 e B24 já foram amplamente discutidas em seções anteriores, onde foi verificada a formação de estruturas de tubos de níquel para a solução em pH 6,5 (Figuras 4.26 e 4.27). No caso da amostra B25 (mais porosa) foi realizado o estudo da estrutura final após mergulhar em soluções com pH entre 4,5 a 7,5 respectivamente. A estrutura morfológica desta amostra é apresentada na Figura 4.64a a 4.64d.

Similarmente aos casos anteriormente estudados, para esta amostra mergulhada em solução de pH 4,5, a estrutura morfológica continua tendo a mesma característica mostrada pelo substrato de MPS antes da imersão, mostrando novamente um efeito de passivação da superfície que inibe a dissolução do Si (Figura 4.64a). Em pH 5,5, diferente da amostra B20, a superfície não é totalmente corroída (Figura 4.64b), sendo esta atribuída, principalmente, aos efeito da dissolução química. Para a solução de $\mathrm{pH}$ 6,5, a estrutura morfológica apresenta um aspecto esquelético de $\mathrm{Si}$ com poros com diâmetros maiores que os poros originais, evidenciando que as paredes internas foram corroídas quimicamente (Figura 4.64c). Este resultado é completamente diferente ao observado nas estruturas obtidas a partir do silício poroso formado em HF:DMF (baixa porosidade), onde foram formados tubos de silício. 


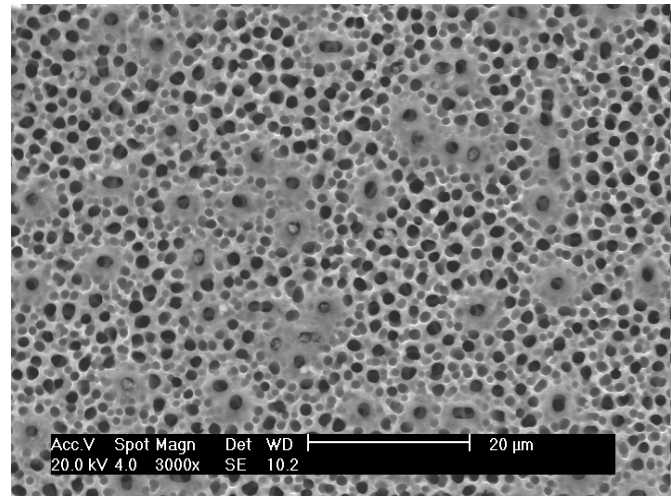

(a)

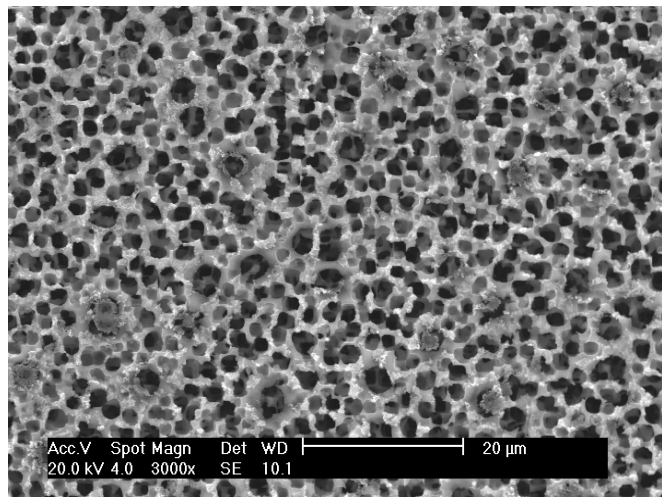

(b)

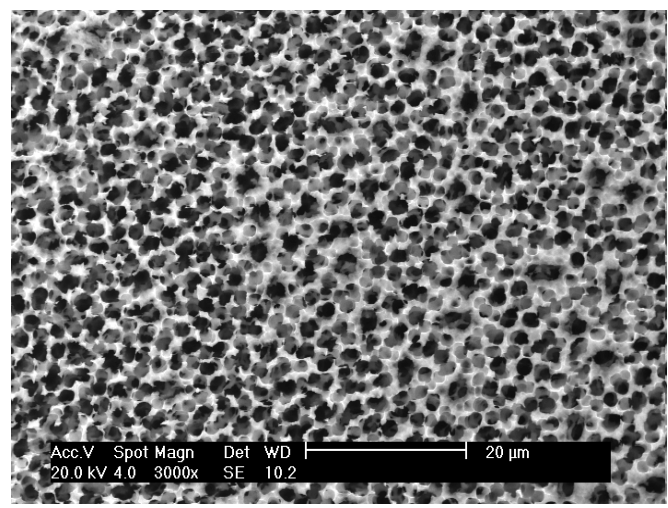

(c)

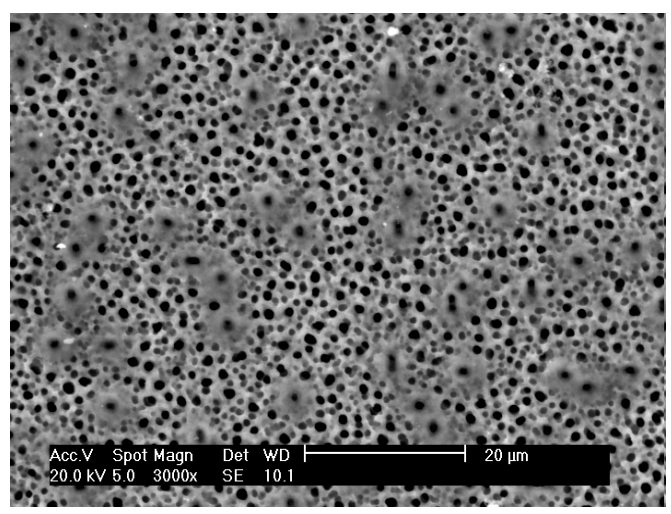

(d)

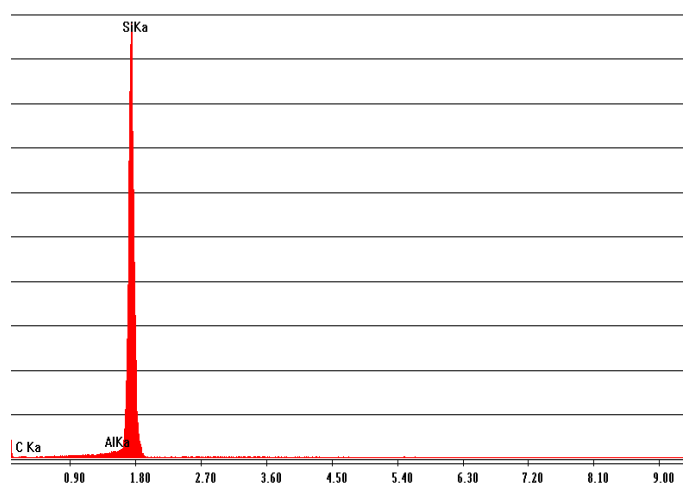

(e)

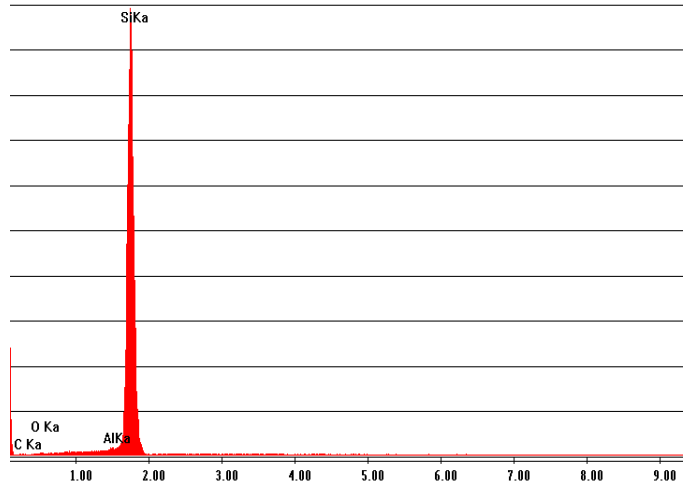

(f)

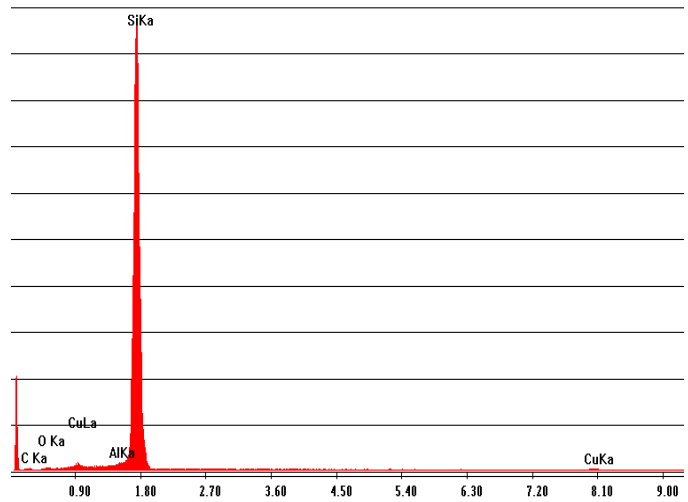

$(\mathrm{g})$

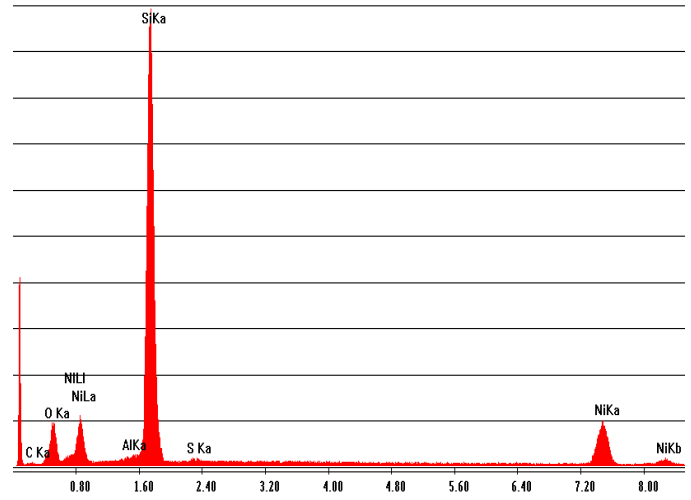

(h)

Figura 4.64 Estrutura superficial e analise química da amostra B25 imersa em $5 \times 10^{-2} \mathrm{M}$ $\mathrm{NiSO}_{4}+0,25 \mathrm{M} \mathrm{NH}_{4} \mathrm{~F}$ com pH 4,5(a,d); pH 5,5(b,e); pH 6,5 (c,g ) e pH 7,5 (d,h). 
Para a solução em pH 7,5 a morfologia superficial da amostra apresenta

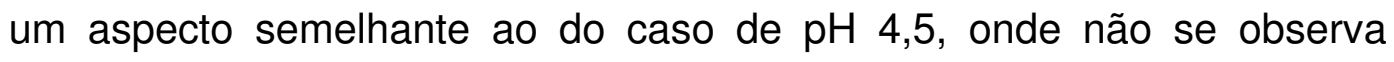
evidências da corrosão do silício, de forma similar aos da outras amostras (B20 e B24), sugerindo a possível passivação pela formação de uma camada de $\mathrm{Ni}(\mathrm{OH})_{2}$ desde que o espectro EDS desta amostra evidencie a existência de $\mathrm{Ni}$ e $\mathrm{O}$ na sua superfície (Figura 4.64h)

A inibição da formação das estruturas tubulares em $\mathrm{pH}$ 6,5, para substratos de elevada porosidade sugere que a distância entre os poros é um parâmetro altamente relevante na formação das estruturas tubulares, que pode estar ligado com a camada de depleção entre as paredes dos poros. Estas camadas podem estar superpostas quando a distância D entre os poros for pequena (equação 4.36), como no caso das camadas de silício poroso formados em HF:etanol (mais poroso) e esta condição seria um fator limitante para a troca de cargas evitando a corrosão destas regiões. Este resultado mostra a importância da camada de depleção na formação das estruturas tubulares de $\mathrm{Si}$. O mecanismo de corrosão de silício bem como a participação da camada de depleção e da distancia entre poros já foram amplamente discutidos na seção 4.2.2.

Para a validação quantitativa do efeito da porosidade do silício poroso (distância entre os poros) na formação das estruturas MTSs foi realizado um estudo estatístico da distribuição do tamanho dos poros e as suas distâncias. Para este fim foi utilizado o algoritmo GRANUL [134] cujos resultados são mostrados na Figura 4.65. A distribuição de distâncias entre os poros na amostra B25 (alta porosidade) está entre 0,338 $\mu \mathrm{m}$ a $0,614 \mu \mathrm{m}$. Esta faixa de distâncias são menos extensas em comparação com largura da camada de depleção entre as paredes minimizando assim a corrosão do Si nesta região. Este resultado é bem correlacionado com a não formação de estruturas tubulares de Si na amostra B25. A distribuição de distâncias entre os poros, na amostra B20 (baixa porosidade), esta compreendida na faixa de 0,616 $\mu \mathrm{m}$ a $1,287 \mu \mathrm{m}$; como se vê, algumas distâncias são maiores à largura da camada de depleção, 
tornando viável a corrosão do $\mathrm{Si}$ e a formação de estruturas tubulares como efetivamente foi observado. Os resultados discutidos neste item mostraram claramente a importância da porosidade do substrato inicial na formação de estruturas tubulares de Si. As estruturas de MTSs foram formadas a partir de estruturas macroporosas, onde as distâncias entre os poros são maiores que a largura da camada de depleção. Não foi observada a formação de estruturas tubulares de Si quando o substrato inicial foi uma camada de silício microporoso.

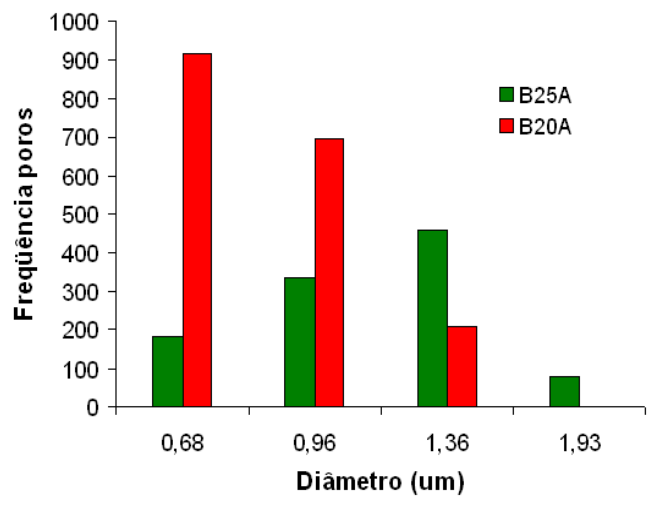

(a)

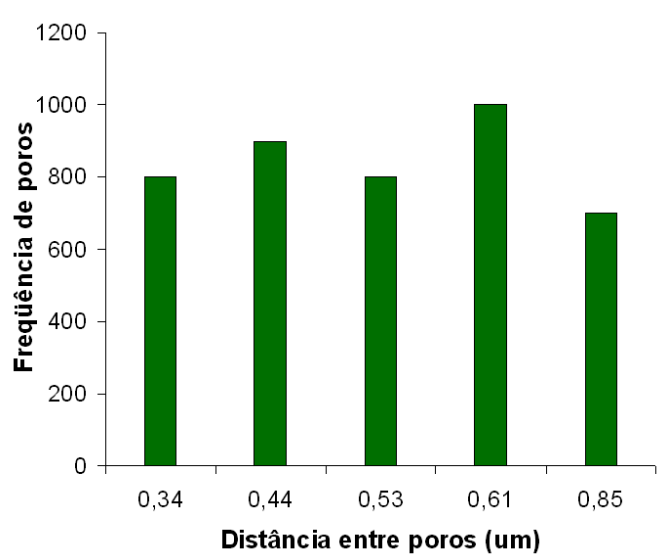

(c)

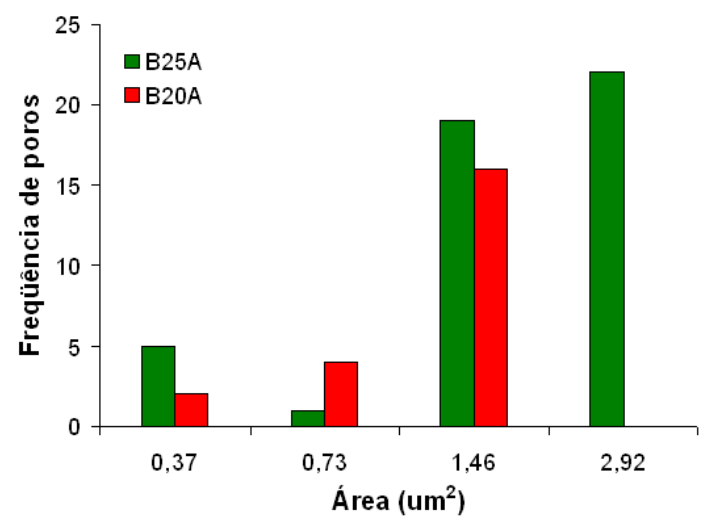

(b)

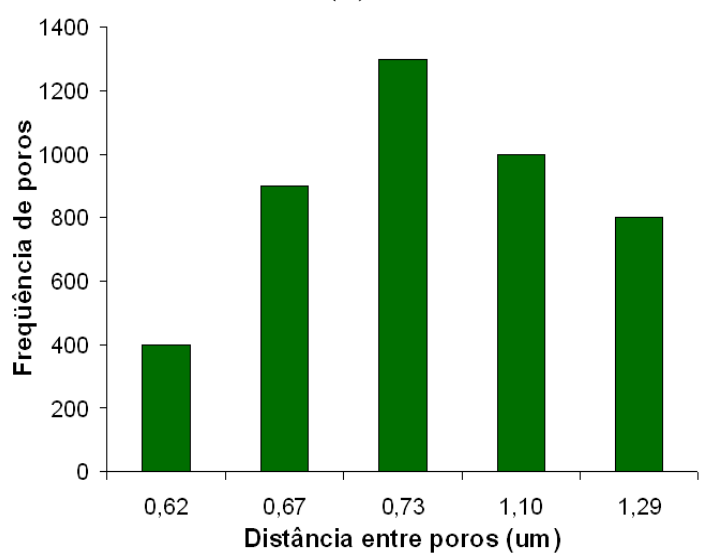

(d)

Figura 4.65. Histogramas da freqüência de poros (a) semicirculares, (b) retangulares, bem como da distância entre poros vizinhos da amostra B25 (c) e B20 (d).

A porosidade das camadas porosas de $\mathrm{Si}$, além de ser moduladas pelo tipo de eletrólito, também podem ser modulados pelo tipo e concentração dos dopantes das lâminas de silício $[64,65,173]$. As lâminas de silício, altamente dopadas, quando anodizadas em solução eletrolítica de HF:etanol produzem estruturas mesoporosas com tamanho de poros 
menores que $100 \mathrm{~nm}$. Como as estruturas mesoporosas ocupam uma condição intermediaria entre as estruturas microporosas e macroporosas, a questão é se será possível formar tubos de silício a partir de camadas mesoporosas. Nesse sentido, foram realizados ensaios experimentais sobre camadas mesoporosas de $\mathrm{Si}$, e cujos resultados serão apresentados a seguir.

\subsubsection{Efeito da concentração de dopantes do substrato silício sobre a formação dos microtubos de silício.}

Foram preparados dois tipos de estruturas mesoporosas utilizando lâminas de silício tipo $p(100)$ altamente dopados $(\rho=0,005 \Omega \mathrm{cm})$. A formação da estrutura porosa foi realizada através da anodização da lâmina de Si em HF:etanol (3:7) com $50 \mathrm{~mA} / \mathrm{cm} 2$ de densidade de corrente por 10 minutos. Posterior à formação, a camada porosa foi imersa numa solução de $5 \times 10^{-2} \mathrm{M} \mathrm{NiSO} O_{4}+0,25 \mathrm{M} \mathrm{NH}_{4} \mathrm{~F}$ sendo a mesma solução utilizada nas amostras B20, B24 e B25.

As amostras D80 e D82 foram processadas a partir da lâmina de $\mathrm{Si}$ altamente dopadas sem nenhum processo prévio de metalização com Al, isto é, a formação da camada porosa, e seu subseqüente processo de imersão na solução fluorada para a formação dos NTS, foram realizados sobre lâmina de Si não-metalizado. As amostras A7 e A8 foram processadas a partir de uma lâmina de Si previamente metalizadas com Al na sua superfície polida. A imersão de todas as amostras na solução de $5 \times 10^{-2} \mathrm{M} \mathrm{NiSO}_{4}+0,25 \mathrm{M} \mathrm{NH}_{4} \mathrm{~F}$ foi por nove horas utilizando-se níveis de $\mathrm{pH} 5,5$ e 6,5, respectivamente.

Os resultados das estruturas imersas em pH 5,5 mostradas nas Figuras 4.66a-4.66d correspondem a diferentes áreas da amostra D80. A região mostrada na imagem MEV da Figura 4.66a, revela uma superfície com arranjo randômico em forma de ilhas agrupadas, com regiões dissolvidas devido à ação do eletrólito que não permite a formação de tubos. Em 
regiões próximas da borda da área correspondente ao filme de silício poroso, a estrutura mostra-se quase completamente corroída, mas com alguns nanotubos de silício (NTS) sobre a superfície corroída (Figura 4.66c). O NTS observado tem um diâmetro da ordem de $75 \mathrm{~nm}$ e comprimento de $6 \mu \mathrm{m}$. No caso da amostra imersa em pH 6,5 (D82), a superfície assume uma forma randômica com morfologia semelhante a folhas (Figura 4.66e). As imagens aumentadas da região correspondente às folhas mostradas nas Figuras $4.66 \mathrm{f}$ e $4.66 \mathrm{~g}$ mostram estruturas de NTS cujos diâmetros estão compreendidos entre $67 \mathrm{~nm}$ a $137 \mathrm{~nm}$ e comprimento de $12 \mu \mathrm{m}$. Para evitar o carregamento das superfícies durante a análise MEV, e assim obter imagens com maior resolução, as amostras B80 e B82 foram metalizadas com um filme fino de carbono e após este processo, as imagens MEV aumentadas dos NTSs correspondente às amostras B80 e B82 são apresentadas nas Figuras $4.66 \mathrm{~d}$ e $4.66 \mathrm{~h}$, respectivamente. A partir destas imagens aumentadas foi possível medir os diâmetros internos e externos do NTSs, e aquelas que correspondem à amostra B80 apresentam diâmetros internos de $57 \mathrm{~nm}$ e diâmetros externos da ordem de $114 \mathrm{~nm}$, enquanto que os NTSs da amostra B82 apresentaram diâmetros internos da ordem de $40 \mathrm{~nm}$ e diâmetros externos de $75 \mathrm{~nm}$. A espessura das paredes dos NTSs correspondente às amostras B80 e B82 são da ordem de 28 e $17 \mathrm{~nm}$ respectivamente. Este valor de espessura esta dentro da ordem de magnitude da largura da camada de depleção de um substrato de silício tipo $\mathrm{p}^{+}\left(10^{20} \mathrm{~cm}^{-3}\right)$, mais especificamente se considerarmos a espessura dos tubos como sendo a largura da camada de depleção a concentração de dopantes seria da ordem de $1,6 \times 10^{18}$ e $4,4 \times 10^{18} \mathrm{~cm}^{-3}$, respectivamente, logo, a concentração de dopantes correspondente praticamente a um substrato de Si tipo $\mathrm{P}^{+}$. 
(a)

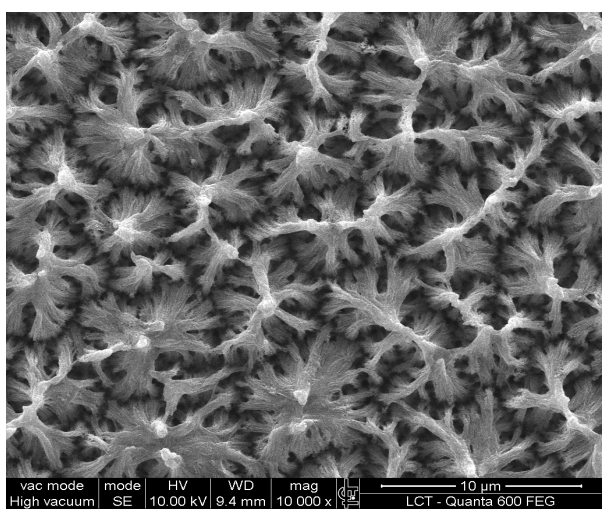

(b)

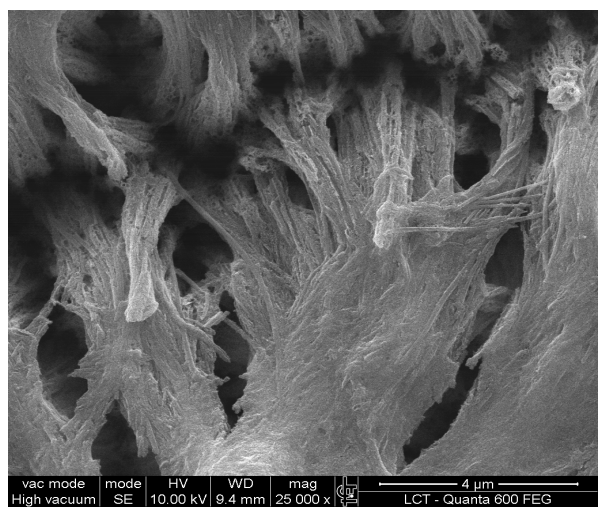

(c)

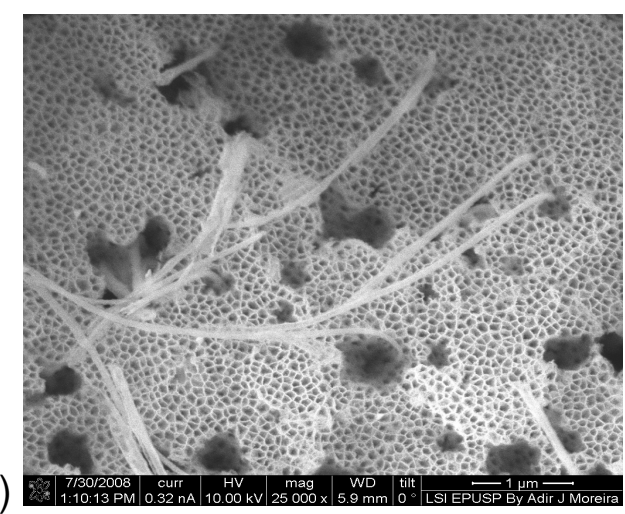

(d)

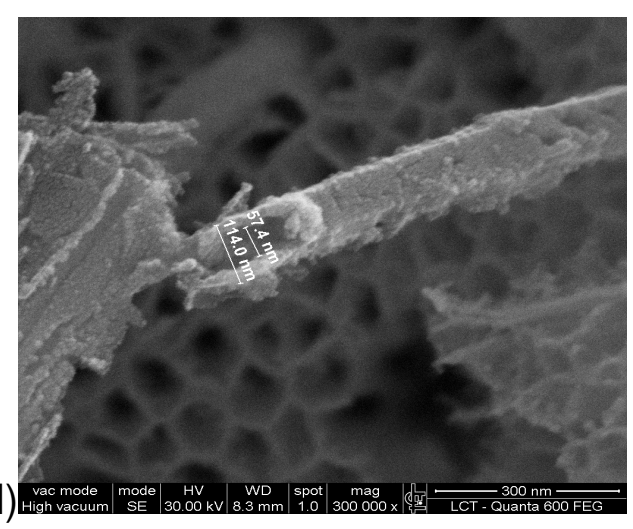

(e)
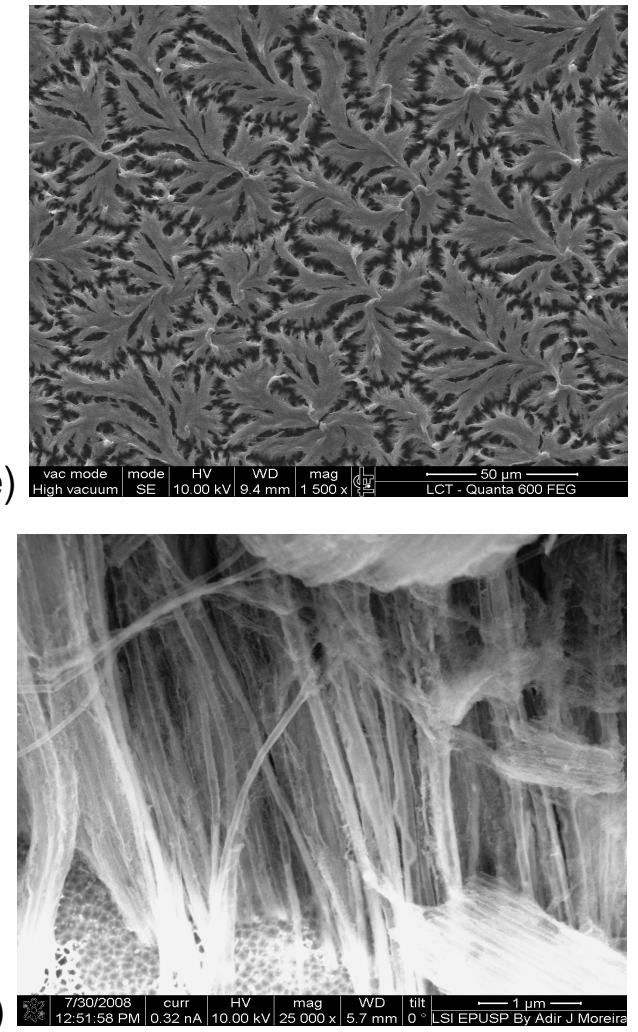

(g)

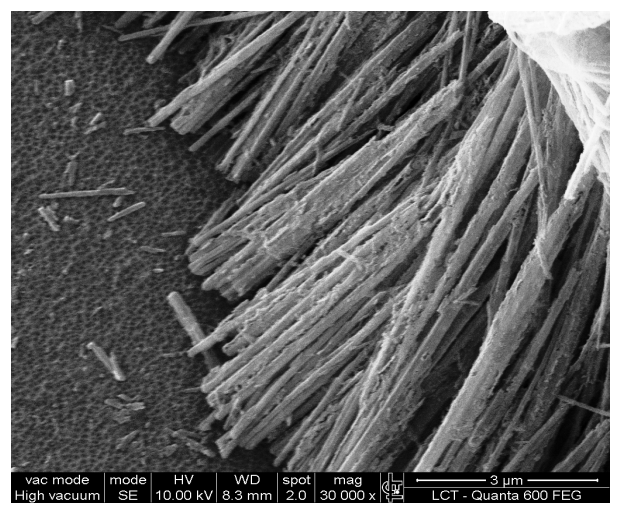

(h)

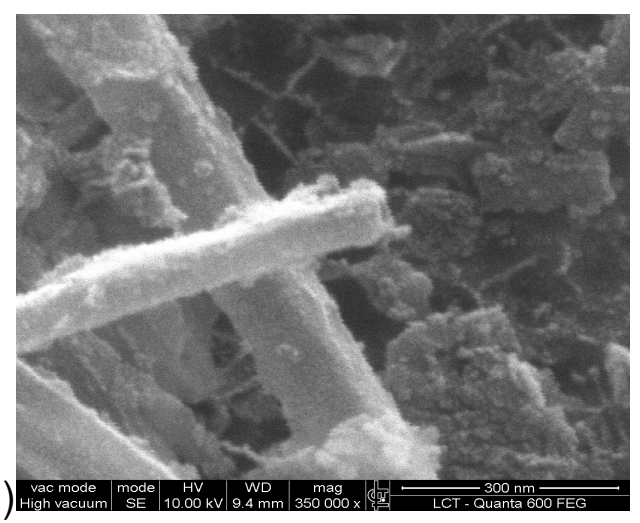

Figura 4.66 Imagens MEV dos nanotubos de silício obtidas nas amostras D80 (a-d) e D82 (e-h) em pH 5,5 e 6,5, respectivamente. 
A amostra A7 (obtida após metalização) imersa em pH 5,5 mostra uma morfologia superficial diferente ao da amostra D80 com ilhas de áreas extensas e interconectadas, e regiões com gretas abertas. Nestas ultimas regiões, foi identificada a formação das estruturas de NTS (Figura 4.67a). As imagens MEV aumentadas dos NTSs da amostra A7 são mostradas nas Figuras $4.67 \mathrm{~b}$ e $4.67 \mathrm{c}$, respectivamente, a partir dos quais foi possível determinar os diâmetros interno e externo dos tubos, apresentando valores da mesma ordem de magnitude encontrados na amostra D80. Para a amostra A8 que foi submersa numa solução de $\mathrm{pH} 6,5$ a morfologia superficial mostra ilhas extensas de superfícies suaves correspondentes a filmes depositados de Ni (Figura 4.67e) e entre estas ilhas observa-se a existência de gretas abertas onde após obter imagens MEV aumentadas, foi possível identificar a formação de NTSs nestas regiões (Figuras $4.67 \mathrm{e}$ e $4.67 \mathrm{f}$ ). Novamente aqui, os NTSs apresentam diâmetros interno e externo semelhantes ao da amostra B80.

Os espectros EDS, mostrados na Figura 4.68, correspondente às amostras B80, B82 e A7 sugerem que os NTSs são constituídos quase totalmente por átomos de $\mathrm{Si}$, isto é, os nanotubos efetivamente são de silício. O espectro EDS da amostra A8 evidencia uma presença significativa de átomos de $\mathrm{Ni}$ e $\mathrm{Si}$ sugerindo que os tubos podem estar constituídos por tubos de $\mathrm{Si}$ cobertos com metal de $\mathrm{Ni}$ ou algum complexo de Ni depositado.

As diferenças de estruturas obtidas para as amostras D80 e A7 estão completamente correlacionadas com 0 diferente comportamento eletroquímico destas amostras. Na Figura 4.69a, é mostrada o comportamento do potencial de circuito aberto (PECA) destas amostras. Em pH 5,5, o comportamento do PECA para ambas as amostras apresenta uma característica irregular, apesar de ambas as curvas apresentarem formatos semelhantes. A tendência para o estado estacionário final do PECA da amostra $A 7$ tende a valores mais negativos relativos ao PECA da amostra B80. Importante mencionar que o PECA 
observado na interface SMP/eletrólito (anteriormente discutido) mostra também um perfil randômico, com a diferença que a amplitude de oscilação do potencial foi pequena se comparada com os observados nas amostras B80 e A7, respectivamente. As elevadas oscilações de potencial podem estar relacionadas com a formação das gretas nestas estruturas, que posteriormente favoreceriam a formação dos nanotubos.

(a)

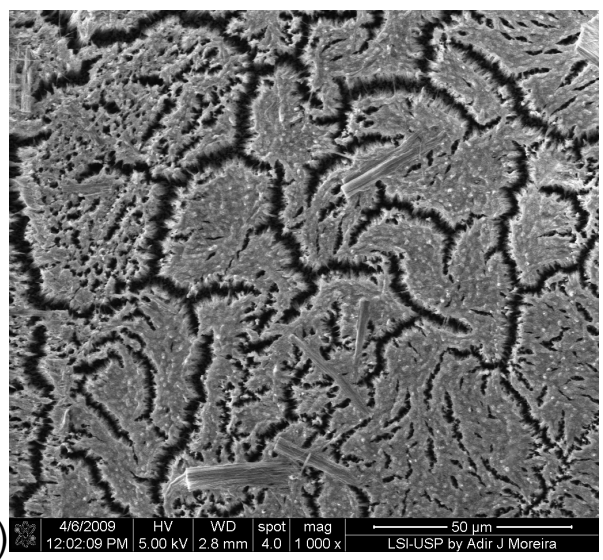

(b

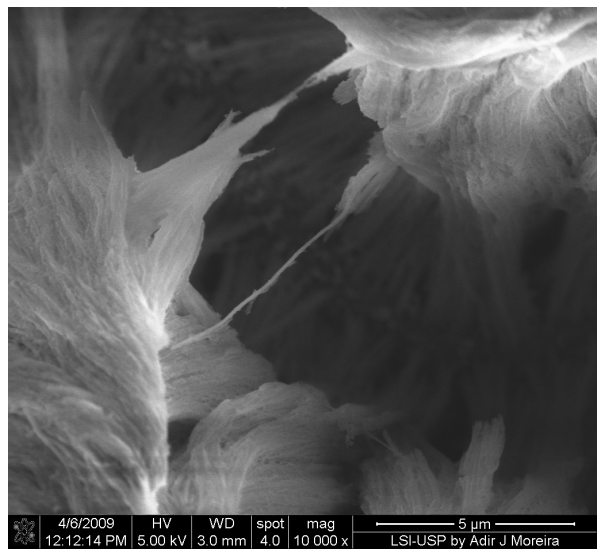

(c)

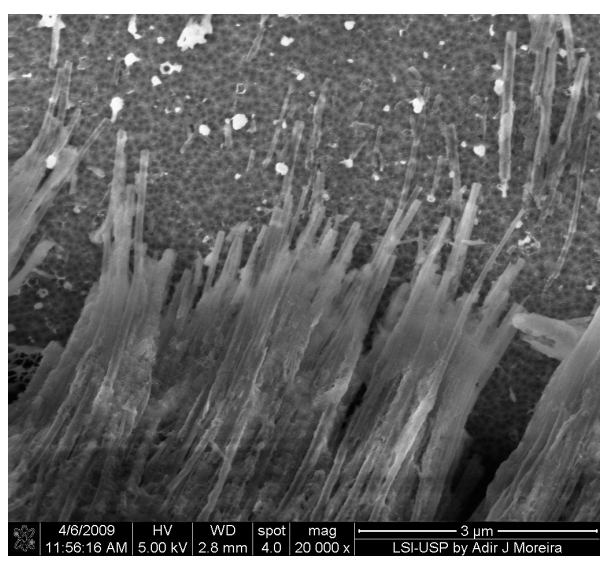

(d)

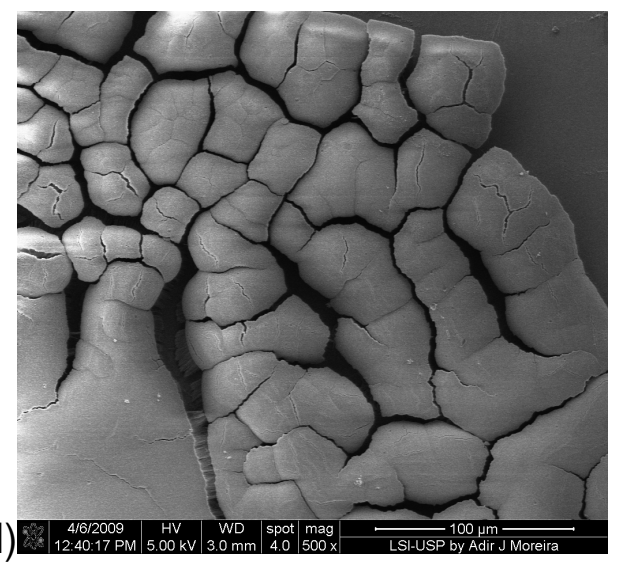

(e)
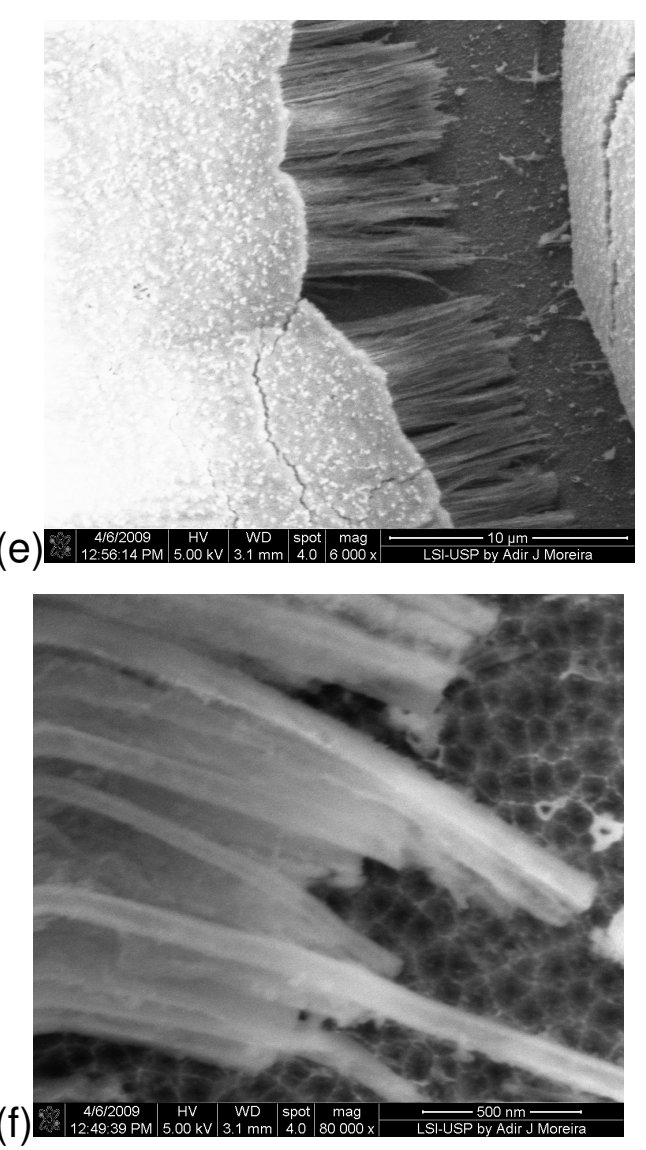

Figura 4.67 Imagens MEV dos nanotubos de silício obtidas nas amostras A7 (a-c) e A8 (d-f) em pH 5,5 e 6,5, respectivamente. 


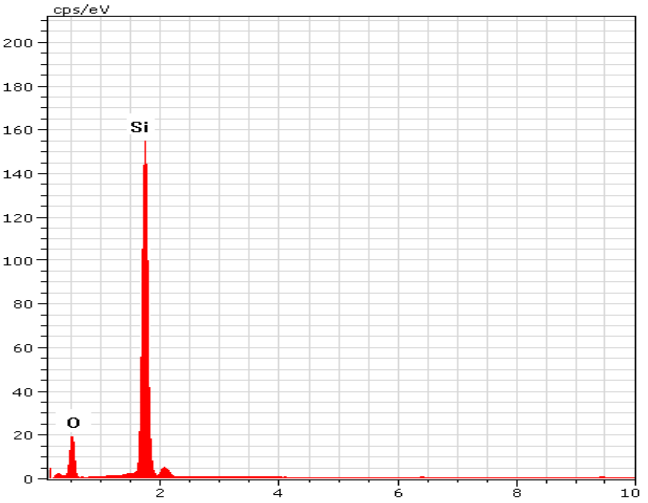

(a)

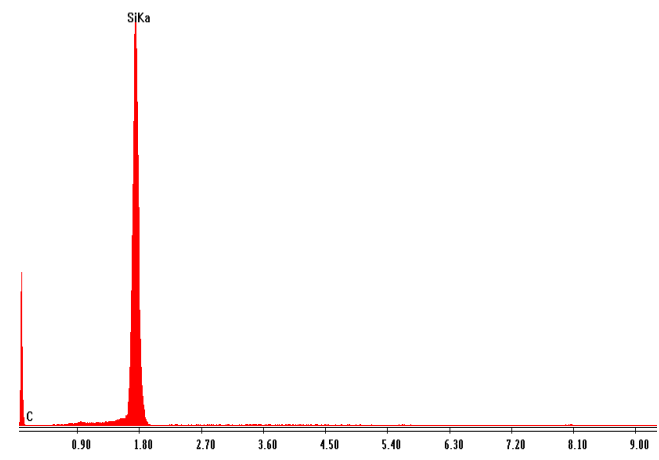

(C)

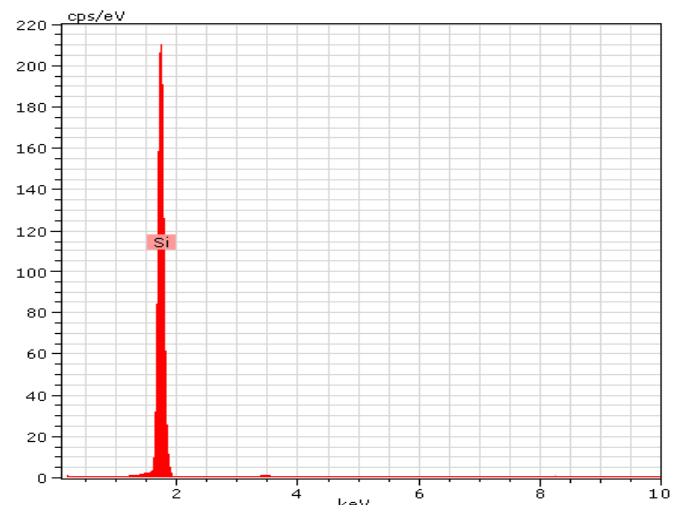

(b)

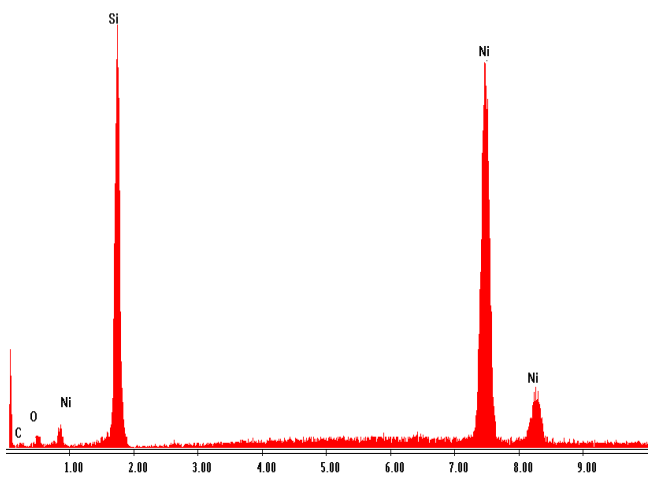

(d)

Figura 4.68. Espectros EDS das amostras: (a) D80 (pH 5,5), (b) D82(pH 6,5), (c) A7 (pH $5,5)$, e (d) A8 (pH 6,5)
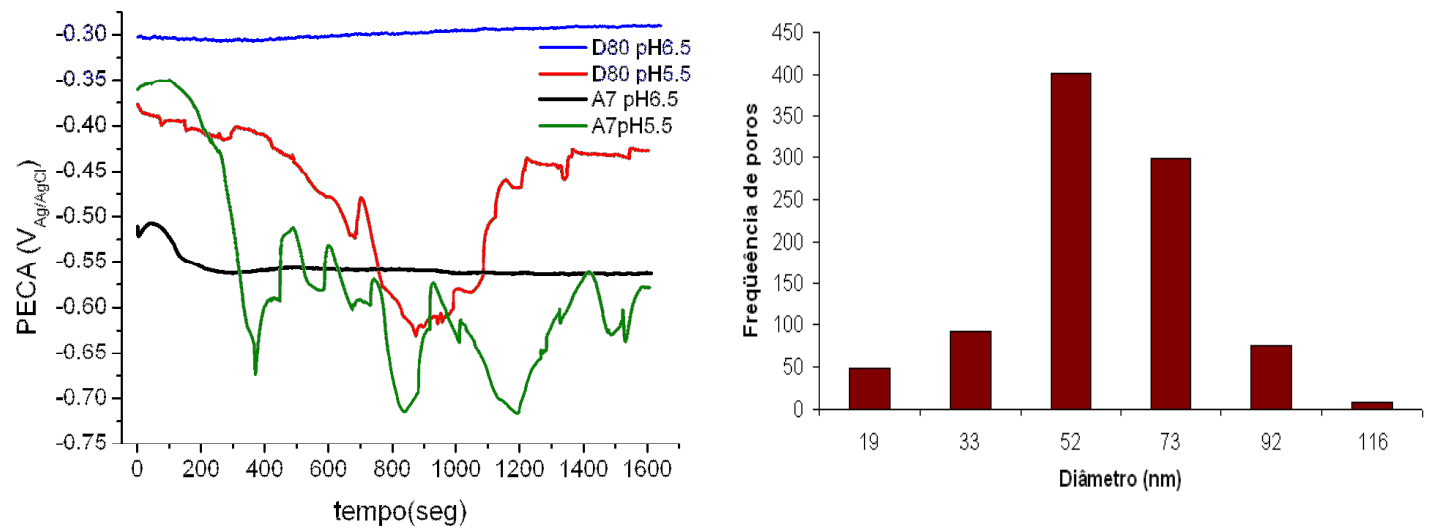

Figura 4.69. (a) variação do PECA ao longo do tempo, e (b) histograma da distribuição do diâmetro dos NTS.

Analisando as curvas PECAs das amostras B80 e A7, em pH 5,5, temos que, para um tempo de 1600 segundos (26 min), o valor do PECA para a amostra B80 foi de $-0,43 \mathrm{~V}_{\mathrm{Ag} / \mathrm{AgCl}}$ e de $-0,57 \mathrm{~V}_{\mathrm{Ag} / \mathrm{AgCl}}$ para a amostra $\mathrm{A} 7$. 
Se considerarmos que para este nível de $\mathrm{pH}$, o diagrama de Pourbaix do $\mathrm{Ni}$ (Figura A4) [150] aponta que o potencial redox do $\mathrm{Ni}$ é de $-0,5 \mathrm{~V}_{\mathrm{Ag} / \mathrm{AgCl}}$, sendo este valor da mesma ordem de magnitude do PECA de $A 7$ e mais negativa que o PECA de B80. Nessas condições, não deveria acontecer deposição de Ni sobre a amostra B80 e existiria alguma probabilidade de deposição na amostra A7. No entanto, os espectros EDS destas amostras não evidenciaram a presença de Ni nas estruturas dos NTSs. Analisando detalhes mais finos das curvas PECAs, foi observado que no instante próximo de 800 segundos, os valores dos potenciais de ambas amostras se deslocam para potenciais mais negativos em relação ao potencial redox do $\mathrm{Ni}$, condicionando ao eletrodo para uma possível deposição de $\mathrm{Ni}$, já que as condições termodinâmicas seriam favoráveis para a redução $\mathrm{Ni}^{2+} / \mathrm{Ni}$ e do $\mathrm{H}^{+} / \mathrm{H}_{2}$, competindo entre eles [126,169]. Adicionalmente, neste particular instante, as condições também seriam favoráveis para a redução do $\mathrm{SO}_{4}^{2-}$ nas suas diferentes formas (Figura A2) [150]. Assim, neste curto instante de tempo, onde o potencial atinge valores bem negativos existe a possibilidade de reduzir o níquel em pequenas concentrações que não seria detectável pelas limitações da técnica.

As curvas PECAs correspondentes às amostras $\mathrm{B} 80$ e A7, em pH 6,5, mostram um comportamento estável, isto é, os potencias de circuito aberto atingiram rapidamente o estado estacionario. A tendência final do PECA de $B 80$ é da ordem de $-0,30 \mathrm{~V}_{\mathrm{Ag} / \mathrm{AgCl}}$ e de $-0,56 \mathrm{~V}_{\mathrm{Ag} / \mathrm{AgCl}}$ para $\mathrm{A} 7$, respectivamente (Figura 4.69a). O valor do PECA para B80 está acima do potencial redox do $\mathrm{Ni}\left(-0,5 \mathrm{~V}_{\mathrm{Ag} / \mathrm{AgCl}}\right)$ [150], sendo esta uma condição desfavorável para a redução do $\mathrm{Ni}^{2+} / \mathrm{Ni}$. No entanto, as condições são favoráveis para a reação anódica expressa pela equação (4.22), onde preferencialmente se consome lacunas e libera íons $\mathrm{H}^{+}$e estes podem, eventualmente, modificar localmente o $\mathrm{pH}$ da superfície tornando-o mais ácido e, possivelmente, passivando-o localmente através da formação de ligações Si-H que daria origem a uma corrosão controlada cujo efeito 
efetivo seria formação dos NTSs. Efetivamente, nesta amostra foi observada a formação de NTSs (Figura 4.66f a 4.66h).

No caso da amostra A7 em pH 6,5, observa-se na Figura 4.69a, que 0 PECA começa em -0,51 $\mathrm{V}_{\mathrm{Ag} / \mathrm{AgCl}}$ e tende ao estado estacionário entorno de $-0,56 \mathrm{~V}_{\mathrm{Ag} / \mathrm{AgCl}}$. Esta condição do eletrodo é favorável para a reação catódica $\mathrm{SO}_{4}^{2-}$ expressa nas equações (4.7) a (4.9). O efeito desta reação catalisa a formação do $\mathrm{SiO}_{2}$, que posteriormente será removido pelas espécies fluoradas. Esta reação pode ser expressa pelas equações (4.18) a (4.21). A oxidação do Si e posterior remoção libera os elétrons que poderiam provocar a redução $\mathrm{Ni}^{2+} / \mathrm{Ni}$. Nestas condições eletroquímicas, a reação anódica (4.22) não é favorável e, como conseqüência, supõe-se que a superfície do substrato não pode ser passivada localmente através da formação de ligações Si-H. Assim, em termos efetivos, podemos ter a redução do $\mathrm{Ni}$ e a corrosão do $\mathrm{Si}$, acontecendo simultaneamente, originado a formação dos NTSs em fase de transformação para nanotubos de níquel.

Como os tubos foram formados a partir de uma camada mesoporosa com poros de dimensões nanométricas, as dimensões destes tubos devem ser da mesma ordem de magnitude à dos poros da estrutura inicial. A análise estatística das dimensões geométricas dos NTSs em uma área de $1 \mu \mathrm{m}^{2}$ mostra que os diâmetros externos dos NTS oscilam entre 19 a $116 \mathrm{~nm}$ com predominância dos de diâmetro externo entre 52 a 73 nm (Figura 4.69b).

A literatura tem reportado a síntese de NTS com dimensões geométricas da mesma ordem de magnitude dos NTSs obtidos no presente trabalho [29-35]. Nesses trabalhos, as tecnologias utilizadas para a obtenção dos NTSs precisam de equipamento altamente sofisticado e uso de substancias agressivas. Assim, a contribuição deste trabalho, em relação aos reportados pela literatura, esta relacionado ao baixo custo e 
simplicidade dos procedimentos experimentais, e podem ser implementados facilmente em condições de temperatura ambiente.

\subsubsection{Análises Raman dos microtubos de silício}

A caracterização estrutural dos diferentes MTS e NTS obtidos durante 0 presente trabalho mostrou tubos bem definidos, enquanto que, a análise química via EDS, mostrou que os MTS estão predominantemente constituídos de silício com pequenas concentrações de outros metais, excetuando aquelas estruturas onde ocorreu a formação dos MTN via deslocamento galvânico (amostras B20, B24, e B50). A estequiométrica química, das estruturas de NTSs e MTSs não pode ser determinada apenas a partir dos espectros EDS. Neste sentido as estruturas tubulares foram caracterizadas por espectroscopia Raman, com a finalidade de determinar a estrutura química dos tubos.

A Figura 4.70 mostra as imagens MEV das amostras imersas em solução de $0,25 \mathrm{M} \mathrm{NH}_{4} \mathrm{~F}$ misturada com $5 \times 10^{-2} \mathrm{M}$ de oxidante em $\mathrm{pH}$ 6,5: P44 $\left(\mathrm{NiSO}_{4}\right), \mathrm{B} 99 \mathrm{~A}\left(\mathrm{Na}_{2} \mathrm{SO}_{4}\right)$; e em pH 7,5: P77D $\left(\mathrm{Na}_{2} \mathrm{SO}_{4}\right)$; B101C e B106C

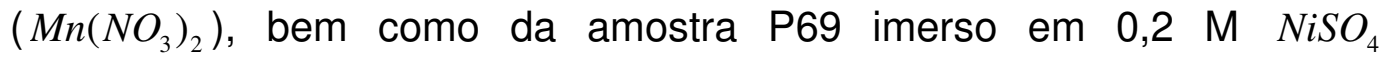
misturado com 2,5 $\mathrm{M} \mathrm{NH} H_{4} \mathrm{~F}$. Independentemente do tipo de oxidante utilizado nessas amostras, observa-se que os MTS apresentam uma aparência rugosa, sugerindo uma estrutura porosa (Figura 4.70), cuja origem não pode ser atribuída apenas às partículas metálicas depositadas na estrutura, já que similar estrutura observa-se nas amostras isentas de metais (B99A e P77D), obtidas em uma solução com $\mathrm{Na}_{2} \mathrm{SO}_{4}$ (Figura 4.70b e 4.70c, respectivamente).

Os espectros Raman das amostras P44, B99C e B101C são mostrados na Figura 4.71. A característica principal destes espectros é a presença de um pico intenso localizado em $521 \mathrm{~cm}^{-1}$ que é atribuído ao deslocamento Raman de primeira ordem do fônon óptico das ligações Si$\mathrm{Si}$, enquanto que os picos localizados em $970 \mathrm{~cm}-1$ atribuem-se aos 
efeitos Raman de segunda ordem [188-190]. É importante indicar que apenas na amostra P44, observa-se um pico adicional localizado entorno de $490 \mathrm{~cm}^{-1}$ que é atribuído aos modos vibracionais das ligações Si-O-Si [189] ou à formação de silício amorfo [191]. Isto sugere a possível formação de uma camada de $\mathrm{SiO}_{2}$ nesta amostra.

(a)

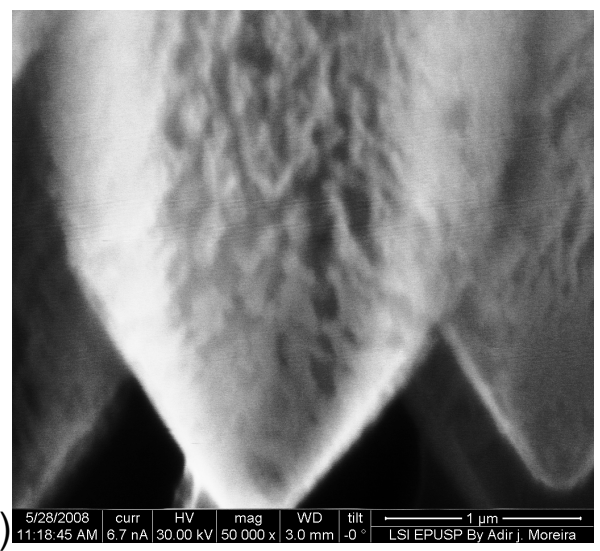

(c)

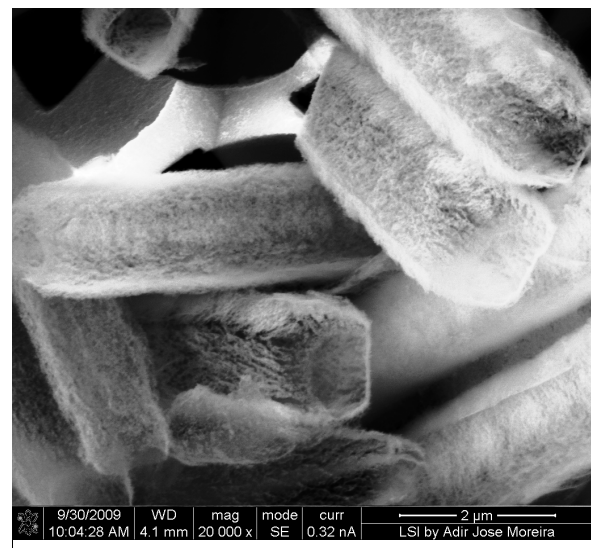

(e)

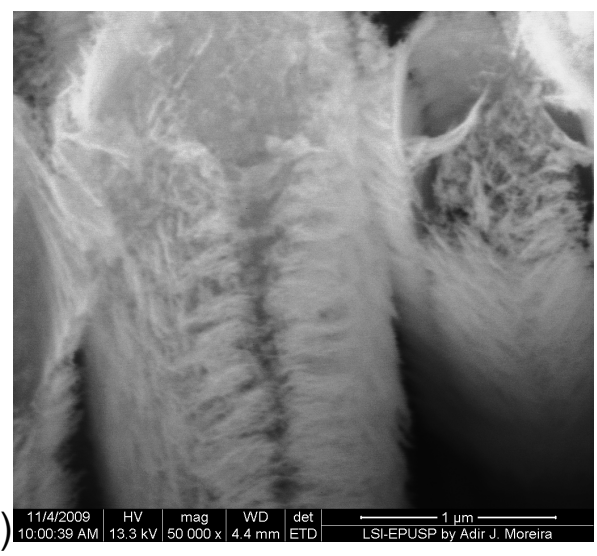

(b)

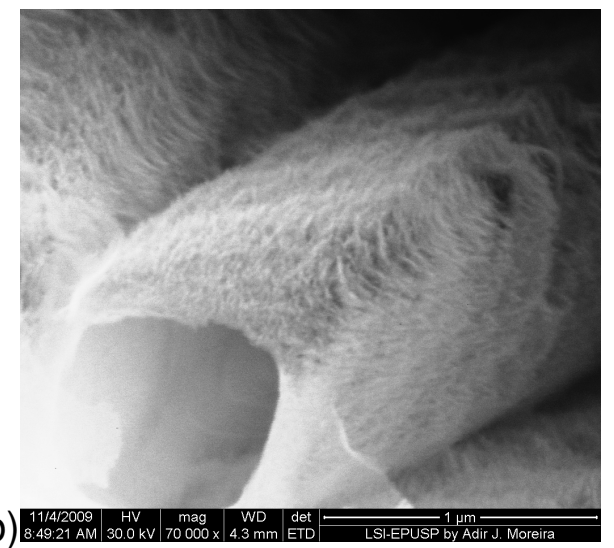

(d)
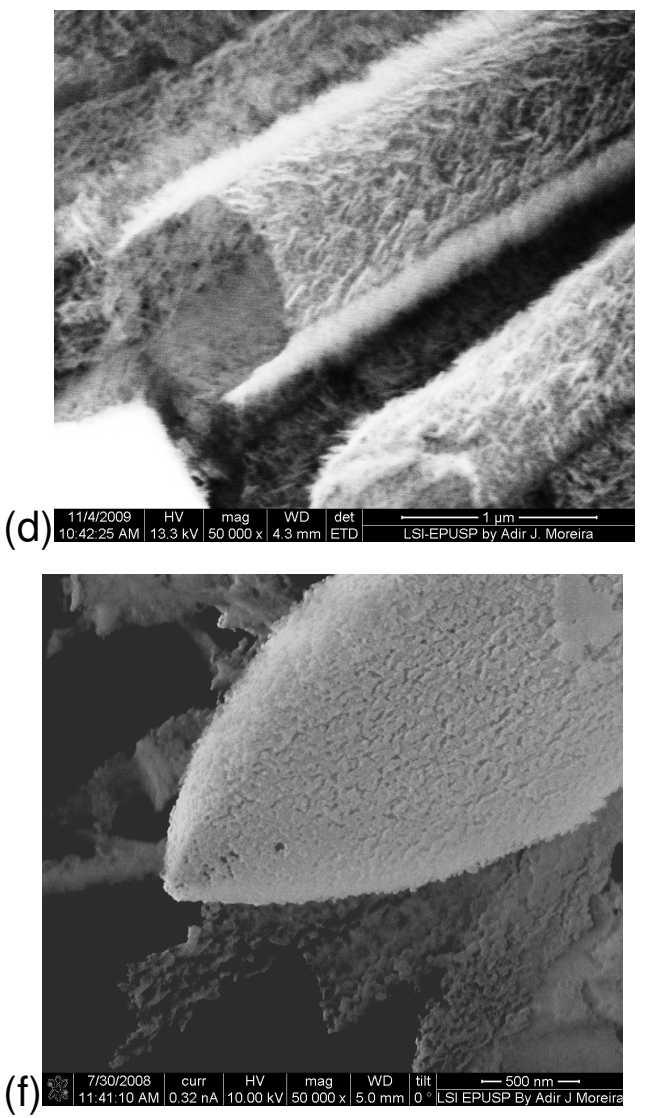

4.70. Imagens MEV das paredes de diferentes MTS obtidos em solução baseado em $\mathrm{NH}_{4} \mathrm{~F}$ e oxidante, em pH 6,5: (a) P44, (b)B99A ; e pH 7,5: (c) P77D, (d) B101C, e (e) B106C; e (f) P69. 


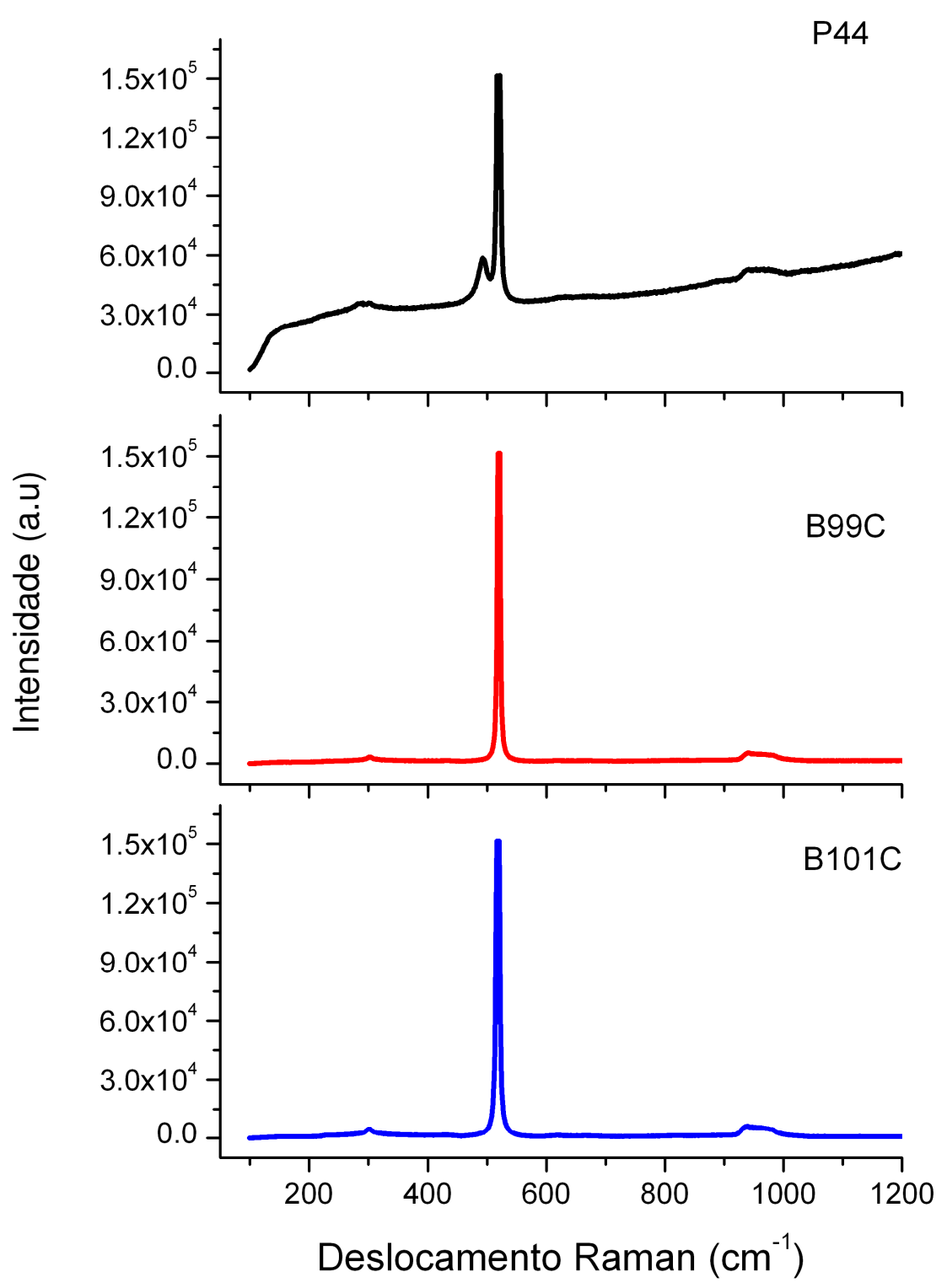

Figura 4.71. Espectros Raman das amostras P44, B99C e B101C.

A literatura em [188-191], reporta que as estruturas de silício microporoso, com diâmetro médio de poros menor do que 2 nm [97,98,192,193], promovem o deslocamento da banda Raman correspondente ao fônon óptico do Si para $510 \mathrm{~cm}^{-1}$ junto com um alargamento da banda. Este comportamento da Banda Raman do Si é atribuído ao efeito do confinamento quântico dos não cristais de Si na estrutura microporosa. Como o espectro Raman dos tubos é praticamente igual ao espectro de uma lâmina de silício podemos afirmar que os tubos são constituídos de estruturas remanescentes do cristal de $\mathrm{Si}$ conservando sua 
estequiométrica e que as dimensões destas estruturas cristalinas não apresentam efeitos de confinamento quântico. 


\section{CAPÍTULO $v$}

\section{Conclusões}

A contribuição do presente trabalho é a proposta de fabricação de estruturas de micro tubos de silício e nano tubos de silício através de processos químicos e eletroquímicos utilizando-se como material de partida as camadas de silício macroporoso e silício mesoporoso, respectivamente.

Para identificar os mecanismos envolvidos na formação das estruturas tubulares de silício, foram realizados ensaios em diferentes condições químicas e eletroquímicas. Para tal fim, foram utilizadas diferentes camadas de silício poroso, diferentes soluções eletrolíticas contendo diferentes agentes oxidantes metálicos e controlando o nível de $\mathrm{pH}$ da solução eletroquímica. O comportamento eletroquímico do processo de formação dos tubos de silício foi estudado a partir da analises das curvas de voltametria, do potencial de circuito aberto e medidas de capacitância em freqüência intermediaria $(10 \mathrm{kHz})$. Análises estruturais e químicas foram realizadas através da microscopia eletrônica de varredura, espectroscopia EDS e espectroscopia Raman, respectivamente.

Os resultados obtidos no presente trabalho nos permitem arribar às seguintes conclusões:

1. Foi mostrada a possibilidade de fabricação dos nano tubos e micro tubos de silício e tubos de níquel através de métodos eletroquímicos utilizando como substrato de partida camadas macro e meso porosas de silício imerso em uma solução aquosa fluorada misturada com agentes oxidantes.

2. A formação das estruturas tubulares de silício esta condicionada a um adequado controle dos parâmetros eletroquímicos como tipo de oxidante e nível de $\mathrm{pH}$ da solução. Outro fator importante a ser levado em consideração na formação das estruturas tubulares de 
Si está relacionado com as características químicas das camadas de silício poroso.

3. Foi verificado que a formação dos microtubos de silício é sensível à variação do $\mathrm{pH}$ e que a formação efetiva dos tubos acontece apenas em soluções eletrolíticas com nível de pH entre 5,5 a 7,5 dependendo do tipo de oxidante empregado.

4. Os resultados obtidos apontam que no processo de formação dos tubos existe uma competência entre um processo de corrosão isotrópica e outro de característica anisotrópica. O predomínio do tipo de corrosão depende do nível de pH da solução.

5. Os Microtubos, bem definidos, foram obtidos em soluções com predominância da corrosão anisotrópica não descartando a participação pequena dos processos de corrosão isotrópica.

6. Foi verificado que os agentes oxidantes fortes permitem a formação dos microtubos de silício em soluções eletrolíticas com nível de $\mathrm{pH}$ na faixa entre 5,5 a 7,5, sendo esta a faixa analisada no presente trabalho, já os agentes oxidantes fracos apenas permitem a formação das estruturas tubulares para soluções com pH entre 6,5 e 7,5.

7. Foi mostrada a possibilidade de formação de microtubos e microbarras metálicas, através do controle das condições químicas e eletroquímicas da solução eletrolítica utilizada para a formação das estruturas tubulares de silício. A condição da solução eletroquímica com nível de $\mathrm{pH} \quad 6,5$, permitiu a formação de estruturas de microtubos de $\mathrm{Ni}$, enquanto que tubos silício e barras de $\mathrm{Mn}$ foram obtidas em soluções com nível de pH 7,5. Em ambos os caso foram utilizados agentes oxidantes originados de sais de $\mathrm{Ni}$ e $\mathrm{Mn}$, respectivamente. Os resultados apontam que o processo de formação destas estruturas metálicas acontece via um processo de deslocamento galvânico.

8. A análise da composição química das estruturas tubulares de silício, realizadas mediante a técnica EDS, junto com os 
resultados da espectroscopia Raman, aponta que as estruturas tubulares obtidas efetivamente são tubos de $\mathrm{Si}$, cuja estrutura estequiométrica é a mesma que a do cristal de $\mathrm{Si}$ 


\section{APÊNDICE}

Nesta seção são apresentados os diagramas de Pourbaix dos elementos usados no presente trabalho que foram extraídas da referência [150]. Inclui-se também o diagrama de Pourbaix do silício e do HF para fines de comparação das condições termodinâmicas das soluções empregadas. Em todos os casos, apenas as equações das reações empregadas no presente trabalho são apresentadas. Os diagramas correspondem aos diferentes elementos em meio aquoso e $25^{\circ} \mathrm{C}$.

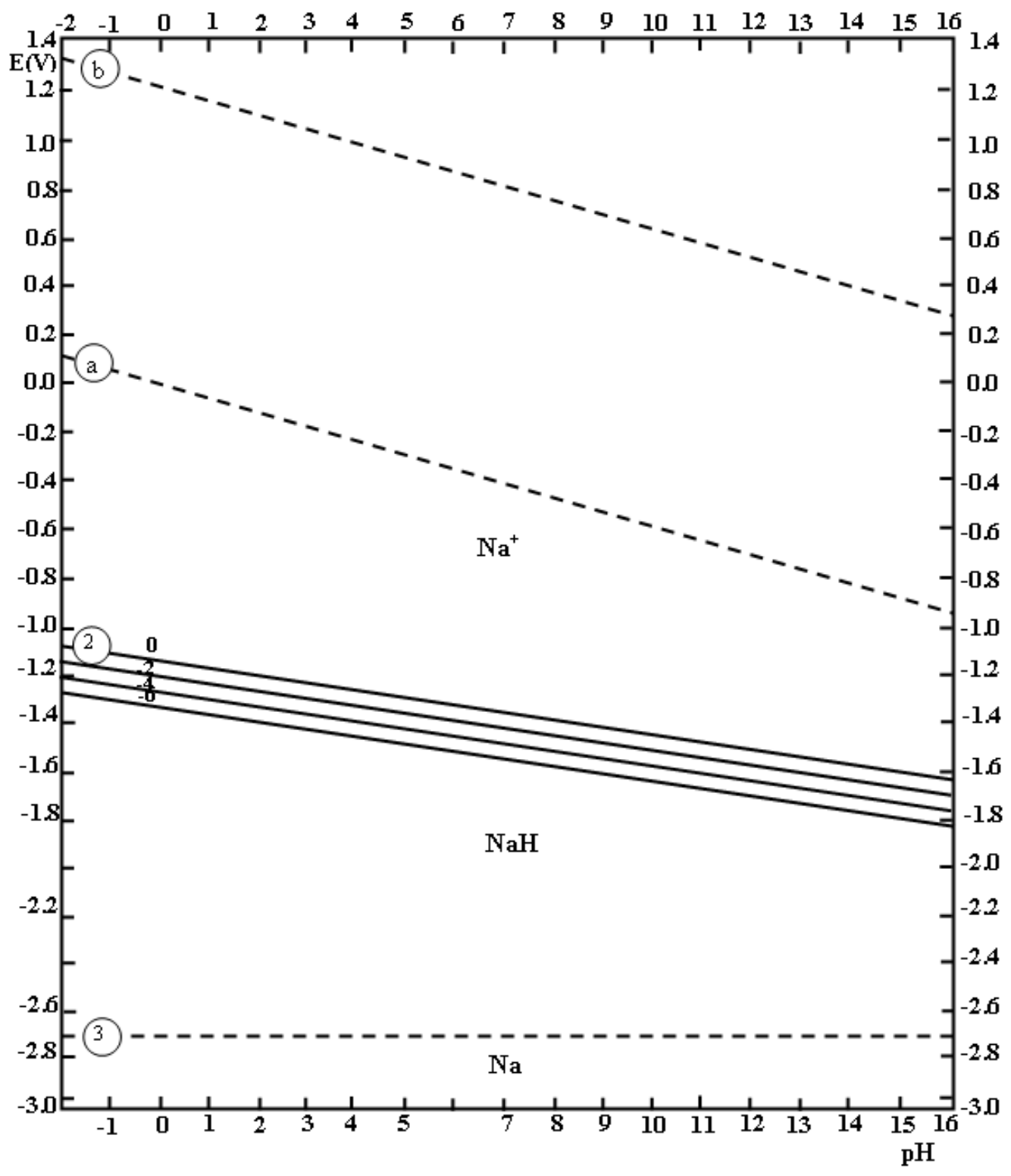

Figura A1. Diagrama de Pourbaix do sistema Sódio-água 
(2) $\mathrm{Na}+\mathrm{H}^{+}+2 e \longrightarrow \mathrm{NaH} \quad E_{o}=-1.162-0.0295 \mathrm{pH}+0.0295 \log \left(\mathrm{Na}^{+}\right)$

(3) $\mathrm{Na}+e \longrightarrow \mathrm{Na} \quad E_{o}=-2.714+0.0591 \log \left(\mathrm{Na}^{+}\right)$

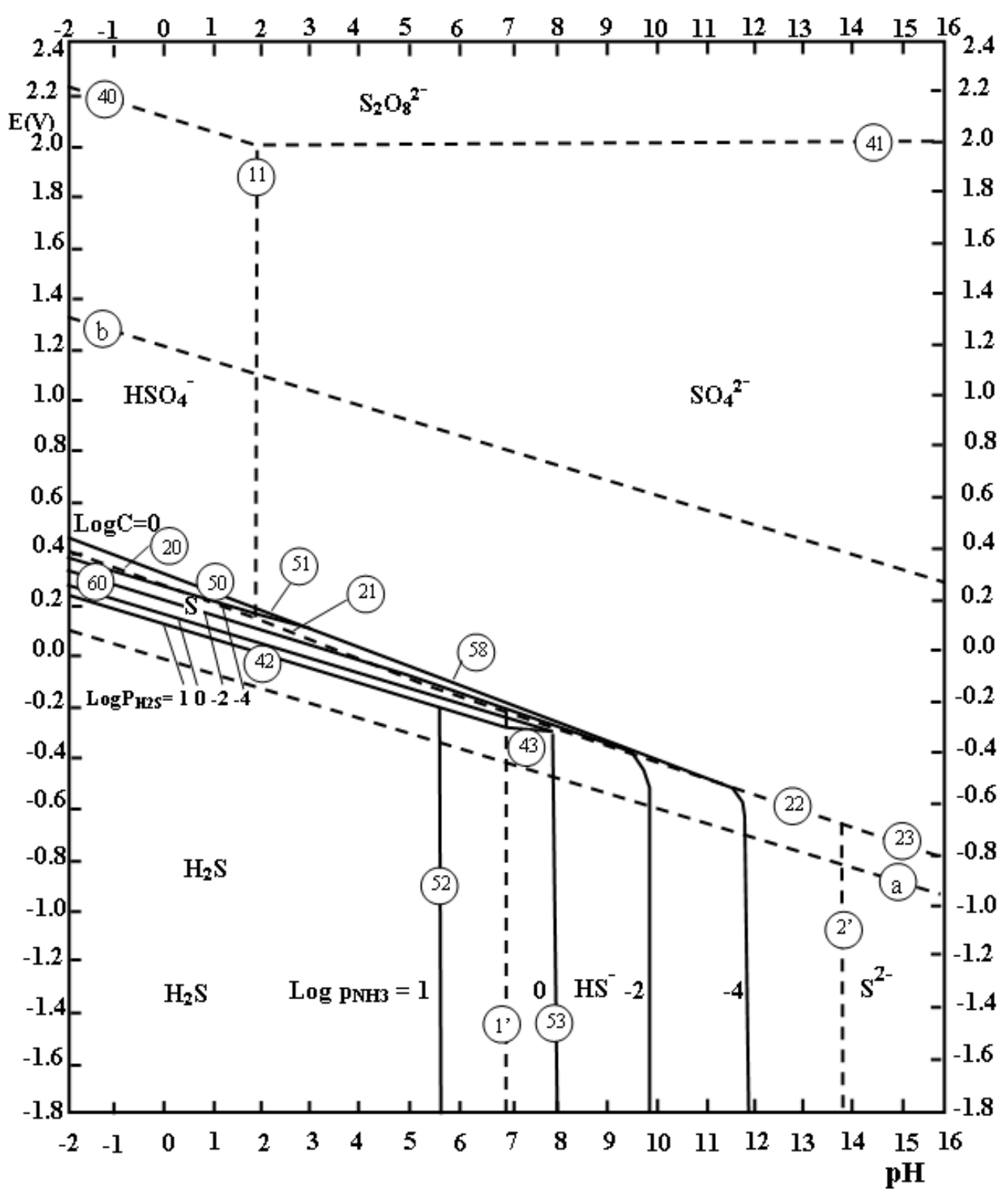

Figura A2. Diagrama de Pourbaix do sistema Enxofre-água
(21) $\mathrm{SO}_{4}^{2-}+10 \mathrm{H}^{+}+8 e \longrightarrow \mathrm{H}_{2} \mathrm{~S}+4 \mathrm{H}_{2} \mathrm{O}$
$E_{o}=0.303-0.0739 \mathrm{pH}$
(51) $\mathrm{SO}_{4}^{2-}+8 \mathrm{H}^{+}+6 e \longrightarrow \mathrm{S}+4 \mathrm{H}_{2} \mathrm{O} \quad E_{o}=0.357-0.0788 \mathrm{pH}+0.0098 \log \mathrm{C}$
(60) $\mathrm{H}_{2} \mathrm{~S} \longrightarrow \mathrm{S}+2 \mathrm{H}^{+}+2 e$ $E^{0}=0.171-0.0591 \mathrm{pH}-0.0295 \log p_{\mathrm{H}_{2} \mathrm{~S}}$ 


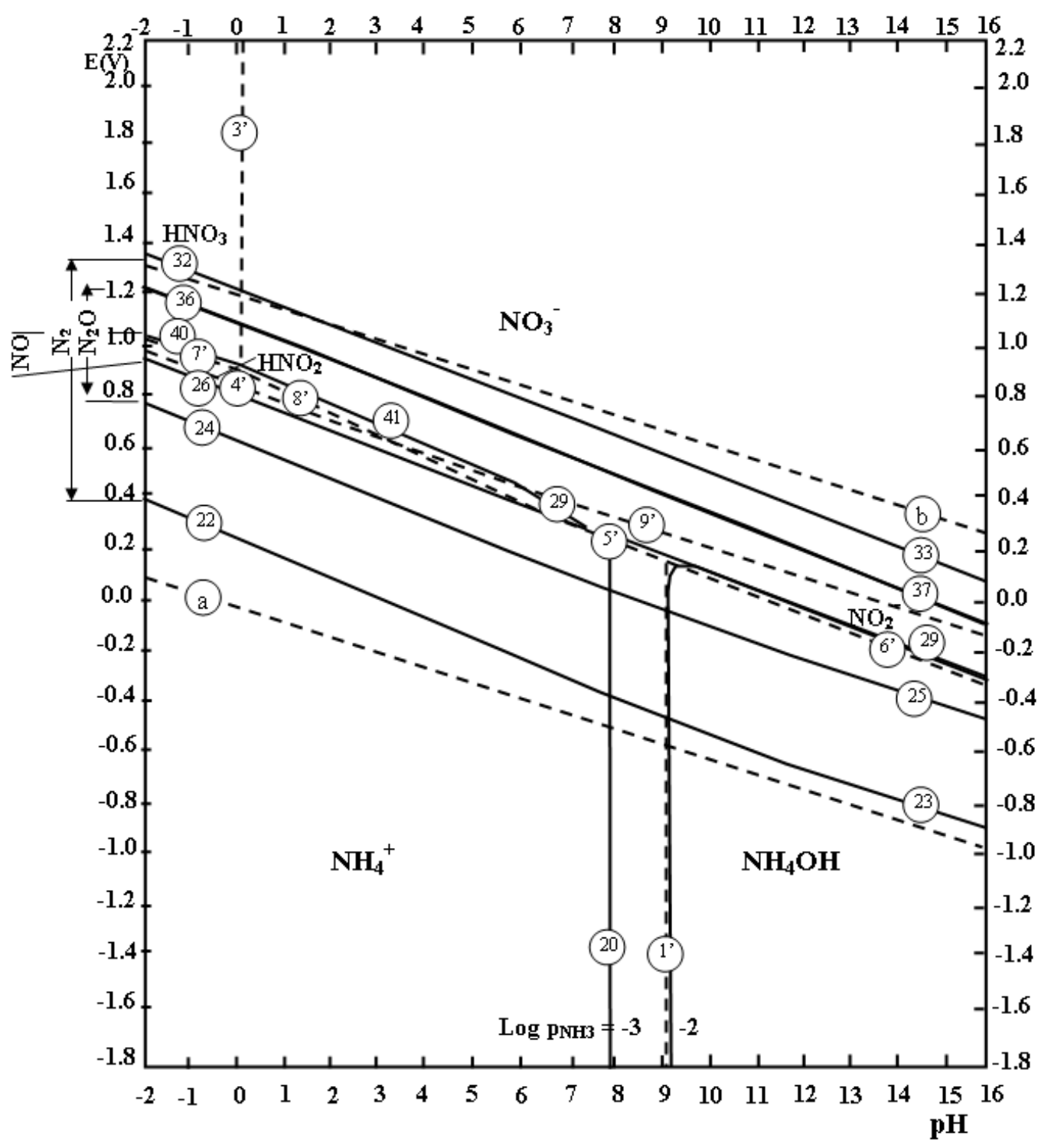

Figura A3. Diagrama de Pourbaix do sistema Nitrogênio-água

(5') $\mathrm{NH}_{4}^{+}+2 \mathrm{H}_{2} \mathrm{O} \longrightarrow \mathrm{NO}_{2}^{-}+8 \mathrm{H}^{+}+6 e$

$$
\begin{aligned}
& E^{0}=0.897-0.0788 p H \\
& E_{o}=0.934-0.0886 p H \\
& E_{o}=0.835-0.0591 p H
\end{aligned}
$$

(8') $\mathrm{HNO}_{2}+\mathrm{H}_{2} \mathrm{O} \rightleftarrows \mathrm{NO}_{3}^{-}+3 \mathrm{H}^{+}+2 e$

(9') $\mathrm{NO}_{2}^{-}+\mathrm{H}_{2} \mathrm{O} \rightleftarrows \mathrm{NO}_{3}^{-}+2 \mathrm{H}^{+}+e$

(20) $\mathrm{NH}_{4}^{+} \rightleftarrows N H_{3}+H^{+}$

$$
\log \left(\frac{p_{N H_{3}}}{N H_{4}^{+}}\right)=-11.02-p H
$$

(22) $2 \mathrm{NH}_{4}^{+} \rightleftarrows N_{2}+8 H^{+}+6 e \quad E_{o}=0.275-0.0788 p H+0.0098 \log \frac{\left(p_{N_{2}}\right)}{\left(N H_{4}^{+}\right)^{2}}$ 
(24) $2 \mathrm{NH}_{4}^{+}+\mathrm{H}_{2} \mathrm{O} \rightleftarrows \mathrm{N}_{2} \mathrm{O}+10 \mathrm{H}^{+}+8 e \quad E_{o}=0.647-0.0739 p H+0.0074 \log \frac{\left(p_{\mathrm{N}_{2} \mathrm{O}}\right)}{\left(\mathrm{NH}_{4}^{+}\right)^{2}}$

(33) $\mathrm{N}_{2}+6 \mathrm{H}_{2} \mathrm{O} \rightleftarrows 2 \mathrm{NO}_{3}^{-}+12 \mathrm{H}^{+}+10 e \quad E_{o}=1.246-0.0709 \mathrm{pH}+0.0059 \log \frac{\left(\mathrm{NO}_{3}^{-}\right)^{2}}{p_{\mathrm{N}_{2}}}$

(37) $\mathrm{N}_{2} \mathrm{O}+5 \mathrm{H}_{2} \mathrm{O} \rightleftarrows 2 \mathrm{NO}_{3}^{-}+10 \mathrm{H}^{+}+8 e \quad E_{o}=1.116-0.0739 p H+0.0074 \log \frac{\left(\mathrm{NO}_{3}^{-}\right)^{2}}{p_{\mathrm{N}_{2} \mathrm{O}}}$

(41) $\mathrm{NO}+2 \mathrm{H}_{2} \mathrm{O} \rightleftarrows \mathrm{NO}_{3}^{-}+4 H^{+}+3 e \quad E_{o}=0.957-0.0788 p H+0.0197 \log \frac{\left(\mathrm{NO}_{3}^{-}\right)}{p_{N O}}$

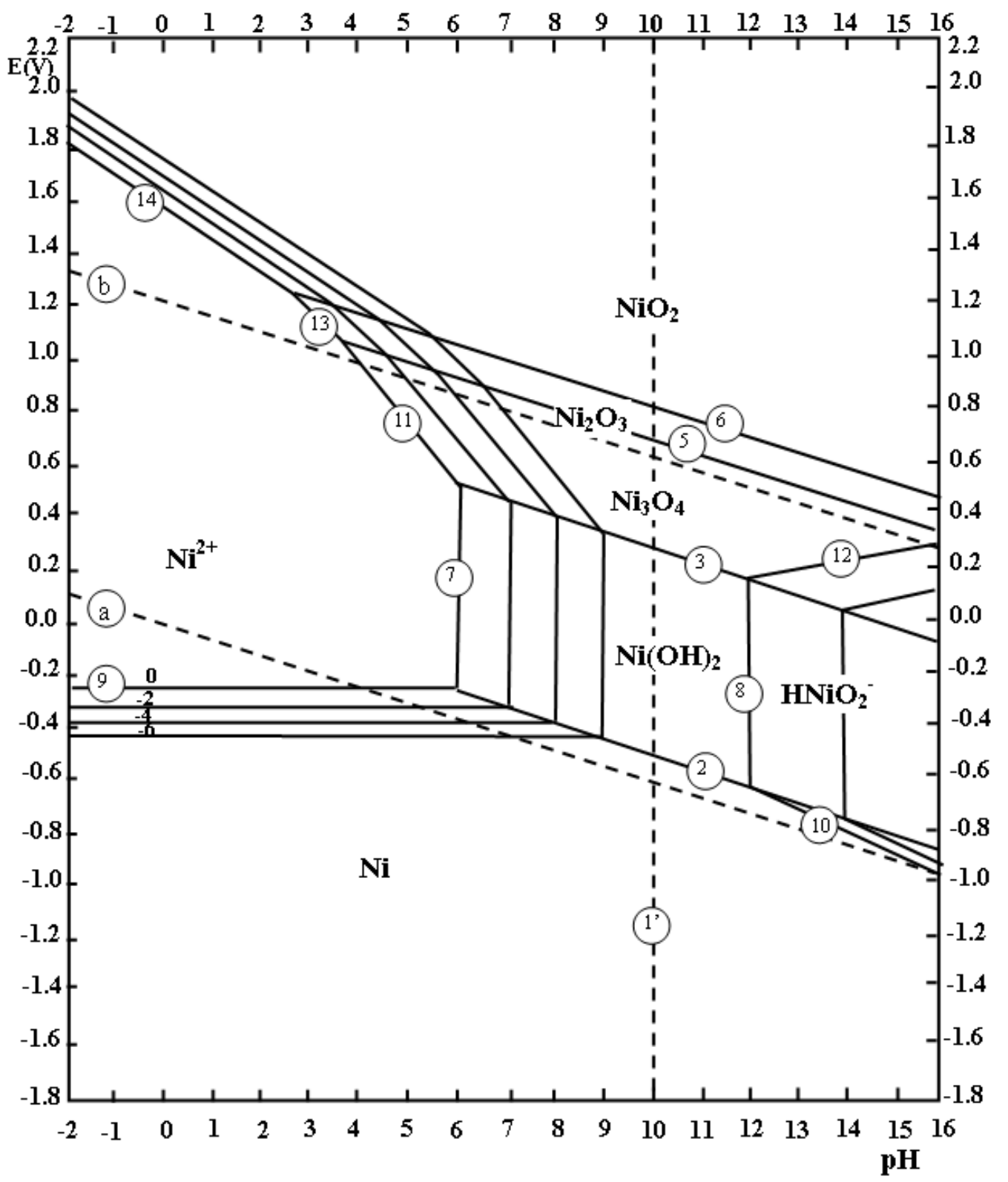

Figura A4. Diagrama de Pourbaix do sistema níquel-água 
(5) $2 \mathrm{Ni}_{3} \mathrm{O}_{4}+\mathrm{H}_{2} \mathrm{O} \rightleftarrows 3 \mathrm{Ni}_{2} \mathrm{O}_{3}+2 \mathrm{H}^{+}+2 e \quad E_{o}=1.305-0.0591 \mathrm{pH}$

(6) $\mathrm{Ni}_{2} \mathrm{O}_{3}+\mathrm{H}_{2} \mathrm{O} \rightleftarrows 2 \mathrm{NiO}_{2}+2 \mathrm{H}^{+}+2 e \quad E_{o}=1.434-0.0591 \mathrm{pH}$

(7) $\mathrm{Ni}^{2+}+\mathrm{H}_{2} \mathrm{O} \rightleftarrows \mathrm{NiO}+2 \mathrm{H}^{+} \quad \log \left(\mathrm{Ni}^{2+}\right)=12.18-2 \mathrm{pH}$

(9) $N i^{2+}+2 e \rightleftarrows N i \quad E_{o}=-0.258+0.0295 \log \left(N i^{2+}\right)$

(11) $3 \mathrm{Ni}^{2+}+4 \mathrm{H}_{2} \mathrm{O} \rightleftarrows \mathrm{Ni}_{3} \mathrm{O}_{4}+8 \mathrm{H}^{+}+2 e \quad E_{o}=1.977-0.2364 \mathrm{pH}-0.0886 \log \left(\mathrm{Ni}^{2+}\right)$

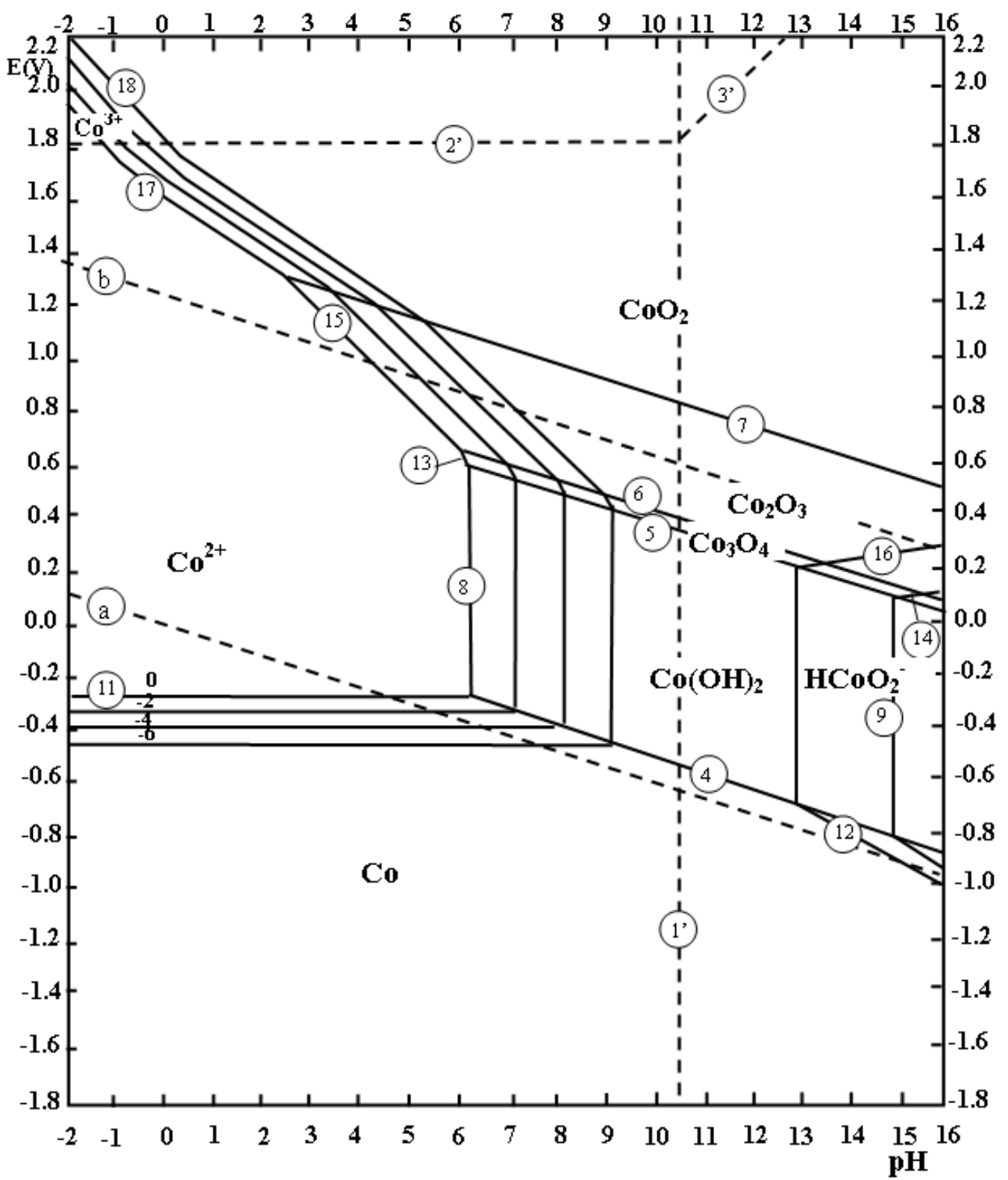

Figura A5. Diagrama de Pourbaix do sistema Cobalto-água 
(6) $2 \mathrm{Co}_{3} \mathrm{O}_{4}+\mathrm{H}_{2} \mathrm{O} \rightleftarrows 3 \mathrm{Co}_{2} \mathrm{O}_{3}+2 \mathrm{H}^{+}+2 e \quad E_{o}=1.018-0.0591 \mathrm{pH}$

(7) $\mathrm{Co}_{2} \mathrm{O}_{3}+\mathrm{H}_{2} \mathrm{O} \rightleftarrows 2 \mathrm{CoO}_{2}+2 \mathrm{H}^{+}+2 e \quad E_{o}=1.477-0.0591 \mathrm{pH}$

(8) $\mathrm{Co}^{2+}+\mathrm{H}_{2} \mathrm{O} \rightleftarrows \mathrm{CoO}+2 \mathrm{H}^{+} \quad \log \left(\mathrm{Co}^{2+}\right)=12.60-2 \mathrm{pH}$

(11) $\mathrm{Co}^{2+}+2 e \rightleftarrows C o \quad E_{o}=-0.277+0.0295 \log \left(\mathrm{Co}^{2+}\right)$

(13) $3 \mathrm{Co}^{2+}+4 \mathrm{H}_{2} \mathrm{O} \rightleftarrows \mathrm{Co}_{3} \mathrm{O}_{4}+8 \mathrm{H}^{+}+2 e \quad E_{o}=2.112-0.2364 \mathrm{pH}-0.0886 \log \left(\mathrm{Co}^{2+}\right)$

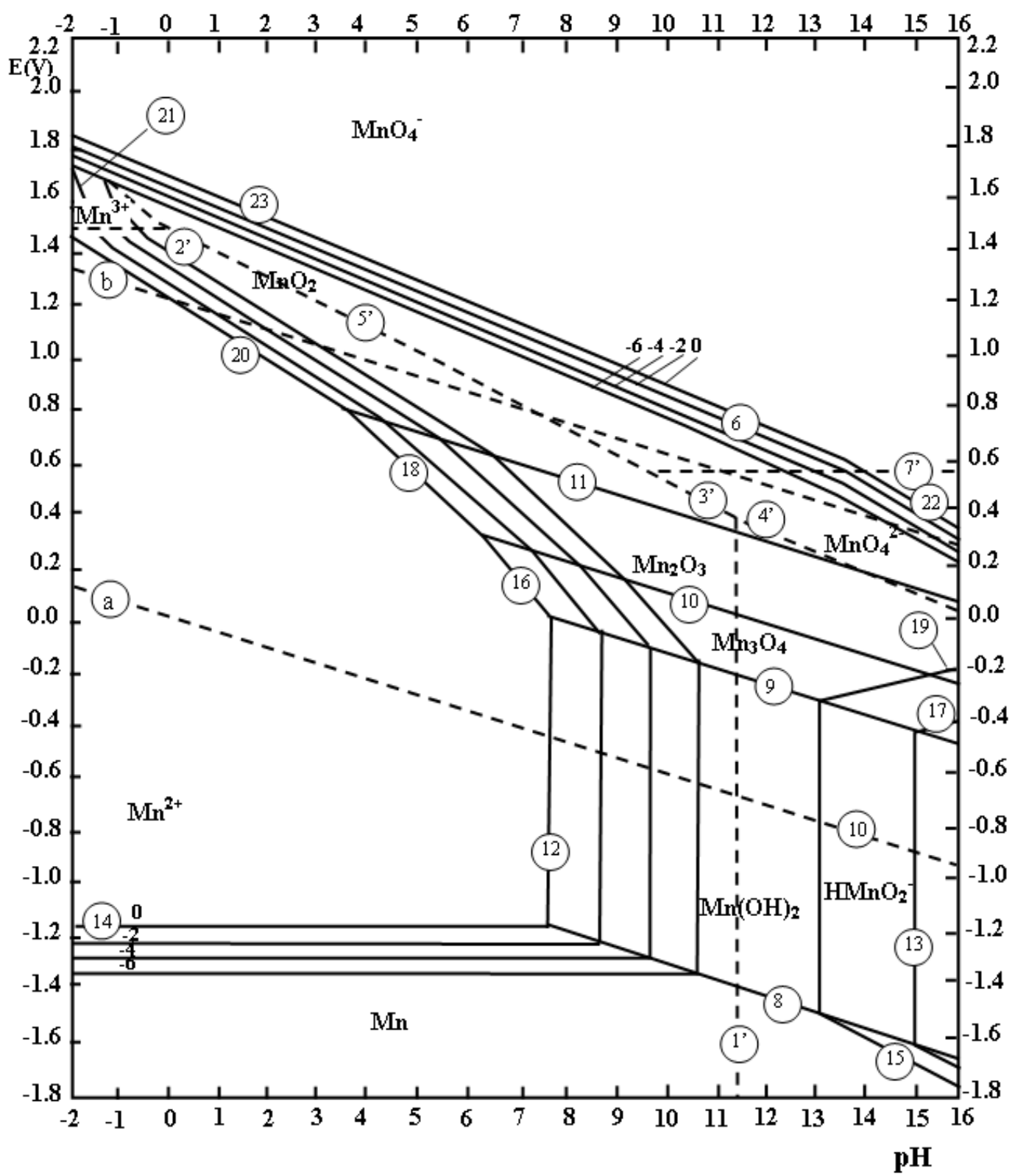

Figura A6. Diagrama de Pourbaix do sistema Manganês-água 
(10) $2 \mathrm{Mn}_{3} \mathrm{O}_{4}+\mathrm{H}_{2} \mathrm{O} \rightleftarrows 3 \mathrm{Mn}_{2} \mathrm{O}_{3}+2 \mathrm{H}^{+}+2 e \quad E_{o}=0.689-0.0591 p H$

(11) $\mathrm{Mn}_{2} \mathrm{O}_{3}+\mathrm{H}_{2} \mathrm{O} \rightleftarrows 2 \mathrm{MnO}_{2}+2 \mathrm{H}^{+}+2 e \quad E_{o}=1.014-0.0591 \mathrm{pH}$

(12) $\mathrm{Mn}^{2+}+\mathrm{H}_{2} \mathrm{O} \rightleftarrows \mathrm{MnO}+2 \mathrm{H}^{+}$ $\log \left(M n^{2+}\right)=15.31-2 p H$

(14) $\mathrm{Mn}^{2+}+2 e \rightleftarrows M n$ $E_{o}=-1.179+0.0295 \log \left(M n^{2+}\right)$

(16) $3 \mathrm{Mn}^{2+}+4 \mathrm{H}_{2} \mathrm{O} \rightleftarrows \mathrm{Mn}_{3} \mathrm{O}_{4}+8 \mathrm{H}^{+}+2 e \quad E_{o}=1.824-0.2364 \mathrm{pH}-0.0886 \log \left(\mathrm{Mn}^{2+}\right)$

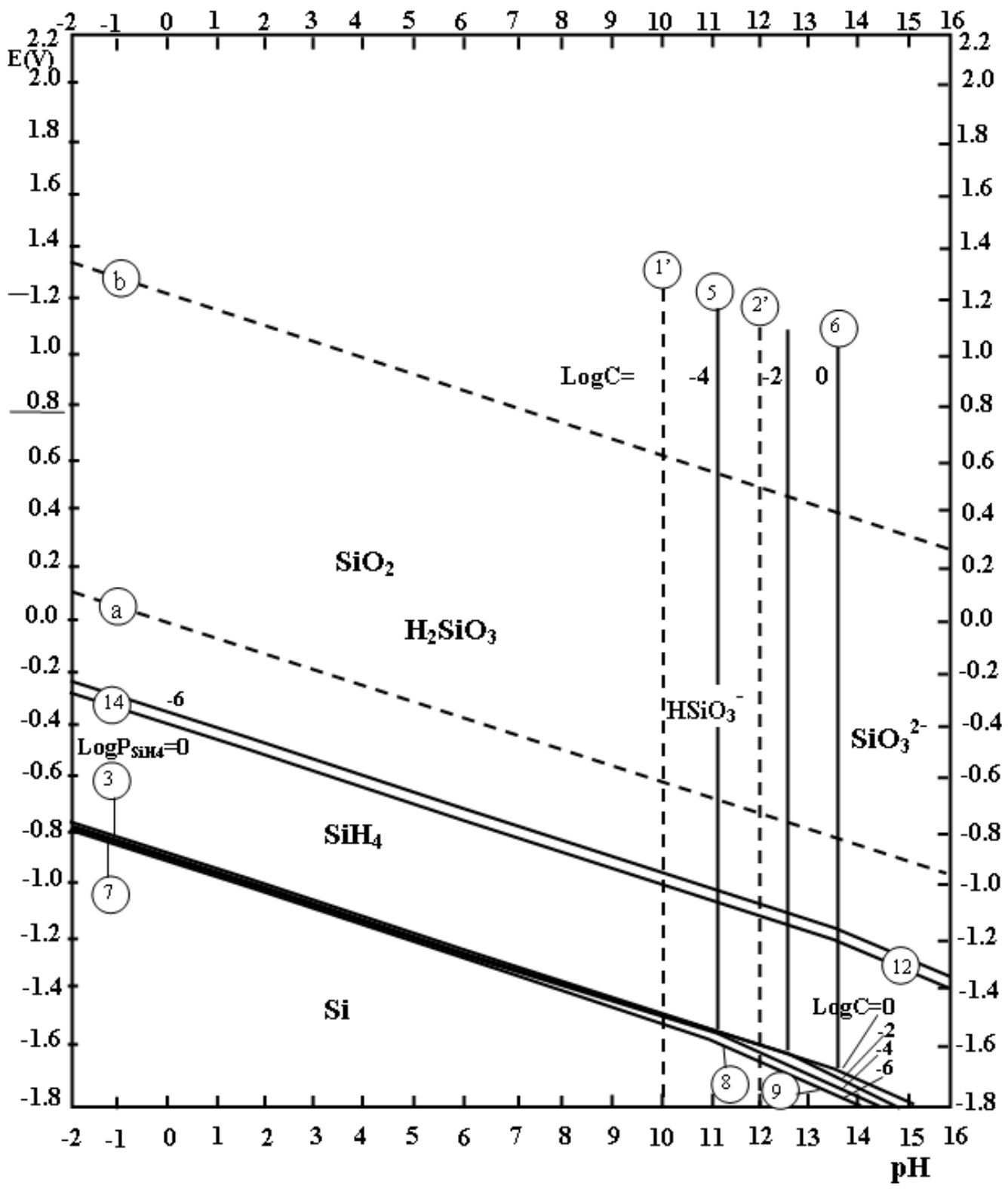

Figura A7. Diagrama de Pourbaix do sistema Silício-água 
(3) $\mathrm{Si}+2 \mathrm{H}_{2} \mathrm{O} \rightleftarrows \mathrm{SiO}_{2}+4 \mathrm{H}^{+}+4 e \quad \mathrm{E}_{o}=-0.857-0.0591 \mathrm{pH}$

(7) $\mathrm{Si}+3 \mathrm{H}_{2} \mathrm{O} \rightleftarrows \mathrm{H}_{2} \mathrm{SiO}_{3}+4 \mathrm{H}^{+}+4 e \quad E_{o}=-0.780-0.0591 p H-0.0148 \log \left(\mathrm{H}_{2} \mathrm{SiO}_{3}\right)$

(14) $\mathrm{SiH}_{4} \rightleftarrows \mathrm{Si}+4 \mathrm{H}^{+}+4 e \quad E_{o}=0.102-0.0591 \mathrm{pH}-0.0148 \log \left(p_{\mathrm{SiH}_{4}}\right)$

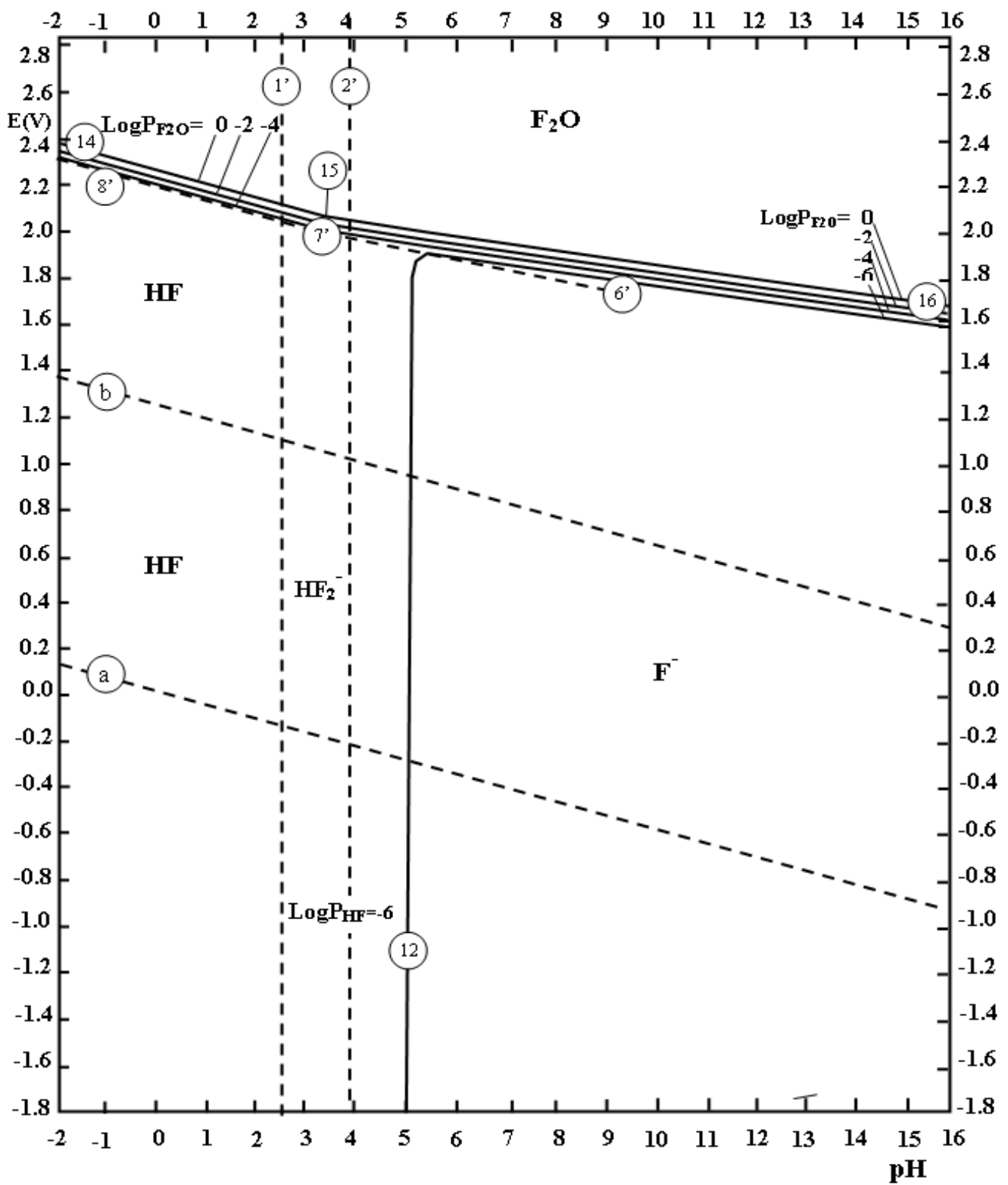

Figura A8. Diagrama de Pourbaix do sistema Flúor-água 


\section{ARTIGOS E TRABALHOS ACEITOS EM EVENTOS}

1. HUANCA, D. R.; SALCEDO, W. J.; Fabrication of Nickel Microtubes by Galvanic Displacement Method Using Macroporous Silicon as Template, ECS Transactions, V. 81, (2010)

2. HUANCA, D. R.; SALCEDO, W. J.; Silicon macrotubes fabrication using the porous silicon as starting material, Mateials Science in Semiconductor Processing, submitted for publication.

3. MARUTA, R. H.; KIM, H. Y.; HUANCA, D. R.; SALCEDO, W. J.; A new correlation-based granulometry algorithm with application in characterizing porous silicon nanomaterials, ECS Transactions, V. 81, (2010)

4. HUANCA, D. R.; RAMIREZ-FERNANADEZ, F. J.; SALCEDO, W. J.; Morphological and Structural Effect of Aluminum on Macroporous Silicon Layers, Journal of Materials Science and Engineering, Julho (2010)

5. HUANCA, D. R.; KIM, H. Y.; ELIAS, V. F.; SALCEDO, W. J.; Nickel Salt Effect on Macroporous Silicon Immersed in Fluoride Solutioon: From Silicon Microtubes to Nickel microtubes, ECS Transactions, V. 81, (2010

6. A new correlation-based granulometry algorithm for the structural porous silicon nanomaterials characterization, Porous Semicondutor Science and Technology 2010. Valencia, Espanha.

7. From porous silicon to silicon nanotubes, Porous Semicondutor Science and Technology 2010. Valencia, Espanha.

8. Morphological and structural effect of aluminum on Macroporous silicon layers, The 11th International Conference on Advanced Materials (ICAM) 2009, Rio de Janeiro. Brasil 
9. Silicon Nano-tube fabrication by Using a Macroporous Silicon as Starting Material, The 11th International Conference on Advanced Materials (ICAM) 2009, Rio de Janeiro. Brasil 


\section{REFERENCIA BIBLIOGRÁFICA}

1. LIJIMA, S; Helical Microtubules of Graphitic Carbon, Nature, V. 354, p. 56-58 (1991)

2. HU, J.; ODOM, T. W.; LIEBER, E C. M.; Chemistry and Physics in One Dimension: Synthesis of Nanowires and Nanotubes, Accounts of chemical Research, V. 32, p. 435-444 (1999).

3. RAO, C. N. R., GOVINDARAJ, E. A.; Nanotubes and Nanowires, RSC Publishing, Norfolk, Reino Unido (2005).

4. TENNE, R.; Inorganic Nanotubes and Fullerene-like Materials of Metal Dichalcogenide and related Layered Compounds, in Nanomaterials Handbook, Taylor Francis, Editor Yuri Gogotsi, p. 317-337 (2006)

5. ROCHE, S.; AKKERMANS, E.; CHAUVET, O.; HEKKING, F.; ISSI, J.; MARTEL, P. R.; MONTAMBAUX, G.; PONCHARAL, P.; Transport Properties, In Understanding Carbon nanotubos: From Basic to Applications, Springer, Editors A. Loiseau, P. Launois, P. Petit, S. Roche, J. P. Salvetat, p. 335-438 (2006)

6. REICH, S.; Carbon Nanotubes: Basic Concepts and Physical Properties, Wiley-VCH, Cambridge (2004)

7. COLLINS, P. G.; AVOURIS, E P.; Nanotubes for Electronics, Scientific American, p. 62-67 (2000)

8. LIU, A.; Towards Development of Chemosensors and Biosensors with Metal-Oxide-Based Nanowires or nanotubos, Biosensors and Bioelectronics, V. 24, p. 167-177 (2008)

9. WHITBY, M.; QUIRKE, E N.; Fluid Flow in Carbon Nanotubes and Nanopipes, Nature Nanotechnology, V. 2, p. 87-94 (2007)

10. BIANCO, A.; KOSTARELOS, K.; PRATO. M.; Applications of Carbon nanotube in Drug Delivery, Current Opinion in Chemical Biology, V. 9, p. 674-679 (2005)

11. FISCHER, J. E.; Carbon Nanotubes: Structure and Properties, in Nanomaterials Handbook, Taylor Francis , Editor Yuri Gogotsi, p. 69104 (2006)

12. DAI. H.; Carbon Nanotubes: Opportunities and Challenges, Surface Science, V. 500, p. 218-241 (2002)

13. HOENLEIN, W.; DUESBERG, G. S.; GRAHAM, A. P.; KREUPL, F.; LIEBAU, M.; PAMLER, W.; SEIDEL, R.; UNGER. E.; 
Nanoelectronics Beyond Silicon, Microelectronic Engineering, V. 83, p. 619-623 (2006)

14. DRESSELHAUS, M. S.; LION, Y. M.; RABIN, O.; JORIO, A.; SOUZA FILHO, A. G.; PIMENTA, M. A.; SAITO, R.; SAMSONIDZE, G. G.; DRESSELHAUS, G.; Nanowires and Nanotubes, Materials Science and Engineering C, V. 23, P. 129-140 (2003)

15. PODLAHA, E. J.; LI, Y.; ZHANG, J.; HUANG, Q.; PANDA, A.; LOZANO-MORALES, A.; DAVIS, D.; GUO. Z.; Electrochemical Deposition of Nanostructured Materials, in Nanomaterials Handbook, Taylor Francis , Editor Yuri Gogotsi, p. 475-495 (2006)

16. INGUANTA, R.; PIAZZA, S.; SUNSERI. C.; Influence of electrodeposition Techniques on $\mathrm{Ni}$ Nanostrutures, Electrochimica Acta, V. 53, p. 5766-5773 (2008)

17. CAMPBELL, S. A.; The science and Engineering of Microelectronic Fabrication, Oxford University Press, New York (2001)

18. MARSEN, B.; SATTLER, K.; Fullerene-structured Nanowires of Silicon, Physical Review B, V. 60, p. 11593-11599 (1999)

19. CHEN, W.; YAO, H.; TZANG, Z. H.; ZHU, J.; YANG, M.; LEE, S.; Silicon Nanowires for High-Sensitivity Glucose Detection, Applied Physics Letters, V. 88, 213104 (2006)

20. LI, B.; CAO, P.; ZHANG, R. Q.; LEE, S. T.; Electronic and Geometric Structure of Thin Stable Short Silicon Nanowires, Physical Review B, V. 65, 125305 (2002)

21. FAGAN, S. B.; BAIERLE, R. J.; MOTA, R.; Ab Initio Calculations for Hypothetical Material: Silicon Nanotubes, Physical Review B, V. 61, p. 9994-9996 (2000)

22. SEIFERT, G.; KÖHLER, T.; URBASSEK, H. M.; HERNÁNDEZ, E.; FRAUENHEIM, T.; Tubular Structures of Silicon, Physical Review B, V. 63, 193409 (2000)

23. ZHANG, R. Q.; LEE, S. T.; LAW, C.; LI, W.; TEO, B. K.; Silicon Nanotubes: Why not?, Chemical Physics Letters, V. 364, p. 251$258(2002)$

24. ZHANG, M.; KAN, Y. H.; ZANG, Q. J.; SU, Z. M.; WANG, R. S.; Why Silicon Nanotubes Stably Exist in Armchair Structure?, Chemical Physics Letters, V. 379, p. 81-86 (2003)

25. BAI, J.; ZENG, X. C.; TANAKA, H.; ZENG, J. Y.; Metallic SingleWalled silicon Nanotubes, PNAS, V. 101, p. 264-2668 (2004) 
26. YANG, X.; NI, J.; Electronic Properties of single-Walled Silicon Nanotubes Compared to Carbon Nanotubes. Physical Review B, V. $72,195426(2005)$

27. ZHANG, R.Q.; LEE, H.; LI, W.; TEO, B. K.; Investigation of Possible Structures of Silicon Nanotubes Via Density-Functional Tight-Binding Molecular Dynamics Simulations and ab Initio Calculations, Journal of Physical Chemistry B, V. 109, p. 8605-8612 (2005)

28. ZHAO, M.; ZHANG, R. Q.; XI, Y.; SONG, C.; LEE, S. T.; Faceted Silicon Nanotubes: Structure, Energetic, and Passivation Effects" Journal of Physical Chemistry B, V. 109, p. 8605-8612 (2005)

29. PEREPICHKA, D. F.; ROSEI, F.; Silicon Nanotubes, Small, V. 2, p. $22-25$ (2006)

30. CHEN, H. B.; LIN, J. D.; YI, J.; CAI, Y.; WEI, G.; LIN, Y. Z.; LIAO, D. W.; Novel Silicon Nanotubes, Chinese Chemical Letters, V. 12, p. 1139-1140 (2001)

31. CHEN, Y. W.; TANG, Y.H.; PEI, L. Z.; UOC, G.; Self-Assembled Silicon Nanaotubes Grown from Silicon Monoxide, Advanced Materials, V. 17, p. 564-567 (2005)

32. SHA, J.; NIU, J.; MA, X.; XU, J.; ZHANG, X.; YANG, Q.; YANG, D.; Silicon Nanotubes, Advanced Materials, V. 14, p. 1219-1221 (2002)

33. JEONG, S. Y.; KIM, J. Y.; YANG, H. D.; YOON, B. N.; CHOI, S. H.; H. KANG, K. C.; YANG, W.; LEE, Y. H.; Synthesis of Silicon Nanotubes on Porous Alumina Using Molecular Beam Epitaxy, Advanced Materials, V. 15, p. 1172-1176 (2003)

34. XIE, M.; WANG, J.; FAN, Z.; LU, J. G.; YAP, Y. K.; Growth of p-type Si Nanotubes by Catalytic Plasma Treatments, Nanotechnology, V. 19 , p. 1-4 (2008)

35. CASTRUCCI, P.; SCARSELLI, M.; DE CRSCENCI, M.; DIOCIAIUTI, M.; CHAUDHARI, P. S.; BALASUBRAMANIAN, C.; BHAVE, T. M.; BHORASKAR, S. V.; Silicon Nanotubes: Synthesis and Characterization, Thin Solid films, V. 508, p. 226-230 (2006)

36. LIEBER, C. M.; WU, E. X. L.; Scanning Tunneling Microscopy Studies of Low-Dimensional Materials: Probing the effects of Chemical Substitutions at the Atomic Level. Accounts of chemical Research, V. 24, p 170-177 (1991). 
37. MAMALIS, A. G.; VOGTLÄNDER, L. O. G.; MARKOPOLOUS. A.; Nanotechnology and Nanostructured Materials: Trens in Carbon Nanotubes, Precision Engineering, V. 28, p 16-30 (2004)

38. NATH, M.; GOVINDARAJ, A.; RAO, C.N.R.; Simple Synthesis of $\mathrm{MoS}_{2}$ and $\mathrm{WS}_{2}$ Nanotubes. Advanced Materials, V. 13, p. 283-286 (2001)

39. ZHANG, J.; SUN, L.; LIAO, C.; YAN, C.; A simple route towards tubular ZnO, Chemical Communications, V. 3, p. 262-263 (2002)

40. LIN, A. P.; MOU, C. Y.; LIU, S. D.; Formation of Mesoporous Silica Nanotubes. Advanced Materials, V. 12, p. 103-106 (2000)

41. GUO, Y.; LEE, N.; OH, H.; YOON, C.; PARK, K.; LEE, W.; LI, Y.; LEE, H.; LEE, K.; KIM, S.; Preparation of Titanate Nanotube Thin Film Using Hydrothermal Method, Thin Solid Films, v. 516, p. 8363-8371 (2008)

42. NIEDERBERGER, M.; MUHR, H.; KRUMEICH, F.; BIERI, F.; GÜNTHER, D.; NESPER, R.; Low-Cost Synthesis of Vanadium Oxide Nanotubes Via Two Novel Non-Alkoxide Routes, Chemistry of Materials, V. 12, p. 1995-2000 (2000)

43. ZHANG, H.; CHEN, Y.; Boron Nitride Nanotubes: Synthesis and Structure, in Nanomaterials Handbook, Taylor Francis, Editor Yuri Gogotsi, p. 339-360 (2006)

44. SPANIER, J. E.; One-Dimensional Semiconductor and Oxide Nanostructures, in Nanomaterials Handbook, Taylor Francis, Editor Yuri Gogotsi, p. 283-316 (2006)

45. RAO, C. N. R.; NATH, M.; Inorganic Nanotubes, Daltons Transactions, p. 1-24 (2003)

46. SETTON, R.; Carbon Nanotubes: Geometrical Considerations, in Carbon Nanotubes, Pergamon, Editors: M. Endo, S.lljima, M.S. Dresselhaus, p. 59-64 (1996)

47. MA, D. D. D.; LEE, C. S.; AU, F. C. K.; TONG, S. Y.; LEE, S. T.; Small-Diameter Silicon Nanowire Surfaces, Science, V. 299, p. 1874-1877 (2003)

48. KANG, J.; BYUN, K. R.; HWANG, H. J.; Twist of Hypothetical Silicon Nanotubes, Modelling and Simulation in Materials Science and Engineering, V. 12, p. 1-12 (2004)

49. SPAHR, M.E.; BITTERLI, P.; NESPER, R.; MÜLLER, M.; KRUMEICH, F.; NISSEN, H. U.; Redox-Active Nanotubes of 
Vanadium Oxide, Angewandte Chemie International Edition, V. 37, p. 1263-1265 (1998)

50. CHEN, R. J.; FRANKLIN, N.R.; KONG, J.; CAO, J.; TOMBLER, T. W.; ZHANG, Y.; DAI, H.; Molecular Photodesorption from SingleWalled Carbon Nanotubes, Ap.lied Physics Letters, V. 79, p. 22582260 (2001)

51. LIU, A.; HONMA, I.; ICHIHARA, M.; ZHOU, H.; Poly(acrylic acid)Wrapped Multi-Walled Carbon Nanotubes Composite Solubilization in Water: Definitive Spectroscopic Properties, Nanotechnology, V. 17, p. 2845-2849 (2006)

52. LIU, A.; HONNMA, I.; ZHOU, H.; Simultaneous Voltammetric Detection of Dopamine and Uric Acid at Their Physiological Level in The Presence of Ascorbic Acid Using Poly(Acrylic Acid)-Multiwalled Carbon-Nanotube Composite-Covered GlassyCarbon Electrode, Biosensor and Biolectronics, V. 23, 74-80.

53. MORA, G. K.; VARGHESE, O. K.; PALOUSE, M.; ONG, K. G.; GRIMES, C. A.; Fabrication of Hydrogen Sensors with Transparent Titanium Oxide Nanotube-Array Thin Films as Sensing Elements, Thin Solid Films, V. 496, p. $42-48$ (2005)

54. DU, N.; ZHANG, H.; CHEN, B. D.; MA, X. Y.; LIU, Z. H.; WU, J. B.; Porous Indium Oxide Nanotubes: Layer-by-Layer Assembly on Carbon-Nanotube Templates and Application for RoomTemperature $\mathbf{N H}_{3}$ Gas Sensors, Advanced Materials, V. 19, p. 1641-1645 (2007)

55. LI, Y.; HUANG, Z.; RONG, S.; A Vanadium Oxide Nanotube-Based Nitric Oxide Gas Sensor, Sensor and Materials", V. 18, p. 241-249 (2006)

56. ZHANG, G.; GUO, B.; CHEN, J.; MCo2O4 (M = Ni, Cu, Zn) nanotubes: Template Synthesis and Application in Gas Sensors, Sensors and Actuators B, V. 114, p. $402-409$ (2006)

57. WANG, J.; Carbon-Nanotube Based Electrochemical Biosensors: A Review, Electroanalysis, V. 17, p. 7-14 (2005)

58. RAKOV, E. G.; Chemistry of Carbon Nanotubes, in Nanomaterials Handbook, Taylor Francis , Editor Yuri Gogotsi, p. 339-360 (2006)

59. BAUGHMAN, R. H.; ZAKHIDOV, A. A.; DE HEER, W. A.; Carbon Nanotubes-The Route Toward Applications, Science, V. 297, p. 787-792 (2002)

60. KREUPL, F.; GRAHAM, A. P.; DUESBERG, G. S.; STEINHÖGL, W.; LIEBAU, M.; UNGER, E.; HÖNLEIN, W.; Carbon nanotubes in 
Interconnect Applications, Microelectronic Engineering, v. 64, p. 399-408 (2002)

61. HOENLEIN, W.; DUESBERG, G. S.; GRAHAM, A. P.; KREUPL, F.; LIEBAU, M.; PAMLER, W.; SEIDEL, R.; UNGER, E.; Nanoeletronics Beyond Silicon, Microelectronic Engineering, V. 83, p. 619-623 (2006)

62. AN, K. H.; KIM, W. S.; PARK, Y. S.; MOON, J.-M.; BAE, D. J.; LIM, S. C. Y.; LEE, S.; LEE, Y. H.; Electrochemical Properties of HighPower Supercapacitors Using Single-Walled Carbon Nanotube Electrodes, Advanced Functional Materials, V. 11, p. 387-392 (2001)

63. NIU, C.; SICHEL, E. K.; HOCH, R.; MOY, D.; TENNENT, H.; High Power Electrochemical Capacitors Based on Carbon Nanotube Electrodes, Applied Physic Letters, V. 70, p. 1480-1482 (1997)

64. ZHANG, X. G.; Electrochemistry of Silicon and its Oxide, Kluwer Academic Publisher, New York (2001).

65. LEHMANN, V.; Electrochemistry of Silicon, Wiley-VHC, München (2002)

66. GOROSTIZA, P.; Metal Deposition on Silicon From Fluoride solutions, Tese de doutorado, Universidade de Barcelona, Barcelona (1999).

67. WILLEKE, G.; KELLERMANN, K.; Crystalline Silicon Etching in Quiescent Concentrated Aqueous Hf Solutions, Semiconductor Science and Technology, V. 11, p. 415-421 (1996)

68. S. HU, M.; KERR, D. R.; Observation of etching of n-type silicon in aqueous HF solutions, Journal of Electrochemical Society, V. 114, p. 414 (1967)

69. MATSUMURA, M.; FUKIDOME, H.; Enhanced Etching Rate of Silicon in Fluoride Containing Solutions At Ph 6.4, Journal of Electrochemical Society, V. 143, 2683-2686 (1996)

70. FUKIDOME, H.; OHNO, T.; MATSUMURA M.; Analysis of Silicon Surface in Connection with Its Unique Electrochemical and Etching Behavior, Journal of Electrochemical Society, V. 144, p. 679-682 (1997)

71. JUDGE, J. S.; A Study of the Dissolution of $\mathrm{SiO}_{2}$ in Acidic Fluoride Solutions, Journal of Electrochemical Society, V. 118, p. 1772-1775 (1971)

72. YAHYAOUI, F.; DITTRICH, TH.; AGGOUR, M.; CHAZALVIEL, J.N.; OZANAM, F.; RAPPICH, J.; Etch Rates of Anodic Silicon 
Oxides in Dilute Fluoride Solutions, Journal of Electrochemical Society, V. 150, p. B205-B210 (2003)

73. VERHAVERBEKE, S.; TEERLINCK, I.; VINCKIER, C.; STEVENS, G.; CARTUYVELS, R.; HEYNS, M. M.; The Etching Mechanisms of $\mathrm{SiO}_{2}$ in Hydrofluoric Acid, Journal of Electrochemical Society, V. 141 , p. 2852-2857 (1994)

74. ALlongUe, P.; KIELING, V.; GERISCHER, H.; Etching Mechanism and atomic structure of $\mathrm{H}-\mathrm{Si}(111)$ surface prepared in $\mathrm{NH}_{4} \mathbf{F}$, Electrochimica Acta, V. 40, p. 1353-1360 (1995)

75. ALlongue, P.; KIELING, V.; GERISCHER, H.; Etching Mechanism and atomic structure of $\mathrm{H}-\mathrm{Si}(111)$ surface prepared in $\mathbf{N H}_{4} \mathbf{F}$, Electrochimica Acta, V. 40, p. 1353-1360 (1995)

76. Allongue, P.; DE VILENUEVE, C. H.; MORIN, S.; BOUKHERROUB, R.; WAYNER, D. D. M.; The preparation of flat $\mathrm{H}-\mathrm{Si}(111)$ surfaces in $\mathbf{4 0} \% \mathrm{NH} 4 \mathrm{~F}$ revisited, Electrochimica Acta, $\mathrm{V}$. 45 , p. $4591-4598$ (2000)

77. NIWANO, N.; TAKEDA, Y.; ISHIBASHI, Y.; KURITA, K.; MIYAMOTO, $\mathrm{N}$.; Morphology of hydrofluoric acid and ammonium fluoridetreated silicon surfaces studied by surface infrared spectroscopy, Journal of Applied Physics, V. 71, p. 5646-5649 (1992)

78. NIWANO, M.; KONDO, Y.; KIMURA, Y.; In situ infrared observations of etching and oxidations process on $\mathrm{Si}$ surfaces in NH4F solution, Journal of Electrochemical Society, V. 147, p. 1555-1559 (2000)

79. HOLDCROFT, S.; FUNT, B. L.; The energies of Electron Transfer at the Polypyrrole/silicon Interface, Journal of Electrochemical Society, V. 135, p. 3106-319 (1988)

80. MEMMING, R.; SCHWANDT, G.; Potential distribution and formation of surface states at the silicon-electrolyte interface, Surface Science, V. 4, p. 97-110 (1966)

81. SERRE, C.; BARRET, S.; HERINO, R.; Influence of the electrolyte composition of p-type $\mathrm{Si}$ in aqueous HF solutions, Journal of Electroanalytical Chemistry, V. 370, p. 145-149 (1994)

82. KOLASINSKI, K. W.; Silicon Nanostructures from Electroless Electrochemical Etching, Current Opinion in Solid State and Materials Science, V. 9, p. 73-83 (2005)

83. CHEMLA, M.; HOMMA, T.; BERTAGNA, V.; ERRE, R.; KUBO, N.; OSAKA,T., Survey of the Metal Nucleation Process on Silicon 
Surfaces in Fluoride Solutions: From Dilute HF to Concentrated $\mathrm{NH}_{4} \mathrm{~F}$ Solutions, Journal of Electroanalytical Chemistry, V. 559, p. 11-123 (2003)

84. MITSUGI, N.;NAGAI, K.; Pit Formation Induced by Copper Contaminations on Silicon Surface Immersed in Dilute Hydrofluoric Solution, Journal of Electrochemical Society, V. 151, p. G302-G306 (2004)

85. DOUANI, R.; SI-LARBI, K.; HADJERSI, T.; MEGOUDA, N.; MANSERI, A.; Silver-assisted Electroless Etching Mechanism of Silicon, Physica Status Solidi (a), V. 205, p. 225-230 (2008)

86. TURNER, D. R.; On the Mechanism of Chemically Etching Germanium and Silicon, Journal of Electrochemical Society, V. 107, p. $810-816$ (1960)

87. ZWICKER, W. K.; KURTZ, S. K.; Anisotropic etching of silicon using electrochemical displacement reactions, in Semiconductor Silicon, H. R. Huff and R. R. Burgess (eds.), p. 315, Electrochemical Society, Pennington, 1973.

88. MURAOKA, H.; OHASHI, T.; SUMITOMO, Y.; Controlled preferential etching technology, in Semiconductor Silicon, H. R. Huff and R. R. Burgess (eds.), p. 327, Electrochemical Society, Pennington, 1973.

89. ROBBINS, H.; SCHWARTZ, B.; Chemical Etching of Silicon I. The System HF, HNO, and H2O, Journal of Electrochemical Society, V. 106, p. 505-508 (1959)

90. KOOIJ, E. S.; BUTTER, K.; KELLY, J. J.; Silicon Etching in $\mathrm{HNO}_{3} / \mathrm{HF}$ Solution: Charge Balance for the Oxidation Reaction, Electrochemical and Solid-State Letters, V. 2 , p. 178-180 (1999)

91. ALLONGUE, P.; COSTA-KIELING, V.; GERISCHER, H.; Etching of Silicon in $\mathrm{NaOH}$ Solutions II. Electrochemical Studies of $\mathrm{n}$ Si(111) and (100) and Mechanism of the Dissolution, Journal of Electrochemical Society, V. 140, p. 1018-1026 (1993)

92. PALIK, E. D.; GRAY, H. F.; KLEIN, P. B.; A Raman study of etching silicon in aqueous $\mathrm{KOH}$, Journal of Electrochemical Society, V. 130, p. 956-959 (1983)

93. SEIDEL, H.; CSEPREGI, L.; HEUERGER, A.; BAUMGÄRTEL, H.; Anisotropic etching of crystalline Silicon in alkaline Solutions. I. Orientation dependence and behavior of passivation layers, Journal of Electrochemical Society, V. 137, p. 3612-3626 (1990) 
94. PALIK, E. D.; BERMUDEZ, V. M.; GLEMBOCKI, O. J.; Ellipsometry study of orientation-dependent etching of silicon in aqueous KOH, Journal of Electrochemical Society, V. 132, p. 871-884 (1985)

95. ALLONGUE, P.; COSTA-KIELING, V.; GERISCHER, H.; Etching of Silicon in $\mathrm{NaOH}$ Solutions I. In Situ Scanning Tunneling Microscopic Investigation of $\mathbf{n}-\mathbf{S i}(111)$, Journal of Electrochemical Society, V. 140, p. 1009-1018 (1993)

96. GHANDHI, S. K.; VLSI Fabrication Principles, John Willey \& Sons, New York, 1983.

97. O. Bisi, S. Ossicini, L. Pavesi. "Porous Silicon: A quantum Sponge Structure for Silicon Based Optoelectronics", Surface Science Reports, V. 38, p. 1-126 (2000)

98. H. Föll, M. Christophersen, J. Carstensen, G. Hasse, "Formation and Application of Porous Silicon", Materials science and Engineering R, V. 39, p. 93-141 (2002)

99. KOCHERGIN, V.; FOELL, H.; Novel Optical Elements made from Porous Si, Materials science and Engineering R, V. 52, p. 93-140 (2006)

100. HUANCA, D. R.; SALCEDO, W. J.; Porous silicon heterostructures for refractometer device application, ECS transactions, V. 23, p. 499-506 (2009)

101. HUANCA, D. R.; RAMIREZ-FERNANADEZ, F. J.; SALCEDO, W. J.; Porous silicon optical cavity structure applied to high sensitivity organic solvent sensor, Microelectronics Journal, V. 39, p. 499506 (2008)

102. ACOSTA, A. A.; RAIMUNDO, D. S.; HUANCA, D. R.; AND SALCEDO, W. J.; Nanocomposite of Porous Silicon and Methylene Blue Molecules for Optical Gas Sensor Application, ECS Transactions, V. 14 , 57 (2008)

103. ASTROVA, E. V.; BOROVINSKAYA, T. N.; PEROVA, T. S.; ZAMORYANSKAYA, M. V.; Quartz microtubes based on macroporous silicon, Semiconductors, V. 38, p.1084-1087 (2004)

104. ZHAO, L.; STEINHART, M.; YOSEF, M.; LEE, S. K.; GEPPERT, T.; PIPPEL, E.; SCHOLZ, R.; GÖSELE, U.; SCHLECHT, S.; Lithium Niobate Microtubes within Ordered Macroporous Silicon by Templated Thermolysis of a Single Source Precursor, Chemistry of Materials, V. 17, p. 3-5 (2005)

105. CARRARO, C.; MABOUDIAN, R.; MAGAGNIN, L.; Metallization And Nanostructuring of Semiconductor Surfaces by Galvanic 
Displacement Processes, Surface Science Reports, V. 62, p. 499525 (2007)

106. HUANCA, D. R.; SALCEDO, W. J.; Silicon macrotubes fabrication using the porous silicon as starting material, Mateials Science in Semiconductor Processing, submitted for publication.

107. MEGOUDA, n.; HADJERSI, T.; PIRET, G.; BOUKHERROUB, R.; ELKECHAI, O.; Au-Assisted Electroless Etching of Silicon in Aqueous $\mathrm{HF} / \mathrm{H}_{2} \mathrm{O}_{2}$ Solution, Applied Surface Science, V. 255, p. 6210-6216 (2009)

108. HADJERSI, T.; Oxidizing agent effect on the metal-assisted electroless etching mechanism in HF-oxidizing- $\mathrm{H}_{2} \mathrm{O}$ solutions, Applied Surface Science, V. 253, p. 4156-4160 (2007)

109. KOLASINSKI, K. W.; Silicon Nanostructures from electroless electrochemical etching, Current Opinion in Solid State and Materials Science, V. 9, p. 73-83 (2005)

110. FUKIDOME, H.; OHNO, T.; MATSUMURA M.; Analysis of Silicon Surface in Connection with Its Unique Electrochemical and Etching Behavior, Journal of Electrochemical Society, V. 144, p. 679-682 (1997)

111. CHAZALVIEL, J.-N.; ETMAN, M.; OZANAM, F.; A voltammetric study of the anodic dissolution of $\mathrm{p}-\mathrm{Si}$ in fluoride electrolytes, Journal of Electroanalytical Chemistry, V. 291, p. 533-540 (1991).

112. DEWALD, J. F.; The Kinetics and Mechanism of Formation of Anode Films on Single-Crystal InSb, Journal of Electrochemical Society, V. 104, p. 244-251 (1957)

113. PENG, K.; YAN, Y.; GAO, S.; ZHU, J.; Dendrite-assisted growth of Silicon nanowires in electroless metal deposition, Advanced functional Materials, V. 13, p. 127-132 (2003)

114. PENG, K.; HU, J.; YAN, Y.; WU, Y.; FANG, H.; XU, Y.; LEE, S.; ZHU, $\mathrm{J}$; Fabrication of single-crystalline silicon nanowires by scratching a silicon surface with catalytic metal particles, Advanced functional Materials, V. 16, p. 387-394 (2006)

115. XU, W.; PALSHIN, V.; FLAKE, J. C.; Nickel monosilicide contact formation in electrolessly etched silicon nanowires deposited onto nickel electrodes, Journal of Electrochemical Society, V. 156, p. H544-H547 (2009)

116. HERINO, R.; Nanocomposite materials from Porous Silicon, Materials Science and Engenieering B, V. 69-70, p. 70-76 (2000) 
117. GRANITZER, P.; RUMPF, K.; PÖLT, P.; SIMIC, S.; KRENN, H.; Magnetic nanocomposites Fabricated by Selective Metal Deposition in and on Self-Assembled Mesoporous Silicon, Superlattices and Microstructures, V. 44, p. 436-441 (2008)

118. BELKACEM, W.; MLIKI, N.; SAIKALY, W.; YANGUI, B.; Nanostructured cobalt on Porous Silicon Substrate: Structure and Magnetic Behaviour, Physical Status Solidi (a), V. 204, p. 3321-3332 (2007)

119. BALAKRISHNAN, S., GUN'KO, Y. K., PEROVA, T. S., VENKATESAN, M.; ASTROVA, E. V.; Magnetic Nanoparticles Porous Silicon Composite Material, Physical Status Solidi (a), V. 202, p. 1698-1702 (2005)

120. BELL, T. E.; GENNISSEN, P. T. J.; DEMUNTER, D.; KUHL, M.; Porous silicon as a sacrificial material, Journal of micromechanics and microengineering, V. 6, p. 361-369 (1996)

121. LAMMEL, G.; SCHWEIZER, S.; RENAUD, PH.; Microspectrometer based on a tunable optical filter of porous silicon, Sensors and Actuators A: Physical, V. 92, p. 52-59 (2001)

122. HUANCA D. R.; Estruturas multicamadas de silício poroso para aplicação em dispositivos de cristais fotônicos, Dissertação de Mestrado, Escola Politécnica da Universidade de São Paulo, São Paulo (2007)

123. CHARTIER, C.; BASTIDE, S.; LÉVY-CLÉMENT, C.; Metal-assisted chemical etching of silicon in $\mathrm{HF}-\mathrm{H}_{2} \mathrm{O}_{2}$, Electrochimica Acta, V. 53, p. $5509-5516$ (2008)

124. HARRAZ, F. A.; SAKKA, T.; OGATA, Y. H.; Immersion Plating of Nickel onto Porous Silicon Layers from Fluoride Solutions, Physical Status Solidi (a), V. 197, p. 51-56 (2003)

125. ZHANG, X.; TU, N. K.; XIE, Y. H.; TUNG, C. H.; High Aspect Ratio Nickel structure fabricated by electrochemical replication of hydrofluoric acid etched Silicon, Electrochemical and Solid-State Letters, V. 9, p. C150-C152 (2006)

126. XU, C.; ZHANG, X.; TU, K.; XIE, Y.; Nickel Displacement Deposition of Porous Silicon With Ultrahigh Aspect Ratio, Journal electrochemical Society, V. 154, p. D170-D174 (2007)

127. ARAVAMHUDAN, S.; LUONGO, K.; PODDAR, P.; SRIKANTH, H.; BHANSALI, S.; Porous Silicon templates for Electrodeposition of Nanostructures, Applied Physics A, V. 87, p. 773-780 (2007) 
128. OGATA, Y.; KOBAYASHI, H. K.; MOTOYAMA, M.; Electrochemical Metal Deposition on Silicon, Current Opinion in Solid State and Materials, V. 10, p. 163-172 (2006)

129. KOBAYASHI, K.; HARRAZ, F. A.; IZUO, S.; SAKKA, T.; OGATA, Y. $\mathrm{H}$.; Microrod and microtube formation by electrodeposition of metal into ordered macropores prepared in p-type silicon, Journal electrochemical Society, V. 153, p. C218-C222 (2006)

130. FUKANI, K.; KOBAYASHI, K.; MATSUMOTO, T.; KAWAMURA, Y. L.; SAKKA, T.; OGATA, Y. H.; Electrodeposition of noble metals ito ordered macropores in p-type silicon, Journal electrochemical Society, V. 155, p. D443-D448 (2008)

131. HARRAZ, F. A.; KAMADA, K.; SASANO, J.; IZUO, S.; SAKKA, T.; OGATA, Y. H.; Pore filling of maropores prepared in p-type silicon by Cooper deposition, Physica Status Solidi (a), V. 202, p. 1638-1687 (2005)

132. ASOH, H.; ARAI, F.; ONO, S.; Effect of noble metal catalyst specie in the morphology of macroporous silicon formed by metal-assisted chemical etching, Electrochimica Acta, V. 54, p. 5142-5148 (2009)

133. WAN, L.; GONG, W.; JIANG, K.; LI, H.; TAO, B.; ZHANG, J.; Preparation and surface modification of silicon nanowires under normal conditions, Applied surface Science, V. 254, p. 4899-4957 (2008)

134. MARUTA, R. H.; KIM, H. Y.; HUANCA, D. R.; SALCEDO, W. J.; A new correlation-based granulometry algorithm with application in characterizing porous silicon nanomaterials, ECS Transactions, V. 81 (2010).

135. WOLF, S.; TAUBER, R. N.; Silicon Processing for the VLSI Era. V. II (Lattice Press, New York, 1986), p. 111.

136. HUANCA, D. R.; RAMIREZ-FERNANADEZ, F. J.; SALCEDO, W. J.; Morphological and Structural Effect of Aluminum on Macroporous Silicon Layers, Journal of Materials Science and Engineering, será publicado em julho 2010.

137. BLACK, J. R.; Electromigration Failure Modes in Aluminum Metallization for Semiconductor Devices, Proceeding of the IEEE, V. 57, p. 1587-1594 (1969)

138. SCHNABLE, G. L.; KEEN, R. S.; Aluminum MetallizationAdvantages and limitations for integrated Circuit Applications, Proceeding of the IEEE, V. 57, p. 1570-1580 (1969) 
139. S. M. Sze, "Physics of Semiconductor Devices", John Wiley and Sons, New Jersey (1981)

140. FAITH, T. J.; IRVEN, R. S.; REED, L. H.; O'NEIL, J. J.; JONES, M. C.; contact Resistance Monitor for Silicon Integrated Circuits, Journal of Vacuum Science and Technology B, V. 2, p. 54-57 (1984)

141. MIKESKA, K. R.; BENNISON, S. J.; Corrosion of Alumina in Aqueous Hydrofluoric Acid, Journal of the American Ceramic Society, V. 82, p. 3561-3566 (1999)

142. HUANCA, D. R.; RAIMUNDO, D. S.; SALCEDO, W. J.; Backside contact effect on the morphological and optical features of porous silicon photonic crystals, Microelectronics Journal, V. 40, p. 744-748 (2009)

143. CHRISTOPHERSEN, M.; CARSTENSEN, J.; VOIGT, K.; FÖLL, H.; Organic and Aqueous electrolytes Used for Etching Macro- and mesoporous Silicon, Phisica Status Solidi (a), V. 197, p. 34-38 (2003)

144. THEISS, W.; Optical Properties of Porous Silicon, Surface Science Reports, V. 29, p. 91-192 (1997)

145. ZHANG, X. G.; Morphology and Formation Mechanisms of Porous Silicon, Journal electrochemical Society, V. 151, p. C69-C80 (2004)

146. ROSSOW, U.; Optical Characterization of Porous Materials, Physica Status Solidi (a), V. 184, p. 51-78 (2001)

147. BERTAGNA, V.; ERRE, R.; ROUELLE, F.; CHEMLA, M.; Corrosion rate of $\mathrm{n}$ - and p-silicon substrates in HF, HF + HC1 and aqueous solutions, Journal of Electrochemical Society, V. 146, p. 83-, 1999

148. BeRTAGNA, V.; PLOUGONVEN, C.; ROUELLE, F.; CHEMLA, M.; p- and n-type silicon electrochemical properties in dilute hydrofluoric acid solutions, Journal of Electrochemical Society, V. 143, p. 3532-3538 (1996)

149. GOROSTIZA, P.; ALLONGUE, P.; DIAZ, R.; MORANTE, J. R.; SANZ, F.; Electrochemical Characterization of the Open-Circuit Deposition of Platinum on silicon from Fluoride solutions, Journal of Physical Chemistry B, V. 107, p. 6454-6461 (2003)

150. M. Pourbaix, Atlas of Electrochemical Equilibria in Aqueous Solution, p. 333, National Association of Corrosion Engineers, Houston (1974) 
151. ALLONGUE, P.; DE VILLENEUVE, C.; PINSARD, H. L.; BERNARD, M. C.; Evidence for hydrogen incorporation during porous silicon formation, Applied Physics Letters, V. 67, p. 941, (1995)

152. OSSEO-ASARE, K.; WEI, D.; MISHRA, K. K.; Dissolution Windows for Wet Chemical Processing of Silicon and Silicon Dioxide: Potential-pH Diagrams for the Si-F- $\mathrm{H}_{2} \mathrm{O}$ System, Journal electrochemical Society, V. 143, p. 749-751 (1996)

153. KOLASINSKI, K. W.; Etching of silicon in Fluoride Solutions, Surface Science, V. 603, p. 1904-1911 (2009)

154. WILLEKE, G.; KELLERMANN, K.; Crystalline silicon etching in quiescent concentrated aqueous HF solutions, Semiconductor Science and Technology, V. 11, p. 415-421 (1996)

155. KIKUYAMA, H.; WAKI, M.; MIYASHITA, M.; YABUNE, T.; MIKI, N.; A study of the dissolution state and the etching reaction for HF solutions of extremely low concentration, Journal electrochemical Society, V. 141, p. 366-374 (1994)

156. HARAM, S. K.; Semiconductor Electrodes, in Handbook of Electrochemistry , Elsevier, Oxford (2007)

157. PLIETH, W.; Electrochemistry for Materials Science, Elsevier, Dresden (2008)

158. PENNER, R. M.; Metal Deposition, in Handbook of electrochemistry, in Handbook of Electrochemistry, Elsevier, Oxford (2007)

159. LYSKO, J. M.; Anisotropic Etching of the Silicon Crystal-surface Free Energy Model, Materials Science in Semiconductor Processing, V. 6, p. 235-241 (2003)

160. GERISCHER, H.; LÜBKE, M.; On the Etching of Silicon by Oxidants in Ammonium Fluoride Solutions. A mechanistic Study, Journal electrochemical Society, V. 135, p. 2782-2786 (1988)

161. NIWA, D.; HOMMA, T.; OSAKA, T.; Deposition Mechanism of Ni on $\mathrm{Si}(100)$ Surfaces in Aqueous alkaline Solution, Journal of Physical Chemistry B, V. 108, p. 9900-9904 (2004)

162. BELAIDI, A.; SAFI, M.; OZANAM, F.; CHAZALVIEL, J.-N.; GOROCHOV, O.; Surface Chemistry During Porous-Silicon Formation in Dilute Fluoride Electrolytes, Journal electrochemical Society, V. 146, p. 2659-2664 (1999) 
163. KLEIMANN, P.; Toward the Formation of Three-dimensional Nanostructures by Electrochemical Etching of Silicon, Applied Physics Letters, V. 86, 183108 (2005)

164. LEHMANN, V.; The Physics of Macropore Formation in Low Doped n-Type Silicon, Journal electrochemical Society, V. 140, p. 2836-2843 (1993)

165. LYSKO, J. M.; Anisotropic Etching of the Silicon Crystal-surface Free Energy Model, Materials Science in Semiconductor Processing, V. 6, p. 235-241 (2003)

166. BAUM, T.; SCHIFFRIN, D. J.; Mechanistic aspects of Anisotropic dissolution of Materials Etching of Single-Crystal Silicon in Alkaline Solutions, Journal of the Chemical Society, Faraday Transactions, V. 94, p. 691-694 (1998)

167. PAUNOVIC, M.; SCHLESINGER, M.; Fundamentals of Electrochemical Deposition, John Wiley and Sons Inc., (2006)

168. IRKHIN, V. Y.; IRKHIN, Y. P.; Electronic structure, Correlation effects and Physical properties of $d$ - and f-transition metals and their Compounds, Cambridge International Science Publishing, Cambridge (2007)

169. HARRAZ, F. A.; SASANO, J.; SAKKA, T.; OGATA, Y. H.; Different Behavior in Immersion Plating of Nickel on Porous silicon from Acid and Alkaline Fluoride media, Journal electrochemical Society, V. 150 , p. C277-C284 (2003)

170. VANYSEK, P.; Electrochemical Series, in CRC Handbook of Chemistry and Physics 87th, D. R. Lide, Editor, p. 8-20, Taylor and Francis, Boca Raton, Florida (2007)

171. GRANITZER, P.; RUMPF, K.; KRENN, H.; Ferromagnetic Nanostructures Incorporated in Quasi-One-Dimensional Porous Silicon Channels Suitable for Magnetic Sensor Applications, Journal of Nanomaterials, V. 2006, p. 1-7 (2006)

172. DHAR, S.; CHAKRABARTI, S.; Electroless Ni Plating on $\mathbf{n -}$ and $\mathbf{p}-$ type Porous Si for Ohmic and Rectifying Contacts, Semiconductor Science and Technology, V. 11, p. 1231-1234 (1996)

173. ORINAKOVA, R.; TURONOVA, A.; KLADEKOVA, D.; GALOVA, M.; SMITH, R. M.; Recent Developments in the Electrodeposition of Nickel and Some Nickel-Based Alloys, Journal of Applied Electrochemistry, V. 36, p. 957-972 (2006) 
174. JAYASHREE, R. S.; KAMATH, P. V.; Nickel Hydroxide electrodeposition from Nickel Nitrate Solutions: Mechanistic Studies, Journal of Power Sources, V. 93, p. 273-278 (2001)

175. HUANCA, D. R.; SALCEDO, W. J.; Fabrication of Nickel Microtubes by Galvanic Displacement Method Using Macroporous Silicon as Template, ECS Transactions, V. 81 (2010).

176. GOROSTIZA, P.; KULANDAINATHAN, M. A.; DÍAZ, R.; SANZ, F.; ALLONGUE, P.; MORANTE, J. R.; Charge Exchange Processes during the Open-Circuit Deposition of Nickel on Silicon from Fluoride Solutions, Journal of The Electrochemical Society, V. 147, p. $1026-1030(2000)$

177. MARTINS, L. F. O.; SELIGMAN, L.; SANTOS FILHO, S. G.; D'AJELLO, P. C. T.; HASENACK, C. M.; PASA, A. A.; Electrochemical Evidence of a Copper-Induced Etching of $n$ Type Si in Dilute Hydrofluoric Acid Solutions, Journal electrochemical Society, V. 144, p. L106-L108 (1997)

178. GERISCHER, H.; LÜBKE, M.; On the Etching of Silicon by Oxidants in Ammonium Fluoride Solutions. A mechanistic Study, Journal electrochemical Society, V. 135, p. $2782-2786$ (1988)

179. CARTER, P.; GLEESON, B.; YOUNG, D. J.; Rapid Growth of $\mathrm{SiO}_{2}$ Nanofibers on Silicon-Bearing Alloys, Oxidation of Metals, V. 56, p. 375-394 (2001)

180. $\mathrm{LI}, \mathrm{X}$. BOHN, P. W.; Metal-assisted chemical etching in $\mathrm{HF} / \mathrm{H}_{2} \mathrm{O}_{2}$ produces porous silicon, Applied Physics Letters, V. 77, p. 2572$2574(2000)$

181. LIDE, D. R.; Electronegativity, in CRC Handbook of Chemistry and Physics 87th, D. R. Lide, Editor, p. 8-20, Taylor and Francis, Boca Raton, Florida (2007)

182. BELAIDI, A.; FOTOUHI, B.; CACHET, H.; KERBACHE, T.; CHARI, A.; OZANAM, F.; CHAZALVIEL, J.-N.; GOROCHOV, O.; ETMAN, M.; Cation Effects on the Anodic Dissolution of $\mathrm{n}$-Si in Fluoride Electrolytes, Journal of electronalytical Chemistry, V. 455, p. 191195 (1998)

183. CHARTIER, C.; BASTIDE, S.; LÉVY-CLÉMENT, C.; Metal-assisted chemical Etching of Silicon in $\mathrm{HF}-\mathrm{H}_{2} \mathrm{O}_{2}$, Electrochimica Acta, V. 53 , p. 5509-516 (2008)

184. SZE, S. M.; Modern Semiconductor Device Physics, John Wiley \& Sons, Inc. (1998) 
185. DE MIERRY, P.; BALLUTAUD, D.; AUCOUTURIER, M.; Effect of surface preparations on electrical and chemical surface properties of p-type silicon, Journal of Electrochemical Society, V. 137, p. 2966-2973 (1990)

186. ZHAO, Y.; Li, D.; YANG, D.; Al-Assisted Anodic Etched Porous Silicon, Journal of Materials Science, V. 41, p. 5238-5286 (2006)

187. FAUST, J. W.; PALIK, E. D.; Study of the Orientation Dependent Etching and Initial Anodization of Si Aqueous KOH, Journal of Electrochemical Society, V. 130, p. 1413-1420 (1983)

188. SALCEDO, W. J.; RAMIREZ-FERNANDEZ, F. J.; RUBIM, J. C.; Polarization Effects on the Raman and Photoluminescence Spectra of Porous Silicon Layers, Journal of Raman Spectroscopy, V. 30, p. 29-36 (1999)

189. SALCEDO, W. J.; RAMIREZ-FERNANDEZ, F. J.; RUBIM, J. C.; Changes in the Porous Silicon Structure Induced by Laser Radiation, Journal of Raman Spectroscopy, V. 32, p. 151-157 (2001)

190. KANG, Y.; QIU, Y.; LEI, Z.; HU, M.; An application of Raman spectroscopy on the measurement of residual stress in porous silicon, Optics and Lasers in Engineering, V. 43, p. 847-855 (2005)

191. BRODSKY, M. H.; CARDONA, M.; CUOMO, J. J.; Infrared and Raman Spectra of the Silicon-Hydrogen Bonds in Amorphous Silicon Prepared by Glow Discharge and Sputtering, Physical Review B, V. 16, p. 3556-3571 (1977)

192. MARTINS, L. F. O.; SELIGMAN, L.; SANTOS FILHO, S. G.; D'AJELLO, P. C. T. ; HASENACK, C. M.; PASA, A. A.; Electrochemical Evidence of a Copper-Induced Etching of $n$ Type Si in Dilute Hydrofluoric Acid Solutions, Journal electrochemical Society, V. 144, p. L106-L108 (1997)

193. MUNDER, H.; ANDRZEJAK, C.; BERGER, M. G.; KLEMRADT, U.; LÜTH, H.; HERINO, R.; LIGEON, M.; A detailed Raman study of porous silicon, Thin Solid Films, V. 221, p. 27-33 (1992) 